\title{
The Corporate Social Responsibility (CSR) approach as a framework for business involvement in health promotion in the welfare state
}

Phoenix JDP Dynamics of Health and Welfare Joint Degree

Linköping University, Linköping, Sweden and

Escola Nacional de Saúde Pública, Lisboa, Portugal 
(C) Michelle Sara Monachino, 2016

Printed in Sweden by LiU-Tryck 2016

ISSN 0282-9800

ISBN 978-91-7685-642-O 
The Corporate Social Responsibility (CSR) approach as a framework for business involvement in health promotion in the welfare state

By

Michelle Sara Monachino

\author{
October 2016 \\ ISBN 978-91-7685-642-0 \\ The title of the series \\ No. 704 \\ ISSN 0282-9800 \\ Department of Culture and Communication \\ Linköping University \\ SE-581 83 Linköping, Sweden
}


This dissertation is to be situated in the debate about the development of the contemporary Western European welfare state, its displacement of responsibilities from state to non-state societal actors and the resulting concerns vis-à-vis the optimal distribution of responsibilities. Drawing, in interdisciplinary fashion, from the fields of political sociology, political economics, welfare studies, public health policy, and management, it focuses upon the involvement of for-profit, non-state actors into a field traditionally of state competence, that of public health. In order to do so, are considered two spheres of research and practice that frame and motivate the involvement of business actors in public health in the welfare state, and that have been seldom crossed: the Corporate Social Responsibility (CSR) approach and the health promotion approach. Through the means of a qualitative policy analysis relying on a variety of methods, literature review, document analysis, case studies and participant observation, this dissertation sets out to identify the features of business involvement in health promotion through CSR, and to examine and discuss the issues arising from such involvement in the context of the Western European welfare state. Specifically, the purpose is that of participating to the clarification and discussion of the potential contributions and dilemmas CSR initiatives pose for health promotion policy and practice, as well as unveiling the limits to such contribution. The findings suggest that initiatives formulated within the CSR framework are apt to allow business actors to further contextual health promotion priorities and approaches, as well as enabling the advancing of social capital and trust building at local level. Nevertheless, such contributions were found to be partial, limited by a number of specific boundaries inherent to the way the CSR approach is configured and to the way it is applied. Boundaries are resumed in terms of: coexistent rationalities and partial understandings concerning the CSR approach; lack of awareness of business actors concerning the health promotion approach and its dimensions; positive understanding of social responsibility; and limited instruments for cross-sectoral negotiation and collaboration. On the basis of the findings, the dissertation refutes the dilemmas, presented in literature, concerning the potential for CSR initiatives to constitute a mean for the scaling back of governmental responsibilities or the divulgation of a narrow understanding of health. On the other hand, it confirms their potential instrumentality to the pursuit of opportunistic objectives, such as market differentiation and regulation avoidance. The information collected did not allow discussing the aptitude for CSR initiatives to constitute channels for the direct lobbying of political élites or the exercise of organizational control upon employees. The dissertation further warns that the selection of causes, beneficiaries, and social partners operated in absence of mechanisms of alignment with contextual priorities and of inclusion of stakeholder interest into business decision-making may lead to CSR initiatives emphasising, rather than counterbalancing, inequalities in the access to resources and opportunities for health. Ultimately, it is recommended for the term CSR to be modified as to better fit the ensemble of business actors that may engage in the approach, for instance, substituting it with the more encompassing term social responsibility of businesses, or with any other term apt to the depict the dialogic purpose of CSR.

Keywords: Corporate Social Responsibility; health promotion; public health policy; community health and community involvement; welfare state development; crosssectoral health promotion. 


\section{Acknowledgements}

This dissertation could not have been written without the support of others. First and foremost, I would like to thank the PhoenixEM Consortium and its scientific leadership, professors Laurinda Abreu, Ingemar Nordin, Sam Willner, Julian Perelman, Jõao Pereira, Luc Berlivet and Patrice Bourdelais for building the stimulating academic framework that is the JDP Dynamics of Health and Welfare program, and for granting me the opportunity to be a part of it. It has indeed been a full experience, on an intellectual, cultural and human level. I am endlessly thankful to my supervisors professors Paulo Moreira and Lena Högberg for being there at all times needed, providing scientific, practical, and moral support. A sincere thanks goes to the network of $\mathrm{PhD}$ students and friends, both within and beyond the PhoenixEM JDP program, for the constructive co-working sessions and discussions. The final but not least acknowledgement goes to my better half Marc Bernabeu, for encouraging me to pursue the $\mathrm{PhD}$ path, and granting boundless support and motivation ever since. 


\section{Table of Contents}

\section{Chapter 1: Introduction and research objectives ...........................1}

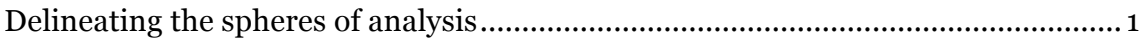

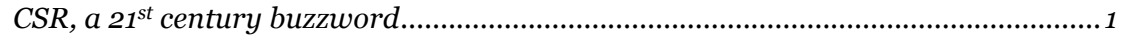

CSR, re- embedded economy and the global public domain .......................................5

CSR for health ........................................................................................................ 9

Problematisation, research questions and contribution .......................................... 14

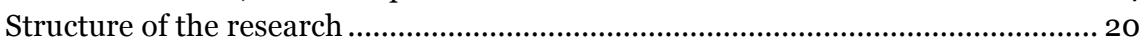

\section{Chapter 2: Research methodology ............................................. 23}

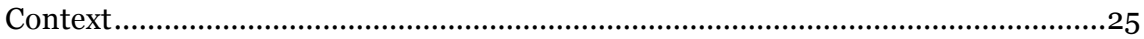

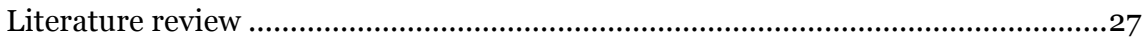

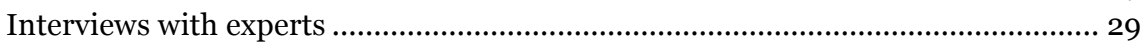

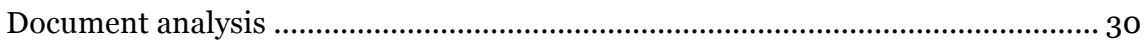

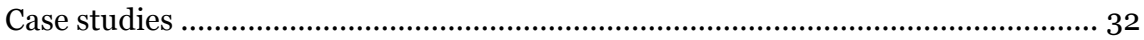

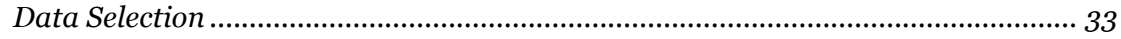

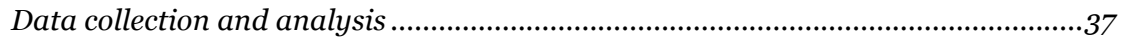

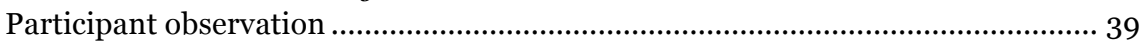

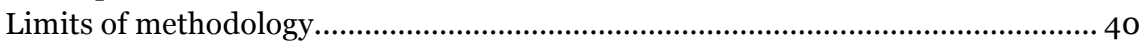

\section{Chapter 3: An introduction to Corporate Social Responsibility ....41}

CSR, a capitalist conception: from philanthropy to social and political

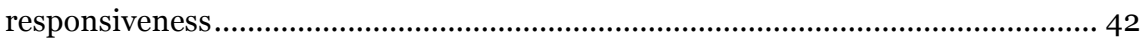

Industrial capitalism, labour rights, and philanthropy .......................................... 42

The post-war period: from Keynesianism to Neoliberalism ...................................... 44

Globalization, CSR and sustainable development ....................................................4 48

Theoretical foundations and underlying CSR rationales ....................................... 51

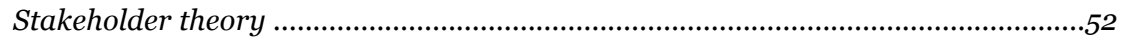

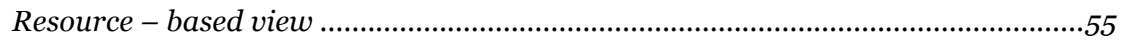

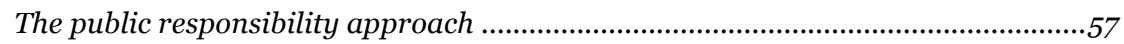

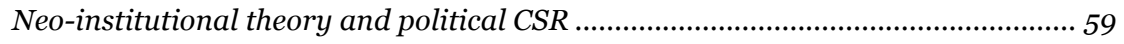

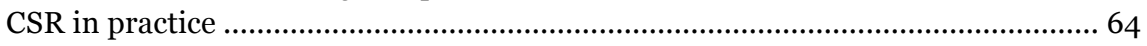

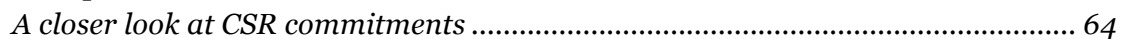

International and supranational CSR policies: problematization, agenda-setting

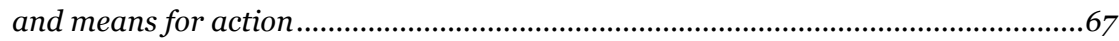

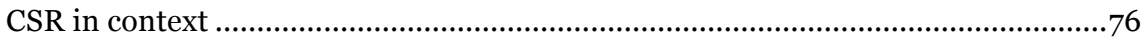

A European approach to CSR: community and regional approaches, national

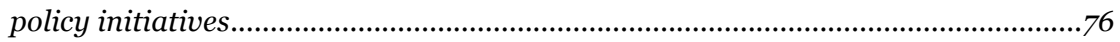

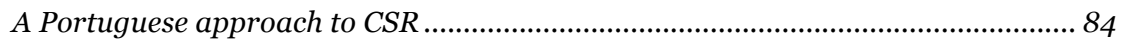




\section{Chapter 4: Health promotion, social responsibility for health, and}

CSR .................................................................................. 93

The health promotion approach as framed by the Ottawa Charter ......................... 94

From sick care to health promotion: biomedical versus salutogenic health ............ 94

Health as a resource, a right, and a social responsibility ........................................ 99

The health promotion approach during globalization............................................104

Threats imposed by global trends upon health .......................................................104

Levels of leverage of the for-profit sector on health: exploring the dimensions of

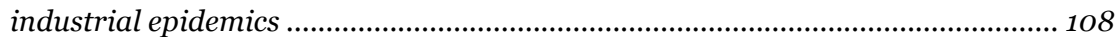

A new meaning of social responsibility for health: actors, expectations and governance for health in the global public domain ............................................... 112

Criticism to the health promotion approach ……....................................................117

Health promotion in context...............................................................................120

Health promotion approaches, issues and objectives in the European Region......12O

Health and health promotion issues and objectives in Portugal..............................126

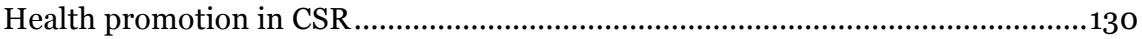

Health promotion in the CSR policy framework ...................................................130

Opportunities and criticalities of CSR initiatives for health promotion: a literature

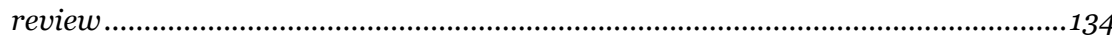

Portuguese public sector health promotion experts' perceptions on CSR initiatives

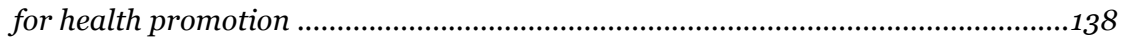

\section{Chapter 5: Real-world CSR practices relevant for health ............. 143}

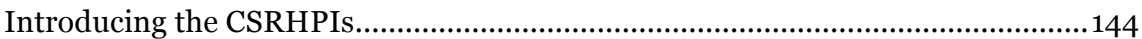

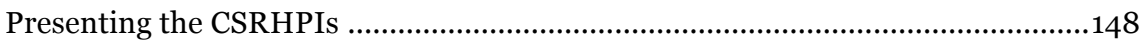

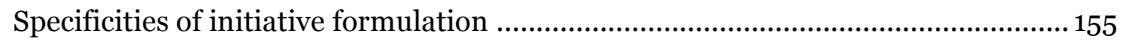

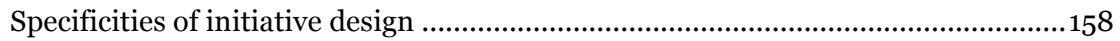

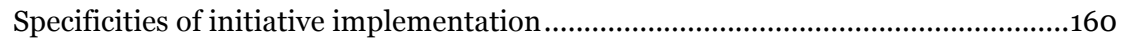

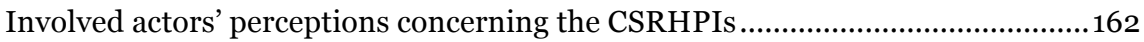

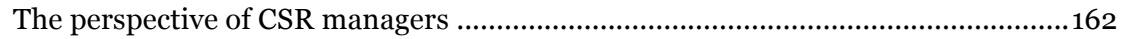

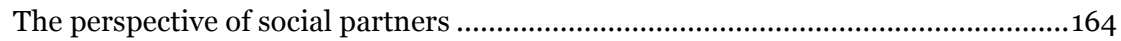

Chapter 6: Analysis and Conclusions ......................................... 167

Implications of CSR initiatives for health promotion ........................................... 167

On the nature of engagement .......................................................................................169

On the participation to the furthering of contextual health promotion priorities and

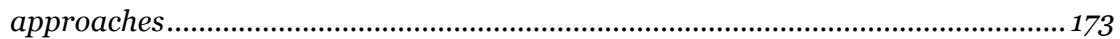

On the advancing of social capital and trust-building at the local level ................. 177

Analysis of the limits encountered and of their determinants .............................. 179

Co-existing rationalities and one-sided CSR approaches...................................... 180

The lack of awareness concerning health promotion ..............................................182

The issue of the positive understanding of responsibility ........................................185

The weak pursuit of social outcomes ........................................................................186

Limited instruments for cross-sectoral negotiation and collaboration ...................188 
Chapter 7: Discussion and Future Perspectives .......................... 191

Imperative adjustments ....................................................................................193

For a stronger normative framing of the CSR approach...................................193

For a health promotion-based public health agenda .........................................194

Two potential alternative developments of the CSR approach ................................196

CSR and partnered governance ……………………………………………...196

CSR and polycentric governance …………………………………………....198

Towards a joint CSR - health promotion policy agenda ..........................................199

Recommendations for further research.....................................................................201

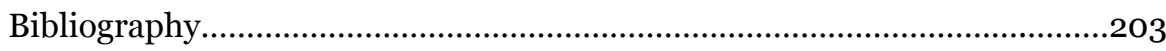

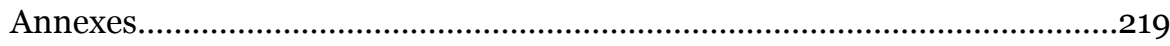




\section{Index of Tables}

Table 1: Interviewed health promotion experts......................................................... 29

Table 2: Company universe for the detection of case studies .....................................35

Table 3: Interviewed partner entities of collaborative CSRHPIs ................................ 38

Table 4: Rationale and guiding principles contained in theory ................................. 63

Table 5: Guiding principles contained in international CSR policies ...........................74

Table 6: Areas of action contained in international CSR policies .................................74

Table 7: Means for action contained in international CSR policies..............................75

Table 8: Areas of action of the health promotion approach.......................................97

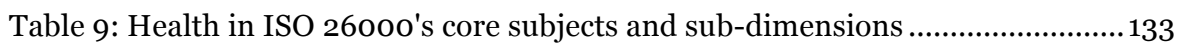

Table 10: Dimensions of CSR management ............................................................ 144

Table 11: Juxtaposition of general CSR statements and areas of action ....................146

Table 12: Universe of CSRHPIs found within the selected companies.......................148

Table 13: List of selected case study CSRHPIs ............................................................149

Table 14: Description of CSRHPIs of pharmaceutical companies .............................150

Table 15: Description of CSRHPIs of private healthcare providers ............................ 151

Table 16: Description of CSRHPIs of ICTs .............................................................. 152

Table 17: Description of CSRHPIs of food retail companies ...................................... 153

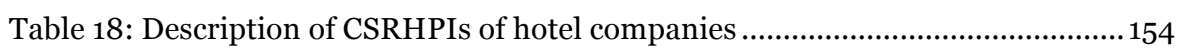

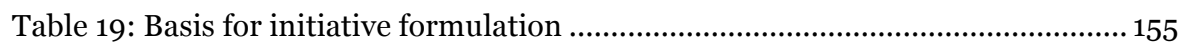

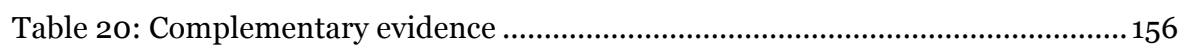

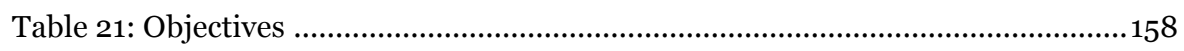

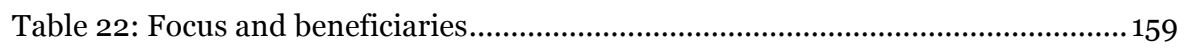

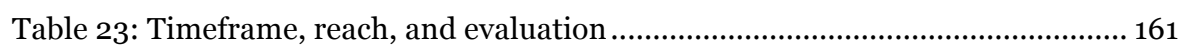




\section{Index of Figures}

Figure 1: The social determinants of health (SDoHs) ............................................... 101

Figure 2: UNGC priority areas for the post-2015 sustainable development agenda.132

Figure 3: Sorting of CSRHPIs in types of commitment ...........................................170 


\section{List of Acronyms}

\begin{tabular}{|c|c|}
\hline AIDS & Acquired Immune Deficiency Syndrome \\
\hline ANI & Assessment of negative impacts \\
\hline APEE & Associação Portuguesa de Ética Empresarial \\
\hline BCSD & Business Council for Sustainable Development \\
\hline BSE & Bovine Spongiform Encephalopathy \\
\hline BSR & Business Social Responsibility \\
\hline CED & Committee for Economic Development \\
\hline $\mathrm{CSO}$ & Civil society organization \\
\hline CSR & Corporate Social Responsibility \\
\hline CSRHPI & Corporate Social Responsibility initiative for health promotion \\
\hline DALYs & Disability-adjusted life year \\
\hline DGS & Direção Geral da Saúde \\
\hline EC & European Commission \\
\hline EU & European Union \\
\hline FCTC & Framework Convention on Tobacco Control \\
\hline GDP & Gross Domestic Product \\
\hline GM & General Motors \\
\hline GMO & Genetically modified organism \\
\hline GRACE & Grupo de Reflexão e Apoio à Cidadania Empresarial \\
\hline IGO & International governmental organization \\
\hline HIA & Health impacts assessment \\
\hline HIAP & Health in All Policies \\
\hline HIV & Human Immunodeficiency Virus \\
\hline HSPH & Harvard School of Public Health \\
\hline ICT & Information and communication technology \\
\hline ILO & International Labour Organization \\
\hline INSA & Instituto Nacional de Saúde \\
\hline MNE & Multi-national enterprises \\
\hline NCD & Non-communicable disease \\
\hline NGO & Non-governmental organization \\
\hline NHS & National Health Service \\
\hline NHP & National health plan \\
\hline NPM & New Public Management \\
\hline OECD & Organisation for Economic Co-operation and Development \\
\hline OPSS & Observatório Português dos Sistemas de Saúde \\
\hline PHP & Private healthcare provider \\
\hline RSO & Responsabilidade Social das Organizações \\
\hline SDoHs & Social Determinants of Health \\
\hline SMEs & Small and medium enterprises \\
\hline SPA & Salus per Aquam \\
\hline SUV & Sports utility vehicle \\
\hline UK & United Kingdom \\
\hline UN & United Nations \\
\hline UNGC & United Nations Global Compact \\
\hline UNESCO & United Nations Educational, Scientific and Cultural Organization \\
\hline UNICEF & United Nations Children Emergency Fund \\
\hline USA & United States of America \\
\hline TRIPS & Trade-Related Aspects of Intellectual Property rights \\
\hline TTIP & Transatlantic Trade and Investment Partnership \\
\hline UCL & University College London \\
\hline WEF & World Economic Forum \\
\hline WHA & World Health Assembly \\
\hline WHO & World Health Organization \\
\hline WTO & World Trade Forum \\
\hline
\end{tabular}




\section{Chapter 1: Introduction and research objectives}

The present research is to be situated in the debate about the development of the contemporary Western European welfare state, its displacement of responsibilities from state to non-state societal actors, and the resulting concerns vis-à-vis the optimal distribution of responsibilities. Drawing, in interdisciplinary fashion, from the fields of political sociology, political economics, welfare studies, public health policy, and management, the thesis focuses upon the involvement of for-profit, nonstate actors into a field traditionally of state competence, that of public health. Are considered two spheres of research and practice that frame and motivate the involvement of business actors in public health in the welfare state, and that have been seldom crossed: the Corporate Social Responsibility approach (from now on CSR), and the health promotion approach. The research sets out to identify the features of business involvement in health promotion through CSR, examining and discussing the issues arising from such involvement in the context of the Western European welfare state.

The first part of this opening chapter begins by briefly introducing the notions of CSR and health promotion, continues by clarifying the perspectives through which they will be considered, and ends by pointing out the ways in which they are related. After a brief problematisation, the second part of the chapter specifies research questions as well as the contribution intended for the fields of CSR and health policy and practice. The chapter ends by briefly presenting the structure upon which the research was conceived.

\section{Delineating the spheres of analysis}

CSR, a $21^{\text {st }}$ century buzzword

During roughly the past twenty years the topics of business ethics and CSR have become "a vital part of the business conversation" (Pearce and Doh, 2005, p. 30), with the majority of large transnational corporations and an ever-growing number of 
small domestic companies actively investing in the implementation and communication of CSR practices (Vogel, 2005). The business world's interest has consequently spilled over, making so that CSR has become a focus of attention of media, academia, national governments, intergovernmental organizations (IGOs), and non-governmental organizations (NGOs) (Perrini, 2012). The survey launched in 2011 by the world's largest corporate sustainability initiative, the United Nation's Global Compact (from now on, UNGC), as to assess the advancement of the Initiative after its launch in 2000 , found that 1.810 companies worldwide had joined the UNGC in 2011, an increase in 54\% the number of the previous year (UNGC, 2011). At the time of redaction, almost 9.000 companies and 4.000 non-business actors are signatories of the Initiative, numbers that are expected to continue experiencing an ascending trend (UNGC, 2015). Coherently, in 2011 the European Commission (from now on, EC) affirmed that the number of companies of the European Union (from now on, EU) signatories of the UNGC rose from 600 in 2006 to over 1900 in 2011 (EC, 2011). Two clarifications are worth making before continuing. In a first instance, as specified by the UNGC survey report of 2011, the terms CSR, corporate sustainability and sustainability are in practice used interchangeably, although they underlie slightly different meanings, all referring to an organization's alignment with, and participation to, what is commonly referred to as the sustainable development agenda. Sustainable development is an approach to development that foresees the harmonization of economic, social and environmental issues, in the perspective that economic development does not alone guarantee social justice and environmental sustainability (Eberhard Harribey, 2006). Other than offering a wider focus than that of economic wealth, the sustainable development frame proposes an anew approach to time, stressing an accent on the need to respect and preserve future generations through long-term sighted management (ibid). As if the interchangeability of terms and the broadness of their realm of application was not sufficient to rise confusion, the terms CSR and corporate sustainability are not necessarily used to depict the efforts of alignment to the development agenda of corporations ${ }^{1}$, but come to substitute the notion of company. Hence, the term CSR is used in common practice, as well as in this research, to depict the alignment to the sustainable development agenda of all for-profit entities, notwithstanding type of ownership or size. The author preferred to use the term CSR as opposed to corporate sustainability, or

${ }^{1}$ By corporation is intended a form of for-profit ownership that distinguishes itself from proprietorship 
sustainability, as the term sustainability is generally used to depict commitments brought forward by all types of organizations (companies, public entities and civil society entities) whilst the term CSR refers solely to the contribution of for-profit actors to the sustainable development agenda (Eberhard Harribey, 2006; Moon, 2007). Additionally, and more importantly, the choice to use the term CSR stirs from the consideration that the term sustainability is often used exclusively to depict commitments that are environmental in nature, whilst the term CSR addresses commitments that intend to bring together economy, society and environment (Lelé, 1991).

But what exactly is intended when speaking of the CSR approach and of CSR practices? Here again a great panoply of definitions exist. In very broad terms it can be said that the CSR approach deals with the non-legally bound obligations and expectations concerning the role that business actors play, or should play, in the physical, social economic and political environments in which they are embedded. Research focuses upon different features of the CSR approach. Molteni and Pedrini (2009 p. 26) stress an accent on the management dimension of CSR, depicting it is an approach to organizational governance that foresees a "renovation, more or less profound, in the firm's strategy, processes and activities". Kotler and Lee (2006) and Moon (2007), among many others, focus upon the relational dimension, clarifying that CSR foresees a mediating effort among the interest of the firm and the claims of legal, ethical, and social nature brought forward by a range of stakeholders, all sharing different expectations concerning the firm in question. Castelo Branco and Delgado (2011 p. 203) highlight both the relational and consequentialist facet of CSR, stressing the approach deals with the "companies' impacts on, relationships with, and responsibilities to, society”. Of a different opinion, Argadoña and von WeltzienHoivik (2009) argue that the CSR is an intrinsically moral category, one that does not represent a tick-the-box response to external claims or impacts, but can be resumed as doing the right thing from an ethical perspective.

As this brief review is apt to prove, the realm of CSR is an essentially contested one, crossed by divergent, and at times competing, perspectives concerning the role of companies in society, and rationalities concerning the purpose of CSR. Whilst such issues, together with others, will be approached in detail in the next section and throughout the research it is sufficient to say, at this moment, that CSR practices all share the same two core features: participation to the sustainable development agenda and voluntariness. This said, the researcher proposes the following 
operational definition of CSR practices: commitments that are discretionary, it is to say that go beyond the requirements set by law, developed by a given company independently or in collaboration with other organizations, as to tackle, through the redefinition of business practices and the deployment of resources, the furthering of objectives that are compatible with sustainable development. The initiatives elapsing from CSR commitments (although not always such commitments are acted upon), can be broadly resumed in terms of socially oriented investments and innovation on one side, and self-regulation on the other. Only secondly, and depending on the perspectives through which they are looked at, such commitments are depicted as featuring ethical, relational, consequentialist, or even strategic dimensions. Concerning the latter dimension, it is worth highlighting that the potentially strategic nature of CSR participated, as Crook (2005) puts it, in CSR's "winning of the battle of ideas" resulting in the mainstream acceptance of CSR practice. The strategic dimension has allowed overcoming the stream of reticence summarized by the 1970's famous quote of the Nobel laureate Milton Friedman "the social responsibility of business is to increase its profits", by promoting CSR as a means to simultaneously achieve profit and social goals through the refinement of processes and the reduction of risks of litigation. The strategic perspective is resumed, in contemporary literature, by Porter and Kramer's $(2006 ; 2011)$ analysis of the link between competitive advantage and CSR and subsequent formulation of the notion of shared value, and, more generally, by what in this research will be deemed as the strategic CSR literature (Hart, 1995; McWilliams and Siegel, 2006; 2010). According to the strategic perspective not only CSR practices are purposeful to the furthering of the sustainable development agenda, they are also beneficial to the bottom line; they may increase operational efficiency through the revisiting of processes and the enhancing employee satisfaction, facilitate access to capital through the bettering of investor relations, and enhance competitiveness and market positioning due to diminished risk of litigation. Yet, according to Vogel (2005) there isn't sufficient evidence to prove that there is a business case for CSR outside of a niche group constituted by larger and direct-to-consumer companies. 
CSR, re- embedded economy and the global public domain

The reader may object, at this point, that the efforts dealt with by CSR pre-existed what has been depicted at the beginning of this chapter as the explosion of its practice. Such objection would be more than appropriate, in the measure that, as we will see throughout this research, CSR depicts the embedding of entrepreneurial and society relations that existed since before the industrial revolution, and that were made more relevant after it, when the needs for negotiation of social and labour issues between business entities, labour unions and civil representation groups intensified (Argadoña and von Weltzien-Hoivik, 2009; Perrini, 2012). In this sense, as we will see further on, CSR can be viewed as capitalistic conception, securing labour protection and social development as desirable and necessary conditions for the instalment and development of the capitalistic economic model (Vogel, 2005; Carroll, 2008). As we will see throughout Chapter 3, in the context of the Western European welfare state model, although with due differences, both demands for CSR and CSR practice have been, historically, implicit. This means that CSR practice was internalized within normal business activity and mediated by the state, the central actor dealing with the allocation and negotiation of responsibilities among social parties. The welfare state is a crucial aspect to consider when looking at CSR in Europe (Brejning, 2012); "the traditional welfare state encounters, translates, and gives the worldwide idea of CSR a particular shape" (De Geer at al., 2003 p. 9 in Argadoña and von Weltzien-Hoivik, 2009 p. 10) as "once the welfare state is defined with its components, principles, and rules of action, the social responsibility of a company is in some ways, also defined" (Argadoña and Weltzien-Hoivik, 2009 p. 10).

This research understands, coherently with Midtun (2005 p. 396; 2008), Sherer and Palazzo (2011), and Vallentin (2012), among others, the current attention dedicated to CSR as a form of social "re-embedding" of markets within changing national and supranational political domains and political economies. The novelty that the CSR approach proposes, hence, is to be understood in the perspective of the development of the welfare state first, and of the extension of the public domain from national to global then (Ruggie, 2004). The developments of the western welfare state are to be resumed preponderantly with the rise of collaborative forms of policymaking involving different societal actors in which the state is not longer the sole actor. Examples of collaborative policy-making are best resumed by both the New Public Management (from now on, NPM), and by the societal corporatism approaches to 
public administration developed in the late 1970s. As explained by Midtun (2005 p. 372) societal corporativism is to be defined as a modality of arrangement of the policymaking process in which interest associations are viewed as partners and coresponsible for public decision-making and implementation. The NPM approach, on the other hand, is characterised by the introduction of managerial-like practices within public administration, and by the contracting out of public services to private actors. It has been depicted as the "steering not rowing approach" (Osborne and Gaebler, 1992) where governments give strategic direction, as opposed to being both coordinators and providers, in a polycentric system constituted upon the involvement of public and private actors alike (Pollitt et al., 2007). Both NPM and societal corporativism approaches share the collaborative nature of forms of policymaking, defined in terms of partnered, relational or polycentric governance.

The term governance originates from the fields of economics and political science and is a term that, similarly to the one of CSR, has become of mainstream usage in the last twenty years. The term can be used descriptively, as in this research, to portray a set of formally or informally organized processes apt to stir a system towards a given priority (Buse and Lee, 2005; Barbazza and Tello, 2014), or it can be used normatively, describing the qualities of a said arrangements: good governance, smart governance or bad governance (Barbazza and Tello, 2014). If the boundaries of the term governance are difficult to clear-cut it will be sufficient, in this context, to describe governance, similarly to what was done for CSR, on the basis of its core features: polycentrism, and strive for convergence of action and goals, carried out through both formal and informal systems of rules (Dogson et al. 2002; Barbazza and Tello, 2014). This means, for instance, that in governance are preferred collaborations, partnerships and self-regulation over hard regulation. Perhaps the most comprehensive, as well as most often quoted, definition of governance to date, is that furnished by the political scientist James Rosneau (1992 p. 4) at the beginning of the 1990 as to depict the changing international relations of the globalized world order. The definition goes as follows:

\footnotetext{
"Governance is not synonymous with government. Both refer to purposive behaviour, to goal oriented activities, to systems of rule; but government suggests activities that are backed by formal authority...whereas governance refers to activities backed by shared goals that may or may not derive from legal and formally prescribed responsibilities and that do not necessarily rely on police powers to overcome defiance and attain compliance."
} 
The main difference between NPM and societal corporativism stands, on the other hand, on the relevance they attribute to negotiation among parties in the policymaking process. Due to its focus on competitiveness and outcomes, rather than on negotiation and processes, NPM, as opposed to societal corporativism, has been long discussed as underlying a disembedded approach to political economy and a form of "actually existing neoliberalism" (Brenner and Theodore, 2002 p. 349; Goodin, 2009). The NPM model is traditionally linked to the Thatcherian UK administration, and societal corporativism to Scandinavian public administration approaches, being Continental and Mediterranean approaches somewhere in between (Midtun, 2005). According to Pollitt et al. (2007 p. 6), nevertheless, in the first decade of the $21^{\text {st }}$ century in the European Union, Continental, Scandinavian and Mediterranean countries alike had, with due differences, embraced what the authors define " the instruments of the NPM toolbox".

Under such premises the author understands, coherently with Sherer and Palazzo (2011) and Vallentin (2012), the CSR approach as an effort to re-embed the economy that makes sense in a perspective of counteracting the rise of neoliberal market and public administration models of the 1980 s (Midtun, 2005). Vallentin (2012) depicts it as a form of post-liberalism in what it represents a "critique, although moderate, to capitalism" (p. 12), and an "antidote to neoliberalism that promotes social liberalism" (p. 9). Coherently with Albareda et al. (2007) and Steurer (2010), the author stands by the perspective that the CSR approach, with its system of values, processes and means for action, offers a frame facilitating the thinking of, and resolving, of business and society relations. It does so by allowing the creation of patterns of negotiation and allocation, of responsibility and relationship, between governments, businesses, and society stakeholders, under the reference of a common objective, that of sustainable development. Vogel (2008 p. 263) stresses that CSR is a public affairs commitment of businesses towards local communities and domestic governments, one that "politicizes business decision making, pressuring firms to make expenditures and commitments they would not otherwise have made". A "political rationalization" at the cross-road of private management and public policy referring to the acquisition of institutional power and legitimacy by a business-based organization (Kramer, 2000; Eberard Harribey, 2006; Albareda et al., 2007; Vallentin, 2012 p. 9). Such literature, which has been termed the political CSR literature, is depicted as follows by Vallentin (2012 p. 20): 


\begin{abstract}
"The political CSR literature considers governance as a mode of democratization as opposed to marketization. It signifies a postliberal search for discursive and community-oriented forms of democracy and thus seeks to address and cope with the limitations of liberal, representative democracy, its institutions and implied division of labor. It imbues governance with democratic - deliberative, civil - value, and it turns to governance not because it is considered a superior or desired mode of governing but due to the absence of viable alternatives. It is not in favor of deregulation: where regulation (hard law) can be applied, it should be applied. Instead of seeing the global governance of CSR as a instance of neoliberalism-in-action it comes to signify an opposite - democratic-minded as opposed to neoliberal principle: there is, thus far, no alternative to soft law in the global realm".
\end{abstract}

As for what concerns the global public domain, both CSR and the sustainable development agenda are purposeful in terms of legitimization. As specified by Eberhard Harribey (2006) and Matten and Moon (2008), CSR served to strengthen consensus around the liberalization of markets and, at the level of the institutions of the European Union (from now on EU), to allow for the establishment of the single market. On this subject Argadoña and von Weltzien-Hoivik (2009) postulate that there is only one new approach to CSR, the one linked to globalization and to the activities and impacts of Western companies in developing countries or on a global scale, postulating the need to distinguish and separate national, foreign and global approaches to CSR. In this manner, international, supranational and national policies on CSR, developed by IGOs, supranational bodies and formally agreed by governments, or developed by national governments themselves, from now on referred to as the CSR policy framework, become instruments of supranational governance. In this sense, the author understands CSR practice as organized around top-down processes, such as international and supranational CSR policies, only secondly adapted according to contextual local policies and contingencies. Conversely, still according to Brammer et al. (2012 p. 504), the global public domain, intended as an "increasingly institutionalized transnational arena of discourse, contestation and action concerning the production of global public goods", is a formidable source of isomorphic pressure, leading to the institutionalization of CSR practices through adaptation. CSR practices "address the concerns of critics of economic globalization without increasing the regulatory burdens on firms, which would risk undermining their global competitiveness" (Vogel, 2008 p. 263). Further, they allow businesses' participation to the production of global public goods relevant in terms of public health, education, security, human rights and social protection, to name a few (Matten and Crane, 2003; Ruggie, 2004; Midtun, 2008; Nelson, 2008; Sherer and Palazzo, 2011). 


\section{CSR for health}

As previously stated, among all of the public areas of action to which business entities may contribute via CSR, this research considers the realm of public health. Such interest was stirred by the perception that health is being taken on by companies as a CSR cause and area of intervention, concerning employee health and wellbeing as much as the health of consumers, communities and the society at large (Herrick, 2009, Fooks et al., 2011; Sorensen, 2011). As brought forward by the North-American NGO BSR, which stands for businesses' social responsibilities, "some companies are starting to assert stronger roles in improving population health through a wellness and prevention lens" (BSR, 2014 p. 5) leading to a situation in which "the benefits related to corporate health promotion are an expanding practical and academic notion (Bunde Biruste et al., 2010 p. 97). Arguably the first example of CSR initiative for public health was the establishment, in the 1920s, of the International Health Program by the Rockefeller Foundation, destined to curb yellow fever and other tropical diseases through the establishment and funding of public health schools (Buse and Lee, 2005). To date, a number of miscellaneous examples of CSR initiatives addressing health outcomes can be found. Altria's group tobacco companies (constituted, among others, by Philip Morris and John Middleton) have put up, as part of their CSR strategy, QuitAssist $囚$, which, according to the report The Global Economic Burden of Non-Communicable Diseases, redacted conjointly by the Harvard School of Public Health and the World Economic Forum (HSPH and WEF, 2011) is the number one stop smoking website in the world. Herrick (2009 p. 60) elucidates some examples of CSR initiatives implemented by the food and drink industry, promoting health messages often related to physical activity and nutritional habits related to the growing concerns of obesity and food-related ill-health:

\footnotetext{
“Coca-Cola's 'Vida Activa' scheme provides dedicated health advice to Latino communities; its 'Step with it' scheme has one million participants across the US; and its 'Thai Kids on the move' programme had 186,000 participants in 2004 and one million projected by 2007 . Pepsico has been heavily involved in school health promotion with its 'Balance First' programme and, most recently 'Smart Spot Dance' in conjunction with the national NGO America on the Move, whose educational materials are now used by a growing number of US teachers to convey the familiar message of energy balance. While the USDA and NIH have successfully pushed their Dole-sponsored ' 5 a day' campaign, Kraft's ' 3 a day' message encourages the daily consumption of three portions of dairy products; with direct promotional links to its Kraft SinglesTM cheese slices and BreyersTM yoghurt (www.3aday.org)".
} 
Yet, as we will see throughout the research, differently for businesses' involvement in issues such as the environment or human rights, which have been spotlight topics in CSR (Vogel, 2005), existing research concerning business involvement in health through CSR is limited to punctual activities inherent to the CSR strategies of selected and sensitive industry sectors (food and drink industry, tobacco, alcohol above all), and to specific contexts, such as the United States of America (from now on, USA) and the United Kingdom (from now on, UK), or developing countries. In short, as we will see in detail in Chapter 4, CSR initiatives addressing health outcomes have insofar been considered punctually, and not as a phenomenon indicating the progressive involvement of non - state actors, and specifically forprofit actors, in domains that have been traditionally of state competence.

As to motivate the researcher's initial perception, in the first phases of the present research the author conducted a small study upon the CSR initiatives mentioned on their webpages by the corporate members of the network CSR Europe, the European business network for Corporate Social Responsibility. Five major categories of CSR initiatives addressing health outcomes were encountered: workplace health promotion, physical activity and healthy nutrition, hygiene campaigns, initiatives promoting health access and delivery and industry supported scientific and educational activities, of which the first category is the only comprising activities directed exclusively to employees, whilst the remaining target a range among local communities, stakeholders, consumers or the society in general. As to give examples concerning the types of activities implemented within each category it can be said that among the category of workplace health promotion were found initiatives destined to: the creation of focus groups to share and discuss health information, the implementation of worksite fitness centers, the establishment of on site medical units providing physiotherapy, drug and alcohol counseling, skin cancer examination and nutritional advice, and the distribution of wristbands that monitor activity levels and sleeping times, used to track the rhythms of employees returning to work after mental illnesses. Initiatives in the category of physical activity and healthy nutrition figure: the financing of infrastructures, sports clubs or sports material, the reshaping of the dietary profile of ailments, the setting of beyond-the-law food safety and security measures, the sponsoring of sites or professional figures for nutritional advice, and the making available of balanced affordable meals in restaurants. For what concerns CSR initiatives targeting hygiene, were found activities destined to increase literacy upon hand washing and oral health. Among the category of initiatives promoting healthcare access and delivery where found commitments 
destined to: the reduction of drug prices, the offering of vaccines and of infant early diagnosis, the funding of innovations in the areas of health and social care provision through tele-health and tele-care, and as to develop more affordable medicines. Finally, in the category of industry supported scientific and educational activities were found initiatives destined to the sponsoring of independent medical education schemes, the partnering with research institutions to collect scientific basis on the health standards of products, and activities destined to identify, control and prevent problems of abuse or addiction. Were found additional initiatives not fitting within the above-mentioned categories, such as prevention program against AIDS and initiatives for road safety and car accident avoidance. On the basis of such preliminary study it was concluded that CSR initiatives addressing health outcomes are a reality other than a perception, that initiatives are put in place by different industry sectors, not only sensitive ones, within and beyond the context of the Western high income economies and developing countries were they have been studied.

Insofar we have talked of the addressing of health outcomes through CSR initiatives. It is considered relevant to specify, before going on, that by health outcomes are predominantly meant health gains but also parallel objectives, such as equity in access, financial sustainability of health systems, and resolution of complex issues through whole of society involvement. We can distinguish such outcomes in biomedical and non-biomedical (or social) terms. In what they allow for the achievement of non-medical health outcomes, coherently with what stated in the previous sub-section, the researcher argues that CSR practices are means for the business sector to participate to health governance, assumption that mirrors what stated by Buse and Lee (2005). As previously clarified, the term governance refers to the steering of collective action towards a common goal for the realization of a shared outcome. Similarly, health governance refers to the ensemble of actions and means destined to the achievement of health outcomes (Dogson et al., 2002; Buse and Lee, 2005; Barbazza and Tello, 2014). Alike the notion of governance, the notion of health governance has been subject to blurriness of interpretation. As to align understandings concerning health governance Barbazza and Tello (2014) carried out a systematic literature review overviewing fundamental dimensions of health governance. They sorted their findings in values, functions and outcomes of health governance. Their findings showed that the fundamental values associated with health governance are control of corruption, democracy, human rights, ethics, conflict prevention, public good and rule of law. The sub-functions encountered 
envision accountability, partnerships, policy/strategic direction, information/intelligence, adequacy, participation and consensus, transparency, and regulation. Finally, the outcomes of health governance were designated to be: effectiveness, efficiency, equity, quality, responsiveness, sustainability, risk protection and improved health.

"Responsibility is a term commonly associated with the governance of health" (Herrick, 2009 p. 58) and, as explained by Dogson et al. (2002), and previously argued for, the responsibility for health governance has historically been that of governments at the national and sub-national levels. This is a point worth re-stating, as it is important for all the other arguments made in the research. Accordingly to the processes depicted before such allocation of responsibility has evolved, more in intention than in action, towards a partnered or polycentric governance model, intending to include both at the domestic level and transnationally, civil society and for-profit actors in health governance. Such developments in public health policy have lead to a common acknowledgement, among health decision makers and advocates, that, although states are ultimately accountable for the right to health, all members of society, including businesses, have a social responsibility towards health (UN, 2000; UNESCO, 2010, HSPH and WEF, 2011). If throughout this research the grounds motivating the inclusion of the for-profit sector in health governance will be analyzed thoroughly, it is sufficient, at this point, to specify that such inclusion has been motivated upon two considerations. On one hand, the ability for private companies' competences, material resources, communication channels, leverage, and where relevant transnational reach, to be harnessed for public health objectives. On the other, the accountability of private companies in shaping the determinants of ill health through manufacturing, distribution, marketing and advertising, packaging and disposal of products and services, as well as related to labour standards, lobbying, research and public affairs practices, as well as environmental standards. The self-regulation function of CSR allows companies to participate to health governance by setting and enforcing rules that are relevant for health outcomes. On the other hand, the social investment function of CSR is passible of allowing business actors to help advance, through material or non-material contributions, the furthering of public health objectives set by locally and internationally.

This research intends to look at businesses' participation to health governance through CSR by engaging the perspective of the health promotion approach. In very broad terms, as also this theme will be the subject of Chapter 4 , it can be said that the 
health promotion approach, developed in the aftermath of the world wars, shifted the understanding of health from a biomedical to a salutogenic model, where health was no longer considered as the absence of disease, but come to be understood as a resource for both the individual in the coping of threats and in the pursuit of life goals, as well as a common good of the collectivity (Antonovsky, 1996). The health promotion approach, whose milestone document is the declaration that resulted from the first International Health Promotion Conference held by the World Health Organization (from now on, WHO) in Ottawa in 1986, looks at health as determined by the intersection of social and personal factors, where the place of birth and socioeconomic position are considered as weighting on morbidity and mortality factors inasmuch as age or genetic makeup. The health promotion approach was considered a relevant frame for the present research for a number of reasons. In a first instance, in what it considers the non-healthcare dimensions of health, the health promotion approach is inherently concerned with the optimum allocation of responsibilities within social actors, it is to say "how to produce health as an overall systems goal, not just a responsibility of the health sector" (Kickbush, 2003 p. 385). As we will see throughout the research the CSR and health promotion approaches share common features. Both health promotion and CSR define, as their ultimate goal, the improvement of the wellbeing and health of the planet and its inhabitants, to be achieved through an approach that is both transformative, it is to say directed at societal change, and value-laden. The CSR approach is transformative in what it relies on an anew notion of development, the one of sustainable development, considering there are structural causes to poverty and environmental decay that are to be addressed through a change in political, institutional and educational responses (Lelé, 1991). On its side, as we will see in Chapter 4, the notion of health promotion is transformative, in what it has led to the establishment of an anew meaning of health, intended as a complete state of wellbeing instead of the mere absence of disease. Furthermore, both the notions of CSR and health promotion are value-laden, driven by the concepts of ethics, responsibility, solidarity, empowerment, and equity, having both been concretized in a perspective of advocacy and response to public awareness on issues such as labour, the environment, and social and human rights. Finally CSR and health promotion are coherent in the identification of the strategic approaches set to achieve the overall purpose, both arguing for a socio-ecological, assessmentbased, whole-of-society addressing of the determinants of health and wellbeing. In this sense Kickbush (2010) frames the sustainable development (and hence, indirectly, CSR) and the health promotion agendas as being mutually reinforcing, and potentially leading to co-benefits if tackled conjointly. On the other hand, the 
challenges offered by the sustainable development model and CSR to public governance are comparable to the defies the health promotion approach presents to health governance, in terms of need for processes, structures and means allowing, mediating and balancing the whole of society involvement they rely upon.

\section{Problematisation, research questions and contribution}

CSR is a strongly contested subject. It has long been argued that CSR is a freefloating idea that hasn't yet undergone a process of institutionalization, and that the definition of the nature and scope of CSR, varying according to the different actors and contexts in which it is handled, is an empirical question that applies to punctual situations rather than a solid operational concept (Carroll, 1999; Hatch and Godfrey, 2007; Min-Dong, 2008; Sweeney and Coughlan, 2008; Brejning 2012). What has been the core subject of CSR contestation, though, are its nature and purpose. According to Argadoña (2006 p. 1) it is an "amalgam of descriptive, instrumental and normative proposals, based on mutually incompatible ethical, sociological and economic theories". Palazzo et al. (2012) have argued that the moral agency of corporations, as for any other for-profit entity, is blinded, in decision-making, by pragmatic and economic frames, which do not allow effectively including a social perspective. On the other hand, Campbell (2007) has highlighted that the win-win logic according to which business and public objectives are aligned is contrary to the business precept that managers should prioritize obligations towards investors before society. The intertwinement of core business operations and social obligations that distinguishes CSR from philanthropy has been condemned on the grounds of the impossibility to discern the extent to which CSR isn't an additional channel to achieve inner reputational, commercial and strategic objectives (Buse and Lee, 2005). Its "appraisive" nature, in the sense that it is considered valued to be socially responsible as opposed to irresponsible, combined to its voluntariness, it is to say businesses' autonomy in setting the agenda, may incentivise companies to declare engaging in socially responsible practices without truly committing to them (Moon, 2007; Brammer et al., 2012). Nevertheless, it is the frame in which CSR has been developed, that of sustainable development within globalization, which has been most harshly criticized, under the assumption that growth in a global capitalistic perspective is not sustainable per sé. Such critique is based upon the consideration that globalization has harshened social inequalities worldwide, increasing the polarization of resources in the axes north-south, centre-periphery, and high and low classes, both between 
and within countries, leading to the consideration that inequality and unsustainability are structural to the process of globalization (Harvey, 2005; Labonté and Shrecker, 2007; Porter, 2007; Baum and Sanders, 2011; Ayo, 2012). In this perspective CSR, as an approach inherent to both capitalism and globalization, has been deemed to be oxymoronic and instrumental to the persisting of a world order based upon an inequitable distribution of resources as a "remedy that doesn't cure the disease, but partly prolongs it, indeed part of the disease" (Zizek, 2010).

The researcher starts by acknowledging that, although there is evidence and history of business entities, and especially large, multi-national corporations pursuing "opportunistic or predatory behaviour, including the capture and subversion of regulatory authorities" (Campbell, 2007 p. 974), leading to a situation in which the business sector is often depicted almost as a mythological monster always putting profits before people (Frederick, 2006), there are many examples of businesses behaving in socially responsible ways, abiding and exceeding law commitments, investing in social causes, and supporting public policy objectives (Campbell, 2007). CSR is neither an impeccable nor a radical instrument, as evident from the shortcomings depicted above, and particularly the ones that consider its potential to be used as an instrument to vest and perpetuate social and economic asymmetries. Notwithstanding the weaknesses intrinsic to its constitutive features, this research builds on the consideration that CSR is, to date, a mainstream approach to corporate governance; "CSR practice is real and substantive and deserves to be taken seriously by anyone interested in politics, business or the relationships among the two" (Vogel, 2005 p. x). Other than being widespread, CSR, as other essentially contested concepts, such as sustainable development, or justice, it is both innovative and transformative and is, in potency, a vehicle to redefine the role and status of business entities and the outcomes expected from business activities (Moon, 2007). Hence, in a reformist perspective that does not put in question neither the capitalistic model, nor the frame of sustainable development, the CSR approach is passible of constituting a meaningful framework for the reconsideration of the role of business in society, allowing both normative and operational tools for the social embedding of the economy. On the normative level, it offers a morally bound frame for conciliating economic activities and objectives according to the needs, expectations and priorities of the environment in which such activities take place, as well for establishing patterns of accountability connecting economic activities and their positive and negative impacts. At the operational level, it provides a governance frame and relative instruments to favour social dialogue, potentially conducive to what Reich (2014) 
defines "stakeholder capitalism", directed towards democratisation as opposed to marketization, where the company is viewed as a form of collective action "from which everyone should benefit, not just shareholders". Also, CSR allows for embodied business forms to gain an evaluative power under and ethical perspective, allowing the establishment of internal procedures that permit choosing, debating and deciding on moral grounds (Petit, 2007).

CSR within the welfare state has been considered purposeful to foster inclusion and participation of the business sector towards the furthering of social policy objectives, the resolution of complex social issues, and the strengthening of social consensus (Albareda et al., 2007). Furthermore, it has been considered as a vehicle to refine business management processes at the domestic level (ibid). On the other side, "CSR represents a form of self-regulation that may supplement, or even to some extent substitute, public policy-led governance" (Midtun, 2008 p. 409). The substitution potential is to be understood in the perspective that CSR practices allow to bypass the coordination role of the welfare state, being it possible for social issues to be dealt with directly from business actors in consultation with civil and local public actors (Midtun, 2005; Matten and Moon, 2008). In this sense, the opportunities inherent to CSR practices are counterbalanced by preoccupations concerning their potential to distort the allocation of responsibilities between public and private, in a situation in which the crisis and unsustainability of the welfare state has been a subject of political and ideological debate (Brejning, 2012). The last sentence highlights that the welfare state is a crucial context to analyse CSR practices, because, differently from situations inherent to weak or failed states, where private actors are expected to fill in the gap, the core challenge imposed by the CSR approach upon the nation-state is engaging in anew postures as to accommodate the involvement of business actors in social issues in an optimal way. Furthermore, CSR practices call for the individuation of processes and structures allowing the convergence of business efforts and collective objectives, the balancing of potential conflicts of interest and the monitoring of results.

As for what concerns our field of interest, the pursuit of health within CSR has been criticised for being associated with both negative and positive externalities. Being the unveiling and discussion of opportunities and threats associated with CSR practices one of the objectives of the research, it will be sufficient, at this point, to stress that core threats are associated with the commercially-based distortion of health messages and values, and with the displacement of competences and authority from 
public to private actors (Buse and Lee, 2005; Herbert, 2005; Babor, 2009; Friedman 2009; Fooks et al., 2011; Carter, 2015). Opportunities, on the other hand, are envisaged as elapsing from the availability of increased material and non-material resources for public health objectives, the creation of collaborative advantage in the shared addressing of complex social issues - considered more effective than top-down enforcement of health awareness and regulation - and the fostering of social cohesion (Werner 2009; Bunde Birouste et al., 2010; Babor and Robaina, 2013). The contrasting perspectives concerning the nature and scope of CSR, as well as the concerns it raises regarding its desirability for both health promotion policy and practice, highlighted the need for the present research; as stressed by Buse and Lee (2005) the goals, strategies and objectives of the business sector in relation to health need to be further explored and critically assessed. Such examination is considered relevant as to inform and alert policy-makers of the potential underlying lobbying objectives and hidden agendas of CSR activities, other than to discuss optimal involvement in health issues (Mikkelsen, 2005; Fooks et al., 2011; Dorfam et al., 2012). As noted by Wiist (2006) corporate practices provide tangible targets for both advocacy and research, more valuable for policy-making discussion than the debates of market fundamentalism or extreme capitalism.

Such analysis, as highlighted by Herrick (2009 pp 51 and 60) is most relevant in the context of the welfare state, as CSR initiatives bring about issues concerning:

\begin{abstract}
"The implications of this strategic uptake of health or in the viability and legitimacy of the state's own public health role (...). At a time when the appropriate and acceptable degree to which the state can intervene upon individual health or risk behaviours is being debated, the corporate interventionist ethic demands the same degree of empirical analysis currently devoted to that of public health".
\end{abstract}

It is a sensitive issue to deal with, that of the displacement of responsibilities in contemporary societies. The discussion upon private actors taking in charge of public responsibilities for health is comparable, to some extent, to the one concerning the degree of desirability of individual's responsibility for health. The risk is that of privatizing responsibilities, it is true, but on the other hand there is a clear necessity to gain both commitment and action of all societal actors, from individuals, to community actors and organizations, public and private, national and supranational, in order to address complex issues, such as the ones dealt with by public health in a health promotion perspective. 
As stressed in the very beginning of this chapter, the present research intends to identify the features of business involvement in health promotion through CSR initiatives, and to examine and discuss the issues arising from such involvement in the context of the Western European welfare state. The purpose is that of participating to the clarification, in a perspective of welfare state development and reshaping of societal obligations towards a whole-of-society participation to social and health objectives, of the potential contributions and dilemmas CSR initiatives pose for health promotion policy and practice, as well as unveiling the current limits to such contribution. On the basis of the examination of pinpointed threats, contributions, and inherent limits, the research aims to offer recommendations concerning the adjustments to be made, at the level of CSR policy, health promotion policy and business management, as to enhance potentialities, minimize dilemmas, and counteract limits.

The specific questions set for the research are the following:

RQ1. What are the rationales behind the involvement of the business sector in health promotion?

RQ2. In what terms has health promotion been considered in the CSR policy framework?

RQ3. What types of health promotion topics, objectives and beneficiaries are tackled by CSR initiatives addressing health outcomes?

RQ4. What are the dilemmas and limits hindering the potential contributions of CSR initiatives to health promotion policy and practice?

RQ5. How do the determinants of the contributions, dilemmas, and limitations of CSR initiatives for health promotion relate to the CSR policy framework formulation and its contextual application?

The intended original contribution of the research is twofold: a research contribution, and a policy contribution. As for what concerns the research contribution, destined to the fields of health promotion and CSR research, research question number one (from now on RQ1) contributes to clarifying the notion of CSR by identifying, among theoretical stances, the different rationalities underlying CSR and inherent standpoints upon the role of business in society. Specifically, it clarifies which rationalities, present in theory, are brought forward by current CSR policies. Additionally, the knowledge produced through the tackling of RQ1 elucidates the 
rationalities motivating business involvement according to the health promotion approach, establishing a connection with those inherent to the CSR approach. RQ2 and RQ3 set the basis for understanding if and how health promotion has insofar been considered an area of action within the CSR policy framework, exemplifying a number of topics and objectives confronted by CSR initiatives addressing health outcomes, and discussing them in relation to priorities and strategic approaches of health promotion policy. RQ4 and RQ5 allow pinpointing first, and discussing then, the dilemmas, potential contributions and inherent limits of CSR initiatives in a health promotion perspective, as well as identifying critical issues to be addressed by both health promotion and CSR decision-makers in this respect.

As for what concerns the contribution to CSR and health policy and practice, building from the analysis and discussion of the key documents issued by the policy-leading global organisations UN and WHO, the research allows bridging the health promotion and CSR policy frameworks in an a perspective of intersectoriality. According to Kickbush (2010) the linking of the two agendas is beneficial in what it allows for each agenda's normative and strategic goals to reinforce that of the other. From this analysis resulted a number of recommendations directed to the shaping of health-promotion adjusted CSR policy, CSR-adjusted health promotion policy, their application, as well as the development of a joint policy agenda addressed to both private and public policy-makers.

\section{Structure of the research}

The upcoming chapters are structured as follows:

Chapter 2 presents and motivates the methodological approach, describes one by one the methodological instruments chosen to tackle each research question, and terminates by pointing out what the researcher believes to be the limits of the methodology.

Chapter 3 portrays the CSR approach through a mixture of history, policy and practice. The first section depicts the development of CSR as intertwined with the evolution of business and society relations in Western high-income economies. The second section examines, on the basis of theory, the different underlying standpoints concerning the role of business in society, the principles that define and orient the sphere of responsibility of CSR, and its expected outcomes. After a brief description of the main international policy instruments that make up the CSR policy framework, 
section three discusses the extent to which theoretical stances are reflected in policy (RQ1). The chapter ends by contextualizing CSR according to different political and economic traditions in the Western European welfare state, and by giving examples of ways in which national governments are currently influencing CSR.

Chapter 4 focuses upon the portrait of the health promotion approach and of its connection with CSR. It begins by depicting the constitutive dimensions of health promotion and its purpose in the evolution of public health. It continues by discussing its developments in the global public domain, clarifying the priority issues and challenges of the health promotion agenda in the 21st century. The second section clarifies the leverage of business activities on health, and connects them with the rationalities motivating the involvement of business entities formulated within the health promotion approach (RQ1). The chapter ends by establishing a relation between CSR and health promotion, analysing if and how health promotion has insofar been considered as an area of intervention in CSR policy (RQ2), unveiling health promotion topics tackled by CSR initiatives (RQ3) as well as pinpointing the dilemmas and limits for health promotion they bring about according to research and health promotion experts (RQ4).

Chapter 5 presents the results from the case study. The chapter, which intends to complement the pinpointing of health promotion topics and objectives of CSR initiatives operated in Chapter 4 (RQ3), is divided in four parts. It begins with a brief introduction of the overall approaches to CSR of the five industry sectors participating in the study. It then goes on to present the universe of CSR health promotion initiatives encountered within the case studies as well as delineating the features of the ones selected for in-depth analysis. The third section of the Chapter is dedicated to presenting the specificities of formulation and implementation of the selected CSR-based health promotion initiatives. The last, descriptive, section of the chapter is dedicated to reporting the perceptions of involved actors (CSR representatives and social partners) concerning the potentialities and limits of CSR initiatives in a health promotion perspective (RQ4).

Chapter 6 discusses the findings from the real-world case studies on the basis of the findings relative to the literature review and expert opinions (RQ4). Additionally, on the basis of the findings from the tackling of RQ1, RQ2, RQ3 and RQ4 it scrutinizes how the determinants of the dilemmas, contributions and inherent limitations of CSR initiatives for health relate to the CSR policy framework formulation and its contextual application (RQ5). 
Chapter 7, other than furnishing recommendations, discusses potential future developments of the CSR approach in relation to health promotion, and opens lines for further research. 


\section{Chapter 2: Research methodology}

As clarified in the previous chapter, the research grounds upon the consideration that CSR practice is organized around what as been defined as the CSR policy framework, constituted by international and supranational CSR policies first, then adapted through domestic policies and contextual dynamics. On the basis of such consideration the methodological approach chosen to address the research purpose is that of qualitative policy analysis. As specified by Dunn (1994) policy analysis can be defined as an applied social science, developed since the 1970s, that serves to create, assess and communicate knowledge relevant to policy. Gruening (2001) points out the double functionality of policy analysis: to identify the causes for the failure or success of social policies (analysis of policy) as well as to delineate solutions for the problems encountered, with the objective to instruct policy-makers and inform public debate on policy issues (analysis for policy). Weimer and Vining (2016 p. 23) depict the outcome of policy analysis as being "as simple as linking a proposed action to a likely result"; yet policy analysis is more complicated than that, it is both descriptive and analytical, allowing an analysis that is at the same time: retrospective, understanding potential causes of failures and successes; prospective, making conjectures upon consequences of intention and action, as well as prescriptive, serving to inform decision-making (Dunn, 1994, Walt et al., 2008). As specified by Weimer and Vining (2016) not all support to decision making constitutes a policy analysis; in order to qualify as such it has to be based on social values and related to decisions with public effects. If traditionally the decision-makers considered concerning decisions with public effects were merely public sector-based, policy analysis is nowadays considering the policy-making of a much wider array of actors, namely the private sector (Hajer and Wagenaar, 2003; Walt et al., 2008).

Walt et al. (2008) depict different frameworks engaged by researchers to detect and organize elements and relationships consisting of their policy analysis: stages heuristic, policy triangle and network. This research engages the stages heuristic framework, apt to cover all phases of the policy process, from intention to action, as to comprehend how CSR policy objectives are formulated and prioritized, and discern what happens when they are applied within local contexts (Walt et al., 2008; 
Gruening, 2001; Birkland, 2007). Birkland (2007) defines the stages of the policy process in terms of problematization, agenda setting, means for action, and implementation. The former three relate to the sphere of intention, whilst the latter to the sphere of action. Problematization depicts the "why" underlying the policy process. It is based upon a framework, value or process-driven, that motivates intervention upon a certain issue (ibid). Agenda setting defines the "what", it is to say the definition, among alternatives, of areas in which intervention is to be carried out (ibid). Both problematization and agenda setting are politically laden, in what they rely on normative principles and priority setting; as highlighted by Birkland (2007 p. 66) quoting Schattschneider (1960/1975) "the definition of the alternatives is the supreme instrument of power". Means for action specify the "how to" in a given intervention, defining instruments, processes and structures purposeful to achieve identified goals. The last stage, the one of implementation, depicts the "what happens", it is to say the way the activities inherent to the previous stage take shape in real world situations.

Policy analysis can be carried out through qualitative, quantitative or mixed methods (Dunn, 1994). The researcher chose to engage a qualitative approach for the present research. Four characteristics of qualitative methods have motivated such choice: they are exploratory, interpretative of complex causes and effects, and context-based. Given that CSR practices have been seldom considered in relation to the health promotion approach, it has been considered relevant to engage in a qualitative methodology, purposeful for experimental studies, and for areas in which little knowledge exists (Stake, 2010). Qualitative research further serves to understand phenomena holistically, trying to detect, through interpretation, trends among the multiple meanings attributed to phenomena and inherent processes; in other words, to detect the "multiple realities" associated to a phenomenon according to the perspective from which it is interpreted (Stake, 2010 p. 65; Cresswell, 2009). This is relevant for CSR practices that, as previously contended, are subjected to innumerous and contrasting understandings, normative, instrumental and pragmatic. As specified by Hajer and Wagenaar (2003), interpretative approaches to policy analysis are relevant to detect how specific meanings shape problematization, as well as how they are understood in practice. Qualitative research is appropriate for contextbound analysis, being relevant to comprehend how processes work on general grounds as well as how they work in a specific situation (Stake, 2010). As suggested by Stake (2010) qualitative research is suitable to comprehend potential causes for given processes, and predict effects for others, based on interpretation rather than 
correlation as in quantitative methodologies. The researcher's choice to adopt a qualitative methodology approach in relation to the object of study is backed by both literature approaching CSR and health promotion interventions. McWilliams et al. (2006) have called for CSR research to move beyond quantitative and correlational studies to more qualitative explorations. Furthermore, they have argued that qualitative analysis is particularly purposeful to analyse the social, as opposed to the business, outcomes of CSR. Brejning (2012) has argued that qualitative research is purposeful to analyse the connections between CSR and the welfare state. Also, the qualitative approach is coherent with the approach to research on health promotion interventions, which, differently from the quantitative approach characteristic of epidemiological and clinical studies, is constructed qualitatively, through the study of knowledge, values and dynamics impacting health both at the individual and political level (Walt et al., 2008). All research presupposes a collection of information and data; participant observation, case studies, interviews and document analysis are the methods most commonly employed in qualitative policy research as to achieve understanding, produce meaning, and develop empirical knowledge (Bowen, 2009). The researcher chose to answer the research question by engaging all of the aforementioned research methods, preceded by a literature review. Each method's purposefulness for the answering of the research question, choices inherent to data selection, collection and analysis are depicted in detail below. Before clarifying the research method, a moment will be took to explain the choice of context.

\section{Context}

As specified in the first chapter, the political and economic space in which the CSR will be contextualized is that of the Western European welfare state. As we will see in Chapter 3 there isn't one Western European welfare state model but a variety thereof, broadly to be summarized, according to the traditional distinction made by EspingAndersen (1990), in Scandinavian, Continental, Anglo-Saxon and Mediterranean. This research takes place in the context on the Mediterranean welfare state, and more specifically, in Portugal. The choice to focus on the Mediterranean welfare state and Portugal was motivated by two sets of considerations connected to the development of CSR in Portugal and to the nature of the Portuguese welfare state. CSR practice has been scarcely researched in the Portuguese context, both theoretically and in practice, being the majority of studies on CSR in the European context focused on continental or Anglo-Saxon Europe (Maignan and Ralston, 2002; Castelo Branco and 
Rodrigues, 2008; Castelo Branco and Delgado, 2011). At the same time, CSR is an issue that has still been scarcely approached by the Portuguese government, one of the few in Europe not disposing of a national plan on CSR at the time of redaction (EC, 2014). In 2010 the European corporate-based network CSR Europe reported that public awareness concerning CSR in Portugal was still very fable due to a lack of governmental sponsoring and scarce media coverage. According to Esping-Andersen (1990) first, and Albareda et al. (2007) then, Mediterranean countries are characterised by comparatively less developed welfare states, which translate in a reduced coordination of business and society relations, and scarcer participation and cohesion among societal parties. Given that CSR efforts in countries disposing of a more developed welfare state have been defined in a residual way, countries with less developed welfare states find a major action span for CSR practices (Maignan and Ralston, 2002). Within such contexts CSR has been identified as a potential vehicle to increase cohesion and participation (Albareda et al., 2007). Mozzicafreddo (1992 p. 82) depicted the development of the Portuguese welfare state as "uncompromised" and a quasi-welfare system. Although these aspects will be dwelled upon throughout the thesis, it is important, at this point, to briefly specify some features of the Portuguese welfare state today, as to be able to understand the potential that CSR practices underlie for the context. Portugal is a country in which the funding of social expenses has been deemed as being unsustainable to be borne by the government alone, even more so after the international market crisis of 2008 (OPSS, 2012). For what concerns health promotion investments in specific financing in Portugal has, comparably to the rest of Europe, been deficient (Ziglio et al, 2000; WHO, 2010). Portugal is amongst the EU countries with higher and persistent social inequality (OPSS, 2012). In relation to health promotion, Cunha Filho et. al, (2010) first, and Crisp et al., (2014) then, denunciate a lack of intersectoral dialogue and collaboration among civil, business and public societal actors highlighting the need to establish processes and structures to bring forward collaboration among societal actors. Finally CSR may prove to be a vehicle to foster businesses' awareness and responsiveness to national and international health promotion priorities and accountability for health impacts and compliance with existing regulations, in a situation in which health promotion rulemaking and enforcement at the national level have appeared weak (Cunha Filho et. al, 2010). 


\section{Literature review}

The researcher carried out a literature review, coherently with its established purposes, with the intention to get an understanding of the advancement of research in relation to the research object, identify gaps and hence motivate the research, as well as delineate the conceptual framework necessary for the interpretation of the information inherent to documents and case studies (Cresswell 2009). Yet, given the scarce amount of literature available on the research object, the literature review was also used to make a comprehensive portrait of a range of threats and opportunities for health promotion identified as inherent to CSR practices, to be then discusses on the basis of the findings from a real-world scenario. As stated in the introduction of this chapter, the opportunities and criticalities of CSR practices in relation to health gains and governance have seldom been studied comprehensively or in the perspective of the health promotion approach. Given the absence of a conceptual framework specific to the research object it was considered relevant to carry out three types of literature review: historical, theoretical and integrative. Historical literature review serves to capture the developments within a certain area of study, theoretical literature focuses on identifying and discussing different theoretical approaches upon the same, and integrative literature review synthesizes literature on a given topic through conceptual categories, capturing, for instance, studies presenting similar research hypothesis or research problems (Cresswell, 2009). The historical and theoretical literature reviews were dedicated to delineating the features of the two spheres of analysis, CSR first, and health promotion then, as to build a frame for thinking of, and analyzing, CSR practices in terms of health promotion. The historical literature review upon CSR practices operated in Chapter 3 (3.1) was deemed purposeful to understand how and why the notion came to be, how its consideration developed within scholarship, and how its enactment took shape in practice. Given, as we will see, that different theoretical standpoints upon the rationale, purpose and criteria framing CSR practice developed and coexisted within scholarship, it was deemed necessary to proceed, in Chapter 3 (3.2), to a theoretical analysis. The theoretical analysis was purposeful to detect what have been depicted, accordingly to Vallentin (2012), as the ideological ramifications of CSR, providing diverging, and at times concurrent, rationales and inherent principles motivating the engagement of business entities in CSR practices as well as defining value-based criteria for the choice of issues to get involved in. For the present research the analysis of the theoretical framework was deemed crucial, in what it allowed the understanding of 
the problematizations of the key CSR policies shaping CSR practice. Smaller historical, theoretical and integrative literature reviews concerning the core dimensions of the health promotion approach were then operated in Chapter 4 (4.1 and 4.2), capturing: the development of the health promotion approach (historical); the identification of the normative basis underlying the notion of social responsibility (theoretical); the documentation of threats and potentialities associated with business activities in terms of health gains and governance (integrative); the pinpointing and discussion of instruments of governance envisaged by the health promotion approach for the inclusion of the business sector into health promotion governance (integrative); and, finally, the inherent developments they brought to the notion of social responsibility for health (historical).

For the text in the last section of Chapter 4 (4.3.2) an in-depth integrative literature review was carried out, gathering and analyzing literature focusing on the health impacts of CSR practices. According to (Cresswell, 2009) an in-depth integrative research meets the standards of clarity, rigor and replication by setting definite inclusion and exclusion criteria. The specific objectives set for the literature review were to: (a) portray the context and main industry sectors investigated; (b) describe the type of commitments engaged through CSR practices; (c) ascertain the main negative and positive health impacts associated to CSR practices; and (d), identify the recommendations formulated on the subject. The database Academic Search Premier (EBSCO) was searched for articles over the period 2003-2013. Were considered merely articles whose subject was the analysis or description of CSR initiatives addressing health outcomes, containing an abstract, and published in English in a scholarly, peer reviewed journal. Were not considered articles relative to businessbased practices not framed as CSR, and CSR initiatives belonging to organizations other than for profit sectors. The information collected through the articles was organized around conceptual categories and then analyzed through content analysis. Content analysis is a research methodology that allows interpreting information in a homogeneous form, and has been widely used in CSR studies (Maignan and Ralston, 2003; Bouten et al, 2011). This literature review resulted in the publication of an article in a scientific peer-reviewed journal contributing to the identification of some of the dimensions of CSR initiatives addressing health outcomes (participating industries, focus of activities, objectives, and recipients of CSR health-related activities), supporting a discussion on the need for definitions, critical approaches, increased monitoring and setting of parameters for CSR initiatives inherent for health promotion, as well as making a case for further field research on the subject 
(Monachino and Moreira, 2014). This research project has followed the call for further field research on the subject made within the article.

\section{Interviews with experts}

As to complement the information gathered through the integrative literature review, the author went on to capture the perspectives concerning the object of analysis and their contextual determinants by interviewing seven local health promotion experts, also reported in the last section of Chapter 4. As brought forward by Bogner et al (2009), expert interviews are an efficient and concentrated method of gathering data and insider knowledge that is relevant and surrogates that of a wider circle of actors. Health promotion experts were individuated among former and current members of the Presidency and Priority Programs of the Portuguese General Health Directory (DGS - Direção Geral da Saúde) of the Portuguese Ministry of Health (Table 1). The Portuguese General Health Directory is a body that has the mission to regulate, orient, and coordinate the activities of health promotion, disease prevention and definition of the technical conditions for the healthcare provision in Portugal. Governmental experts in the field of health promotion were preferred over civil society actors due to the policy-oriented nature of the research. Health promotion experts were interviewed through semi-structured interviews administered with the support of an interview protocol (Annex I). Interviews took place in the period January 2015 - February 2015. They were registered, transcribed verbatim and then freely translated by the researcher. Interviews were then analysed through content analysis.

Table 1: Interviewed health promotion experts

\begin{tabular}{|l|}
\hline Spokesperson for the National Program for Mental Health \\
\hline Spokesperson for the National Program HIVIAIDS \\
\hline Spokesperson for the National Program for Diabetes \\
\hline Spokesperson for the National Program for Neuro-Cardiovascular diseases \\
\hline Spokesperson for the National Program for Healthy Nutrition \\
\hline Spokesperson for the General Health Directorate \\
\hline Spokesperson for the former General Health Directorate \\
\hline
\end{tabular}




\section{Document analysis}

As specified by Bowen (2009) documents can assist the researcher to develop understanding and build knowledge relative to a given research problem in a manner that is less time-consuming and more cost-effective than experiential research methods (observation, participation and interviews). As further specified by Bowen (2009) document analysis is generally used together with, or in support of, other research methods. This is the case of the present research for which document analysis was coupled with case studies and expert interviews. Within the present research document analysis was used to discern how CSR practices are supposed to work, purposeful, in a first instance, to find causes of opportunities and criticalities of CSR practices inherent to the level of intention, and secondly to set the basis for the analysis of CSR practices in real-world scenarios through case studies.

CSR is voluntary, yet different policies defining its normative basis, areas of action and means of implementation are in place. Policies serve the objectives of raising awareness, creating dialogue and setting standards concerning what it is to be socially responsible, but also, and more importantly, constitute a source of isomorphic pressure, promoting the operationalization of CSR within business practices (Brammer et al, 2012). The CSR policy documents taken into consideration are the key CSR policies, developed by international intergovernmental bodies, supranational intergovernmental bodies and private professional entities orienting CSR practices for the context of analysis (EC, 2013): (a) the United Nations' Global Compact Initiative (UN, 2000), (b) the OECD Guidelines for Multinational Enterprises (OECD, 2000), (c) the International Labour Organization's Tripartite Declaration of Principles concerning Multinational Enterprises on Social Policy (ILO, 1977; 2000; 2006), (d) the EU's Strategy for Corporate Social Responsibility (EC 2001/2006/2011), and the (e) ISO 260oo Guidance Standard on Social Responsibility (ISO, 2010). (A), (b) and (c) pertain to the category of international policies developed by intergovernmental bodies, (c) is a supranational policy, whilst (e) is a privately developed international policy. The Global Reporting Initiative (GRI), although prominent for the context in analysis, has not been considered, as it is not used to develop CSR practices, which are the object of this research, but merely to posteriorly report on them. It was impossible to scrutinize the national Portuguese CSR policy in the measure it has not been formulated at the time of redaction of the present research, as previously argued for. 
The health promotion policy documents taken into consideration are the Ottawa Charter for Health Promotion (WHO, 1986), the father document defining the problematization, agenda-setting and means for action of the health promotion approach, the Jakarta Declaration New Players for a New Era: Leading Health Promotion into the 21st Century (WHO, 1997) and the Bangkok Charter for Health Promotion in a Globalized World (WHO, 2005), pinpointing the same in relation to the role of private actors in health, the WHO European Region health strategy Health 2020: a European policy framework supporting action across government and society for health and well being (WHO Europe, 2012) as well as the Portuguese National Health Plan 2012 - 2020 (DGS, 2015).

Two levels of analysis were considered to detect causes: in a first instance, the analysis of the CSR policy process per sé, and secondly, the analysis of the CSR policy process in relation to the normative and operational principles contained in the scrutinized health promotion policies. The analysis of CSR documents per sé, operated in Chapter 3, has followed the heuristic stages approach. The first step was represented by the analysis of the problematization of CSR policies, it is to say the rationale and principles underlying CSR practices. Since the rationalities and guiding principles inherent to the CSR approach were identified through a theoretical literature review, a second step was represented by the detection of said rationalities in the different policies making up the CSR policy framework. The analysis continued with the review of agenda-setting and the consideration of health promotion. The means for action, methods, processes and structures set for implementation, were then ascertained. The stages of CSR policies were analysed, as recommended by Bowen (2009), through superficial examination, deep examination and interpretation of each stage. Interpretation was supported by relevant literature review. In Chapter 4 the analysis of the CSR policy process was put in relation to the health promotion approach. In specific, the Jakarta Declaration (WHO, 1997) and the Bangkok Charter (WHO, 2005), served to appraise the potential for the problematization, agenda-setting and means for implementation contained within CSR policies to reinforce the problematization, agenda-setting and means for implementation foreseen by the health promotion approach for what concerns the social responsibilities for health of business actors. The ascertainment of the priorities and objectives set by the document Health 2020 (WHO Europe, 2012), as well as by the Portuguese National Health Plan (DGS, 2015) served as a basis to discuss the choice of issues and objectives of the case study CSR initiatives, as explained below. 


\section{Case studies}

Within the present research case studies were used to comprehend how CSR practices work in action. Such comprehension served a twofold purpose: to discern the causes of criticalities and opportunities that relate to implementation, it is to say to the way the problematization, agenda-setting, and means for action foreseen by CSR policies are applied, as well as to discuss, on the basis of their analysis, the implications identified through literature review and experts interview. Case studies have been deemed relevant in what they are apt to describe with accuracy a phenomenon in its real-life context using a limited number of examples, producing a "nuanced view of reality" (Yin, 1994; Stake, 1995, Flyvbjerg, 2004; Baxter and Jack, 2008). Furthermore, case studies are appropriate to explore areas of little knowledge, as it is the case of CSR practices relevant for health promotion (Stake, 1995). As brought forward by Cresswell (2009) a first issue to address in case study methodology is the definition of what is the case to be studied. The cases chosen for the present research are multiple CSR health promotion initiatives (from now on CSRHPIs) pinpointed within five industry sectors. The choice to engage in multiple case studies serves the purpose of capturing and illustrating the variety and multifaceted nature of CSR practices relevant for health promotion, as well as to decrease the issues of generalization inherent to the case study methodology, although concerning the latter point Flyvbjerg (2004) has observed that more relevant discoveries have come from in-depth observation rather than numerous samples of analysis. Given the exploratory nature of the research, it was considered relevant to consider CSRHPIs as illustrative rather than comparative, capturing case studies that are at the same time significant and apt to reproduce variety as to capture as many dimensions inherent to the object of study as possible. The CSRHPIs are defined, within the present study, and accordingly to the definition of health promotion shaped by the Ottawa Charter (WHO, 1986), definition whose features will be considered in detail in Chapter 4, as initiatives, planned, designed and implemented in the context of businesses' CSR agenda, directed at increasing people's control over the determinants of their own health through individual, social and environmental interventions. 


\section{Data Selection}

As explained by Flyvbjerg (2004) case studies can be randomly sampled, purposefully selected, or strategically selected. Strategic selection relates to cases that are either extreme, or likely to be representative of a great number of situations (ibid). Given the descriptive and analytical purpose of the research it was decided to purposefully select case studies for them to be apt to be both relevant and apt to capture the diversity of CSR practices relevant for health promotion.

Three following steps led to the selection of case study CSRHPIs:

1. Identification of industries;

2. Selection of participating business entities within selected industries;

3. Identification of universe of CSRHPIs within participating business entities;

4. Selection of case study CSRHPIs.

1. The first challenge was presented by the choice of which industries to include in the research. The identification of industries was motivated predominantly by the findings of the literature review and partly in consideration of the nature of the Portuguese business environment. As we will see in the end of Chapter 4 the industries identified as being most apt to negatively and/or positively impact health through core business activities and CSR practices are: pharmaceuticals, private healthcare providers (from now on, PHPs), food-related industry, information and communication technologies (from now on, ICTs) sports, industries dealing with addictive products, alcohol, gambling and tobacco, as well as with air, soil and water adulteration. Were a priori excluded industry sectors, as it is the case for the industries of alcohol, gambling and tobacco, whose involvement in health promotion activities has been already largely and critically scrutinized, and for which the health promotion community largely suggests engagement through binding, as opposed to voluntary initiatives as CSR, as we will see in Chapter 4. On the basis of the findings of the literature review, the following five industries, a number deemed both manageable and illustrative, were selected: pharmaceuticals, private healthcare providers, ICTs, food retailers and hypermarkets, and the tourism industry (Diário Económico, 2012). Food retail was preferred over food manufacture in the perspective that food retailers and hypermarkets occupy the second and third ranking for business volume in 
Portugal after the petrol and gas company Petrogal, ranking first (Diário Económico, 2012). Similarly, although not deemed by the literature review as an industry most apt to negatively and/or positively impact health through core business activities and CSR practices, the tourism industry was included for being a major industry in terms of economic relevance in Portugal (Diário Económico, 2012). The researcher did try to include companies from the major industry, petrol and gas, as well as from the sports industry, failing to obtain agreement to participate by targeted businesses within the research project's schedule.

2. A second step was represented by the choice of relevant businesses within selected industries. Here again, the choice to select three companies for each industry, totaling a sum of fifteen companies considered, was motivated by criteria of manageability and feasibility defined by the researcher's program schedule. Business entities for each industry with presence in Portugal were contacted by email starting from the largest (in terms of employees and business revenue). The strategy to prioritize larger companies was motivated in the perspective that larger company size has been identified as an indicator of greater CSR involvement (Minkes and Minkes, 2005; Campbell, 2007). This consideration stands true for the Portuguese context; although Portugal's economic structure is characterised by a prevalence of small and medium enterprises (SMEs), Rego et al. (2003) found that the top socially responsible companies are large corporations located in the metropolitan Lisbon area. Were then selected the first three companies for each sector that accepted to participate in the study. The ten major companies for each sector were identified according to the ranking of 1000 major companies in Portugal (Diário Económico, 2012), for a total of 50 companies initially considered. The tourism poll of candidates was defined using the Portuguese national registry of tourism (Turismo de Portugal, 2012). The universe of companies that accepted to participate in the present research (Table 2) is characterised preponderantly by multi-national enterprises (from now on, MNEs) (twelve out of fifteen), with headquarters situated in the Lisbon metropolitan area (fourteen out of fifteen). 
Table 2: Company universe for the detection of case studies

\begin{tabular}{|ll|l|}
\hline Sector & Company & Code \\
\hline Pharmaceuticals & AstraZeneca & A1 \\
& Amgen & A2 \\
& Merck Sharp \& Dome & A3 \\
\hline Private Healthcare Providers & Diaverum & B1 \\
& Éspirito Santo Saúde & B2 \\
& José de Mello Saúde & B3 \\
\hline Information and Communication Technologies & Nos & C1 \\
& Portugal Telecom & C2 \\
& Vodafone & C3 \\
\hline Food Retail & Auchan & D1 \\
& Continente & D2 \\
& Jerónimo Martins & D3 \\
\hline Hotel & Ritz Four Seasons & E1 \\
& Inspira Santa Marta & E2 \\
& Neya Hotels & E3 \\
\hline
\end{tabular}

3. A third step was represented by the choice of CSRHPIs to consider within the universe of CSRHPIs implemented by the companies that accepted to participate to the research. The researcher made the choice to take into consideration, for case study selection, merely CSRHPIs directed to stakeholders external to the company, broadly identified as consumers, local communities and the society as a whole, and to leave out CSRHPIs directed to internal stakeholders, broadly identified as shareholders and employees. The choice to look at CSRHPIs destined to external stakeholders, as opposed to internal ones, was motivated upon the fact that workplace health promotion practices, within or beyond the frame of CSR, have been researched extensively (Holmqvist, 2008; Montero et al., 2009), whilst the implementation of CSR initiatives relevant for the promotion of the health of consumers, local communities and the society as a whole, is, at the same time, a practice made explicit by the CSR approach, and a topic seldom researched, as argued in the previous chapter. As we will see throughout the research, one of the difficulties related to health promotion interventions is their far-reaching and multi-dimensional nature, foreseeing initiatives at the behavioural, social and environmental levels. Given the broadness of the concept of health promotion, and the lack of previous research establishing a pattern for CSRHPIs, the researcher chose to let the CSR spokesperson for each company (also addressed as CSR manager) delineate the universe of CSRHPIs. The choice to let CSR managers identify the universe of CSRHPIs allowed limiting the universe sample, detecting core CSR initiatives for each business selected, gaining insight on what CSR business actors consider as being relevant for health promotion, as well as identify core initiatives, it is to say 
initiatives to which substantial material and non-material resources for planning, design and implementation have been devoted, as well.

4. After the universe of CSRHPIs had been mapped the researcher selected, through a coding effort, 15 case study CSRHPIs, 3 for each sector, to make up the body of case studies. The number of 15 CSRHPIs was decided a priori as to match the number of companies participating in the study, also in this case being considered a manageable number. The CSRHPI selection strategy was aimed at selecting both core initiatives, as well as to have CSRHPIs from the 3 typologies of initiatives identified by Husted (2003) in-house, sponsoring and partnering was chosen (the information concerning the types of CSR initiatives will be deepened in Chapter 3). Hence, the three CSRHPIs selected for each sector were one inhouse, one sponsoring and one partnering initiative. According to Yin (1994) multiple case studies in order to be analysed conjointly, have to be homogeneous. The choice to include one initiative for each typology serves hence the purpose of furnishing a comprehensive portrait of the universe of potential CSRHPIs on one side, and the one of being standardised, and hence comparable, among each sector (Yin 1994). It should be noted that the fifteen CSRHPIs selected are representative of sectors and not of companies; hence it may occur that more than one CSRHPI stirs from one company and none from the other, as explained below.

In specific, the coding effort to select the key 15 CSRHPIs was carried out according to the following steps:

- CSR managers were asked to expose all initiatives present within their CSR strategies that they considered relevant in term of external health promotion (CSRHPIs);

- The researcher then coded the initiatives according to the priority given to each initiative by the respondent;

Ex:

\begin{tabular}{|c|c|c|c|c|c|}
\hline Sector & Respondent & $1^{\circ}$ & $2^{\circ}$ & $3^{\circ}$ & $4^{\circ}$ \\
\hline A & a1 & CSRHPla & CSRHPIb & CSRHPIc & CSRHPId \\
\hline A & a2 & CSRHPle & CSRHPI & & \\
\hline A & a3 & CSRHPIf & CSRHPIg & CSRHPIh & \\
\hline
\end{tabular}

The researcher then sorted the list of priorities according to their typology: in-house initiative (IH), partnering initiative (PT) and sponsoring initiative (SP). 
Ex:

\begin{tabular}{|c|c|l|l|l|c|}
\hline Sector & Respondent & \multicolumn{1}{|c|}{$1^{\circ}$} & $2^{\circ}$ & $3^{\circ}$ & $4^{\circ}$ \\
\hline A & a1 & CSRHPla $(\mathrm{IH})$ & CSRHPIb (IH) & CSRHPIc (SP) & CSRHPId (IH) \\
\hline A & a2 & CSRHPle (PT) & CSRHPI (IH) & & \\
\hline A & a3 & CSRHPIf (IH) & CSRHPIg (SP) & CSRHPIh (SP) & \\
\hline
\end{tabular}

- For each sector were chosen one in-house, one partnering and one sponsoring CSRHPI according to their overall priority independently from their company of identification. In the case given in the example, for what concerns in-house initiatives CSRHPIa and CSRHPIf were both ranked as 1st, hence a random selection was operated among the two resulting in the definition of either CSRHPIa or CSRHPIf. Only one partnering initiative was ranked as 1st, CSRHPIe, and hence selected. Given that no sponsoring initiative was ranked as 1st, choice was moved to the 2nd position, resulting in the choice of CSRHPIg.

Ex:

\begin{tabular}{|c|c|l|l|l|c|}
\hline Sector & Respondent & $1^{\circ}$ & $2^{\circ}$ & $3^{\circ}$ & $4^{\circ}$ \\
\hline A & a1 & CSRHPla (IH) & CSRHPIb (IH) & CSRHPIc (SP) & CSRHPId (IH) \\
\hline A & a2 & CSRHPle (PT) & CSRHPI (IH) & & \\
\hline A & a3 & CSRHPIf (IH) & CSRHPIg (SP) & CSRHPIh (SP) & \\
\hline
\end{tabular}

\section{Data collection and analysis}

Data concerning the CSRHPIs, both universe and sample case studies, was collected through the interaction with CSR representatives and of partner entities of collaborative CSRHPIs (partnering and sponsoring) as to be able to capture different perspectives, the multiple realities, concerning the object in analysis. As brought forward by Peloza and Shang (2011) and Costa and Menichini (2013) the worldview of those likely to engage in decision-making relatively to a given initiative, as well as those likely to be affected by them, constitutes a sound basis to understand a given intervention. The representatives of partner institutions to interview, generally the one responsible for the collaboration, were identified and at times put in contact by CSR representatives as a follow-up to their interviews. The total of collaborative CSRHPIs is ten as each social partner partnered with only one business entity, but only seven social partners of CSRHPI (Table 3) accepted to participate in the study. 
The experience of both categories of actors was collected through semi-directive interviews. Semi-directive interviews were considered an instrument relevant for the purpose of this study in what they are used for issues upon which little is known and whose addressing requires depth, as the interviews' flexibility and openness allows to detect questions regarding information that had not been previously considered by the interviewer, as well as to deepen given aspects with follow-up questions (Cresswell, 2009). The interviews were conducted in Portuguese with the support of two different interview protocols administered to CSR managers and social partners (Annexes II and III). The questions of the interview protocols were formulated on the basis of the literature review. Interviews took place in the period January 2013 February 2015. They were registered, transcribed verbatim and then freely translated by the researcher. The interviews with the CSR representatives served to gain knowledge concerning the company's overall approach to CSR (history, policy references engaged, responsible department, areas of action) identify the universe of CSRHPIs realized (projects implemented), identify key CSRHPIs, and gain detailed information concerning the formulation and implementation of CSRHPIs. In specific the information concerning the CSRHPIs aimed at capturing the specificities of implementation (grounds for initiative formulation, criteria and evidence, population involved, resources deployed, evidence-basis, evaluation/assessment methods). The interviews with the representatives of partner entities served to gather information concerning the entities' experience of collaboration and suggestions in relation to the CSRHPI, as well as corollary perspectives on the potential contribution of CSR initiatives to further the goals of other societal sectors, in general as well as in relation to health promotion, as well as on the role envisaged for the public sector towards CSR.

Table 3: Interviewed partner entities of collaborative CSRHPIs

\begin{tabular}{|c|c|c|}
\hline Sector & CSRHPI & Social Partner \\
\hline A & $\begin{array}{l}\text { CSRHPI (PT) } \\
\text { CSRHPI (SP) }\end{array}$ & Portuguese Doctors Without Borders \\
\hline$B$ & $\begin{array}{l}\text { CSRHPI (PT) } \\
\text { CSRHPI (SP) }\end{array}$ & Advita - Caregivers Association \\
\hline C & $\begin{array}{l}\text { CSRHPI (PT) } \\
\text { CSRHPI (SP) }\end{array}$ & Faqtos - Technical University of Lisbon \\
\hline $\mathrm{D}$ & $\begin{array}{l}\text { CSRHPI (PT) } \\
\text { CSRHPI (SP) }\end{array}$ & $\begin{array}{l}\text { Portuguese Coeliac Disease Association } \\
\text { General Directorate of Education - Ministry of Education }\end{array}$ \\
\hline$E$ & $\begin{array}{l}\text { CSRHPI (PT) } \\
\text { CSRHPI (SP) }\end{array}$ & $\begin{array}{l}\text { Municipality of Campolide, Lisbon } \\
\text { APPDA - Association for the Spectrum of Autism, Lisbon }\end{array}$ \\
\hline
\end{tabular}


Information collected throughout the interviews was analysed through content analysis. The analysis of both interviews of CSR managers and representatives of partner entities followed categorical aggregation, first, in relation to the different stages of CSRHPIs planning design and implementation, being the categories considered the rationale underlying CSR involvement, the criteria and evidence used for issue selection, the choice of specific objectives, focus, beneficiaries, resources deployed and evaluation method intended for each of the case study CSRHPIs and the allocation of responsibilities inherent to such phases (in the case of collaborative CSRHPIs).

\section{Participant observation}

As brought forward by Stake (2010) interpretation within qualitative analysis relies heavily upon experience. As explained by Cresswell (2009) participant observation activities are apt to allow the researcher proximity with the studied reality and a first hand experience of processes and mechanisms governing said reality. According to Kawulich (2005) they are apt to provide a holistic and detailed written photography of a given phenomenon or situation. Participant observation may allow the researcher to gain information of elements not considered through, for instance, interviews, and gain insights on issues that may be problematic to discuss through direct confrontation. Furthermore, as explained by Kawulich (2005) participant observation serves to gain a detailed understanding of how things are organized and prioritized within a given context, useful for interpretation. As to complement the information gained through case studies and interviews with experts, and more specifically to gain insight on how CSR problematization, agenda-setting and means for action are streamlined, organized and prioritized within the Portuguese business environment the researcher participated, in the period $2012-2015$, to seven events and meetings organized by the key CSR organizations present in Portugal, all based in Lisbon: GRACE (Grupo de reflexao e apoio à cidadania empresarial), BCSD Portugal (Portuguese Business Council for Sustainable Development), APEE (Portuguese Association of Entrepreneurial Ethics). During the meetings the researcher took notes using as much detail as possible, at times made questions upon specific issues of the CSR policy process and following observation organized the notes according to aggregates of categories. 


\section{Limits of methodology}

The main limitations encountered for the study are to be found, coherently with the limitations inherent to qualitative approaches, in the role of the researcher as instrument of research in data selection, collection and analysis. The researcher may influence data selection by choosing sources that validate initial assumptions, or distort analysis by interpreting categories subjectively rather than objectively in light of personal worldviews (Cresswell, 2009; Stake 2010). Further, qualitative data analysis is limited by the capacity of the researcher to map themes and explore connections (Cresswell, 2009). The lack of previous research has led to the tentative formulation of the methodology proposed. In relation to policy analysis, Dunn (1994) warns that the great complexity behind both policy formulation and implementation makes so that it is very rarely to possibility to claim the coverage of all issues. Stake (2010) warns that there is no such thing as exact cause detection in qualitative analysis, given the absence of exercises of correlation. As for what concerns the limits relative to each method, Bowen (2009) warns that document analysis may provide insufficient detail and basis for interpretation, although the researcher tried to counteract such limitations by coupling it with the remaining methodological approaches. The case study selection was subjected to what have been depicted as arbitrary choices of the researcher concerning the number of sectors, companies and CSRHPIs to consider. As previously contended such choices were motivated by considerations of feasibility and appropriateness, although such considerations are limited in what subjective to the researcher. As also previously stated it was not possible to interview all of the social partners of the case study CSRHPIs, hence the perspective of social partners may be incomplete. Another issue relevant to discuss concerning the limits the case studies, but also pertinent in relation to expert interviews and participant observation, is the estranged position of the researcher as a foreigner within the context. Furthermore, data was collected in Portuguese, which is not the researcher's first language and then translated and redacted in English, which also isn't the researcher mother tongue, leading to the possibility that some meanings or expression may have gone lost in translation. Although the researcher's position as a foreigner to the research context may have led to a misreading both at the level of comprehension and of interpretation, Walt et al. (2008) observe that an outsider researcher may be less biased than an internal one, and hence allow the uncovering of a more objective perspective that that of a local one. 


\section{Chapter 3: An introduction to Corporate Social Responsibility}

Chapter 3 intends to introduce and explain the core features that delineate the broad and contested nature of the first sphere of analysis of this research: Corporate Social Responsibility (CSR). Section 3.1 resumes the historical path through which the notion that business entities have responsibilities that transcend the creation of profits was constituted. Given, as mentioned in Chapter 1, that CSR is intertwined with the instalment, development and legitimization of the capitalistic system, of which it is by all means an outgrow, the path towards CSR is narrated as originating in first industrial era of Western societies. Furthermore, given that the notion of CSR is one that originated in the Anglo-Saxon capitalistic environments, and more specifically in the US, preserving in many ways features specific to its American roots to date, this first historical section gives salience to the key social and macroeconomic processes and the role of CSR in the context of Western Anglo-Saxon highincome economies, namely the US and the UK, setting the grounds for the explanation of how such dynamics were translated within the European context in general, and in Portugal in specific, later on in the chapter. By coupling the stages of development of CSR to the main turns in economics, political economy and social demands that marked the last century of the $20^{\text {th }}$ century, the first section of this chapter deepens and refines what already stated in Chapter 1, highlighting the relevance of CSR as a proxy to describe the evolution of the fields of study of economics and business management, and picturing its functionality in the progression of business and society relations. Other than these aspects, section 2.1 serves the purpose of setting the timeline for the evolution of CSR as an academic area of study and a field of practice, elucidating the development of the main theoretical approaches on one side, as well as the tools and organizational processes put in place as to prepare for CSR, then deepened in sections 2.2 and 2.3. Section two is the theoretical core of the chapter, discussing the main theoretically based rationalities, developed throughout the last century, concerning the role of business entities in society as well as the scope of CSR practices. The identification of rationalities is purposeful for understanding to discuss the outcomes CSR practices 
are apt to produce. Furthermore, the identification of the theoretical streams serves as a basis to be able to discuss which of the are contained within the reference policies and operational standards that frame CSR practice nowadays, and hence infer which theoretical approaches are promoted by international and supranational frameworks of CSR portrayed in section three. Hinting at the timeline set in the first section, it is explained how theories have been built in parallel and how to a certain extent they still exist, thus participating to the confusion existent upon the notion of CSR and to its qualification as a free-floating idea. Section four contextualizes CSR. It begins by seeking to discussing the existence and delineating the features of a European approach to CSR, as distinguishable from its North-American counterpart. It then explains the functionality of the approach within the constitution and legitimization of the European political and economic Union as well as why the North-American approach has gradually migrated towards European countries. Four European approaches to CSR, Scandinavian, Continental, Anglo-Saxon and Mediterrenean are presented, furnishing practical examples of common social issues approached as well as of governmental stances and initiatives concerning CSR. Ultimately, a panorama for the Portuguese context is set, beginning with the portray of the core phases of constitution and development of the welfare state, the main features of the national business environment, and of the ties linking both, before proceeding to delineate the features of CSR in Portugal.

\section{CSR, a capitalist conception: from philanthropy to social and political responsiveness}

\section{Industrial capitalism, labour rights, and philanthropy}

Although private initiative and patronage have shaped, since their very origins, the contours of human development, finding solutions to social problems through the sponsoring of arts, science, education and community infrastructures, the roots of CSR (as a concept and as a practice) as we would today describe it, can be retraced to the first industrial era, and in specific to the efforts of labour protection and community development. During this time reformers and business entrepreneurs individuated a series of threats connected to labourers' concentration in urban setting, hard labour conditions and the change in the nature of work: poverty, slums, transmission of diseases, female and child labour and riots (Carrol, 2008). As to minimize these threats, and allow the successful development of industrialization, 
employers allowed labourers pensions connected to age, health and work status. In what they allowed for the establishment of a minimal consensus amidst employers and workers, as well as setting the conditions for productivity to gain a level of efficiency, labourer's social pension were "an uneven mixture of humanitarianism, philanthropy, and business acumen" intertwined with the sustainment of the industrial model to the extent it was not possible to distinguish "what organizations are doing for business reasons, such as making the workers more productive, and what the organizations are doing for social reasons, such as helping to fulfil their needs and make them better and more contributing members of society" (Wren 2005 in Carroll, 2008 p.21). As argued by Esping-Andersen (1990) labourer's social rights during industrialization became both possible and necessary, other than constituting the basis of what today would be described as the modern social protection schemes. In a second instance, businesses' social commitments were destined to community welfare, making available, through philanthropy, social investments destined to the general sanitation of water, the building of local infrastructures such as hospitals, schools, Sunday schools, churches, bathhouses and other recreational spaces (Carrol, 2008). At first, philanthropic investments destined to community development struggled to gain a status of legitimacy within the business environment, being accused of betraying the entrustment of shareholder property and not generating direct quantifiable economic returns (ibid). The struggle can be exemplified by the Hutton versus West Cork Railway Co. law case, which saw the company director confront the shareholders over the decision to compensate employees for the dismantlement of West Cork Railway Co. The sentence, still largely quoted in business law, ruled against the director, concluding that the payments were to be considered as charity and not justified, given that shareholder's money, even for charitable causes, was to be spent only in case it allowed the perpetration of business (ibid).

If in the first industrial era the social involvement of businesses' was primordially instrumental to the creation of conditions allowing economic growth and the instalment of capitalism, it was after the American Great Depression of 1929 that socially responsible business practices also became a means to achieve the acceptance and legitimization of business activities within society. Legitimization was needed after the general perception that it was business - and in specific corporate wrongdoings that led to the collapse of the economic system that resulted in the Great American Depression of 1929. The consequences of the Depression spilled out to European economy, setting the basis for a new period of business and society 
relations. By the first decade of the $20^{\text {th }}$ century corporations had reached great wealth and power after being entrusted, starting from the mid-180os, the construction of basic infrastructures within early industrial nation states the (Vogel, 2005). The legal personality of the corporation and its boundaries, in vigour to this date, were set in the UK in 1855 by the means of the Limited Liability Act. The Act established that the owners of the corporation, the shareholders, although accountable to creditors for the quantity of shares of the organization they possess, are not personally responsible for the action, or debts, the corporation engages as a separated entity of law. It is precisely the elimination of boundaries of corporate owners and managers' personal liability, the great concentration of power that followed, and its spiralling, that ultimately led to the Great Depression, creating the urgency to discuss the responsibilities of businesses vis-à-vis society, from this moment on connoted as corporate social responsibilities (CSR) (Carroll, 2008). Eberstadt (1973 p. 21), quoted by Carroll (2008 p. 23), argues: "indeed, business might never have turned back toward responsibility and accountability if the culmination of corporate irresponsibility had not been the collapse of the economic system". In the two decades following the Depression, corporations continued to grow in number and power, and given that labour protection had by the time been legally bound, philanthropic investments became the central social activity of businesses. In this period, the reflection upon the social responsibilities became an issue of consideration within the business environment, as shown by the publishing of Barnard's (1938) The Functions of the Executive, Clarks' Social Control of Businesses (1939) Kreps' Measurement of the Social Performance of Business (1940) and Bowen's Social Responsibilities of the Businessman (1953) considered as the father document of CSR (Carroll, 2006; 2008).

\section{The post-war period: from Keynesianism to Neoliberalism}

The immediate post-war period can ideally be split in two phases, marked by two radically opposed approaches to political economy that more or less homogenously pervaded Anglo-Saxon high-income economies after the world war period (Budge, 1997). Belong to the first phase the decades experiencing the long economic boom: the 1950 and 1960 s until the early 1970s. By the late 1950 s the Marshall Plan had successfully contributed to the rebuilding of Western Europe, supported by a stateled Keynesian approach to political economy (ibid). Keynesian economics, developed by the British Economist John Maynard Keynes during the Great Depression in opposition to classical laissez-faire economics, relies on the consideration that 
market freedom does not lead to optimal macroeconomic efficiency alone, and that private interests are not automatically channelled into public needs, being state intervention required to overcome market failures related to interest rates, public debt and private credit (ibid). This is also the time of the expansion of social welfare schemes in Europe that, with the due differences that we will explore in section 3.4, gradually guaranteed publicly funded access to education, health and social protection for all citizens.

The 1960 s were a period of revolutionary change; the counterculture, originating in the USA and migrated to Europe, questioned the 1950s social norms and models of authority. The 1960 s counterculture translated, especially within the circle of middleclass educated youngsters, into activism in support of societal causes, increasing public awareness on specific issues such as labour, the environment, social and human rights. According to Frederick (2006 p. 29) "Each social movement (Blacks, greens, women, workers) stood in direct opposition to one or more central practices, values or traditions of business" leading to an "enormous wave of anti-business sentiment" (p. 23). Again according to Frederick (2006), the 1960s embodied the failure of the laissez faire as an economic and political order, a period were a new order was to be re-established. It is to respond to the claims made by civil society groups, as well as to align to Keynesian model of state-led market, that the idea of corporate agents as public trustees came forward in the 1960 s (ibid). In this time the practice of businesses' social responsibilities shifted from philanthropic investments to issues relevant for the public opinion and directly connected to the negative and positive externalities of business activities, hence constituting the nucleus of the current understanding of CSR (Carrol, 2008). Pioneer business-based voluntary codes of conduct, social investment funds, and rankings of social performance were developed as large corporations were questioned and put under accusation concerning their role in the creation of patterns of social injustice and inequality (Vogel, 2005). Carrying the wave of the 1960s, the 1970s begun with a statement issued by the Committee for Economic Development (CED) of the US, statement titled The Social Responsibilities of Business Corporations, in turn based on a symposium of the same Committee held in 1967, Corporate Decisions for Social Progress (CED, 1971). Pointing at the changing social contract, the Statement invited business actors to consider themselves as socioeconomic institutions called to address social needs defined at the governmental level. The Statement pointed out the need for the effort, to be carried out by the business sector, of "finding the appropriate role in helping solve the social problems faced by the nation" (CED, 1971 
p.8), suggesting the practice of "a government - business partnership for social progress destined to overcome the limits of voluntariness" (CED, 1971 p.43), and going as far as foreseeing the implementation of regulation inherent to the social responsibilities of businesses, in the case of failure of other incentives to socially responsible business practices. In the 1970s, for the first time within the scholarly management environment, the book Private Management and Public Policy (Preston and Post, 1975) openly discussed business responsibilities in the perspective of their link with, and responsiveness to, public, state-based policies, arguing for the adoption of the principle of public responsibility, as we will see in detail in the forthcoming section (3.2).

The second half of the 1970s, marked by the oil crisis of 1973 and the phenomenon of stagflation, high inflation and high unemployment levels that refuted the stable trade-off contemplated by the Keynesian economy, led to a breaking point in the Western post-war growth. Together with the failure of the Keynesian model, a counter approach to the role of the government in defining political economy gradually pervaded Western high-income economies. By the 1970s the leading approach to capitalism at an international level, led by the University of Chicago and the economists Hayek and Friedman, was one considering that the role of the government should be downsized as to leave greater autonomy to the market (Frederick, 2006), inaugurating an approach today derogatorily termed neoliberalism. As described by Harvey (2005 p. 2) "neoliberalism is a theory of political economic practices that proposes that human well-being can best be advanced by liberating individual entrepreneurial freedoms and skills within an institutional framework characterised by strong property rights, free markets and free trade". Hence the main features of neoliberalism can be described by processes of privatization, fiscal austerity, market de-regularization and reductions in government intervention and spending based on objectives of economic competition, market efficiency, economic performance and the creation of wealth (ibid). According to Harvey (2005 p. 3), the distinctive feature of neoliberalism is not to be retraced in political and economic sciences, but rather, in its essence as a cultural project, an ethics in the Weberian sense of the term, which, through its conceptual apparatus, has been "incorporated into the common sense way we (...) understand the world" influencing, on a global scheme, labour organization, social welfare, lifestyle and reproductive habits by relying on values of human dignity, individual freedom, personal responsibility, and other crucial aspects of personal and social life. According to Brammer et al. (2012) and Kinderman (2013), the promotion of CSR 
became a core channel for the promotion of the neoliberalist project, as it served as its political counterpart and justification, showing the human face of free market through the possibility of good governance. In this perspective, CSR has been depicted as form of embedded capitalism and a product of neoliberal imagination, mirroring, and justifying, its main features: voluntariness, unnecessariness of state intervention, and fulfilment of social duties through market categories, such as ethical consumption or social marketing (Steurer et al., 2005; Kinderman, 2013). The logic behind the last point, is resumed, sarcastically, by Zizek's (2010) quote of the Starbucks Fair Trade Coffee Campaign:

\begin{abstract}
"Its not just our campaign, its what you are buying into: when you buy Starbucks, whether you realize it or not, your are buying into something more than a cup of coffee, you are buying into a coffee ethics. Through our Starbucks shared planet program, we purchase more fair trade coffee than any company in the world, ensuring that the farmers receive a price for their hard work, and we invest in coffee growing practices and communities around the globe'...it's a good coffee karma!"
\end{abstract}

The late 1970s was also the period when high profile international boycotts of corporations originated, of which the most famous is probably the one targeting Nestlé's baby formula milk substitute in poor-income countries, accused of discouraging breastfeeding (Vogel, 2005). The boycott, which originated in USA in 1977 and went on to spread in Europe, still holds today. Within the business environment the debate upon CSR shifted towards a more practical level, debating how business responsibilities were to be operationalized in practice and institutionalized at a corporate governance level, scrutinizing issues such as the role of the management board in the balancing of public and private objectives and the inclusion of tools to assess corporate social performance (Carroll, 2008). On its side, far from its public-private coalition approach of 1971, CED's publications saw a detour towards a more market centred approach, shifting the focus from market as a function of social welfare to welfare as a function of market. As said by Frederick (2006, p 50) "it is almost as if a small embarrassment prevailed within the ranks for CED over the excessive attachment to non-market orientations that one finds in the 1971 report". 


\section{Globalization, CSR and sustainable development}

The 1980 s begun with the US president Ronald Reagan coming to office by "promising to get the government off our backs" (Frederick 2006 p. 64). In Europe, Margaret Thatcher had been elected the prime minister of Britain in May 1979, showing since the beginning the intention to downsize the welfare state that had come to be erected after 1945 by famously declaring: "there is no thing as society, only individual men and women” (Harvey, 2005 p. 23). In her book Corporate Social Responsibility and the Welfare State Jeannette Brejning (2012) depicts the 1980s as a period of welfare state crisis not only for the UK, but all over Europe, being the responsibility of the government over its citizens challenged by the hegemony of the neoliberal discourse of Anglo-Saxon origin. According Brejning (2012), it is in this period that the relevance of the social responsibility of non-state actors, namely civil and social actors, was intensified in a perspective of mixed economy of welfare. At the same time, the 1980 s were termed the "decade of greed" (Vogel, 2005) as market expansion was accompanied by numerous corporate scandals (Carroll, 2008) and a parallel rise in NGO activism intended to counteract and influence corporate governance and behaviour (Doh and Guay, 2006). In this period, the furthering of CSR is to be regarded on the basis of business environment's acknowledgement that the path of profit-maximisation of the first era of capitalism was no longer sufficient without the sound basis of the wide-ranging economic expansion that accompanied the post-war period first, and consideration that society was increasingly empowered and critical towards the private for-profit sector and its dynamics (Kinderman, 2013). The efforts towards the operationalization of CSR continued, mainly through the contributions of management and organizational studies, which developed the stakeholder theory (Freeman, 1984) and the resource-based view of the firm (Wernerfelt, 1984), which still largely influence the debate upon what it is to be a socially responsible business (forthcoming - 3.2.). The first business-based social responsibility report was issued in 1989, by the ice-cream company Ben and Jerry (Carroll, 2008).

As depicted in Chapter 1, the 1980 s is characterised by the internationalization of free trade, which led to the economic and geopolitical phenomenon today identified as globalization, phenomenon that went into a crescendo after the first internet connection was established in 1986, and the soviet block dismantled beginning from the fall of the Berlin 1989 eliminating the dichotomy between the two power blocks of 
capitalism and communism. With globalization came the constitution of what we have previously defined, according to Ruggie (2004), the global public domain, calling for the involvement of IGOs, NGOs and MNEs in (global) governance processes whose authority progressively transcended the one of nation-states (Campbell, 2007; Vogel, 2008). In this context, according to Sherer and Palazzo (2011), commitments undertaken in the sphere of CSR started to go beyond a compliance with social expectations, becoming a vehicle for the political involvement of business actors in regulation and the provision of public goods in cases where "the state is principally unable or unwilling to do so" (Matten and Crane, 2005 in Sherer and Palazzo, 2011 p. 900), being inability deeply linked to the processes of internationalization of trade and to the retrenchment of state intervention in macroeconomics. The involvement of business actors through CSR also passed by the responsiveness to issues considered fundamental at the global development level. In this respect, one issue crucial to the progression of CSR throughout the late $1980 \mathrm{os}$ and 1990 s is its embedding within the sustainable development agenda, framed by the Rio Declaration on Environment and Development (UN, 1992) and the Business Council for Sustainable Development (BCSD, also created in 1992), as the new development model for the capitalistic system, one that according to Vallentin (2012) can be depicted as post-liberalist, as previously argued for

Sustainable development is an approach to development that raised in the second half of the 1980s "as a form of societal change that, in addition to traditional development objectives (...) such as the satisfaction of basic needs (...) has the objective and constraint of ecological sustainability" (Lelé, 1991 p. 610). The sustainable development agenda adopts a perspective according to which social and environmental objectives are "interdependent and, in the long term, mutually reinforcing (Tolba, 1984 in Lelé, 1991 p.612) being "ecological conditions necessary to support human life at a specified level of wellbeing for further generations" (Lelé, 1991). Sustainability was a notion that originated in the context of renewable resources and the environment, referring to the existence of the "ecological conditions necessary to support human life at a specified level of wellbeing for further generations" (Lelé, 1991 p. 610), and that gradually evolved towards a broader meaning including the social and structural roots of poverty and ecological sustainability. According to Tolba (1984) as quoted by Lelé (1991 p. 681) sustainable development is driven by the intention to appraise linkages among social and environmental causes as: 


\begin{abstract}
"There are structural, cultural and technological causes to poverty and environmental degradation; (substantiating the need to) develop methodologies for estimating the relative importance of and interaction between these causes in specific situations, and explore political, institutional and educational solutions to them (as social and environmental objectives are) interdependent and, in the long term, mutually reinforcing".
\end{abstract}

Due to its instrumentality to participate to both the global public domain and the sustainable development agendas, starting from the 1990s CSR practice became mainstream, with the majority of large corporations actively investing in the realization and promotion of socially responsible initiatives (Vogel, 2005). As clarified by Vogel (2005) an additional motive for the rise of CSR practice was to be found in the occurrence of a number of public opinion scandals of which arguably the most crucial were the ones that involved the MNEs Nike and Royal Dutch Shell. Nike, leader within the sportswear sector, was targeted by activists concerning violations of human rights and child labour taking place in its subcontracting companies in Asia. The boycott affected the company's financial returns, leading to the redefinition of supply policies as to cease child labour under the age of 14 , as well as to the enrolment of 6000 children in village education business-funded projects (Vogel, 2005). In 1995, the execution of the Nigerian activist Ken Saro-Wiwa, involved in the promotion of protests against Royal Dutch Shell's social and environmental practices in its Niger Delta oil plant shocked the international community, leading Shell's management to be accused by labour unions, environmental activists, human right organizations and even its own shareholders, of connivance with Nigerian authorities and responsibility for Ken Saro-Wiwa's murder (Vogel, 2005). Following the scandal, in 1997, Shell revised its business principles as to include the support of fundamental human rights within the legitimate role of business, setting a benchmark for the extractive industry as a whole (ibid). As these occurrences are apt to prove, throughout the 1990 os CSR served as a "social tax" which had the objective of legitimising the ever-growing power of business entities as well as marginalising the risk of malpractice and boycotts. If throughout the $20^{\text {th }}$ century the realm of CSR had essentially by designed by activities of social investment, the cases above show that social concerns started to be considered in terms of the establishment of negative boundaries through private self-regulation initiatives, directed to redefine business operations, supply chains, and decision-making processes as to take into account the social impacts of business activity (Carroll, 2008; Semplici, 2011). In the World Economic Forum of 1998 the UN general director Kofi Annan officially encouraged national governments to incite businesses to uptake socially responsible practices through tax incentives, public procurement and cross-sectoral partnerships. The 
speech gave input for the establishment, in 2000, of the UN Global Compact Network, the world's largest multi-stakeholder and cross-sectoral initiative directed to the achievement of sustainable development whose features we will look at in section 3.3. The 200os were the decade of empirical research, with CSR becoming one of the most important themes for discussion in all economic sectors and academia (Carroll, 2008). In theoretical terms, it was the time that CSR started to be explored concerning its link with its host environment, giving origin to studies on the institutional determinants and causes of CSR (Ruggie, 2004; Matten and Crane, 2005; Young, 2006; Sherer and Palazzo, 2011, Brammer et al, 2012), which went to add to, other than replace, the pre-existent theoretical streams, as we will see in detail in the following section (3.2 - forthcoming). In 2010 the Guidance Standard on Corporate Social Responsibility ISO 2600o, formerly linked, for the first time, the understanding of CSR to impacts elapsing from business activities, establishing that "an organization is responsible for the impacts of decisions and activities on which it has formal or de facto control" (ISO, 2014).

\section{Theoretical foundations and underlying CSR rationales}

In theory, the approaches relative to CSR, debating issues such as the role of business entities in society, the rationale and principles guiding socially responsible action as well as the outcomes it is expected to produce, have evolved throughout what Leitão and Silva (2007) define "theoretical swarms", fluctuations whose standpoints coexist whilst differing greatly. For the purpose of this study the swarms are resumed into two broad categories, differentiated on the basis of their diverging standpoints concerning the role business entities play in society and the rationale motivating CSR engagement. Each category is in turn divided into two stances, discerned on the basis of the appraisal criteria and moral principles used to detect relevant social issues to be tackled through CSR. The first standpoint is one that considers business entities as rational economic actors whose primordial duty is the carrying out of efficient and effective business activities. The rationale behind the inclusion of social concerns is, hence, instrumental to the increase of financial performance in what it allows lowering risks of litigation, enhance reputation, foster innovation, avoid binding regulations and gain policy access (McWilliams and Siegel, 2006; Porter and Kramer 2006; 2011). This study discusses the stakeholder and resource-based-view approaches as categories of the economy-oriented approach. The second standpoint, referred to as legitimacy-oriented, considers business entities as economic, social and 
political institutions embedded in a wider institutional context to which they tend to conform. In their strive to conformity, business entities may modify their very own identity, getting as far as reconsidering what it is to be a prosperous business and which concerns should be pursued (Hoffeberth et al., 2011). In this case the objective of CSR is fundamental rather than instrumental, the focus set on the social, other than corporate outcomes of CSR. Whilst not refuting the argument that CSR is driven, to some extent, by the pursuit of economic performance, in a legitimacy perspective the profit maximisation motive is considered not sufficient to explain the complex economical, social and political context in which CSR development finds its roots. According to Brammer et al (2012 p. 5) "the argument that businesses engage in CSR just as one of many other ways of increasing the firm's performance seems patently unfit to explain why businesses engage or disengage in socially desirable outcomes" given that, as further clarified by Campbell (2007), business history proves that irresponsible behaviour is most likely to lead to profit-maximisation by allowing private entities to free ride other than contribute to public goods. This stream of though has found scarcer attention within literature on CSR, as Brammer et al (2012 p. 4) point out in turn re-stating and argument expressed by Margolis and Walsh (2003):

\begin{abstract}
"It is fair to say that the literature on CSR, most of it published in management or business studies journals, has neglected the societal aspects of CSR by large. Most of the literature has treated the 'social' element as a black box, as a set of external requirements which are translated into a functionalist, instrumental and business case rationale for social engagement by companies".
\end{abstract}

The public responsibility approach as well as neo-institutional political approach to CSR will be discussed as pertaining to the legitimacy-based standpoint on CSR.

\title{
Stakeholder theory
}

Stakeholder theory, a field of management and business ethics, isn't merely one of the views on CSR, it is the nucleus from which current CSR originates and to which it still largely refers. The theory originated in 1984 with the publishing of the book Strategic Management: A Stakeholder Approach (Freeman, 1984). The book contained a fundamental innovation for business management, arguing that the process of managerial decision-making was to consider the interest of a category other than the shareholders, the stakeholders. The coining of the word itself represented a neologism apt to capture the property possessed by this category of 
individuals: the stake in the outcome of business activities. The argument that business practices may be a matter of interest for individuals, groups or entities other than its owners, starts from the consideration that business activities have social and economic externalities affecting parties external to the business enacting them, being externalities defined as the impact of the actions of an economic agent on the wellbeing of the bystander (McWilliams and Siegel, 2010). Stakeholder theory relies on the principle of stakeholder responsiveness, which entails the need for business entities to respond to claims and pressures of third parties, in this context identified as stakeholders, starting from the acknowledgement that such claims are morally grounded on existent or potential externalities linked to business activities, and impacting the same third parties claiming for responsiveness (Frederick, 2006). Its operationalization is carried out through the descriptive identification and sorting stakeholders (stakeholder analysis) with the objective to prioritize and include stakeholders' interests into managerial decision-making. The Poletown Case described by Goodpaster in his seminal work Business Ethics and Stakeholder Analysis (1991) is a good example to elucidate the reasons stakeholder theory came to be, and explain which are the dynamics it deals with. The Poletown Case describes a situation that took place in the 1980s, when the General Motors (GM) Corporation was considering opening a new subsidiary in the Poletown neighbourhood of Detroit, which would have to be cleared for this purpose. At this time, given the ongoing backlashes of the 1970 s crisis, Detroit's economy was characterised by strong levels of inflation and unemployment, and the city government was eager to cooperate with the corporation, although the Poletown municipality was contrary. The new plant would employ 6000 individuals, but would come at an increased cost for the company, the one of the clearance, as opposed to an installation in other areas of the USA. In this context, GM's management found itself in a classic case of stakeholder analysis, having to respond, at a time, to different and competing interests potentially impacted by managerial decision-making: the ones of owners, suppliers, current and prospective workers, the Detroit community, and finally, the Poletown municipality. All companies face a similar range of entities having a stake in their activity at different stages of their production line, be it sourcing, manufacturing, distribution, sales or waste management. Stakeholders can be roughly generalized as investors, employees, consumers, NGOs, governments, academia and local communities. Once stakeholders have been identified, they are sorted according to the measure in which they are affected by, or apt to affect, a given business action. In this sense categories of stakeholders are not homogeneous: there are primary stakeholders (investors, employees and consumers) on whom the survival of the organization depends, and 
there are secondary stakeholders, whose claims don't threaten the organization's existence. Mitchell et al. (1997 p. 865) developed a theory of stakeholder identification and salience based on the ownership of power, legitimacy, and urgency, where power is defined as "the extent it has or can gain access to coercive, utilitarian, or normative means, to impose its will in the relationship"; legitimacy as "a generalized perception or assumption that the actions of an entity are desirable, proper, or appropriate within some socially constructed system of norms, values, beliefs, and definitions"; and urgency as "the degree to which stakeholder claims call for immediate attention".

Stakeholder theory does establish a connection between business entities and their host environments, and envisage a normative principle, the one of responsiveness. Indeed, as explained by Crane et al. (2014), stakeholder theory is a complex theoretical framework which seeks to re-conceptualise the firm and its relationship with the environment on different levels: at a strategic level, at a descriptive level, and at a normative level. Being apt to refer at the same to normative and strategic categories, stakeholder theory encounters a paradox in the measure that it could be considered unethical, on strategic management grounds, to consider priority standpoints other than the one of stakeholders (Goodpaster, 1991). Despite such complexity, within this research stakeholder theory will be considered as an inherently economy-oriented and instrumental approach, in what stakeholder literature has stressed an accent on the fact that stakeholder interests should not be considered per sé, but only to the extent to which the violation of such interests may, in turn, affect the financial return of the company (Mitchell, 1997). In the case above, for instance, the threats imposed by the violation of the interests may result in employee strike, consumer boycott or political repercussion at the level of the council of Detroit. Further, as stressed by Clarkson (1995), stakeholder theory is conceived and modelled around strategic management categories - the term being created to be comprehensible to a business environment estranged to social issues. Finally the descriptive potentiality of stakeholder theory allows stakeholders to be identified and sorted, without providing guarantees that interests will be answered (Crane et al., 2014). Following these arguments it can be said that stakeholder theory, although an economy-oriented approach to business engagement to social issues, furnishes a noteworthy account on how CSR works. Through stakeholder theory, for the first time, business scholars acknowledge that companies are embedded in societies towards which they have to be responsive, as well as admit the existence of a causality of CSR in regard to the social and environmental externalities that business activities 
generate, introducing mechanisms for their consideration within the organization, although merely for the stakeholders capable to defend their interests (Pedersen, 2006). The notions of stakeholder responsiveness linked the acknowledgement of externalities originating in stakeholder theory are central to the current understanding of CSR, as we will see in section $3 \cdot 3$.

\section{Resource - based view}

The resource-based view on CSR finds its basis in Wernerfelt's management theory paper A Resource-based View of the Firm (1984), paper that acknowledges resources, material and non material, to be the "basic constitutive elements out of which firms transform inputs into outputs, or generate services" (Mathews, $2002 \mathrm{p}$. 7), where social involvement is considered as a non-material resource. According to the resource-based view, the link between social involvement and financial performance is bi-directional, being CSR both a cause and a consequence of competitive advantage. It is a cause in what it is believed that CSR is conducive to competitive advantage of the firm by improving reputation, favouring market expansion, avoiding binding regulations and allowing policy access (Hart, 1995; Mc Williams and Siegel, 2006; 2010). It is a consequence in what greater financial assets are a predictor of greater social involvement, purposeful to legitimize business activity (Waddock and Graves, 2003); as we have seen, the development of CSR discourse and action is intimately linked to the rise of large corporations. According to this approach CSR is realized through the creation of positive social externalities, termed capitalization, carried out through the expansion of business activities, services, and products strictly related to core business activities as to respond to social needs or claims. Such positive externalities will be designated throughout this study as social investments in a resource-based perspective, as to distinguish them from the philanthropic social investments, which are unrelated to core business. In the resource-based view the principle guiding social commitments is the one of opportunity: companies identify the societal issue they are most equipped to deal with coherently with core business operations by assessing the demand for CSR, they then consider business cost of responding to such demand, and verify the existence of gains (Porter and Kramer, 2006). Husted (2003) specifies the realm of opportunity using the indicators of centrality, it is to say the convergence of core business and CSR activities and specificity, the targeting of specific population/areas so that the return on investment can be better measured. An example of social investments in a resource-based perspective is innovation. As McWilliams and Siegel (2010) explain, 
innovation is a classic example of positive externality in what its benefits are not of full ownership of its inventor, but spill out to the society as a whole, in the same way that pollution is a archetypical example of negative externality (ibid). The expected outcome of the resource-based view of CSR is the creation of what Porter and Kramer (2011) define as shared-value, and McWilliams and Siegel term strategic value (2010). Both terms indicate the effort of finding opportunities for the simultaneous advancement of social and commercial objectives by identifying unmet social needs to be responded through business-driven innovation (Porter and Kramer, 2011). The notion of shared value, which Porter and Kramer (2011 p. 49) go as far as defining the channel through which to "reshape capitalism and its relationship with society", has achieved great success within the business community since its launch by advocating for the consideration of CSR as an investment rather than a cost (Crane, 2014). By advocating its beneficence for the bottom line, the notion of shared value in general has constituted a valuable instrument to help CSR win "the battle of ideas" (Crook, 2005 p. 1), by furthering "a unequivocal elevation of social goals to a strategic level" (Crane, 2014 p.4). On the other side, Crane et al (2014) have criticised the idea of shared value on the grounds of it not being particularly innovative, being its fundamental consideration already covered by instrumental stakeholder theory as well as a practice within social entrepreneurship. On general grounds the resourcebased view on CSR has been criticised for being completely economically embedded and inner-oriented, perceiving the firm as the centre of all activity, almost a "monad" (Moldaschl and Fischer, 2004). Coherently with a neoliberal perspective the resource-based view on CSR considers that the solving of social issues can be fixed entirely by market dynamics (Carter, 2015). Furthermore, the view subjects all action to economic value creation, making it clear that the objective of business activities is not the redistribution of wealth and power, or the furthering of social justice, but the mere creation of a greater amount of wealth (Vallentin, 2012). Probably the most challenging aspect of the resource-based view on CSR is its engagement a seemingly unproblematic win-win approach to social and business objectives, one that assumes that the interests of shareholders are in all cases aligned with those of society, not taking into consideration the existence of trade-offs between social and business activities, and eluding that social and environmental issues dealt by CSR are at least partly generated by the creation of business-led negative externalities (Barley, 2007). In sum, the resource-based perspective encounters an insurmountable limit in its positive approach to CSR; as clarified by Semplici (2011) it is a positive approach calling in cause opportunities rather than responsibilities, when "true" responsibilities are negative, setting limits or imposing to take remedy for actions by 
links of causality (Castelo Branco and Rodrigues, 2008). In this sense the resourcebased approach to CSR is a more refined model of philanthropy, one that Semplici (2011) dubs "strategic philanthropy" rather than CSR.

Both stakeholder theory and the resource-based view on CSR are based on the premise that the responsiveness to their host environment's claims and the creation of social externalities will ultimately lead to economic gain. Substantial research has been dedicated to determining whether CSR positively impacts corporate financial performance, and whilst there is a considerable stream of research that advocates the existence of a business case for CSR, criticisms considering the possibility to effectively evaluate CSR in financial terms persists, being the major problem engaged by the fact that CSR is a non-material resource generating non-material outcomes, such as consumer and employee retention, or the establishment of trust relationships with institutions, which are not easily quantifiable (Castelo Branco and Rodrigues, 2008). As Vogel (2005) points out, there is indeed a business case for CSR, but it makes sense for certain types of companies, the ones that are most visible and that work directly with consumers, but not for all of them. In this sense, the return on investment discourse is a niche one, rather than a far-reaching business strategy, and even in this case the relationship between social and economic performance is positive but not linear.

\section{The public responsibility approach}

As referred in the previous section, the public responsibility approach to CSR came to life in the early 1970s, after that in the tumultuous 1960 s business governance had been put under attack by social movements. Rooted on a system's theory-based perspective according to which social and business systems interpenetrate each other, the public responsibility approach to CSR was consolidated during this period, relying on the consideration that business actors had to establish a link with their socioeconomic system (Post, 2002). The public responsibility approach constitutes the roots of the legitimacy and environment-oriented approaches to CSR, bringing to the table concerns external to economic motives as well as the notion that business entities need to engage in responsiveness towards public constituencies. The public responsibility approach to CSR is almost entirely resolved by Preston and Post's seminal work Private Management and Public Policy (1975), which depicted the phases of socialization of business actors to their social environments first, and the need for them to be responsive to them then. Socialization is depicted as the 
interaction with different groups of "publics", holding together shared claims and interests, which they are apt to hold against business entities and their activities and to which business entities ought to be responsive. By doing so, the public responsibility approach was also the first approach to hinder a view of business entities as social and economic institutions, view that will later be further developed by the political view on CSR (forthcoming). When depicting the phase of responsiveness, Preston and Post (1975) stress and accent on the differences existing between businesses' responsibilities towards positive and negative impacts. According to the authors the consideration of positive impacts merely reinforces already taken managerial decisions as to confirm the managerial status quo. Negative impacts, on the other hand, are identified as being at the core of the socialization process in what they shift the consideration of business responsibilities from the cans and the mights to the ought tos.

As clarified by Carroll (2008), Preston and Post's (1975) reasoning was based on a previous, but almost contemporary, reflection on CSR made by Votaw (1973 in Preston and Lee, 1975 p. 11), reflection that questioned the broadness of the concept of CSR and the difficulties linked to its operationalization:

\begin{abstract}
"The term [social responsibility] is a brilliant one; it means something, but not always the same thing, to everybody. To some it conveys the idea of legal responsibility or liability; to others, it means socially responsible behavior in an ethical sense; to still others, the meaning transmitted is that of 'responsible for', in a causal mode; many simply equate it with a charitable contribution; some take it to mean socially conscious; many of those who embrace it most fervently see it as a mere synonym for 'legitimacy', in the context of 'belonging' or being proper or valid; a few see it as a sort of fiduciary duty imposing higher standards of behavior on businessmen than on citizens at large".
\end{abstract}

Preston and Post (1975), who agreed on the free-floating nature of the notion of CSR, proposed that businesses' socialization with their social environments should take place on the grounds of objectives and priorities set by the public policy framework, following a criteria that they term the principle of public responsibility. The engagement of the public responsibility principle, businesses' appraisal of public policy objectives within CSR is apt to furnish a sound moral basis to guarantee beneficence all publics, as well as create a clear support for the identification and implementation of initiatives. Preston and Post (1975 p. 9) suggested to rename the concept, accordingly, public, rather than social, responsibility. Their argument is reported below: 


\begin{abstract}
"In the face of the large number of different, and not always consistent, usages, we restrict our own use of the term social responsibility to refer only to a vague and highly generalized sense of social concern that appears to underlie a wide variety of ad hoc managerial policies and practices. Most of these attitudes and activities are well intentioned and even beneficent; few are patently harmful. They lack, however, any coherent relationship to the managerial unit's internal activities or to its fundamental linkage with its host environment. (the term public responsibility) stresses the importance of the public policy process, rather than individual opinion and conscience, as the source of goals and appraisal criteria" .
\end{abstract}

In the authors' perspective, in fact, a CSR approach based predominantly upon the creation of business benefits could not be appointed as a social responsibility, but rather as a private responsibility to make profits. Although furnishing sound basis for further CSR theoretical developments, the principle of public responsibility didn't produce a swarm; in fact, it didn't find much pursuit in CSR theory at all, having been described by contemporary authors as the least researched issue in CSR (Nelson, 2008) and the lacking policy case for CSR (Midtun, 2008). The lack of development of the theory may be explained by the neoliberal turn took in the second part of the 1970 s as explained in the first section of this chapter. As expressed by Vallentin (2012 p. 11) quoting Frederick (1986) "The prospects of relying on public policy (as an inclusive, deliberative process) to set the perimeter for corporate responsibility did not seem very attractive in a burgeoning era of deregulation", where business entities moved to being agenda-setters, rather than agenda-followers.

\title{
Neo-institutional theory and political CSR
}

Building upon the same approach envisaged by Preston and Post (1975), according to which social and business systems interpenetrate each other, neo-institutional perspectives consider that businesses dialogue with the social, political and institutional environments in which they are embedded. The relationship that business entities install with their environments is bi-directional, meaning that business entities are both influenced by their environments as well as apt to influence them (Campbell, 2007). Further, given the singularity of the interpenetration created in each social and economic system, there can be no one-size-fits-all approach to business and society relations (Argadoña and von Weltzien-Hoivik, 2009). Neoinstitutional theory can arguably be considered the principal frame of the contemporary legitimacy-oriented approach to CSR. The term neo-institutionalism was created in 1991 by Powell and DiMaggio to designate a new area of study in 
institutional theory, exploring the processes, defined by history, culture and policy, through which institutions - social structures which have gained a status of resilience - behave and seek legitimacy for their existence (Powell and DiMaggio, 1992). As Brammer et al (2012) point out, institutional theory gained momentum within the 200os as a theoretical tool for CSR research, due to its validity to argument both the diversity and dynamics of CSR. As previously mentioned, the diversity facet relies on the argument that contextual environments shape distinct business behaviour, hence that different contexts give origin to different CSR approaches (Doh and Guay, 2006; Campbell, 2007; Wry, 2009). Diversity is also cause of the heterogeneity of perspectives on CSR (Brammer et al, 2012). Such argument is substantiated, for instance, by the differences in European and North American CSR approaches originated to the same cradle of Western industrialization (forthcoming - 3.4). The dynamics facet serves to describe the activities business entities engage in to achieve legitimacy, and the role of other institutions in shaping CSR. In antagonism with the resource-based perspective, the institutional approach is based on the argument that institutions play a crucial role in enhancing both social and economic performance through different levels of enablement and regulation, resumed by Campbell (2007, ass. pp) in the seven points reported below:

1. Corporations will be less likely to act in socially responsible ways when they are experiencing relatively weak financial performance and when they are operating in a relatively unhealthy economic environment where the possibility for near-term profitability is limited.

2. Corporations will be less likely to act in socially responsible ways if there is either too much or too little competition. That is, the relationship between competition and socially responsible corporate behavior will be curvilinear.

3. Corporations will be more likely to act in socially responsible ways if there are strong and well enforced state regulations in place to ensure such behavior, particularly if the process by which these regulations and enforcement capacities were developed was based on negotiation and consensus building among corporations, government, and the other relevant stakeholders.

4. Corporations will be more likely to act in socially responsible ways if there is a system of well organized and effective industrial selfregulation in place to ensure such behavior, particularly if it is based on the perceived threat of state intervention or broader industrial crisis and if the state provides support for this form of industrial governance.

5. Corporations will be more likely to act in socially responsible ways if there are private, independent organizations, including NGOs, social movement organizations, institutional investors, and the press, in their environment who monitor their behavior and, when necessary, mobilize to change it.

6. Corporations will be more likely to act in socially responsible ways if they operate in an environment where normative calls for such behavior are institutionalized in, for example, important business publications, business school curricula, and other educational venues in which corporate managers participate. 
7. Corporations will be more likely to act in socially responsible ways if they belong to trade or employer associations, but only if these associations are organized in ways that promote socially responsible behavior.

8. Corporations will be more likely to act in socially responsible ways if they are engaged in institutionalized dialogue unions, employees, community groups, investors, and other stakeholders.

The political view is but one of the interdisciplinary approaches of CSR embedded within institutional theory, which have been explored in relation to political, law, economic and sociology processes (Brammer et al, 2012). The political perspective on CSR took shape in the first decade of the 200os, researching CSR as an instrument for business participation to governance processes. According to Brammer (2012) the governance lenses in CSR are particularly relevant to analyze the development of CSR in the global public domain, as, as previously argued for, large and transnational business entities have become key socioeconomic institutions through the process of globalization. Within this approach CSR is considered as a political process that in turn delivers public policy outcomes in the form of social investments and social standards produced by business entities alone (self-regulation) or in collaboration with other public or civil institutions (co-regulation) (Matten and Crane, 2003; Moon et. al 2005; Hofferberth et al. 2011; Sherer and Palazzo, 2011).

In what it acknowledges businesses' search for legitimization the neo-institutionalbased political view on CSR (from now on, political CSR) considers, similarly to stakeholder theory and the public responsibility approaches, that CSR isn't a voluntary commitment, but rather that it represents a reaction to expectations, claims and pressures that originate outside of the business realm following the principle of social responsiveness. Two rationalities can be identified as informing CSR practices within political CSR. The first one is the one is the one that has until now been described and that will be depicted, following March and Olsen (2004) as the logic of appropriateness. The concept of logic of appropriateness was engaged by March and Olsen (2004 p. 2) to depict public policy actions, identities and roles deemed by an agent to be "natural, rightful, expected, and legitimate" according to the rules, practices and institutions accepted or rejected within a given context. Hence, when applied to firms, the principle of appropriateness can be depicted as the one determining the possibility and relevance (the cans and mights) of business entities' to participate to the resolution of social issues in connection to their role as socioeconomic and political institutions. A second rationality to be found is a consequentialist one that, similarly to the one engaged by stakeholder theory, foresees the need for CSR commitments as elapsing from the expected impacts of 
business activities. Following (2006) this logic will be depicted as hindering a logic of social connectedness, a principle of moral liability that 'derives from legal reasoning to find guilt or fault for a harm' (Young, 2006 in Sherer and Palazzo, 2011 p. 912), a negative responsibility (the ought tos) linked to the consideration that "business actors bear responsibility for problems of structural injustice to which they contribute by their actions and from which they themselves benefit" (Sherer and Palazzo, 2011 p. 913). Through the principle of social connectedness the political approach to CSR explicitly takes on a perspective of liability and accountability, that brings forward the notion of responsiveness foreseen by stakeholder theory, stressing an accent on the fact that "the issue of doing harm (intentionally or not) largely has been ignored in the literature on corporate social responsibility" (Campbell, 2007 p. 951). According to Brammer et al (2012 p.6) the issue of accountability has re-emerged in the post-2008 era of financial crisis, claiming for a harshening of the responsibilities placed on the corporation in exchange for its legal limited liability, given that, the crisis has shown, the boundaries the limited liabilities of the corporation "re-emerge as the collective responsibilities of the society". The rationale according to which the social involvement of businesses is based both on causality for impacts and appropriateness, is, according to Sherer and Palazzo (2011 p. 913) what defines their political nature:

\begin{abstract}
"Problems of responsibility in globally expanded value chains demand collective action embedded in processes of democratic deliberation in order to change existing processes and institutions that produce the observed cases of harm and injustice. Such a model not only imposes a new modus of legitimacy on corporations, it embeds them in the emerging global governance movement and transforms them into political actors."
\end{abstract}

The political approach is a valid instrument to the analysis of CSR because it allows considering different levels of analysis of businesses' social involvement, from the local, community level, to the national and supranational levels (as it is the case for the sustainable development framework) whilst maintaining a context-specific perspective. Further, it stresses an accent on both the participation and liability facets of CSR, giving specific salience to the issue of harm remedy. In what it revolves around the concept of adaptation of business entities to their social, political and institutional environments, it gives continuation to Preston and Post's (1975) principle of public responsibility, according to which CSR should interpenetrate with the public policy framework. In postulating that business entities are not only influenced by, but also influence the setting in which they are embedded, the political approach to CSR takes a step forward from the principle of public responsibility, 
postulating a role in the co-production of public policy, defined by Midtun (2008) partnered governance.

Table 4: Rationale and guiding principles contained in theory

\begin{tabular}{|l|c|c|}
\hline \multicolumn{1}{|c|}{ Theoretical Swarm } & Guiding Principle & Main Rationale \\
\hline \hline Stakeholder Theory & Stakeholder responsivenes & Relational \\
Resource-based View & Opportunity & Strategic \\
\hline Public Responsibility Approach & Public Responsibility & Fundamental \\
\hline Political CSR & Appropriateness / Expected Consequences & Fundamental / Consequential \\
\hline
\end{tabular}

Table 4 resumes the rationalities found in theoretical streams, divided into strategyoriented and legitimacy-oriented, as depicted within this second section. From the table it is possible to observe that both legitimacy-oriented standpoints, the public responsibility approach and political CSR, as well as stakeholder theory, follow a rationale that is externally-driven, envisaging CSR practices as business entities response to their host environment. Only the resource-based view considers CSR to be an essentially internally driven activity informed by the achievement of strategic objectives. If the stakeholder theory, the public responsibility approach and political CSR shame the same external pressure, they underlying rationalities are distinct. Although the rationalities hindering each perspective are difficult to clear-cut, as $t$ different rationalities may co-exist, as it is the case, for instance of stakeholder theory were relational, consequentialist and strategic rationales may be detected, the author considers that the principle of stakeholder responsiveness hinders a predominantly relational rationale as its focus is that of negotiation with stakeholders, whilst the principle of expected consequences is predominantly consequentialist as its focus is one the effects caused by business activities. Similarly, although the rationales of public responsibilities and appropriateness share common features, namely the will to harmonize with public priorities and expectations, the former calls for practices based on the appraisal of the public policy process, whilst the latter more broadly defines practices as appropriate, rightful and legitimate. 


\section{CSR in practice}

\section{A closer look at CSR commitments}

Section three looks at how CSR standpoints take shape in practice. Initiatives undertaken in the context of a CSR agenda can be distinguished on the basis of the outcomes they intend to produce, on the direction and nature of the commitments they engage (inner or outer-oriented, positive or negative), on whether they are carried out by business entities alone (in-house initiatives) or in collaboration with third parties (multi-stakeholder initiatives), or, finally, for being permanent or project-based (Husted, 2003). Following the categorization of levels of value creation of CSR made by Porter and Kramer (2011) and previously introduced in Chapter 1 of this research, CSR practices will be distinguished as giving origin to commitments and activities relevant in terms of:

a) Core business innovation and adaptation;

b) Value chain reconfiguration;

c) Local development;

CSR practices engaging in innovation and adaptation and value chain reconfiguration are inner-oriented and directly relate to core business, and as such business actors generally carry them out alone through in-house initiatives or by the means of traderelated associations. The level of core business innovation and adaptation (a) depicts the application of business-based core competences and abilities to develop anew methods, concepts or products and services, or adapt existing ones to a broader audience, with the objective to tackle undeserved needs whilst maintaining the productivity, ethicality and sustainability of products and services (Asongu, 2007). In this case CSR is envisaged as a vehicle to refine and ameliorate productivity and business practice. The level of value chain reconfiguration (b) identifies the adjustments of the different phases of the production chain, also termed value chain, from sourcing, to product development, pricing, distribution, marketing and disposal, with the objective of minimizing adverse impacts and capitalizing on positive ones. Commitments pertaining to this level of value creation are realized through the formulation, implementation and reporting of social standards that set boundaries for business practice. CSR practices directed at local development are, on the other hand, externally-oriented and hence often conduct through collaborations 
and partnerships with civil and public actors. Initiatives directed at local development (c) aim to the fortification of the environment, proximal or distal, in which a given business activity is placed through the deployment of human capital, products, and services, as well as logistical capabilities destined to enhance infrastructures, capacities or institutions. This type of commitments is destined to creating physical or relational conditions for the thriving of business activities. In this sense they can be likened to the philanthropic investments of the first industrial era, although in the CSR jargon they are referred to as corporate citizenship, term which stresses a focus on CSR as being an instrument of business participation in the community in which it is embedded. As noted by Semplici (2011), commitments pertaining to the levels of core business innovation and local development are positive commitments that expand the sphere of action of business activity; featuring new roles, services and products towards causes, relevant for community actors or prospective clienteles, for which companies believe that further investment is needed, whilst value chain reconfiguration implies a negative responsibility to set boundaries to business activity. Commitments directed to a reconfiguration of the value chain, on the other side, are negative responsibilities that set restrictions whose boundaries exceed the requests made by existing laws, creating compelling obligations that expand the liability of business entities (ibid). If social investments fulfilling the demand of a social need, or participating to the resolution of a problem, had been a determinant feature of CSR since its origins in the forms of philanthropic social investment first, and innovation-based investments then, and commitments related to innovation are somewhat part of the mission of all business entities bringing little novelty to the picture, the creation of business-based social rules and standards, through self or co-regulation can be said to be an evolution of the CSR sphere of action, coherently with the perspective of partnered or polycentric governance. Establishing a connection with the different CSR rationales underlying the theoretical streams analysed in the previous section, it can be said that the mere uptake of positive CSR commitments brought forward by innovation and local development activities is coherent with the opportunity rationale of the resource-based view on CSR, providing a benefit for society whilst assuring a direct return on investment through the creation of a competitive advantage, that derives from the answering of issues considered relevant for both stakeholders and the business entity. On the other hand, the consideration of both positive and negative externalities (value chain reconfiguration) is aligned with the rationale of social responsiveness for impacts in a connectedness perspective, seeking for a mediation of social and business objectives, 
which although apt to create gains in a long-term perspective, may also impose additional costs in the short period.

Collaborative and multi-stakeholder CSR practices may further distinguished on the basis of the type of relationships they give origin to. In this respect Googins and Rochlin (2000) make a distinction between passive donor-recipient collaborations, normally enacted through sponsorship, and mutually engaging collaborations, such as the ones realized through partnerships. As we will review in detail in the following subsection, CSR is often identified as a territory for the establishment of "new partnerships" (UNGC, 2000; EC, 2001/2006/2011) that cross the boundaries between private, public and civil sector. The partnership approach of CSR has been defined by Seitanidi and Crane, (2009 p. 413) as "one of the most exciting and challenging ways that organisations have been implementing CSR in recent years". Exciting in what partnerships are passible of creating value through polling different economic sectors' action in the same direction, and challenging, due to the separateness of sectors' visions, objectives and methods and lack on shared criteria for successful collaborations (ibid). Further, according to Hamann and Acutt (2003) the commitment to partnering through CSR is authentic, as it allows, in the long period, the legitimization of corporate choices and actions, thus lowering risks and costs of business operations. Waddock (1986 in Seitanidi and Crane, 2009 p. 413) defines cross-sectoral partnerships as:

\begin{abstract}
"A commitment by a corporation or a group of corporations to work with an organisation from a different economic sector (public or nonprofit) (...) co-operatively to solve problems that affect them all. The problem can be defined at least in part as a social issue; its solution will benefit all partners. Social partnership address issues that extend beyond organisational boundaries and traditional goals and lie within the traditional realm of public policy - that is, in the social arena. It requires active rather than passive involvement from all parties. Participants must make a resource commitment that is more than merely monetary."
\end{abstract}

According to Googins and Rochlin's (2000 p. 131), there is a rhetoric of partnerships that outpaces reality and a scarceness of "true partnerships" within cross-sectoral collaborations. The authors distinguish between three types of cross-sectoral partnerships: reciprocal exchange, developmental value creation and symbiotic partnerships. Reciprocal exchange partnerships are based upon a transactional relationship where each party contributes with goods or resources expecting in exchange a material or non-material offset. Partnerships based on developmental value creation request, rather than an exchange, for the parties to work jointly to 
achieve a given objective; in this case partners collaborate though polling in specific resources each. Finally symbiotic partnerships "create relationships that are mutually dependant”, in which the resources are created in the moment of collaboration (Googins and Rochlin, 2000 p. 139). True partnerships, which the authors define as giving origin to developmental or symbiotic relationships (characterised by collaborative advantage, mutuality of choices, agreement on partnership composition and definition, and trust) are to be distinguished from reciprocal relationships enacted by mere transfers of resources among parties. All of these collaborations are often designated as partnerships without making the due distinctions. In Googins and Rochlin's (2000 p. 138) perspective developmental and symbiotic patterns of value creation, as opposed to reciprocal ones, "require partners to work jointly in order to create benefits", benefits that partners would not have been able to achieve individually. Worth noting, within this frameset, is that the escalation of collaboration between partners does not necessarily contend that symbiotic relationships are apt to produce better outcomes than reciprocal ones. On the other hand, it is specified that symbiotic partnerships are to be preferred over developmental ones, and the latter over exchange relationships. This because higher level partnerships give origin to greater commitment, engagement and the building of trust relations, and hence be a vehicle of social change.

\section{International and supranational CSR policies: problematization, agenda- setting and means for action}

As explained in the previous chapters, a range of policies shapes CSR practice before contextual determinants. Not only do the existing policy frameworks share roots and purpose, but also they pinpoint almost coincident areas of action, encountering only slight and often difficult to find differences, as we will see throughout this sub-section and then resumed in Table 2. For this reason they have been criticised for competing among each other and lacking univocal guidance (Fransen, 2012). This section presents and analyses the selected CSR policies already listed in Chapter 2 in a perspective of problematization, agenda setting and means of action set for implementation. CSR policies can be differentiated and according to the actors implementing them: international policies developed by intergovernmental bodies; international policies developed by intergovernmental bodies and formally agreed by governments; supranational policies, such as the European policy on CSR; privately developed international policies and national policies. This section focuses on international and supranational policies, being domestic policies dealt with in the 
next section. Broadly, the international CSR policies in review this sub-section can be distinguished in two categories, principle-based and operational. The UNGC, the OECD Guidelines for Multinational Enterprises (from now on, OECD Guidelines), the International Labour Organization Tripartite Declaration of Principles concerning Multinational Enterprises on Social Policy (from now on, ILO Tripartite Declaration) and the policy documents produced by the EC are principle-based frameworks which define the "what" in CSR: normative principles, practice-oriented principles and short term objectives. The Guidance Standard on Corporate Social Responsibility ISO 26000 (from now on, ISO 26000), a privately developed initiative, although containing guiding principles, is focused on the operational side of CSR, specifying "how to" plan, design and implement CSR initiatives.

Launched by the United Nations (UN) in 2000, following the secretary-general Kofi Annan's appeal, during Davos' World Economic Forum in 1999, to “create a global compact of values and principles, which will give a human face to global markets " (UN, 2010), the UNGC was the first initiative, led by the UN and directed at business managers worldwide, to formalize social responsibility as a policy to be integrated in strategies and operations. Other than inciting companies to advance broader societal goals the UNGC sets Ten Principles ${ }^{2}$ according to which business actors are expected to act. The principles cover four areas of action: human rights, labour conditions, environmental protection and anti-corruption, and to report upon their

1. ${ }^{2}$ Businesses should support and respect the protection of internationally proclaimed human rights; (Human Rights)

2. Make sure they are not complicit in human rights abuses; (Human Rights)

3. Businesses should uphold thefreedom of association and the effective recognition of the right to collective bargaining; (Labour)

4. The elimination of all forms of forced and compulsory labour; (Labour)

5. The effective abolition of child labour; (Labour)

6. The elimination of discrimination in respect of employment and occupation; (Labour)

7. Businesses should support a precautionary approach to environmental challenges; (Environment)

8. Undertake initiatives to promote greater environmental responsibility; (Environment)

9. Encourage the development and diffusion of environmentally friendly technologies; (Environment)

10. Businesses should work against corruption in all its forms, including extortion and bribery (Anti - corruption). 
implementation. As mentioned in Chapter 1 the UNGC was conceived as to address MNEs although it currently represents a reference for all types of business entities notwithstanding size, as well as for non-business entities. Within his speech Kofi Annan engages a perspective of sustainable development, exhorting business actors to participate in the resolution of the imbalances existing between the social, economic and political realms rather than taking upon a path or mere profitmaximisation. As in his speech Kofi Annan stresses the networked nature of business and society objectives focusing on shared values and principles in a perspective of social harmony, political consensus and stability to be furthered on a global scale, it can be said that the UNGC relies on the logic of appropriateness, rather than on strategic or consequentialist rationalities. Although being a principle-based document the UNGC gives some indication concerning how businesses are to carry out socially responsible business practices. In a first instance, it is recommended they encourage and advocate, within states and multilateral institutions, for the preservation and furthering of issues relative to human rights, labour conditions, the environment and the prevention of bribery. In a second instance, a more active stance is suggested calling for the taking of action within the business sphere through conduct, products and services. It should be noticed in this sense that the UNGC considers the focus of socially responsible practices to be businesses' values and related activities, rather than the impacts generated by said activities. It is specified that, within this context, the role of the UNGC is one of streamlining and normalization of practices within the business community, as well as one of enablement vis-à-vis the dialogue and collaboration with other social parties.

Both the OECD Guidelines and the ILO Tripartite Declaration pertain to the category of international policies developed by intergovernmental bodies and formally agreed by governments. They contain recommendations addressed by governments to business actors inviting to good practice and harmonization with existing laws. Also in this case the policies, although addressing MNEs in a first place, also refer to domestic companies. Similarly to the UNGC, both policies engage a perspective of appropriateness, although in addition to it they also consider what has been termed the principle of public responsibility. The OECD Guidelines, whose first formulation dates back to 1976 and whose last and fifth edition was published in 2011, call for the coherence among social, economic and environmental objectives and harmonization with government policies, as to allow the building of trust relations. As for what concerns areas of action the OECD Guidelines contemplate: employment and industrial relations, the environment, bribery, competition, taxation, consumer 
interest, and science and technology. The ILO Tripartite Declaration was first formulated in 1977 following the 1960s and 1970s discussions concerning the relations of MNEs entities with host governments, and their influence on social and labour policy. It was later updated in 2000 and 2006 to include the impacts of globalization on labour, and economic and social welfare. Also in this case, the rationality brought forward is one of harmonization with general policy objectives of host countries affirming that businesses should act "within the framework of development policies established by governments" (ILO, 2006 p. 1) as to "be in harmony with the development priorities and social aims and structure of the country in which they operate" (ILO, 2006 p. 9). The areas of action contemplated for the enactment of the social responsibilities of business are those of employment and industrial relations.

At the EU level, the need to redirect business efforts to include social objectives was first expressed in 1993 in a plea launched by the commission's president of the time, Jacques Delours, which led to the creation of the European Business Network for Social Cohesion in 1996 (Eberhard-Harribey, 2006). In 1994, in Denmark, the Minister of Social Affairs launched a CSR campaign and founded the Copenhagen Centre for Corporate Social Responsibility, whilst in France some legislative documents, such as the Barnier Law (1995) and the Orientation Law for Territorial Planning and Sustainable Development (1999) proven the recognition of the practice of CSR (ibid). Few years later, the Conclusions of the Lisbon Special European Council held in March 2000 made a "special appeal to companies' sense of social responsibility”, calling for the inclusion of socially responsible practices for lifelong learning, work organization, equal opportunities, social inclusion and sustainable development (EC, 2001 p. 3). Only in 2001, following the UNGC, did the European Commission start to confront itself with the term CSR, issuing the Green Paper Promoting a European Framework for Corporate Social Responsibility (EC, 2001). The green paper famously defined CSR as the inclusion of social and environmental concerns, and the interaction with stakeholders, into business operations on a voluntary basis, specifying that it should not be considered as a "substitute for regulation or legislation concerning social rights or environmental standards, including the development of new appropriate legislation (EC, 2001 p. 7). The Green Paper also individuated the list of areas of action pertinent to socially responsible business practices, differentiated in issues considered relevant for the internal or external dimension of a given company. Are depicted as being issues relevant for the internal dimension: human resources management, health and safety at work, 
adaptation to change (which describes practices coherently with the level of value creation of innovation and adaptation, as described in the beginning of this section) and management of environmental impacts and natural resources. Are depicted as issues being relevant for the external dimension: local communities, business partners, suppliers and consumers, human rights and global environmental concerns (which go beyond productivity value chain). In 2006, the EC published the policy Implementing the Partnership for Growth and Jobs: Making Europe a Pole of Excellence on Corporate Social Responsibility (EC, 2006). The policy emphasizes the importance of CSR practices for sustainable growth, taking a step forward from the publication of 2001 by pointing out the aptitude of socially responsible practices to contribute to a number of public policy areas: social inclusion, public health, poverty reduction, human rights and skills development:

The Guidance Standard on Corporate Social Responsibility ISO 26000 (from now on, ISO 26000), a privately developed initiative, although containing guiding principles, is focused on the operational side of CSR, specifying "how to" plan, design and implement CSR initiatives. ISO 26000 was released in 2010 by the certification body International Organization for Standardizion (ISO) after a lengthy multi-stakeholder consultation that involved thousands of contributors from 90 countries over a period of six years. ISO 26000 is not a management system standard, nor is it certifiable for regulatory and contractual use (ISO, 2010). After its release, ISO 26000 was endorsed as the official operational frame of the UNGC through the issuing of the UN policy document An Introduction to Linkages Between the UN Global Compact Principles and ISO Core Subjects (UN, 2010) with the intention to disseminate, build capacity and streamline a common understanding of corporate social responsibility (UNGC, 2010). The UNGC-ISO referential is today the major operational reference for CSR planning and implementation among European enterprises (EC, 2013). Other than specifying seven areas of action which the standard terms core subjects and relative sub-dimensions, ISO 26000 offers guidance for two different phases of the formulation of CSR initiatives: planning and implementation. According to the standard, the planning phase is to be carried out through the pinpointing, within the seven core subjects and relative sub-dimensions of the "relevant and significant issues" relative to the organization's "sphere of influence" (ISO, 2010 p. 5). The notion of sphere of influence is defined as an area or political, contractual or economic relationships across which an organization has formal or de facto control (ISO, 2010). The pinpointing of relevant and significant issues follows the subsequent itinerary: 
Step1. Organizations choose, at their discretion, the areas of action (core subjects) they wish to address through CSR;

Step2. They then carry out an assessment of negative and positive impacts within the areas of action, pinpointing a range of issues that present risks and opportunities (for instance, within the core subject relative to the environment, to reduce footprint by decreasing energy consumption at the production line);

Step3. Finally, they engage with stakeholders that had been previously mapped by the company through stakeholder analysis. Stakeholders furnish insight concerning preferred activities within the range of issues detected by businesses, being engagement focused on the collection, rather than provision of information.

Differently from the former, ISO 26000 stresses a clear rationality of consequentialism, focusing on the fact that CSR practices are concerned with the impacts of business operations rather than with the harmonization with social values and norms. In the perspective of ISO 26000, the identification of impacts isn't merely a neutralization action applied at the end of the bottom line to fix outcomes. Rather, it is intended as a proactive mindset to be incorporated, across all levels of planning, execution and stakeholder interaction leading to an overall reformulation of the management model rather than an appendix to it (ISO, 2010). ISO 26000, similarly to the ILO Tripartite Declaration and the EC Strategy on CSR identifies interactions of businesses with their host environments in terms of stakeholder engagement, rather than cross-sectoral partnerships.

Following the formulation of the ISO 26000 guidance standard in 2010, the EC presented a second strategy document on CSR, A renewed EU strategy 2011-14 for Corporate Social Responsibility, aimed at incorporating the guidance standard's principle of expected consequences, adding to its former definition the notion that CSR is "the responsibility of enterprises for their impacts on society" (EC, 2011 p. 6). The policy also made an explicit invitation to European enterprises to make a commitment by 2012 to take account of at least one of the following sets of principles and guidelines when developing their approach to CSR: the UN Global Compact, the OECD Guidelines for Multinational Enterprises, or the ISO 26000 Guidance Standard on Social Responsibility as well as to "develop or update by mid-2012 their own plans or national lists of priority actions to promote CSR in support of the 
Europe 2020 strategy" (EC, 2006 p. 13). Within the renewed strategy, which also highlighted the importance of socially responsible business practices to help mitigate the effects of the economic crisis, beneficial impacts are clarified in terms of: the promotion of research, education and innovation as well as the transparent and accountable communication with stakeholders. Negative impacts, on the other side, are not specified, yet a call is made to identify, prevent and mitigate negative impacts through due diligence risk assessment. Although specifying that "the development of CSR should be led by enterprises themselves", the renewed strategy affirms that public authorities, intended predominantly at the level of national governments, with the support and coordination of supranational European bodies "play a supporting role through a smart mix of voluntary policy measures and, where necessary, complementary regulation, for example to promote transparency, create market incentives for responsible business conduct, and ensure corporate accountability" (EC, 2011 p. 7). In one of the recommended actions of the document it is asked to member states to "develop or update by mid-2012 their own plans or national lists of priority actions to promote CSR in support of the Europe 2020 strategy, with reference to internationally recognised CSR principles and guidelines and in cooperation with enterprises and other stakeholders" (EC, 2011 p. 13).

Section 3.2 was apt to convene the principles that motivate business engagement in social issues as put forwards by different theoretical swarms on CSR: stakeholder responsiveness, opportunity, public responsibility, appropriateness and expected consequences. The presentation and discussion of CSR policies within this section has furnished information relevant to discuss which principles shaped by theory are concretized in CSR policy frameworks. A foremost remark that can be made is that CSR policy frameworks, on a general basis, discard the inner-oriented resource-based view on CSR and its logic of opportunity. CSR practice is hence motivated following multiple rationalities that differ among policies (resumed in Table 5 below). All in all policies can be distinguished among the ones following predominantly a fundamental logic to be enacted following the principles of appropriateness (UNGC), appropriateness and public responsibility (OECD Guidelines and ILO Tripartite Declaration), and the ones following a relational and consequential logic, to be concretized following the principles of expected consequences and stakeholder responsiveness (EC Renewed Strategy and ISO 26000). 
Table 5: Guiding principles contained in international CSR policies

\begin{tabular}{|l|c|c|c|c|c|}
\hline & UNGC & OECD & ILO & EC & ISO \\
\hline \hline Stakeholder responsiveness & & & & $\checkmark$ & $\checkmark$ \\
\hline Opportunity & & & & & \\
\hline Public responsibility & & $\checkmark$ & $\checkmark$ & & \\
\hline Appropriateness & $\checkmark$ & $\checkmark$ & $\checkmark$ & & \\
\hline Expected consequences & & & & $\checkmark$ & $\checkmark$ \\
\hline
\end{tabular}

Table 6 resumes the areas of action covered by the international and supranational policy approaches described. The table shows what previously hinted, it is to say that CSR policies cover similar, although slightly differing, areas of action. It is furthermore possible to argue the existence of primary areas, covered transversally by the different frameworks, such as human rights, fair operating practices, environmental issues and labour issues, and secondary issues, such as community development, competition, taxation and disclosure, and science and technology.

Table 6: Areas of action contained in international CSR policies

\begin{tabular}{|l|c|c|c|c|c|}
\hline & UNGC & OECD & ILO & EC & ISO \\
\hline \hline Organizational Governance & & & & $\checkmark$ & $\checkmark$ \\
\hline Human Rights & $\checkmark$ & $\checkmark$ & $\checkmark$ & $\checkmark$ & $\checkmark$ \\
\hline Fair Operating Practices & $\checkmark$ & $\checkmark$ & & $\checkmark$ & $\checkmark$ \\
\hline Environment & $\checkmark$ & $\checkmark$ & & $\checkmark$ & $\checkmark$ \\
\hline Labour Issues & & $\checkmark$ & $\checkmark$ & $\checkmark$ & $\checkmark$ \\
\hline Consumer Issues & & $\checkmark$ & & $\checkmark$ & $\checkmark$ \\
\hline Community Issues & & & & $\checkmark$ & $\checkmark$ \\
Science and Technology & & $\checkmark$ & & & \\
\hline Competition & & $\checkmark$ & & & $\checkmark$ \\
\hline Taxation & & $\checkmark$ & & & \\
\hline Disclosure & & $\checkmark$ & & & $\checkmark$ \\
\hline
\end{tabular}

As for what concerns the means envisaged for the formulation and implementation of CSR practices (Table 7), the UNGC and OECD Guidelines specify the relevance of cross-sectoral partnerships. The UNGC focuses upon "creative" cross-sectoral partnerships on a global level, putting a special focus on public-private partnerships as to "overlap with public sector priorities underpinning peace, security and poverty reduction" and "develop more integrated solutions to global challenges" (UNGC, 2016). The OECD Guidelines, whilst also calling in cause the establishment of partnerships, broaden the range of partners from governments to trade unions and NGOs, pointing out the priority role of national governments in providing domestic CSR policy frameworks that maintain and promote business contribution to public policy objectives (OECD, 2000). The ILO Tripartite Declaration brings forward 
stakeholder consultation, to be realized "between multinational enterprises, the government and, wherever appropriate, the national employers' and workers' organizations concerned" (ILO, 2006 p.3). In addition to stakeholder consultation and cross-sectoral partnerships the OECD Guidelines and the ILO Tripartite Declaration highlight the appraisal of public policies as a means for action of socially responsible practices. In its first 2011 strategy the EC, although emphasizing the need for business management practices apt to translate principles into action the EC Strategy does not specify which such managements practices are claiming, generically, that "managers and employees are required to make business decisions based on additional criteria to those they were traditionally trained to expect" (EC, 2001 p. 16). The 2001 strategy further stresses that socially responsible business practices are to be carried out through the development of "new partnerships and new spheres for existing relationships (...)" (EC, 2001 P. 3). In the EC renewed strategy of 2011, as mentioned previously a call is made for impacts to be assessed following due diligence risk assessment. The means envisaged by ISO 26000, more structured than the others and already comprehensively detailed, can be resumed in terms of stakeholder engagement and impacts assessment based on the identification of a sphere of influence.

Table 7: Means for action contained in international CSR policies

\begin{tabular}{|l|c|c|c|c|c|}
\hline & UNGC & OECD & ILO & EC & ISO \\
\hline \hline Cross - sectoral partnerships & $\boldsymbol{V}$ & $\boldsymbol{V}$ & & & \\
\hline Stakeholder consultation & & & $\boldsymbol{V}$ & & $\boldsymbol{V}$ \\
\hline Appraisal of public policies & & $\boldsymbol{V}$ & $\boldsymbol{V}$ & & \\
\hline Impacts assessment & & & & $\boldsymbol{V}$ & $\boldsymbol{V}$ \\
\hline
\end{tabular}




\section{CSR in context}

A European approach to CSR: community and regional approaches, national policy initiatives

The building of a European CSR strategy has been described by Eberhard Harribey (2006) and De Shutter (2008) as a political effort of the EC, aiming, at the same time, at consolidating its public policy (both internally at the level of the union and globally), by offering a governance platform for supranational convergence, strengthening the consensus regarding the single market via the responsibilization of business practices, promoting economic growth together with social and territorial development, and setting a regulatory framework for business activity along transnational borders within and beyond the EU. De Shutter (2008 p. 235) points out that, somewhere along the way, such effort was "hijacked" by the business community, who, by lobbying to avoid any kind of regulation, somehow undermined the Commission's political intention to build a pact among social parties based on extended consensus, thus strongly limiting the boundaries of a European model of CSR, whilst maintaining its grounds faithful to the North American neoliberal roots of separation among business and political mandates, and to its functionality as a “market referential" Eberhard Harribey (2006 p. 362). De Shutter (2008) claims that there are two possible explanations to argument the EC's impossibility to stay truthful to its initial mandate: either the EC acted naïvely, being convinced by business leaders that a regulated CSR approach would not have the same levels of reception and results; or the Commission's initial political orientation shifted somewhere along the implementation process, willingly starting to favour economic objectives over social purposes. Of a divergent opinion Eberhard Harribey (2006 p. 365) states that the lack of regulation within the EC served the purpose of specializing CSR as a channel for governance, and as a vehicle to overcome the market referential, rather than re-affirm it:

\footnotetext{
"The Commission, by legitimizing a Community action in terms of a converging Community interest and while proposing a framework of cooperation rather than a framework of rules, almost naturally exercises the role of regulator, that is, of political decision maker (...) In proposing a Community framework of reference, the Commission acts as conciliator (...) The European framework becomes the place of negotiation needed for good regulation."
} 
As previously stressed the frame of CSR envisaged today by international policy frameworks and the European strategy on the subject is one of Anglo-Saxon and North-American rooting; in this sense its utilization as a tool to strengthen the public policy of the European Union is daring, as argued for by Eberhard Harribey (2006). Secondly, as also previously stressed, the "demands for CSR and CSR practices have existed since before the industrial revolution” Argadoña and von Weltzien-Hoivik (2009 p. 13), having labour and social issues been traditionally negotiated between business entities, union memberships and civil representation groups, at both a sectoral and national before being taken in charge by welfare states (Perrini, 2005). This led, historically, to an internalization of the social mission within European business entities (Matten and Moon, 2008).

The question as to what extent CSR in Europe is today linked to its American counterpart is a fundamental one, and one that as given origin to a considerable amount of literature concluding that it is possible, on general terms, to distinguish an European as opposed to a North-American approach to CSR (Maignan and Ralston, 2002; De Shutter, 2008; Eberhard Harribey, 2006; Matten and Moon, 2008; Argadoña and von Weltzien-Hoivik, 2009), but that at a closer look it is more accurate to say that various approaches co-exist within the Union (Maignan and Ralston, 2002; Albareda et al., 2007; Argadoña and von Weltzien-Hoivik, 2009). In their paper Corporate Social Responsibility: One Size Does Not Fit All, Argadoña and von Weltzien-Hoivik, (2009) explain that, although the demands for CSR are long-standing in Western high income economies disposing of a class of entrepreneurs first, and of business organizations and corporations then, their content varies "depending on historical, cultural, political and socioeconomic drivers, which may differ for the same context in different periods of time" (Argadoña and von Weltzien-Hoivik, 2009). This happens because CSR, as previously argued for, can be described as a proxy for the relationships existing between business and society within a given context and for a given time, and, as such, it does not originate from a void or by the means of an abstract model, but is to be understood within its setting. The European approach to CSR can be said to be distinguishable from its USA counterpart on the grounds of the roles expected from the state and the private sectors and the differences existing in terms of political financial, educational, labour systems in the two contexts (Matten and Moon, 2008). With the due differences that we will review later on in this section, and as already referred in Chapter 1, it can be said that more or less homogeneously within the European context the state has been the institution in charge of the production and regulation of public goods and social 
welfare, and of the coordination of the encounter, litigation and negotiation between capital and labour (Matten and Moon, 2008). In Europe capitalism has faced considerable scepticism and cynicism (Maignan and Ralston, 2002); on the other side of the pond, conversely, the role of business entities in society business entities are identified as bearing "substantial responsibility for the moral and physical character of the communities in which they have invested" (Vogel, 1992 p. 42 in Maignan and Ralston, 2002 p. 510). Labour rights, on the other hand, have been more often set at the corporate level rather than by union negotiation (Matten and Moon, 2008). This perspective is reiterated by Matten and Moon (2008 p. 408) in the following terms:

\begin{abstract}
"Americans are regarded as having a relative capacity for participation (De Tocqueville, $1956 / 1835$ ), a relative capacity for philanthropy (Bremner, 1988) and a relative capacity of business people for philanthropy (Dowie, 2001), relative skepticism about big government (King, 1973), and relative confidence about the moral worth of capitalism (Vogel, 1992). Thus, there is a much stronger American ethic of stewardship and of "giving back" to society, epitomized in Carnegie's view that "the duty of the man of Wealth [is] to consider all surplus revenues which come to him simply as trust funds, which he is called upon to administer...in a manner...best calculated to produce the most beneficial results for the community (2006/1889: 10). (...) This contrasts with the greater European cultural reliance on representative organizations, be they political parties, unions, employers' associations, or churches, and the state (Lipset \& Rokkan, 1967).”.
\end{abstract}

For what concerns the public or private nature of control of economic processes, Matten and Moon (2008) note that European governments, and particularly Continental and Scandinavian ones, are more likely to be involved in direct ownership of insurance companies and banks, whilst Continental and Anglo-Saxon countries are likely to dispose of high levels of public investment and ownership in private industry. In the US the public domain has been traditionally more fragmented, less community-oriented, more pragmatic and open to negotiated, private-based agreements.

After having argued for the pre-existence of CSR in Europe before of the importation of the term CSR, it is important to explain why businesses' socially responsible practices in Europe have shifted from being implicit and internalized, considered as an approach embedded within the normal mission of all business entity, to being explicit, it is to being individuated as a distinct, innovative and at times additional area of governance relative to business and society. As explained by Matten and Moon (2008 p.10) "Implicit CSR is not conceived of as a voluntary and deliberate 
corporate decision but, rather, as a reaction to, or reflection of, a corporation's institutional environment, whereas explicit CSR is the result of a deliberate, voluntary, and often strategic (Porter \& Kramer, 2006) decision of a corporation”. Matten and Moon (2008) explain this passage with the struggles experienced by the European welfare states and corporatist strategies, predominantly within AngloSaxon, Continental and to some extent Scandinavian countries, to address the crisis related to stagflation in the period between the 1970 and the 1990, struggles that ultimately led to phenomena of privatization of public goods and deregulation of labour markets. Matten and Moon (2008, p. 415) believe that such struggles motivated the government of the UK to "expressly encourage CSR as part of the restoration of legitimate societal governance, particularly regarding the education and labor system. Simultaneously, concerns about business's own legitimacy pushed corporations toward explicit CSR”. On the other hand, according to Harvey (2005), such governmental stance within the UK is to be explained in terms of Thatcher's turn towards a neoliberal approach aiming at the dismantlement of the welfare, as discussed in the first section of this chapter. Matten and Moon (2008) contend that within the rest of the zone the consolidation of the European Union, and more importantly the creation of the Eurozone, participated in the downsizing of corporatism through the deregulation of markets, labour, services and goods, simultaneously setting the case for explicit CSR practice. Two additional factors participate in the shifting of the European approach towards and explicit CSR model. In a first instance, the processes of globalization and the related creation of the institutions and policy approaches of the global public domain, as it is the case for the sustainable development frame, as previously contented, towards which the EC strategy declares the intention to harmonize: "we are led to consider that the major theme informing the European literature is not CSR, but sustainable development, a more global concept" adding that "it is also clear that the means of this mission includes the establishment of a internal market, of an economic and monetary union and by the creation of Community policies and actions, but the real objective is a sustainable development; the market is simply the means." (Eberhard Harribey, 2006 p. 363). In a second instance to what Matten and Moon (2008 p. 406) describe as an "Americanization" of management concepts, technologies and practices processes where hubs of greater innovation and technological development are acknowledged as legitimate and understood as best-practice (Maignan and Ralston, 2002; Matten and Moon, 2008). The former, coherently with the neo-institutional perspective, is depicted as a source of coercive isomorphism, the latter as an example of mimetic process (Matten and Moon, 2008). 
Overall it can be said that, together with the developments of the European policy framework for CSR, there has been a substantial development of national governmental policies and initiatives concerning CSR within member states, coherently with the plea made in the EC Green Paper of 2011 to take on national initiatives upon the topic (Albareda et al., 2007; Matten and Moon, 2008). National public policies on CSR in Europe serve the objectives of shedding context-based light on the nature and scope of socially responsible business management, setting guidelines, objectives and targets, and framing the stance the public sector intends to assume towards CSR. If insofar we have tried to detect the outline of a European approach to CSR, several distinctions can be made concerning sub-approaches and local contingencies with respect to CSR within Europe. Relying on the institutional perspective, and using as an independent variable national governments' postures towards CSR (existence of national policy on CSR, government departments and ministries, and regulation), Albareda et. al (2007) individuate four different approaches to CSR in Europe: a partnership approach specific to the Scandinavian countries; a business-in-the-community Anglo-Saxon model; a sustainability model characteristic of continental Europe; and an agora model, specific of Southern countries, where CSR development, although weak, is believed to be a potential vehicle for the creation of a so-far weak social consensus. Also in this case the distinction made by Albareda et. al (2007) is not new, being it grounded upon consolidated typologies of institutional approaches to public policies and welfare states in Europe, as framed by Esping-Andersen's (1990) Three Worlds of Welfare Capitalism. Following Fox's (2002) categorization, governmental postures towards CSR in Europe can be resumed in four stances: mandating, facilitating, endorsing and partnering, although there are not definite lines separating these four roles. Throughout the mandating function governments establish the minimum requirement for businesses' social activities and performance within a given legal framework. Public entities engage in a facilitating role when they stimulate the development of socially responsible practices, furnishing rewards or punishments such as subsidies, tax reductions or penalties, or providing institutional guidelines. The endorsing role is one that gives political support by publicising CSR, engaging socially responsible label schemes, setting benchmarks or favouring socially responsible initiatives in public procurement. The strategy of setting benchmarks for CSR is one that has been used often by international corporate watchdogs for two reasons: first of all, the setting of examples makes the case for a clarification of expectations, being the lack of comprehension among companies and stakeholders a 
major risk for CSR failure, that happens also in presence of channels of communication, due to intrinsic differences in language and objectives of involved parties. Secondly, because the benchmarking logic is appropriate for the competitive nature of capitalistic businesses (Knudsen et al., 2015). Knudsen et al. (2015) have suggested that in Europe the endorsing role of the state towards CSR is yet scarcely developed if compared to the remaining functions, exception made for countries that are more supportive of business activity and associative governance, as it is the case for the UK and Germany. On the basis of the categorization made by Albareda et al. (2007) approaches are briefly resumed as follows:

\section{- The Partnership model}

The partnership model is individuated as pertaining to the Scandinavian countries: Denmark, Finland, the Netherlands, and Sweden. As hinted previously, these institutional environments are characterised by strong welfare states and state coordination of activities between public administration, third sector, labour unions and business sector based upon the precept of all societal agents' participation and inclusion, whose objective is the creation of social consensus and the shared resolution of complex social issues. Within this context CSR is hence understood as a co-responsibility towards a more inclusive and just society, with CSR practices being implemented often implicitly. The working environment for CSR is defined at the national level and predominantly carried out through multi-stakeholder partnerships where local actors play a strong role. Within the Danish context the notion of crosssectoral partnership incorporates the CSR approach (Albareda et al., 2007). Examples of partnering initiatives can be detected in the Swedish government's launch, in 2002, of the Global Answer Initiative, a multi-stakeholder platform whose objective is to incentivise a business awareness of, and alignment with, the principles of the Global Compact, through open seminars, workshops and networking (Bertelsmann Stiftung, 2006). A further example of the partnership posture is the Dutch Social Venture Network (SVN) (Bertelsmann Stiftung, 2006). Although the partnering function can be said to be the most relevant, examples of mandating postures can also be found within the Scandinavian partnership approach; Danish and Swedish companies have been obliged, respectively, since 2008 and 2009, to declare their environmental footprint, in accordance the UN Principles for Responsible Investing and the Global Reporting Initiative (GRI) G3 Guidelines (Moon et al, 2011). Also endorsing initiatives can be found within this context; Dutch and Danish Economic Ministries both issue periodic rankings of top socially responsible industries (EC, 2014). 
- The business in the community model

This model is specific to the Anglo-Saxon European context (UK and Ireland) and most proximal to the US approach. The denomination business in the community "refers to how these governments and companies interpret the role of business in society, particularly as regards social challenges and its role in community development" (Albareda et al, 2007 p. 402). Within this model CSR is seen as an additional resource for social investments and acknowledged and advocated as voluntary. The role of public policies is an endorsing and facilitating one, carried out predominantly through soft regulation and tax incentives (ibid). The countries pertaining to the business in the community model dispose of numerous strategies and ministerial charges dedicated to CSR (EC, 2014). Nevertheless examples of mandating postures can also be found within this model; in the UK the Corporate Responsibility Law (2004) established the business duty to file annual sustainability reports for all major investors (Moon et al., 2011).

- The continental model

The continental model, individuated as pertaining to Austria, Belgium, France, Germany, and Luxembourg relies on a political understanding of the role of large business entities, being CSR the channel individuated for such entities to participate to social policy objectives and refine business management processes. Within this model the role of public policy can be described as hybrid between facilitating and mandating. Examples of facilitation can be found in Belgium's creation of a ministerial charge for CSR (EC, 2014). For what concerns mandating approaches, Albareda et al. (2007) furnish the example of the French state that, in line with its centralistic institutional environment, channels all CSR actions in a manner that activities seem to be directed by the government, rather than the business sector itself. Starting from 2001 in France, all publicly listed companies are required to disclose annual reports containing information concerning 40 social and environmental criteria (EC, 2014). Business disclosure of social and environmental issues is used since 2001 as criteria for public procurement by French, and Belgian governments (Bertelsmann Stiftung, 2006).

- The Agora model

Albareda et al. (2007) use the term agora to describe the search for consensus within a public space (in ancient Greek the term "agora" depicted the gathering space or assembly of a given community) as the principal CSR approach of Mediterranean 
European States: Italy, Greece, Portugal and Spain. These institutional environments are characterised by a weaker welfare state, scarcer coordination of business and society relations, and overall lesser participation and cohesion within different societal stakeholders. Albareda et al. (2007) state that, exception made for Italy, CSR practice is less developed within the countries pertaining to the Agora model than within the rest of the EU, having been predominantly introduced only after the dissemination of the UNGC and the European strategy on CSR. For this reason, an approach of national public policies towards CSR is still under construction, although it seems that governments have a positive approach towards CSR (Albareda et al., 2007). In this sense Steurer (2010) notes that public policies on CSR in Europe emphasise, rather than counterbalance, the gap existing among European countries. Albareda et al. (2007) postulate that CSR may be a vehicle for societal change and the building of inclusion and participation within the countries pertaining to the Agora model, constituting a dialogue for multi-stakeholder dialogue, interaction and collaboration. Examples of endorsing initiatives have been found in Italy, Spain and Portugal being arguably the most salient the Corporate Social Responsibility - Social Commitment (CSR-SC) Project, endorsed by the Italian Government in 2003 (Moon et al., 2011).

At the time of publishing of the document Corporate Social Responsibility National Public Policies in the European Union (EC, 2014) fifteen member states were identified as disposing of National Action Plans (NAPs) on CSR: Belgium, Bulgaria, Cyprus, Czech Republic, Germany, Denmark, Estonia, Finland, France, Italy, Lithuania, the Netherlands, Poland, Sweden and UK. NAPs were identified as being in their completion phase in five countries: Austria, Ireland, Hungary, Malta, Spain; and under development in seven: Croatia, Greece, Latvia, Portugal, Romania, Slovenia, Slovakia. Only Luxemburg was mentioned as not having the intention to develop a plan. On this topic Argadoña and von Weltzien-Hoivik (2009) argue that governments, businesses and civil society actors must be increasingly aware of the need to formulate their own approach to CSR in order to adopt the approach that best suits their welfare state tradition and the existing relationships between government, business and society. 


\section{A Portuguese approach to CSR}

We have insofar stated that CSR is a result of contextual environments, being it influenced, within the welfare state, by the institutional allocation of the business sectors' responsibilities for labour and social issues (as shaped by law and custom) and by the power of control systems of labour unions and civil society movements. As also previously specified, Portugal pertains to the category of Mediterrenean European countries, characterised by scarcely developed welfare and by weaker business and society ties. Before delineating the characteristics of CSR in Portugal, it has been considered relevant to take a step back and analyse the salient steps of development and features of both the welfare state and the business and society environment within the country.

Portugal is a country with a long history of social intervention of which the main actors have been the religion-based institutions "Misericordias" that, supported by the monarchy and aiming at relieving poverty, have been the nation's central institutions of social welfare since the end of the 15th century up to the 20th century (Abreu, 2000). The Misericordias have been dealing traditionally with social protection in a perspective of handouts and charity (ibid). The first roots of social protection as a social right rather than as philanthropy, were set in the second decade of the 1900 by the consolidation of the labourers' social rights brought forward by the union-based movements that crossed Europe and Portugal before the first World War, and by the state intervention in taking care for the war veterans and their families after it (Pererinha and Carolo, 2009). In 1916 the Ministry of Labour was created, and in 1919 was established the compulsory social insurance for labour workers concerning disease, work hazards, old age and invalidity (ibid). In this time payment of social insurance schemes were the responsibility of employers and insures, with the state being merely responsible for the administration (ibid). The state began taking in charge social insurance schemes only during the 1930s, already in the period of the so-called Estado Novo (New State), the authoritarian regime that followed the military coup d'état of 1926 posing end to the first Portuguese republic, and that was to last for roughly fifty years until coming to an end in 1974. A halfcentury after the social insurance schemes had been established in Germany by Bismarck (1883), and twenty-five and five years after they were established in the UK (1911) and France (1930) respectively, the Portuguese began its journey towards becoming a welfare state through the launch of the Social Security Law (Lei de Base 
da Previdencia Social) in 1925 (ibid). The Law guaranteed a social security system based on an individuals' contribution base that, although regulated by the state, was not financed on the basis of general taxation. According to Carolo (2006 p. 46) this aspect is crucial to comprehend social security in Portugal as "the dynamics of evolution of the welfare state obliged, gradually, the participation of the state as both a provider and a financer of social protection, especially in the coverage of healthrelated benefits, but also in the correction of asymmetries and gaps" (free translation). In 1962 the social security system underwent a reform that was purposeful to the unification of the services provided; the coverage of social protection increased and it was possible to notice a tendency towards the universalization of health coverage (Carolo, 2006). Coverage had increased from 35\% to $70 \%$ of the population by 1970 (Pererinha and Carolo, 2009).

A marking moment of the Portuguese last century history was established in 1974, when the authoritarian regime of the Estado Novo was overthrown by a non-violent coup d'état commonly referred to as the Carnation Revolution. After this moment, Portugal emerged as a democratic country ruled by law, whilst civil and political rights were finally granted. The newly born republic took on the development of social protection becoming both the financer and the service provider of the Portuguese social schemes (although predominantly compensatory in nature), as well as the main negotiator of social parties. At this time, the national health system was also created. The establishment of a universal social security system, in a period in which other European welfare states were showing their first signs of decline has been described as a fundamental instrument to guarantee a political consensus and legitimacy of the newly born democratic system (Mozzicafreddo, 1992, Santana, 2002). According to Esping-Andersen (1990) Portugal's delay in reaching a democratic model and an economy that paralleled the one of other European countries, prove that the redistributive powers of the welfare state were motors of economic growth. In 1975 the unemployment subsidy was established and in 1977 were introduced non-contributory social pensions. At the macroeconomic level, the industry was largely nationalized, the banking and insurance systems were completely nationalized, and the economic boom finally reached Portugal (Mozzicafreddo, 1992). In 1984 the National Council for Social Dialogue was established having advisory capacity in terms of monetary, fiscal and economic policy (ibid). 1986 saw another crucial moment for the country, with Portugal's adhesion to the European Union. At this time, both the Portuguese macroeconomic approach as well as its welfare approach were to make an effort to converge with the strategy of 
the Union: the processes of nationalization of the industry came to an end in favour of the privatization of capital, whilst social security became universal, taxation-based and integrated (Pereirinha and Carolo, 2009). As highligheted by Mozzicafreddo (1992) first, and Pereirinha and Carolo (2009) then, beginning in 1986 social expenditure in Portugal started increasing as to meet the other European countries' average. The welfare state, although established, was characterised by weak state interference in the regulation and production of social goods, leaving space to processes of privatization and outsourcing in sectors such as education, housing and health (Mozzicafreddo, 1992). The almost totally of social expenditure was diverted to pensions and vulnerable categories instead of being equally distributed among social hazards (ibid). Also, the government's role in social dialogue has been described as following a neo-corporative and patronage logic, being inclined to favour private, rather than public interest (ibid). Social policies have hence followed a development replying to punctual contingencies and claims by social parties being characterised as being "selective and fragmentary" and "interventional and instrumental" rather than "universal and systematic" (ibid, 1992 p. 68). Furthermore, social policies, together with taxation of property and labour, have been predominantly regressive, comparatively favouring higher strata of the population and leading to high and persistent social inequality (ibid). Labour rights never truly consolidated, being the labour market identified as the most flexible of Western Europe (ibid). In this perspective, Mozzicafreddo (1992 p. 84) describes the Portuguese welfare state as "uncompromised" with social issue although having a persistently high social expenditure. A quasi-welfare system, oscillating between a welfare state and a corporatist model, adding that to a weak welfare state coexists a strong welfare society, characterised by strong kinship, family and community links of rural and peasant heritage. The incremental tendency of the Portuguese social expenditure has been considered as consolidated in the period 1991-2003, period in which increases have been steady, at times overcoming the social expenditure of higher income countries, such as the UK (Pereirinha and Carolo, 2009). Today high social expenditure persists, $25 \%$ of Gross Domestic Product (GDP), above the average of OECD countries of 21\% (OECD, 2016), having spending resulted in positive although uneven results; in fact, although health outcomes and education levels have seen great improvements, high poverty and social inequality rates persist. The levels of social inequality in Portugal, although decreasing, are the second highest in western Europe after the UK, and almost a third of the population is considered as being at risk of poverty or social exclusion (Eurostat, 2016). According to Santana (2002) traditional forms of poverty, linked to ageing and isolation have come to be 
replaced by newer patterns related to increase in temporary work and migration. The financial crisis that has affected international markets since 2008 has deeply impacted the Portuguese Welfare State resources as well as the population, creating the conditions for cutbacks targeting salaries especially, and setting the basis for claims concerning the economic unsustainability of the welfare state mentioned in Chapter 1.

As for what concerns the morphology of the Portuguese business environment and its approach to CSR, as reported by Reis et al. (2008), during the dictatorship regime nation's main companies, all belonging to a handful of elite families, such as the groups CUF, Chamapallimaud, Espirito Santo and the Banks Borges \& Irmão, Fonsecas \& Burnay as well as the national Ultramarine and Atlantic Banks all had social intervention plans consisting of family, health and leisure initiatives destined to employees and their families; yet, the intervention model was one yet based on the principle of benevolence similar to the one adopted by the Misericordias, rather than social rights (Rego et al. 2003). This encompassing approach dissolved after the revolution due to the nationalization of companies and the reinforcement of the welfare state, although business-based philanthropic activities continued (Pinto, 2004; Costa, 2008). The development of socially responsible business practices coherent in a CSR perspective was externally driven, starting after the launch of the UNGC at the beginning of the $21^{\text {st }}$ century. Portugal's economic structure is characterised by a prevalence of small and medium enterprises (SMEs), yet, as previously stated, the top 10 socially responsible companies in Portugal are MNEs located in the metropolitan Lisbon area.. Nevertheless, Abreu and Crowter (2005) argue that there is evidence that proves that Portuguese SMEs involve in several community projects focused on local empowerment, although less systematically and seldom reporting about it. Abreu and Crowther's (2005) study Corporate social responsibility in Portugal: empirical evidence of corporate behaviour (2005) searched for local and cultural specificities to the approach that businesses operating in Portugal have towards CSR, concluding that companies operating locally involve in responsible business practices for reasons that don't differ from the average international business community - stakeholder responsiveness, reputation and market differentiation - although being more likely to involve in environmental practices, cultural-based projects, and initiatives directed at fighting poverty and social exclusion. As highlighted by Pinto (2004) the findings of the questionnaire European SMEs and Social and Environmental Responsibility conducted by The Observatory for European SMEs in 2002, highlighted that $40 \%$ of the interviewed 
Portuguese SMEs identified the main benefits of CSR as lying in the enhancement of community/public authority relations fact that according to Pinto (2004 p. 34) confirms "the high importance of personal relationships in Portuguese business". Pinto (2004) adds that material, project-based donations are more common than permanent and non-material ones, and that contributions are often unrelated to core business. These findings can be explained by three motives. In a first instance, in terms of businesses' sensitiveness of the high poverty and social inequality levels mentioned above; Castelo Branco and Delgado (2011 p. 211) argue: "there is still a strong emphasis on the philanthropic tradition in developing countries, which is often focused on community development". According to the authors Portugal, is a less-developed high-income country and for this reason, social issue are considered important, similarly to what happens in developing countries. Secondly, the focus on environmental and cultural initiatives can be explained by the existence of a Portuguese accounting directive on environmental issues (Comissão de Normalização contabilística, diretiva $\mathrm{n}^{0} 29$; 2002), drawing the attention towards environmental concerns which had been historically underrated in the country, and by the fact that social and cultural-based projects are realized accordingly to the Cultural Philantropy Law (Lei do Mecenato Cultural; Decreto-Lei n.o 258/86) which offers financial discounts for companies willing to donate money for cultural causes. The "Cultural Philantropy Law" was later generalized to be the "Philantropy Law" (Lei do Mecenato; Decreto-Lei n.o 74/99) as to add social, environmental, education, sports and technological causes to the initiatives passible of tax exemption. Ultimately the project-based and add-on nature of initiatives is to be linked with the scarce development of CSR theory and practice in Portugal which Neves and Bento (2005, p. 307) characterise as "incipient", and to the companies' lack of awareness and failure to see the connection with the core business (Pinto, 2004)

As discussed previously, Portugal, within EU, is one of the countries still missing a NAP on CSR, explained by Castelo Branco and Delgado (2011 p. 210) in terms of the "passive attitude and low priority given to CSR by the Portuguese governmental bodies”. In 2010 the European corporate-based network CSR Europe reported that public awareness concerning CSR was still very faible in Portugal due to a lack of governmental sponsoring and scarce media coverage; the same report indicated low consumer pressure for corporate responsible behaviour. On the same subject, Pinto (2004) had stated that only $3 \%$ of the Portuguese population could be considered as potential "social responsibility activists" despite a European average of 26\% (ibid). Comparably, CSR has been found to be low on the agenda of business managers and 
within the portfolio of management education (Castelo Branco and Delgado, 2011). Although not having a specific action plan on CSR the Portuguese government disposes of a number of activities apt to influence socially responsible behaviour, activities indicated by the European commission in terms of awareness raising and partnership building (EC, 2014). Awareness initiatives are identified within the constitution of a inter-ministerial working group on business and human rights, the realization of the Equality is Quality Prize, aiming to promote gender equality in the labour market, as well as a number of awards to support the raise of awareness towards CSR. Partnership stances are identified in the endorsement of the RSO Network (Rede Nacional de Responsibilidade Social), favouring dialogue and communication among more than 250 organizations (ibid). A number of other privately-based corporate citizenship, sustainable development and CSR networks exist: GRACE (Grupo de reflexao e apoio à cidadania empresarial) founded in 2000 and counting 130 members, BCSD (Portuguese Business Council for Sustainable Development) founded in 2001 and counting 90 members; APEE (Portuguese Association of Entrepreneurial Ethics) founded in 2002 and with a 107 membership. The APEE is also responsible for the Global Compact Network in Portugal, representing the Initiative's subscribers operating in Portugal.

The trade based CSR associations mentioned earlier in the text have so far carried out the divulgation and mainstreaming of concepts, guidelines and best-practices concerning responsible business practices. Given such role it was considered of interest to briefly resume the approach that each network has, as to better contextualize what CSR is in Portugal today. The first one to be constituted, and among the most dynamic in terms of member affiliation and events is GRACE (Grupo de reflexao e apoio à cidadania empresarial - Group of support and reflection on corporate citizenship), a business network founded in 2000 by the representatives of the Portuguese branches of IBM, McDonalds, HBI, Xerox and Inapa (Grace, 2013). The constitution of Grace was substantiated by the conclusion's of a study that the Luso-American Foundation FLAD had carried out a couple of years before and whose findings highlighted the lack on national grounds of organisms dedicated to the diffusion and reflection on themes such as entrepreneurial ethics and CSR. To this date, GRACE, the Portuguese Business Council for Sustainable Development (BCSD) founded in 2001, the Portuguese Association of Entrepreneurial Ethics (APEE) founded in 2002 and the Portuguese Global Compact Network founded in 2007 are the main actors dealing with the translation and adaptation of an international CSR referentials (predominantly UNGC, ISO 26000 and the European Strategy) to the 
Portuguese reality as well as the diffusion of principles and the establishment of best practices among the business community. The APEE was responsible for the Portuguese translation of ISO 26000 - NP ISO 2600o. The attendance of a series of meetings and seminars organized by the above-mentioned associations for business representatives as well as the general public has led the author to construct the following categories of most commonly referred to argumentations used to contextualize and motivate the need for an adhesion to CSR principles by the Portuguese business community:

a) The environmentally concerned discourse: the discourse calls for a long-term approach to the consequences of business activity specifically in what concerns resource depletion and potential environmental crisis. Such discourse that relies strongly on the concept of "sustainability" is one focusing predominantly on ecological conservation for future generations. The term "sustainability" often confused with "Corporate Social Responsibility" is nevertheless a narrower concept that seldom stresses an accent on social, political and economic consequences of business operations and for the need to preserve such resources for further generations. This discourse generally relies on non-specific claims to adopt at the corporate governance level, it is to say the level where organizational orientations are defined, calling for a compliance with national and international laws and codes of conduct, a production of indicators of social and environmental impacts together with a claim to carry out business operations according to features of ethics and transparency;

b) The risk management discourse: captures both a consequential and strategic perspective that focuses on the interconnectedness of causes and consequences within a context of globalization of services, products, people and ideas. According to this perspective, problems and solutions have a width that overcome national boundaries; potential economic, social, environmental, political and technological failures or instabilities are seen as potential threats that, given the systematic nature of the global society, are most likely to create breakdowns on business activities. Starting from the consideration that social instabilities, political conflicts and natural disasters annihilate the conditions for economic growth, CSR is seen as a pragmatic stance aiming at the conservation of the business model and as a form of managing risk; 
c) The social responsiveness discourse: focuses on the need to respond to growing societal needs, in a perspective of economic and social crisis were the welfare state is depicted as unable to face all of the claims that the society addresses. This discourse recuperates the idea of businesses as social institutions framed in the notion of corporate citizenship together with the acknowledgement of the growth in power of the civil society and its representative third sector organizations. Under this perspective CSR becomes not only the right thing to do, but something that is perceived and somehow expected from a increasingly demanding society as the right thing to do. In this perspective corporate social intervention follows but a perspective of appropriateness and stakeholder responsiveness, being CSR framed as ethical but also relational, given that NGOs and consumer associations can potentially represent a great threat to businesses for what concerns reputation and competitive differentiation according to ethical factors. This perspective fits with the economic win-win logic at the core of the international sponsoring of CSR.

The three main approaches presented as resuming the main argumentation in favour of an alignment towards CSR concerns within the Portuguese business community all follow a economic/strategic logic, which is not surprising considering that they are forwarded by trade associations, lacking a discourse that contemplates features of justice and social stability rather than discourses are focused on highly technical language that dehumanizes the discourse on CSR making it more similar to a protocol adaptation rather than the inclusion of social concerns. Missing among the CSR discourse is also the notion of accountability intended as the possibility to account for one's actions and respond for the positive and negative outcomes. Within the Portuguese CSR community a lot is spoken about risk management and creating value, yet, there is no mentioning of the adverse impacts that business activities generate in terms of unemployment, or the selling of potentially damaging products for the population or the environment wellbeing. The lack of a self-admission of the potentially critical role that businesses can play and the following of a logic of "risk for the business " rather than one considering the risks for society leaves space for a questioning concerning the plausibility of businesses being in favour of social cause which are not at the same time beneficial to the financial bottom line. During a seminar taking place in 2012 a Professor of Lisbon School of Economics and Management stressed that for CSR to come forward in Portugal there is a need to look at it "from a systematic perspective, and not as a sum of what happens within 
the business environment; there is a need to look at SR at the micro-level, and to link it with its surrounding territories in a clusters perspective" (free translation, Maria João - personally attended) 


\section{Chapter 4: Health promotion, social responsibility for health, and CSR}

Chapter four serves a twofold purpose, that of delineating the features of the second sphere of analysis, health promotion, and putting it in relation with CSR. The first section begins by explaining how the health promotion approach became a distinct field of health policy and practice, marking a shift from a biomedical and pathogenbased to a salutogenic and health-based understanding of health. On the basis of the father document of the health promotion approach, the Ottawa Charter (WHO, 1986), the author discusses the approach's levels of action, strategies, normative principles as well as the positioning societal actors are expected to engage for its enhancement. The second section depicts the developments of the health promotion approach as envisaged by the Ottawa Charter during globalization. It begins by highlighting the health threats imposed by the displacement of human beings, goods, and resources across the globe and especially in urban contexts, namely the recrudescence of communicable diseases, the harshening and spread of NCDs, the rising inequalities, and the threats linked to the health of the environment. It continues by unveiling the ways business practices are apt to impact health through pricing and distribution, marketing and advertising, packaging and disposal, on one side, and labour standards, lobbying, research and public affairs practices, as well as environmental practices on the other. Building on such grounds, the second section continues by articulating how the notion of social responsibility for health developed during globalization as to include private actors, above all NGOs and business actors. The two health promotion documents specifically considering the role of private actors in health, the Jakarta Declaration New Players for a New Era: Leading Health Promotion into the 21st Century (WHO, 1997) and the Bangkok Charter for Health Promotion in a Globalized World (WHO, 2005) are then scrutinized in detail, considering the presence of parallelism with the notions of social responsibility of health for for-profit actors as considered by WHO at the rationalities subjacent to the CSR approach. Examples of both binding and non-binding governance initiatives for health promotion to which business actors are apt to participate are then brought forward. The section is concluded through the depiction of the principal criticisms 
made to the health promotion approach, particularly in what concerns the inclusion of for profit-actors in health promotion governance on a non-regulatory basis. The third section sets some context, focusing on the European region first and Portugal then. As for what concerns the European region are portrayed the main health policy frameworks formulated by the WHO Regional Office and inherent priority areas of action, in turn related to the principal health issues of the population, together with the main problems associated with their implementation and the recommendations formulated to counteract such problems. Finally, a small portion is dedicated to the health promotion developments within the EU, as part of the consolidation of the Union's public health strategy. The fourth section brings together health promotion and CSR. In a first instance by looking at how health is considered in CSR policies. Then by portraying criticalities and opportunities for health associated with CSR practices as found in literature and identified by local health promotion experts.

\section{The health promotion approach as framed by the Ottawa Charter}

\section{From sick care to health promotion: biomedical versus salutogenic health}

In the aftermath of the World Wars, in industrialized countries, the ensemble of sanitation, hygiene and improved housing and labour conditions developed to counteract infectious diseases across the $19^{\text {th }}$ and $20^{\text {th }}$ centuries' "first public health revolution" (Kickbush 2003 p. 386) commenced to produce their effects, causing decreasing acute infection-related morbidity, increased life expectancy and receding fertility. Such changing patterns of causes of death and reproductive behaviours were described as the epidemiological age of low births, low mortality, and chronic, degenerative and man-made disease, also termed non-communicable diseases (from now on NCDs): cardiovascular disease, diabetes, cancer, chronic respiratory diseases and mental illnesses (Saan and Wise, 2011). The shift towards a prevalence of chronic diseases over infectious diseases led to a reconsideration of the efficacy of the healthcare sector in addressing health threats, and to an increasing attention to the non-healthcare determinants of health: the "second public health revolution" (Kickbush, 2003 p. 386). The report A New Perspective on the Health of the Canadians, redacted in 1973 by Marc Lalonde, the Canadian Minister of Health and Welfare, was the "first modern government document in the Western world to acknowledge that our emphasis upon a biomedical health care system is wrong, and that we need to look beyond the traditional health care (sick care) system if we wish 
to improve the health of the public" (Hancock, 1985 p. 10). The Lalonde Report, as the document is also called, introduced the notion of health field. The notion of health field considered health as the product of four distinct determinants: human biology (genetics), lifestyle (behaviours), environment, and health services (Hubley et al., 2013). It should be noted that in this context, the term environments refers to both natural resources, physical settings, and structural organization, which define power dynamics, social norms and social roles for a given context (Nutbeam, 1986). In 1976 in the UK government published the documents Prevention and Health, Everybody's Business and Prevention and Health, whilst in 1978 WHO organized the International Alma Ata Conference on Primary Care. The notion of primary care offered within the Alma Ata Conference, although relying predominantly on a disease-oriented approach to health, managed to shift the focus from acute care to regular and preventive care. Furthermore, it set the grounds for the integration and continuity of health services, establishing that primary care (physician, family and community-based) would be the gateway to first diagnosis and treatment, to which were to follow, only when relevant, the levels of acute care (hospitals and clinics) and long term and palliative care. According to Hubley et al. (2013 p. 15) by the beginning of the 1980 s there was an "increasing disquiet among the health community. While accepting the importance of lifestyle, many felt that not enough attention had been given to the social and economic factors that influenced it”. In this context the health field model, although being acknowledged as valid, was feared of leading to a victimblaming approach, once the attention upon the determinants had been set preponderantly on personal choices and behaviours, and carried out through aggressive education campaigns, rather than on the familiar, community and society factors influencing such choices and behaviours (Hubley et al., 2013). According to Kickbush (2003 p. 386) a crucial step towards the establishment of the health promotion approach, that would constitute the "third public health revolution" acknowledging health as a key dimension of quality of life, was the development of WHO's Health for All programming strategy at the beginning of the 1980s. In the paper The Meaning of Health for All in the Year 20oo, Mahler (1981), at the time Director General of WHO, defined health as follows (Brown et al., 2016 p. 36)

\footnotetext{
"A personal state of wellbeing, not just the availability of health services-a state of health that enables a person to lead a socially and economically productive life. "Health for all" implies the removal of the obstacles to health-that is to say, the elimination of malnutrition, ignorance, contaminated drinking-water, and unhygienic housingquite as much as it does the solution of purely medical problems such as a lack of doctors, hospital beds, drugs and vaccines"
} 
The Health for All strategy took a definite distance from the lifestyle-based understanding of health and disease, being this particularly true for the Europeanbased application of the strategy, as we will see in detail later on in this chapter. As explained by Kickbush (2003 p. 384) a paper issued by WHO’s Regional Committee of the European Region in 1983 specified how lifestyles "needed to be understood as collective behaviours deeply rooted in context (...) at the intersection between personal and social factors". A few years later, the Ottawa Charter deepened and refined Lalonde's health field concept and the understanding of health given by the Health for All strategy, setting the basis for health promotion as a distinct field of health policy and practice (Hubley et al, 2013). Health promotion as shaped within the Ottawa Charter is a multidimensional concept that captures a multiplicity of processes and actors at different societal and policy levels, a far reaching field with shifting balances between "health education and legislation", "individualistic and structuralistic approaches" and "coercive, persuasive and health empowerment approaches" (Hubley et al., 2013, p. 12). The definition provided by the Ottawa Charter is reported as follows:

\begin{abstract}
"Health promotion is the process of enabling people to increase control over, and to improve, their health. To reach a state of complete physical, mental and social wellbeing, an individual or group must be able to identify and to realize aspirations, to satisfy needs, and to change or cope with the environment".
\end{abstract}

According to the Charter, health promotion follows a salutgenic perspective and is to be furthered in five spheres of action. The term "salutogenic orientation of health promotion" as framed by Antonvsky (1996, p. 13) serves to strike an emphasis on the distinction between the public health pathogenic approach (curative and downstream), and the health promotion salutogenic perspective (preventive and upstream) according to which health is built on a daily basis, rather than recuperated through cure and treatment (Kickbush, 2003). The five spheres of action, pictured in Table 8 from a narrower to a broader level are: personal skills, community mobilization, healthy environments, reoriented health services, and healthy public policy, which can be acknowledged as the broader sphere encompassing all the other. 
Table 8: Areas of action of the health promotion approach

\section{Healthy Public Policies}

\begin{tabular}{|l|l|l|l|}
\hline Personal Skills & $\begin{array}{c}\text { Community } \\
\text { Mobilization }\end{array}$ & $\begin{array}{c}\text { Healthy } \\
\text { Environments }\end{array}$ & $\begin{array}{c}\text { Reoriented } \\
\text { Health Services }\end{array}$ \\
\hline
\end{tabular}

Adapted from the Ottawa Charter of Health Promotion (WHO, 1986 p. 3-4)

The first two areas of action, Personal Skills and Community Mobilization, deal with the achievement of population-level change in behaviours impacting health. Personal skills are achieved through the access to education, information and life skills, enabled through schools, domestic, working and community environments, that prepare individuals to make health-related choices as well as to respond to changes health conditions. Although the ultimate recipient in health promotion is the individual, the health promotion approach considers individuals as socially embedded in groups with which they share elements of proximity of geographical, ethnic, cultural, or other nature. In the health promotion approach the achievement of positive change in behaviours impacting health is considered as dependent on participation, self-determination and ownership of choices and processes as we will see in detail in the forthcoming section. In this context, communities are central social units, in what they constitute the elementary social nucleus that offers support, capacity and peer pressure to the individual in the making of health-related choices (Symes, 2007). The area of action of Healthy Environments stresses the influence of context in health outcomes, the "inextricable links between people and their environment" (WHO, 1986 p. 3), where environments are considered in both social and physical terms. To understand the crucial nature of environments in a health promotion perspective it is sufficient to consider that, to this date, the first predictor of longevity for human beings is the place of birth, before genetic heritage (Stuckler and Basu, 2013). The area of action concerning Healthy Environments was the focus of the Third International Conference on Health Promotion: Supportive Environments for Health held in Sundsvall, Sweden, in 1991. The area of action Reorienting Health Services suggests the need to integrate the environmental, community and individual facets of the health promotion approach within healthcare practice, shifting its focus "beyond responsibility for providing clinical and curative services" towards a perspective that takes into consideration the "total needs of the individual as a whole person" (WHO, 1986 p. 4) adapted to each life stage and "balanced against the needs of population groups" (Nutbeam 1986 p. 361). The 
sphere of action stressing the need to build Healthy Public Policy, contemplates the inclusion of health lenses in decision-making in all sectors and at all levels. This means for decision-making to be oriented towards the production and improvement of health outcomes and to the mitigation of health disparities. Healthy Public Policy is, as explained by Saan and Wise (2011), an a priori category to all the others, given that there can be no reconfiguration of environments, individual and community competences, and health services, without the existence of policies that foster such objectives. The Healthy Public Policies action sphere "combines diverse but complementary approaches including legislation, fiscal measures, taxation and organizational change" (WHO, 1986 p. 3). Furthermore, it requires "the identification of obstacles to the adoption of healthy public policies in non-health sectors, and ways of removing them" (WHO, 1986 p. 3). In order to implement the diverse but complementary approaches the Healthy Public Policies action requires assessment and reformation measures, such as health impacts assessment (HIA), purposeful to the prospective calculation of potential health impacts of decision-making. HIA is a term used to describe the ensemble of "procedures, methods, and tools by which a policy, program, or project may be judged as to its potential effects on the health of a population, and the distribution of those effects within the population" (ECHP 1999, p. 4). Hancock (1986 p. 10) in the paper from Public Health Policy to Healthy Public Policy paper, published slightly before the issuing of the Ottawa Charter, argues for the following differences between the public health approach and the Healthy Public Policy action core to the health promotion approach:

\begin{abstract}
"Public health is concerned with the existing sick care system, it is sectoral or analytic in its approach, it is oriented towards present health problems, and it is dominated by a hard technology bio-science approach. In a nutshell the public health approach accepts the givens. By contrast, healthy public policy begins by questioning the givens: why do we have to structure our society in a such a way as to create illhealth? Is there a way to structure our society as to create health? Thus healthy public policy tends to follow a soft or appropriate technology health path, one that emphasizes multiple-scale local solutions to health problems and that involves local communities and individuals in those solutions. Healthy public policy is thus more holistic in its approach, is oriented towards the future state of health, and of necessity deals both with the health problems of the individual and the great global issues of the day - such as energy, food production, pollution and unemployment - that influence the health of humankind within the socio-environmental ecosystem of which we are part".
\end{abstract}

The area of action of Healthy Public Policy was the focus of the second international conference on health promotion held in Adelaide, Australia, in 1988. Other than the five sphere of action the Ottawa Charter postulates three strategies through which to 
enact health promotion: advocacy, at the macro policy level, as to support and enforce the health promotion cause through pressure activities and informationsharing; enablement, at the micro level, as to reduce differences and obstacles to the achievement of egalitarian opportunities in health; and mediation, at the meso-level, coordinating and balancing different and potentially competing interests, among the actors and levels engaged in health promotion, in ways that reconcile health (WHO, 1986; Nutbeam, 1998; Wise and Saan, 2011) Such strategies are resumed by Hubley et al., (2013) as the three all-encompassing axes of the health promotion approach: education, service improvement and advocacy.

\section{Health as a resource, a right, and a social responsibility}

The well-rounded and far-reaching health promotion approach as delineated within the Ottawa Charter contains three key perspectives: empowerment, salutogenesis and holism. These perspectives are considered worth scrutinizing in detail in what they delineate the health promotion approach's understanding of the nature of health and of the positioning society should engage for its enhancement (Antonovsky, 1996; Nutbeam, 1998; Kickbush, 2003). The first dimension, empowerment, relies on the notions of participation and capacity building, as to enable the direct involvement of individuals and communities, the fundamental health promotion agents at the microlevel, in the achievement of health-conducive change. As specified by Wallerstein and Bernstein (1988 p. 380) the empowerment model presupposes "a social action process that promotes participation of people, organizations, and communities towards dialogue". The objective of dialogue is specified as being "critical thinking, by posing problems in such way as to have participants uncover root causes" (p. 382), considering that "participation of people in group action and dialogue enhances control and beliefs in ability to change people's own lives" (p. 379). Both the perspectives of empowerment and salutogenesis, explained in the previous subsection, hinder a positive view of health as a resource, both social and economic. It is a resource at the level of individuals, necessary to meet life demands, which are personal and subjective, as to pursue autonomously chosen goals (Kickbush, 2003; Nordenfelt, 2009). It is a resource relevant at the collective level, creating externalities that transcend the individual's preference and contribute positively to social conditions (Unesco, 2005; 2010). The view of health as a resource was only reaffirmed by the Ottawa Charter. Already in the previously quoted paper The Meaning of Health for All in the Year 20oo, Mahler (1981) had framed health as a resource 
and an opportunity, although a personal rather than a social one: a means to achieve development, and a goal of development itself. The understanding of health as resource was often criticized for potentially hindering a view of health as a commodified economic resource instrumental to the pursuit of economic growth (Baum, 2008; Unesco, 2010; Semplici, 2011). On the other hand, the author stands by the perspective that the framing of health as a resource participates in the comprehension of its instrumentality to achieve other goals and aspirations.

Holism refers to the fact that health is treated as a far encompassing field, one that deals with the ensemble of spheres that make up individuals' and communities' living: biological, but also political, social, environmental, cultural and economic. Health promotion contemplates a critical view of the health-disease process, trying to establish connections between these different spheres. In order to clarify the nonhealthcare spheres and determinants apt to impact health the Ottawa Charter puts forward the notion of pre-requisites of health. The pre-requisites of health, later renamed social determinants of health (from now on SDoHs) can be defined as the ensemble of conditions that allow the access to resources and opportunities for health. The SDoHs are pictured below (Figure 1) coherently with the identification made by Dalghren and Whitehead (1991). It can be seen that the SDoHs are regrouped in different layers. The first three layers; natural environments (a) political, social, economic and cultural environments (b) and built environments (c), determine the socio-economic position of a given community of individuals and their proximal health determinants (income, education, social cohesion, social capital, health systems, etc..), mediated, at the individual level, by biological factors such as sex, age, gender and genetic makeup (d). The SDoHs define the likelihood of individuals and communities to be exposed to causes of ill-health, such as, for instance, the possibility to access diagnosis or care, fresh water or nourishment, or to find appropriate shelter against environmental changes, as well as shape lifestyle behaviours relative to consumption patterns, leisure, sexual attitudes and hygiene. The connections between different spheres are to be made through health impacts assessment (HIA), purposeful to establish relevant connections between distal and proximal determinants of health, then to be resolved by healthy public policies, as previously hinted (Cadet et al., 2011). As specified by Ziglio et al. (2000 p. 49) once the notion of SDoHs shaped, the definition of health promotion contained in the Ottawa Charter should have been changed to: "the process of enabling individuals and communities (people) to increase control over the determinants of health and thereby (and to) improve their health". 


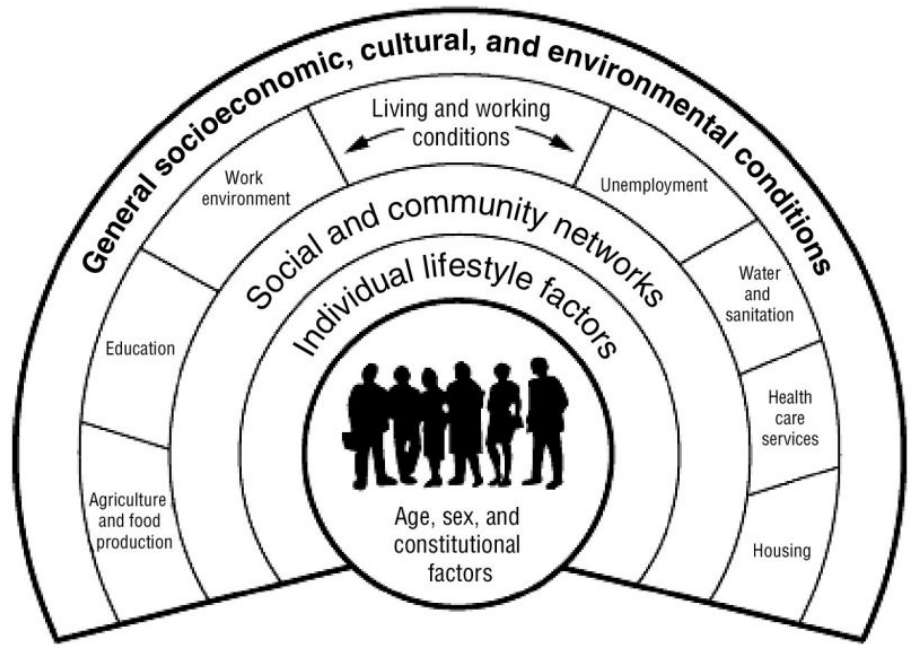

Figure 1: The social determinants of health (SDoHs)

Source: Dahlgren and Whitehead (1991). Used with permission of the Institute for Futures Studies, Stockholm, Sweden.

The orientations towards empowerment, salutogenesis and holism characteristic of the health promotion approach as framed by the Ottawa Charter, had, according to Kickbush (2010), a phenomenal influence in shaping practice. Influence was due to their transformational nature, intended to produce the social change necessary to mitigate the unavoidable differences in individuals' health status at birth as determined by the SDoHs in a perspective of decreasement of social stratification and social solidarity. In this sense, the health promotion approach is an outcome, other than of the developments in the field of health philosophy and policy, of the women's health, self-help and gay rights social movements of the 1970s and 1980s (Kickbush, 2010). Porter (2007 p. 72) likens the health promotion approach contemplated in the Ottawa Charter to a "new social movement discourse" based on precepts of "ecosocial justice" (ibid) and Baum (2008) describes it as a "socially concerned movement with a focus on equity" (p. 464). There are two reformist moral-based postures that authorities and society are expected to adopt towards health according to the health promotion approach: social justice and social responsibility. The social justice stance aims at achieving equity in the distribution and redistribution of opportunities for wellbeing, within populations and among countries. As specified by Nutbeam (1986 p. 355): 


\begin{abstract}
"Equity in health is not the same as equality in health status. Inequalities in health status between individuals and populations are inevitable consequences of genetic differences, of different social and economic conditions, or a result of personal lifestyle choices. Inequities occur as a consequence of differences in opportunity which result, for example, in unequal access to health services, to nutritious food, adequate housing and so on. In such cases, inequalities in health status arise as a consequence of inequities in opportunities in life."
\end{abstract}

Inequalities, shaped by the SDoHs, provoke reduced opportunities and resources for health and lead to inequities and social exclusion, in turn causing inability of individuals or groups to be able to participate fully in the achievement of their own life goals as well as in society (Hubley et al., 2013). Under this perspective health is not merely a resource, it is also and foremost a human right, and in specific, a social citizenship right, part of the category of economic, social and cultural rights that add to civil and political rights (Bambra et al., 2005). As specified by Bambra et al. (2005 p. 188), health became a right with the development of the welfare state, when "a certain standard of living” became a citizenship's right. Already in the 1946 Constitution of the World Health Organization (WHO) and in the International Covenant on Economic, Social, and Cultural Rights, adopted by the UN in 1966, health was established as a dimension of international human rights law (Semplici, 2011). The nature of health as a right was further restated by the United Nations' Committee on Economic, Social and Cultural Rights in the General Comment No. 14 (UN, 200ob) as well in the factsheet The Right to Health issue by the Office of the United Nations High Commissioner for Human Rights and WHO in 2007 (p. 6):

\begin{abstract}
"The importance given to the "underlying determinants of health", that is, the factors and conditions which protect and promote the right to health beyond health services, goods and facilities, shows that the right to health is dependent on, and contributes to, the realization of many other human rights. These include the rights to food, to water, to an adequate standard of living, to adequate housing, to freedom from discrimination, to privacy, to access to information, to participation, and the right to benefit from scientific progress and its applications".
\end{abstract}

According to the health promotion framework the access to opportunities and the allocation of the social determinants of health is not shaped by chance, but comes from a systematic and socially produced inequitable distribution of power, money and resources (Baum, 2008). Given that health is a resource of which some have more than others, and given that the way the SDoHs are to be dealt with is through political interventions, the way in which health inequality are handled is in society is highly political (Bambra et al., 2005). Although admitting the purposefulness of health for development, the health promotion approach considers the prior function 
health to be its nature as a human right, and its pursuit a matter of social justice (Baum, 2008). In this sense, still according to Bambra et al., (2005 p. 192) "the masking of the political nature of health, and the forms of the social structures and processes that create, maintain and undermine health, are determined by the individuals and groups that wield the greatest political power". Semplici (2011) explains how, among human rights, socio-economic rights have been traditionally approached as being second-class and weaker than civil and political rights. To prove his argument Semplici (2011) compares the second article of the International Covenant on Economic, Social, and Cultural Rights (UN, 1966) with the second article of the International Covenant on Civil and Political Rights (UN, 1966). It is highlighted how in the former there is a commitment to respect and ensure civil and political rights through laws or judicial, administrative or legislative measures apt to give effect to the rights. On the other hand in the latter there is no commitment to protect socio-economic rights through restrictive measures, being merely stated that each signatory should take relevant action in order to protect such rights (Semplici, 2011). It is interesting to remind, in this case, what said in Chapter 3 concerning the negative and positive responsibilities within CSR, being the former depicted as compelling obligations (the ought tos), and the latter as weaker obligations (the cans and mights). By this order of logics, health, as a socioeconomic right, is not as much a true obligation as if it were a civil or political right.

In order to activate the quiescent political and social action necessary to produce social reform and equity, the health promotion approach introduces the notion of social responsibility for health, the second moral-based posture that authorities and society are expected to bring forward in order to activate the health promotion approach. In the frame set by the Ottawa Charter the social responsibility for health to ensure the access to, or shielding from, health determinants, is a core responsibility of governments, and only then one of individuals and communities. According to this perspective public policy-makers, in all sectors and at all levels, are asked to accept their social responsibilities for health adopting a whole-ofgovernment perspective to be enacted through HIA-based healthy public policies. The social responsibility approach is transformative in what it sets the focus upon the health outcomes produced, rather than upon the input given; governments are to be held accountable for the shaping of SDoHs and provision of opportunities that determine the health of their populations, not just for the health services they offer (Kickbush, 2003). Furthermore, the fact such social responsibility trespasses policy areas traditionally considered as separated from health, trade, agriculture and the 
environment to name a few, as well as encompassing different levels of governance, creates what Kickbush (2003 p. 385) defines a "categorical imperative" to commitment for dialogue and coordination among actors and agencies. The commitment towards dialogue and coordination is intended to achieve negotiation, coherence and ultimately harmonization of objectives. As further stressed by Kickbush (2003), a consequence of the imperative for commitment is the creation of new dialogic and partnering roles for health professionals, departments and agencies to collaborate with non-health professionals, departments and agencies.

\section{The health promotion approach during globalization}

\section{Threats imposed by global trends upon health}

In the context that set the grounds for the formulation of the Ottawa Charter infectious diseases were receding, life expectancy was on the rise and the fight against patterns of inequality appeared to be providing positive results (De Leeuw et al., 2006). Yet, the approach to health promotion as conceived by the Ottawa Charter, with its local government and community-based focus, was to be readjusted not long after its initial formulation when, by the 1990s, the process of globalization described in the previous chapter brought about new threats, actors and forms of governance to the health promotion agenda. As for what concerns threats, the globalization of trade and market economy to ex-Soviet and third world countries, and the deregulation that enabled it, created unprecedented patterns of displacement of human beings, goods, and resources across the globe with peaks in urban contexts. If these processes created, for some people, opportunities to increase control over their health, for instance, through access to goods and information, they also set the context for the recrudescence of communicable diseases, the displacement and intensification of NCDs, the escalation of inequalities on a global level and the rising of concerns for the health of the planet and subsequently that of its inhabitants (McMichael and Butler, 2006). By the 1990s, on top of the HIV/AIDs pandemics that had reached an unforeseen incidence, communicable diseases that were thought as under control, such as malaria, tuberculosis and cholera, saw fresh outbreaks connected with the mobility of people (ibid). Anew diseases were stirred by the rise in antimicrobial resistance, industrialized farming and the circulation of ailments, as it has been the case for the avian influenza, that travelled from Asia all through the West, and the bovine spongiform encephalopathy (BSE), also known as mad cow disease, that 
spread from the UK to Europe and the US, finally reaching Asia (ibid). As mentioned in the previous section, in high-income countries the epidemiological transition that started in the post-war period had created a situation characterised by low births, low mortality and morbidity, and a prevalence of NCDs over infectious diseases. The prevalence of NCDs is to be attributed to a longer life span as well as to urban and industrial patterns of production, consumption and lifestyle: diets high in processed foods, leisure and transportation habits leading to scarce physical activity, high consumption of alcohol, tobacco and drugs, and high levels of stress (McMichael and Butler, 2007). The breakdown of local cultures in favour of a westernization of lifestyles promoted by globalization gave rise to the uptake of risk factors for NCDs also in low and middle-income countries. Following globalization, low and middleincome countries, which had not yet fully undergone the demographic and epidemiological transition, and were still battling against infectious diseases as the major mortality cause, were brought to face what WHO (2015) depicts as a "triple burden of disease" characterised by coexistent threats associated with NCDs, sociobehavioural illness and infectious diseases. According to WHO (2015) mortality and morbidity connected with NCDs is expected to rise, in low and middle-income countries from less to 5 out of every 10 deaths, to 7 out of 10 deaths by 2020 (ibid).

The rise in inequalities is to be discussed in the context of the disruption of local cultural, social and economic systems and in the displacement of resources, amongst all, wealth and labour. Multilateral trade agreements took place among different countries starting from the 1990s, allowing trade ministries to conjointly make decisions to implement, adjust or abolish regulations with the objective of favouring or controlling trade. They were crucial in the disruption of local economic systems. A first example relevant for this discussion is provided by the agreement on TradeRelated Aspects of Intellectual Property rights (from now on, TRIPS) negotiated by the World Trade Forum (WTO) in 1995 and brought forward by the USA, supported by the EU and Japan, amongst others. The TRIPS agreement envisioned the introduction and enforcement of intellectual property rights in the international trading system, creating conflicts over the issue of price and availability of drugs, medicines and technologies that turned out being particularly controversial for issues such as the treatment of HIV/AIDS in sub-Saharan Africa. In agriculture patents have bonded seeds, pest-control products and plant biotechnology. The patenting of intellectual property in agriculture has lead to a monopolisation of resources such as seeds, fertilizers and pesticides and of their prices and consequent dependence and vulnerability of local farmers towards large producers, leading to issues in terms of 
food justice and food sovereignty (Labonté and Shrecker, 2007b). The Transatlantic Trade and Investment Partnership (from now on, TTIP), a free trade agreement between the USA and the EU expected to be finalized by 2016, provides a contemporary example of trade agreement with potential health repercussions. The TTIP, although still under negotiation at the time of redaction of this research, is feared of being passible of lowering existing health regulation and safety standards in Europe as to match the criteria of the USA market, as to favour international import and export between the two regions. Major fears concern the greater utilization and circulation of genetically modified organisms (GMOs) as well as the employment of hormones in cattle breeding (Vivas, 2015). Globalization impacted employment and wealth worldwide in the sense that it created what Labonté and Shrecker (2007 p. 3) define "new international reorganization of labour" relocating and outsourcing production from industrialized countries to developing countries to cut costs. Relocation and outsourcing of business activities in countries with weak social and labour standards leads to increased population morbidity and mortality related to occupational hazards and different patterns of exploitation among powerless workers (McMichael and Butler, 2006). In industrialized countries the international relocation of labour has led to a decline in wages of non-skilled labour, rise in unemployment, and a competition among national governments for foreign investments often resulting in a race to the bottom of labour standards and social policies (Labonté and Shrecker, 2007). Sub-Saharan Africa was majorly impacted by globalization in terms of loss of human capital due to skilled migration from poorer and undeserved areas to richer regions, widening, rather than decreasing, the resource gap of poorer areas, and thus contributing to "lockin - in" poverty (McMichael and Butler, 2007 p. 18).

As previously contended inequalities, other than being threatening at the level of the individual, are harmful at the social level, as loosely integrated communities and societies are more likely to incur in ill-health. Such point can be proven by the example of the regions of the ex-Soviet union, that following the fall of the Berlin wall experienced a loss of life expectancy remarkable for their level of technological development, explained in terms of the social disintegration that followed the dismantlement of the union, provoking rises in levels of violence, suicide, alcoholism, and cardio-vascular diseases (Ziglio et al., 2000; McMichael and Butler, 2007). As explained by Tugwell et al., (2007), in the period 1995 to 2000 the inequalities in health between rich and poor increased in USA; inequalities were also found to be increasing between and within the European Union's countries, due the harshening 
of the gap between rich and poor, rural and urban areas, and increasing migration as we will see in detail in the following section. As it can be argued on the basis of the examples insofar mentioned, the opportunities inherent to globalization for health promotion were accompanied by a number of threats. The argument according to which opportunities offset costs and losses is true in relative, but not in general terms, as the gains engaged by the processes intrinsic to globalization, have followed patterns of polarization among and within countries: "globalization, as we know it today, is fundamentally asymmetric. In its benefits and its risks, it works less well for the currently poor countries and for poor households within developing countries" (Birdsall, 2006 in Labonté and Shrecker, 2007 p. 2). In this sense, globalization highlighted the creation of a "global class system, in which privileged groups in both developed and developing countries act (often in concert) to protect their own position at the expense of others" (McMichael and Butler, 2007 p. 21). In light of both social and economic opportunities and hazards that globalization created, and under the consideration that such opportunities and hazards are not equally distributed among citizens and nation-states worldwide, it is possible to argue that globalization, although engaging some wealth creation, has threatened the purpose of social justicebased and equity-focused attainment of health and wellbeing as set by the Ottawa Charter by harshening inequalities among and within countries both in developing and developed countries (McMichael and Butler, 2007; Baum, 2008).

On top of the concerns for the resurgence of inequalities to levels that had been considered as eradicated in the 20th century, globalization imposed concerns relative to the impact of faltering environmental health on human and animal health. Already in 1992 the Rio de Janeiro Earth Summit had brought to the attention of world leaders the threats imposed by the patterns of production, circulation and consumption of goods for the sustainment of the planet Earth's life-support systems (De Leeuw, 2007; McMichael and Butler, 2007). Throughout the first years of the $21^{\text {st }}$ century the likelihood of such threats increased, reaching a point for which in 2009 the UCL Lancet commission stated that "climate change could be the biggest global health threat of the 21st century" (UCL Lancet Commission, 2009 p. 1659 in Kjoergard et al, 2011 p. 4), pointing out its potential impacts in patterns of morbidity and mortality in terms of food and water security, climate emergencies and natural disasters and migration, to name a few. Under this consideration, starting from the 1990s, the health promotion approach took on the sustainable development frame. Sustainable development was purposeful to the health promotion approach during globalization for two reasons. In a first instance as a means to stress an accent on the 
interdependence of the wellbeing of living beings, present and future, and their ecosystem: "it will not be possible to sustain the quality of life, for human beings and all living species, without drastic changes in attitudes and behaviour at all levels with regard to the management and preservation of the environment” (WHO, 2009 P. 15). In a second instance it served to bring forward the moral case for social justice and social responsibility for health at a global level, as we will see further on in this section. The sustainable turn took by health promotion starting from the was inaugurated in the third international conference on health promotion, the Sundsvall Statement on Supportive Environments for health (WHO, 1991), in turn relying on the Call for Action: health promotion in developing countries (WHO, 1989) and the report Our Common Future redacted by the World Commission on Environment and Development (WCED, 1987).

\section{Levels of leverage of the for-profit sector on health: exploring the dimensions of industrial epidemics}

When speaking of the forces influencing the SDoHs in the context of globalization it is necessary to devote a specific emphasis on the leverage played by the for-profit sector on health, given, as previously mentioned, that economic and trade dynamics can be pinpointed as the core drivers from which the other processes inherent to globalization, be them social, cultural or political, took ground. Although we know that the for-profit sector is apt to impact health as a private healthcare provider responsible for healthcare financing and delivery, and that the rise of private healthcare financing has experienced, due to the push for deregulation brought about by globalization, a stable growth in the last twenty years both in middle and highincome countries, such as the EU, this section, coherently with the health promotion lenses, will focus on the non-healthcare impacts of business activities upon health. The leverage of the for-profit sector on health will be discussed as connected with the health-threatening or health-promoting nature of goods and services manufactured or offered first, and with the corollary business practices related to goods and services manufactured or offered, on the other. It should be noted that corollary business practices are to be related directly or indirectly with said products and services; relate directly practices such as pricing and distribution, marketing and advertising, packaging and disposal, and relate indirectly labour standards, and lobbying, research and public affairs practices, as well as environmental practices. 
The products in the spotlight for impacting health through exposure and consumption are pharmaceutical products, information and communication technologies, medical devices, food and beverages, tobacco, alcohol, vehicles, and weapons, gambling services, nuclear, oil, cement and chemicals (Wiist, 2006; Jahiel and Babor, 2007; Jahiel, 2008; Freudenberg and Galea, 2008; McDaniel and Malone, 2009; Lindorf et al., 2012; Freudenberg, 2012; 2014). If pharmaceutical products, information and communication technologies, medical devices, and to some extent food and beverages, have been predominantly discussed in relation to their potential to positively impact health, the same food and beverages, together with tobacco, alcohol, vehicles, and weapons, gambling services, and petrochemicals, have been approached concerning their inherently health-threatening nature. Notwithstanding the purposefulness of the nature of certain products and services to be beneficial or critical for health outcomes per sé, what has been put under accusation by the North-American and European schools of public health (Freudenberg and Galea, 2008; Lang 2007, 2010, Wiist 2006, 2010, 2011; Brezis et al. 2011, Freudenberg, 2012; 2014) and the advocacy of organizations such as Corporations and Health Watch, founded in 2007, is industry's positioning in the corollary practices related to such products. It has been argued that pricing, distribution and marketing in consumer societies have done quite the opposite of the goal set by the health promotion approach, to make the healthy choices the easy choices, participating, on the contrary, in making the unhealthy choices the easy choices in leisure, nutrition, transportation, and so on. The potential negative impacts of pricing, distribution and marketing of such products on the health of industrial and global societies have been so relevant as to lead to the formulation of the notion of "industrial epidemics" (Beatrice Majnoni d'Intignano, 1995; Jahiel, 2008). As explained by Jahiel and Babor (2007 p. 102)

\begin{abstract}
"There is a fundamental difference between natural epidemics and industrial epidemics. Classically, epidemics are caused by natural agents (such as Plasmodium falciparum) and are driven by natural forces (such as Anopheles mosquitoes and ecological factors thereof) acting upon these agents. Industrial disease epidemics are driven at least in part by corporations and their allies who promote a product that is also a disease agent."
\end{abstract}

Pharmaceutical products and medical devices' product development and pricing have been accused of augmenting the inequality health gap by leaving behind less profitable therapeutic areas and populations (neglected diseases). ICTs have started to invest in the formulation of innovative technologies reinforcing patient-centred 
healthcare as well as started to offer services relevant for health communication in terms of education and prevention (Haluza and Jungwirth, 2014). The food industry is currently deeply involved in the reformulation and expansion of its portfolio of products, creating a situation in which the "line between food, dietary supplements and pharmaceutical products is becoming harder to draw" (Kickbush, 2003b p. 375). Examples can be found in the formulation and marketing of functional foods, directed at specific chronic or everyday health conditions, or foods with positive health claims (Kickbush, 2003). Finally the tourism sector, other than expanding towards medical tourism, participates to what Kickbush (2003) defines "the wellness revolution" by offering and advertising complementary and alternative health services that contemplate both physical and spiritual elements: SPAs and holistic retreats, water treatments and eastern medicine (Smith and Kelly, 2015). Nevertheless, it is concerning pricing and marketing that the industry has faced its harshest criticisms; On one side in relation to patent and price monopolies that dictate costs that often deny treatment, hence affecting equity in access, on the other, because of direct-to-consumer advertising of prescription drugs leading to overconsumption of pharmaceutical drugs and the preference of cure over prevention (Gruskin and Raad, 2010; Valverde, 2012). Food and beverages have been scrutinized for the central role their consumption plays in human health. According to WHO $1 \%$ of disability adjusted life years (DALYs) and $2.8 \%$ of deaths worldwide related to obesity, cardiovascular diseases, diabetes and cancer, are caused by low consumption of fruit and vegetables and elevated intake of processed foods and sugary drinks with high levels of sugars, fats and salts (WHO, 2015). As explained by Guntham (2006) unhealthy and high calorie food shifted from being a residual to a central component of alimentation of industrial societies due to their relative low cost of production and sales in comparison to fresh produce. Portion sizes have also increased as a means to increase marginal gains (Freundenberg and Galea, 2008). Hence distribution and marketing directly shape consumption, as low-cost highly processed foods also often become the only options available to lower-income population groups, the so-called "food deserts" (Food empowerment product, 2015), as healthier (and more expensive) alimentary retail settle to higher income areas (Freundeberg and Galea, 2008). The impact of what Klein (2000) defines "emotional" marketing, shaping cultural landscapes and health impacting habits has been known since the 1970s, after it was observed that the marketing of breast-milk substitutes led to a reduction to breastfeeding in different regions of the world (Lee, 2006). Today major concerns focus around the marketing of processed foods and drinks to children presented as being related to leisure other than health (Guntham, 
2006; Herrick, 2009). In his book Legal but Lethal Freudenberg (2014) adds that it is not only pricing and distribution to shape consumption but also composition; processed foods are manufactured as to be hyper-palatable, it is to say they are engineered as to produce increased reward systems on the brain, hence creating addictive behaviours towards consumption (ibid). In the context of the beverages a special mention is worth concerning alcohol products that, impacting health in both biological and social terms, have been subject to targeted marketing addressing vulnerable groups (Jahiel and Babor, 2007). The impacts of tobacco upon health are well established to the general audience; nevertheless, what is relevant to add in this context is that the consumption of tobacco has been actively promoted by the industry throughout the 2oth century, as a " quintessentially urban product showing sophistication and modernity", as a means of emancipation for women, youngsters and as a instrument of stress-reduction for the working class and ethnic minorities (Freudenberg and Galea, 2008 p. 466). As for what concerns vehicles, other than in terms of gas emissions, Freudenberg and Galea (2008a) and Freundeberg (2014) identify sports utility vehicles (SUVs) as being a major public health issue in what, other than being more polluting than sedans, they are marketed as being secure, thus leading to risky driving whilst being more likely to roll over killing both occupants and pedestrians.

As for what concerns the corollary business practices indirectly related to products and services the for-profit sector is held responsible, in a first instance, for employees' occupational health and safety. Freudenberg and Galea (2008), quoting data from the International Labour Organization (ILO), argue that an estimate of 2 million deaths per year, an approximation of $4 \%$ of the GDP of a nation, is dispersed due to occupational hazards, adding that a relevant part of such hazards could be prevented in the for-profit sectors gave greater importance to the health and safety of its employees as opposed to profits. Secondly, business entities are considered responsible for the potential health impacts related to lobbying, research and public affairs practices connected with the regulation and policy-making inherent to produced goods and services. As argued by Guntham (2006) the food pyramid is heavily shaped by the politics of the agrifood-business, particularly in terms of recommended consumption of meat and diary. Pharmaceuticals and private healthcare providers have been found to influence health policy-making and regulation, and shape understadings of health and disease (Kitsis, 2011; Haluza and Jungwirth, 2014). Ultimately, the leverage of the for-profit sector on health is to be discussed in relation to the health of the environment, threatened by operations' 
emissions and waste disposal leading to a depletion of natural resources and pollution of natural environments, namely in terms of deforestation, ozone depletion, air and water pollution (Freundenberg and Galea, 2008).

What insofar discussed concerning the leverage of the for-profit sector on health is passible of a number of considerations. A first consideration to be made is that business entities are not to be held responsible for the intrinsic health threatening or health promoting nature of products, given, as Herrick (2009) explains, that individuals may desire to consume or be exposed to products that have harmful health effects even when informed of the their negative effects, preferring the satisfaction of non-health objectives. The author believes, in agreement with Lindorff et al. (2012 p. 94) that "it is nonsensical to define what socially responsible behaviour is on the basis of the particular product that a firm produces". What business entities are hence to be held responsible for is the impact of their business practices be them of pricing, distribution and marketing or concerning labour standards, lobbying and advocacy or environmental standards. It may be argued on this point that for such practices regulatory boundaries exist. Yet, as explained by Freudenberg (2014) the authority of policy-makers in western high income economies, is often overrun by the lobbying power and massive communication resources of the network constituted by consumer product companies, financial institutions, trade associations, and public relations firms, and it is in this sense that business entities are to bring forward their social responsibility.

A new meaning of social responsibility for health: actors, expectations and governance for health in the global public domain

If in the previous section it was reported that in the frame set by the Ottawa Charter the social responsibility for health was a core responsibility of governments, the processes of deterritorialization and deregulation of markets inherent to globalization made so that the responsibilities towards health promotion were progressively considered as trespassing the level of governments. Semplici (2011 p. 356) observes that in The General Comment No. 14 (UN, 2000) mentioned in the previous section, little attention was given to the health obligations of actors other than state parties. Conversely, he argues, in the article 14 of UNESCO's Declaration on Bioethics and Human Rights (2005), discussing social responsibility and health, the furthering of the right to health is seen as a central purpose of governments that 
all sectors of society share. The Report of the International Bioethics Committee on Social Responsibility and Health (UNESCO, 2010), in turn built upon article 14 of UNESCO's Declaration on Bioethics and Human Rights (UNESCO, 2005) restated the relevance to foster a social responsibility for health, which was framed as a "moral obligation moral deeply rooted in social relationships and integral to societies" (p. 19) adding that:

\begin{abstract}
"It is not possible for a sector in society not to feel any responsibility for health and social development, and not to act in a way that promotes health and social development. Article 14 denies the legitimacy of such attitudes. No sector in society or single citizen can isolate themselves from responsibility for the promotion of health and social development."
\end{abstract}

Hence it can be said that, in the health promotion approach during globalization, that whole-of-society approach comes to replace the whole-of-government approach envisaged by the Ottawa Charter. The term whole-of-society depicts a polycentric and participatory approach to health promotion intended to complement public policy where civil society and business actors get involved in public policy-making, financing and delivery, through both formal and informal mechanisms. The wholeof-society approach starts from the consideration that "although the more proximal determinants of health (those directly impacting on individual and community health) have hardly changed, the patterns of distal determinants of health (those factors that set the parameters for proximal proximal determinants), as outlined above, have" (Leeuw et al., 2007 p. 2). The challenge the whole-of-society approach to health promotion faces is first one to establish links between global processes and micro determinants, understanding which global forces and actors shape decisions and lifestyles at the micro-level (ibid), and then to proceed through coordinated and coherent intersectoral action, defined by O' Connor Fleming and Parker on the basis of the WHO definition (2009 p. 398) as a "relationship between part or parts of different sectors of society which has been formed to take action on an issue to achieve health outcomes or intermediate health outcomes in a way which is more effective, efficient or sustainable than might be achieved by the health sector acting alone". Although the health promotion approach has been intrinsically multi-actor and multi-level since its first conception, aiming at furthering an understanding of health as co-produced by many different societal actors, Porter (2007), highlights the existence of a shift, taking place in the health promotion during globalization, in what is intended by private actors; if previously the term was used to depict individuals and communities, global health promotion relies on the action of meso-level 
institutions, IGOs, NGOs, MNEs, research institutions, religious associations and civil society organizations, the central actors of global health governance (Dogson et al., 2002).

This shift of responsibilities is the focus of WHO's international health promotion conferences taking place at the end of last century and beginning of this century: the Jakarta Declaration New Players for a New Era: Leading Health Promotion into the 21st Century (WHO, 1997) and the Bangkok Charter for Health Promotion in a Globalized World (WHO, 2005). The Jakarta Declaration was formulated during the fourth international conference on health promotion "the first to be held in a developing country and the first to involve the private sector in supporting health" (WHO, 2009 p. 17). The Jakarta Declaration starts on the consideration that, by the end of the $2 \mathrm{O}^{\text {th }}$ century, the factors influencing the SDoHs had changed in a manner that has been previously depicted within this chapter, calling for new responses breaking down "traditional boundaries among sectors between government sectors, between governmental and non-governmental organizations and between the public and private sectors" (WHO, 2009 p. 19) as to "unlock each agents' potential in health" (WHO, 2009 p. 19). The Jakarta Declaration specifically addressed both the health-promoting and health-threatening role of the for-profit sector, giving examples of the opportunities embedded in the design and development of media, telecommunications, and technology solutions, as well as evoking the negative effects elapsing from the trade of harmful products, such as tobacco. Five priorities for health promotion are identified within the Jakarta Declaration: the advancement of a social responsibility for health, the furthering of investments in health, the consolidation of anew partnerships, the empowerment of communities and individuals, and the securing of the infrastructure for health promotion. The pursuit of social responsibility for health, competence of both public and private decisionmakers, is framed as follows (WHO, 2009 p. 19):

- Avoid harming the health of individuals;

- Protect the environment and ensure sustainable use of resources;

- Restrict production of and trade in inherently harmful goods and substances such as tobacco and armaments, as well as discourage unhealthy marketing practices;

- Safeguard both the citizen in the marketplace and the individual in the workplace;

- Include equity-focused health impact assessments as an integral part of policy development. 
It can be noted that the Jakarta Declaration considers the environment, labour and marketplace as areas of action for the social responsibility for health coherently with the levels of leverage individuated in the previous sub-section. If the notion of social responsibility for health as framed by the Ottawa Charter relied on the ability to participate of governments and communities, within the Jakarta Declaration the social responsibilities of the for-profit sector are framed in a perspective of accountability, being resumed as the negative responsibility to do no harm. The tools envisaged for the enactment of responsibility are HIA and partnerships. The Bangkok Charter (WHO, 2005) the second Health Promotion Charter after Ottawa, broadens the perspective of the Jakarta Declaration by calling in cause, other than patterns of consumption and commercialization, the raising inequalities and the adverse effects of urbanization and global environmental challenges on health. Also the Bangkok Charter, other than reiterating the opportunities embedded within information and communications technologies, stressed the potential relevance of anew mechanisms of governance for health promotion at the levels of governments, the United Nations and the private sector. Taking a step forward from the Jakarta Declaration, the Bangkok Charter distinguished the responsibilities for health of each societal party, specifically considering, for the first time, the potential role of CSR for the involvement of the for-profit sector in the health promotion approach. The responsibilities of the for-profit sector are depicted as follows (WHO, 2009 p. 27):

\footnotetext{
"The private sector, like other employers and the informal sector, has a responsibility to ensure health and safety in the workplace, and to promote the health and well-being of their employees, their families and communities.
}

The private sector can also contribute to lessening wider global health impacts, such as those associated with global environmental change by complying with local national and international regulations and agreements that promote and protect health. Ethical and responsible business practices and fair trade exemplify the type of business practice that should be supported by consumers and civil society, and by government incentives and regulations."

If we were to categorize the rationalities motivating the responsibilities of business actors in health promotion perspective in the same way we categorized that of the CSR approach, we may say that both the Jakarta Declaration and the Bangkok Charter engage a consequential perspective, framing responsibility as inherently linked to the impacts elapsing from business operations, whilst the Report of the International Bioethics Committee on Social Responsibility and Health, and the UNESCO's Declaration on Bioethics and Human Rights, engage a perspective of appropriateness framing responsibility for health as a moral obligation integral to 
societies. No direct links can be found with the principles of stakeholder responsiveness or public responsibility

Lee (2006) frames the ensemble of norms, rules and institutions that underpin the inclusion of private actors in health promotion typical of the post-Bangkok frame as (global) governance for health. The instruments of governance put in place to enable the participation of business entities to health promotion vary from non-binding to binding. CSR practices are means for the business sector to get involved in nonbinding governance, either autonomously or through public-private partnerships. The partnered or polycentric approach to health promotion has been endorsed since the 1990 s as a veritable strategy by WHO consolidated by both Jakarta Declaration and the Bangkok Charter and substantiated by a stream of articles on the subject that appeared in WHO's bulletin since 2000: Global public-private partnerships: a new development in health? (Buse and Walt, 2000), Global public-private partnerships: part II - what are the health issues for global governance? (Buse and Walt, 2000), Public-Private Health Partnerships: a strategy for WHO (Buse and Waxman, 2001). According to Walt et al.'s article (2002) Working with the private sector: the need for institutional guidelines the establishment of public-private partnerships for health according to WHO should comply with the conditions of: mutual agreement on objectives; mutual agreement on division of labour rights and obligations; screening/declaration/reconciliation of conflicts of interest; and suitability of intended partner. Further, it should be oriented by: beneficence, non-maleficence, autonomy, and equity, in the sense that action should be directed to those most in need (Buse and Walt, 2000). Finally, they should take place in presence of the following minimum capacities and structures: partnership skills, institutional framework clarifying the approach and criteria, guidelines for best practice, dialogue, negotiation and monitoring structures (Buse and Walt, 2000; Buse and Waxman, 2001).

As exemplified by Lee (2006) one of the pioneer examples of non-binding governance instruments involving the private sector in health promotion is the International Code of Marketing of Breast-milk Substitutes launched by WHO in 1981 following the concerns that the marketing of breast-milk substitutes was discouraging breast-feeding worldwide and especially in developing countries. The code has since been adopted by both member states and business actors voluntarily where it has not been translated into national law. A second example is furnished by the WHO Global Strategy on Diet, Physical Activity and Health a non-legal, 
advocacy-based approach launched in 2004 by the World Health Assembly (WHA), and the endorsement of organizations such as the International Union Against Cancer, the International Diabetes Federation and the World Heart Federation (Lee, 2006). The global strategy has the objective to create a global alliance to tackle the nutrition-based determinants of non-communicable diseases (from now on, NCDs) through the reduction of risk factors and the increase of awareness concerning the link between nutrition and NCDs (WHA, 2004). The strategy was developed through six consultations among the member states of WHO, intergovernmental bodies and representatives from the private sector and civil society (WHA, 2004), facing criticism for resulting into a "milder draft" engaging a "balanced approach that takes into account political realities" namely the ones of the food and beverage industries" (Lee, 2006 p. 46). The last form of engagement of private actors in health promotion governance takes place through binding frameworks, of which the most renown and successful example is provided by the World Health Organization Framework Convention on Tobacco Control (FCTC) (Fidler, 2007). The FCTC is a treaty whose negotiations begun in 1998, was adopted by the WHA in 2003, and came into force in 2005, having been ratified by 180 countries worldwide at the time of redaction (FCTC, 2016). The objective of the convention is to allow signatories a common approach to prevent and control tobacco-related diseases by ruling on tobacco production, distribution, marketing, and taxation, engaging in an unprecedented effort of policy coherence both among individual states and at an international level. The FCTC has represented a milestone in international public health, being one of the first multilateral binding frameworks dealing with NCDs' determinants. It was proof that public health officials, in collaboration with civil society organizations, are capable of counteracting the lobbying power and interests of a strong industry, such as the one of tobacco (Lee, 2006). Furthermore, according to Fidler (2006) the launch and uptake of the convention is a testimony to the fact that health promotion can and should be implemented as a foreign policy by the global health development agenda.

\section{Criticism to the health promotion approach}

The notion of health promotion, as with all notions allowing a breakthrough, has faced criticisms concerning scope and application. Due to its multi-level and holistic nature, health promotion has been likened to the definition of happiness rather than health, one that is inflexible and unrealistic given that it is unlikely for anyone to attain all of its dimensions for a reasonable period of time (Saracci, 1997). Further, it 
has been argued that the broadness of the concept has led to the impossibility to produce a model to conduct the field, creating a general incapacity to operationalize the precepts of health promotion, not merely at the whole of government level, but also within the health sector "it has been difficult to achieve and sustain national and local commitment to public health and health promotion and to build their budgets" (Antonovsky 1996; Swerissen and Crisp, 2004; Saan and Wise, 2011 p. ii189; Hendricks et al, 2014). According to Swerissen and Crisp (2004) challenges can be resumed in the requirement of the creation of anew organizations, networks, resources and structures and of their sustainment over time, problematic in terms of the short term span of organizational decision-making, scarcity of investments, and due to the potential dilution that polycentric governance may create in the definition and realization of goals and objectives (Kickbush, 2003; Hendricks et al, 2014). As noted by Kickbush (2003) the health promotion approach has never really overcame the realm of health education; even when the population movement emerged, focusing on the factors that produced health, no linkage was made with the health promotion approach, losing the opportunity to forge an alliance for health.

Additional issues have risen in the health promotion approach as envisaged in the post-Ottawa context. According to Porter (2007) the most critical aspect of both the Jakarta and Bangkok documents is that, notwithstanding the stressing of impacts on health related with globalization in general, and business activities in particular, no links of causality are established between activities and health outcomes, exception made for the Jakarta Declaration's explicit mentioning of the negative impacts of the trade and marketing of harmful products. To this critique the author adds that both documents fail in introducing a perspective of appropriateness, according to which business entities should pursue health promotion because it is their moral responsibility as well as a societal expectation to do so. It is undeniable, as highlighted by Symes (2007), that it is a difficult task for health promotion advocates to exactly pinpoint the complex multi-level forces that generate health promotion challenges, especially in the absence of institutional structures apt to monitor the development of healthy public policies. Yet, the failure to base the involvement of the business sector in health promotion on a rationale of causality, identifying what that Labonte and Shrecker (2007 p. 184) describes "inextricable linkages", denotes, according to Porter (2007), a step back in the health promotion movement, from the social justice perspective inspired by the Ottawa Charter to a "new capitalistic" approach in health promotion, one that introduces a technocratic, economic and legalistic discourse focused upon mechanisms of global governance, one that 
addresses the global threats to health but "works to perpetuate them", in the measure in which it fails to explicitly identify their sources (Porter, 2007 p. 75).

Kickbush (2003) poses the question upon how responsibilities for health are to be allocated, and by whom and to what extent the respect of such responsibilities is to be controlled, and which organizations, networks and resources should be created for such responsibilities to be effectively enacted. In this sense a second focus of criticism is to be found in the collaborative and predominantly non-binding approach towards health promotion governance. Partnerships for health promotion have been criticised first and foremost for being based on a naïve logic that considers that public and private interests in health coincide (Buse and Lee, 2005; Baum, 2008; Baum and Sanders, 2011). As pointed out by UNICEF executive director Bellamy "it is dangerous to assume that the goals of the private sector are somehow synonymous with those of the United Nations, because they most emphatically are not" (Dogson et al, 2002 p. 21). Additionally, partnerships for health promotion have been contested for lacking appropriate criteria concerning the level of involvement required to be a partner, leading to a confusion among partnership and sponsorship (Lee, 2006), involving private actors that lack substantial understanding concerning causes and effects in health and for the absence of evidence considering their potential to result in health gains (Dogson et al, 2002). Ultimately, they have considered as inhibiting the premises for harder governmental regulation and undermining of role and legitimacy of public actors (Buse and Lee, 2005; Herbert, 2005; Ayo, 2012; Guntham 2012; Carter, 2015). Non-binding approaches to health promotion have, on the other hand, been disapproved for having "few means of enforcement beyond public censure" (Lee, 2006 p. 44) and hence being too weak to protect health, in a context of rising non-state power were regulation is deemed as being particularly relevant (Baum and Sanders, 2011). Lee (2006) points out that studies contextualizing the appropriateness of each instruments of governance for different situations are still lacking. As argued for by Wiist (2006) and Jahiel and Babor (2007) public health officials should be not only informed and aware of such criticalities but ready to discuss them openly and to "adduce stronger evidence to convince policy-makers (themselves largely beneficiaries of globalization) to promote public goods. As affirmed by McMichael and Butler (2006 p. 22) the challenge "for the promoters of health (and other forms) of justice is to adduce stronger evidence to convince policymakers (themselves largely beneficiaries of globalization) to promote public goods, even though this may diminish the relative privilege of policy-makers and their constituencies". Finally, it is recommended the public health community focus on the 
power of building alliances with civil groups, labour unions, media and legislators as to advocate for causes and make binding regulations necessary (Jahiel and Babor, 2007).

\section{Health promotion in context}

\section{Health promotion approaches, issues and objectives in the European Region}

The WHO Regional Committee of the European Region ${ }^{3}$ was a driving force behind the shaping of the understanding of health promotion framed by the Ottawa Charter. As previously hinted, it was the adoption of the 38 Health for All targets by the members of the WHO European Region in 1981, the first WHO region to develop specific regional targets, that set a distance from the lifestyle-based understanding of health provided by the Lalonde Report by stressing an accent on lifestyles as "collective behaviors deeply rooted in context" (Kickbush, 2003 p. 384). This perspective distinguished the approach of the WHO European Region from the US individual lifestyle-based approach contained in the strategy Healthy People adopted by the Department of Health in 1979. Both the European Health for All and the US Healthy People approaches were sources of influence and discussion during the Ottawa Conference where the orientation given by WHO Europe's Regional Office

\footnotetext{
${ }^{3}$ The WHO European Region comprises 53 Member States within a territory that stretches from Iceland to Russia. It includes countries with great variations in terms of physical environments, socioeconomic and political conditions and health systems, resulting in different health indicators. Countries that pertain to the WHO European Region are the following: Albania, Andorra, Armenia, Austria, Azerbaijan, Belarus, Belgium, Bosnia and Herzegovina, Bulgaria, Croatia, Cyprus, Czech Republic, Denmark, Estonia, Finland, France, Georgia, Germany, Greece, Hungary, Iceland, Ireland, Israel, Italy, Kazakhstan, Kyrgyzstan, Latvia, Lithuania, Luxembourg, Malta, Monaco, Montenegro, Netherlands, Norway, Poland, Portugal, Republic of Moldova, Romania, Russian Federation, San Marino, Serbia, Slovakia, Slovenia, Spain, Sweden, Switzerland, Tajikistan, The former Yugoslav Republic of Macedonia, Turkey, Turkmenistan, Ukraine, United Kingdom of Great Britain and Northern Ireland, Uzbekistan.
} 
prevailed (Kickbush, 2003). As explained by Kickbush (2003) the socially oriented approach to health promotion that prevailed in the WHO European Region was to be understood in the perspective of the strong link established in the region between health and social health since the first public health revolution, link then consolidated by the welfare state. Furthermore it was to be associated with sociological schools of though, such as the Weber's understanding of lifestyles as collective social categories and Durkheim work upon the social roots of suicide (ibid).

In the European Region the Ottawa Charter led to a strong harmonization process concerning the values and objectives subjacent to health promotion within member countries: the achievement of social justice through equity, and the pursuit of intersectoriality through social responsibility (Ziglio et al., 2000). Another characteristic feature of the approach of the European Region was that political legitimacy for the targets was sough both at the level of the EU, as we will see later on, and in terms of the development of national health policies, of which the first were the ones of Finland (1985) and the Netherlands (1986) (Kickbush, 2003). The USA approach, on the other hand, was lied out as a set of targets developed by experts without any political legitimacy (ibid). Throughout the late 1980s and 1990s a number of innovative health promotion multi-country initiatives were launched in the Region: Healthy Cities, Health Promoting, Schools, Healthy Promoting Hospitals, at the same time, health promotion foundations were erected by some of the member states (Austria, Estonia, Switzerland) (Ziglio et al., 2000). Health promotion activities by labour unions, consumer groups, civil society organizations and the industry also started gaining ground (ibid). In 1998 the WHO Regional Committee of the European Region launched Health21 - health for all in the 21st century the policy for the Region that was to follow Health For All, laying 21 targets for health in the $21^{\text {st }}$ century. Health 21 framed a whole-of-society social responsibility for health as a programmatic target to be achieved by the year 2020 - target 14, multisectoral responsibility for health: (WHO 1998 p. 104):

\footnotetext{
"By the year 2020 all sectors should have recognized and accepted their responsibility for health:

$\circ$ Decision-makers in all sectors should take into consideration the benefits to be gained by investing for health in their particular sector and orient policies and actors accordingly;

- Member states should have established mechanisms for health impacts assessment and ensured that all sectors become accountable for the effects of their policies and actions on health."
}

The policy further focused on the new threats imposed by globalization within the region. As explained by Ziglio et al., (2000), and briefly anticipated in the previous 
section, globalization particularly impacted the European health setting in what it disrupted a long period of stability, created strains of migration from the former Soviet bloc, brought about unemployment and work insecurity caused by the deregulation of labour and relocation of industry outside the Region, and overall harshened inequality in earning and life conditions. Although by the end of the $1990 \mathrm{~s}$ it was possible to say that there was awareness within the Region concerning the need to further health objectives following health promotion thinking, and that some initiatives were surging, Ziglio et al. (2000) stress an accent on the fact that in the majority of countries institutional arrangements, infrastructures and policy action for health promotion were weak or lacking, and that the investments for the furthering of the health promotion approach in its first decade of implementation did not pass, on a general basis, the threshold of $1 \%$ of national health expenditures. This has led, within the Region, to a difficulty to implement the sociological health model and to merely fragmentary health promotion initiatives only seldom based on health impacts assessment and with a tendency to focus on the "production of, rather than the demand for, health care" (Ziglio et al., 2000 p. 151)

In 2012 the states member of the WHO European Region adopted Health 2020: $a$ European policy framework supporting action across government and society for health and well being as their novel health policy framework. Within Health 2020 health is presented as a valuable resource both in social and in economic terms, stressing an accent on the relevance of health for individual's productivity and of the health sector as an employer, a landowner, a builder, and a consumer (WHO Europe, 2012). The policy called the attention upon changing patterns of disease, demography, social cohesion and environmental health threatening life expectancy and the possibilities of response to needs of national health and welfare systems (ibid). The policy further stressed the scarce investments dedicated by national health budgets to health promotion (framed as 3\% of health budgets) calling for the need to reduce health inequalities through the bettering of education, employment and working conditions, social protection and poverty decrease and to increase participatory governance for health (ibid). Health2020 individuates four priority areas for action within the WHO European region:

i. Investing in health through a life-course approach and empowering people;

ii. Tackling communicable and non-communicable diseases;

iii. Strengthening people-centred health systems, public health capacity and emergency; 
iv. Creating resilient communities and healthy environments.

The priority area envisaging a life-course approach to health investment (i) considers that health equity starts with pregnancy and early development and stretches across healthy and active ageing as "healthy children learn better, healthy adults are more productive, and healthy older people can continue to contribute actively to society" (WHO Europe, 2012 p. 6). The priority area considering communicable and noncommunicable diseases (ii) focuses, in a first stance, on the high burden of noncommunicable diseases in the Region, depicted as the highest worldwide. It is explained how "cardio-vascular diseases and cancer cause almost three quarters of mortality in the Region, and three main disease groups, cardiovascular diseases, cancer and mental disorders, cause more than half the burden of disease (measured using disability- adjusted life-years (DALYs)" adding that "estimates indicate that at least $80 \%$ of all heart disease, stroke and type 2 diabetes and at least one third of cancer cases are preventable" through the modification of risks factors such as tobacco and alcohol use, dietary habits and physical activity (WHO Europe, $2012 \mathrm{p}$. 8). It is specified that the modification of risk factors is to take place on the basis of a combination of approaches (including individual behaviours, health services and public policies) in the acknowledgement that behavioural interventions alone have limited impact, and that inequalities in socioeconomic status account for a predominant portion of uptake of risk factors. The relevance of the strengthening of health promotion is re-stated individually, claiming that one in four people in the European Region experience some type of mental health problem during their lives, and that half of people with mental health disorders do not receive any treatment leading to mental health disorders being a major cause of disability within the Region (WHO Europe, 2012). For what concerns communicable diseases, the policy testifies the problems related to polio, measles, rubella and influenza specifying that HIV/AIDS and tuberculosis represent major health challenges. It is explained how the re-insurgence and relapsing of multidrug-resistant tuberculosis in eastern and central areas of the Region, which accounts for $85 \%$ of multidrug-resistant tuberculosis worldwide, are linked to poverty and homelessness. It is stressed the need for timely prevention, diagnosis and treatment of all communicable diseases at the level of health services, education and information, investment for research on anti-microbial resistance as well as drug resistant organisms, all whilst paying attention to the SDoHs. The priority area strengthening people-centred health systems, public health capacity and emergency (iii) addresses the need to increase access to primary care, medicine and to increase investments for health as to 
guarantee the financial sustainability of health systems (WHO Europe, 2012). The last area of action, creating resilient communities and healthy environments (iv) foresees the participation of people in the decision-making of health issues at the local level as well as reiterating the need for the conjoint tackling of potential human and environmental health (WHO Europe, 2012). The latest European Health Report (WHO Europe, 2015) has stated that, although since the 1990 s differences in child mortality and life expectancy have decreased across the Region, and notwithstanding the fact that $67 \%$ of countries of the WHO Europe region have implemented policies to address health inequalities, gaps in the SDoHs among countries of the region remain substantial. The report shows that there still is a gap of 20 deaths per 1000 life births between the lowest (2 deaths per 1000 life births) and highest (22 deaths per 1000 life births) levels within the region; a 11 years inequity gap in life expectancy, a $10.5 \%$ gap in primary education enrolment and a $30.5 \%$ inequity in unemployment. Ziglio et al. (2000 p. 151) give the following recommendations in terms of specific objectives (1-5) and critical success factors (6-10) for the development of national health promotion strategies in the European Region as to close the inequality gap among regions:

(1) Further develop political and managerial understanding of the determinants of population health and foster a focus on health rather than engagement in health care issues.

(2) Affirm the place of health promotion at the heart of social, economic and human development, and influence such development to optimize health, equity and sustainability.

(3) Encourage the establishment of infrastructures that create the capacity for sustainable intersectoral action at national, regional, local and international levels.

(4) Develop tools to assist countries and regions to assess the potential for investment in key sectors and to identify the channels of accountability for population health in those sectors.

(5) Identify incentives which would encourage all the stakeholders who are related directly or indirectly to the promotion and maintenance of the quality of life of populations to come together to work for health.

(p. 150)

(6) Creating and sustaining a national center and/or regional centers for health promotion, as part of the general arrangements for public health, to act as a focus;

(7) for analysis and action, to run country-wide and/or regional programs, and to lend support to the development of local expertise and the implementation of local programs;

(8) Establishing and sustaining local expertise in health promotion and appropriate organizational arrangements, and in acting as a local focus for intersectoral motivation, support and action;

(9) Defining the skills and expertise needed, and setting up appropriate training programmes;

(10) Enhancing capacity in relevant research disciplines and information systems. 
Further, given the broad context of the research, it has also been considered relevant to specify the consideration of health promotion within the EU's public health strategy, in turn intended to influence national health strategies. The EU's public health strategy was progressively erected throughout the 1990s; in 1998 the Maastricht Treaty gave, for the first time, a degree of legal competence to the EU in terms of quality and safety of organs and substances of human origin, blood and blood derivatives and in the field of veterinary and phytosanitary (Eurocare, 2016). The treaty of Amsterdam, signed in 1997 after the failure to protect EU citizens in the context of emergence of the BSE, whilst maintaining the principle of subsidiarity according to which national states are responsible for their own health services and population health specified that "the EU has a specific right to legislate on blood, organs and tissues (safety and quality of blood, blood derivates, human tissues and human cells used in medical treatments)" (Eurocare, 2016). The public health competences of the EU were institutionalized through the establishment of the Directorate General for Consumer Health and Safety DG Sanco within the EC (Ziglio et al., 2000; Koivusalo, 2010). Although the public health competences of the EU were in a first instance directed at health protection in a disease-oriented rather than salutogenic perspective, the SDoHs-based health promotion stance has taken ground starting from 2000s (Koivusalo, 2010). In 2006, during the Finnish presidency, the Health in All Policies (HiAP) strategy was formally adopted by the EU as a means to operationalize the notions of SDoHs, healthy public policies and multisectoral action within the EU at the level of public policies (Koivusalo, 2010). As Koivusalo (2010) explains, strengthening the critique by Ziglio et al., the HiAP frame, core to the operationalization of the health promotion approach, has since its first inception remained predominantly rhetorical, although contributing in preparing the ground for action by starting to break boundaries between health professionals and other sectors. The current EU health strategy Together for Health, adopted in 2007, officially endorses Health2020. A number of health promotion initiatives are currently being funded by the DG Sanco relative to: alcohol, effectiveness, evaluation, inequalities in health, information to patients, mental health, nutrition, physical activities, self-medication, school health, training, workplace health, coordination of health promotion networks (EC, DG Health and Consumers, accessed online 2015). The EU has stressed the relevance of multi-stakeholder initiatives involving the industry, calling for collaborations especially with the food industry (Mikkelsen, 2005). The EU Platform for Action on Diet, Physical Activity and Health was 
launched by the EC in 2006 with the intention to initiate action involving the industry, retailers, supermarkets and fast food companies (ibid).

\section{Health and health promotion issues and objectives in Portugal}

The Portuguese national health system (from now on NHS), universal, publicly funded and tendentially free, was born in 1974 after that the establishment of the democratic republic. Although installed late if compared to other European countries, in its first forty years of life the Portuguese NHS as achieved great results (George, 2012; Loureiro et al., 2013). Infant mortality rates have passed from 58 deaths for every 1000 live births in the 1970 s, to 4.6 deaths every 1000 live births in 2009; one of the lowest rates the EU (Mozzicafreddo 1992; Crisp et al., 2014). Life expectancy at birth has augmented from 64 years for men and 71 for women in 1970, to 78 (men) and 84 (women) in 2015 (Mozzicafreddo 1992; WHO, 2015). According to Mozzicafreddo (1992), in what the betterment of health outcomes has reached fore and foremost the lowest portion of the population, it can be said that the instalment of the Portuguese NHS has had a redistributive effect on the population in its first developments. At presents the major health threat is presented by the increasing rate of NCDs in an ageing population, being specific threats represented by cardiovascular diseases, cancer, diabetes, and chronic respiratory diseases (DGS, 2015). Obesity represents an issue among both adults and children, with an average of $50 \%$ of adults being overweight (1 million obese and 3.5 million pre-obese, being unhealthy nutrition indicated among the major causes for premature mortality and morbidity (ibid). Mental health represents a national issue with the population, presenting the highest level of consumption of antidepressants in the EU (15\% double of the EU average), and alcohol and tobacco consumptions have been found difficult to curb. In 2012 the Portuguese National Survey on Substance Consumption found that roughly a fourth of the population in the age group 15-64 was a smoker (ibid). According to the Global Burden of Disease Index in 2010 tobacco consumption was to be held accountable for 103 deaths each 1000.000 , whilst merely $32 \%$ of youngsters in the age group 15-24 considered tobacco to be a crucial health risk (ibid). Such issues reflect in the principal causes of premature death (below 70 years of age) in Portugal: road accidents, lung cancer, cardiovascular diseases, and suicides (George, 2012). Further these issues are to be contextualised in the perspective of the high percentage of poverty and social inequality present within the country, harshened by the economic crisis started in 2008. The reduction of poverty and social inequality 
(considered in terms of social gradient, gender and rural versus urban settings) is a major issue for health promotion, in what both poverty and social exclusion are linked with an increase of risk behaviours in terms addictive habits, mental health issues, violence, alimentary insecurity and obesity, difficulties to access services and communicate with healthcare professionals (Santana, 2002; Crisp et al., 2014; PNS, 2015). Health inequalities, together with poor behaviours and concerns about financial sustainability of the health systems represent the major threats for the Portuguese NHS (WHO Europe, 2010).

As for what concerns health promotion initiatives Santana (2002) reports that interesting governmental measures have been taken in Portugal towards the decriminalisation of drug consumption in 2001, which has led to a diminution of HIV transmission as well as of drug-related drugs. Health promotion initiatives present on an international scale, such as Healthy Cities and Healthy Schools were implemented at the level of municipalities with the National Network for Integrated Continued Care (WHO Europe, 2015). Graça (2004) points out that the progressive augmentation of occupation health standards has transformed businesses into organizations that are conducive of promoting health, expanding health and safety schemes as to include the promotion of dietary and physical habits and the reduction of addictive behaviours. Legislative measures have been taken concerning the advertising and consumption of alcoholic beverages, being advertising forbidden in sports and cultural events, and the threshold for buying alcohol enhanced to 18 years of age for all beverages (prior it was set at 16 for alcoholic drinks and 18 for spirits) (Cunha Filho et al., 2010). Still, according to Cunha Filho et al. (2010) the enforcement of such measures has often been weak. This has led to the possibility to carry out, for instance, aggressive advertising of products rich in sugars, salts and fats and poor in nutritional intake has been linked to obesity patterns in the Portuguese population, especially children, (Braga, 2007; Craveiro and Cunha, 2007). Similarly, the alcohol industry has also been accused of inciting unhealthy consumption and addictive behaviours by infringing advertisement regulation through the sponsoring of leisure and sports events, as it is the case of the Portuguese soccer team promoting the national beer brand in violation of the limits imposed by the national advertising regulation (Cunha Filho et. al, 2010). Cunha Filho et. al, (2010) point out that, in more than one occasion, the Portuguese industry has lobbied as to soften the translation of international recommendations concerning marketing, distribution and price standards of potentially harmful products into regulations applying to the Portuguese normative frameset. In this perspective, the main problem of establishing 
solid accountability patterns for corporate behaviour in Portugal has been the scarcity of organs destined to these objectives. Santana (2002) points out that little or no governmental measures have been put in place to reduce inequalities in access for rural populations and little political action has been dedicated to increase labour stability, wages and unemployment benefits specifying that initiatives have been fragmentary, based upon subsides rather than structural reforms has to curb poverty and social exclusion, and subject to political mandates and electoral requirements. Often is denunciated a lack of intersectoral dialogue and collaboration, highlighting the need to establish mechanisms for intersectoral collaboration, above all, HIA, necessary to bring forward an informed dialogue and decision-making, practice suggested to be made mandatory (Cunha Filho et. al., 2010 Instituto de Higiene e Medicina Tropical da Universidade de Lisboa, 2011). In this sense the forwarding and fostering of health promotion in Portugal is crucial in what it deals specifically with the decrease of social stratification in a social justice perspective as well as with the fostering of a whole-of-society social responsibility for health.

The Portuguese National Health Plan (from now on, NHP) is a value and actionbased health strategy, specifying values, health priorities, guidelines and measures of monitoring and evaluation, designed to be adapted to national, regional and local needs (WHO Europe, 2015). It is currently in its second window 2011-2016 that was extended to 2020. The first NHP, 2004 - 2010 was criticised from WHO Europe in its end of term of evaluation for "not being strongly linked to tools for change (contracts, regulations, performance standards) and having policy gaps" (WHO Europe, 2010 p. 2) where policy gaps are intended in terms of health inequalities, financial sustainability of the health system and quality and safety in healthcare (ibid). The evaluation also stressed the lack of interministerial and intersectoral collaboration (WHO Europe, 2010). Attention was further brought on the need to curb mortality from AIDS, cervical cancer, stroke, suicide, as well as on the need to reduce the consumption of anti-depressants (WHO Europe, 2010). The evaluation also brought attention to the fact that, notwithstanding the great infant mortality indicators, attention should be paid concerning low birth weights and pre-term weights. In 2011, slightly before the launch of the second NHP, the Portuguese General Health Directorate launched seven health priority programs with competences in terms of health promotion as well as service reorganization: 
i. The National Program for Diabetes;

ii. The National Program for HIV/SIDA infection;

iii. The National Program for Tobacco Control and Prevention;

iv. The National Program for the Promotion of Healthy Nutrition;

v. The National Program for Mental Health:

vi. The National Program for Oncological Diseases;

vii. The National Program for Respiratory Diseases;

viii. The National Program for Cardiovascular Diseases;

In 2014, in the mid-term of the second NHP before its extension was considered the report A Future for Health in Portugal, carried out by Crisp et al. (2014), through the hearing of a number of stakeholders in health brought, and sponsored by the arts and science Foundation Caluste Gulbenkian, the attention upon three major problems of the Portuguese health panorama: unhealthy ageing, financial unsustainability of the NHS as well as upon high levels of diabetes. The report explained how Portugal rates among the EU countries with the highest percentage of elderlies specifying that, although the Portuguese indicators of life expectancy and elderly population are not distant from the ones of other Western European countries, Portuguese elderly are less likely to be healthy, being the expectations for a Portuguese woman over 65 to have 9 remaining years of healthy life, compared to the 15 of Norvegian and Swedish women (ibid). Collaterally, the report points out that the Portuguese consumer and lifestyle culture promotes unhealthiness rather than health, warning that market developments transform citizens in consumers that passively buy health, rather than producing it (ibid). It also vividly highlights the need to reduce the poverty generated by the economic crisis, given its strong impact on health outcomes (ibid). Confirming what stated by literature, the report lamented a lack of intersectoral collaboration affirming that the Portuguese health system's approach had been unable to undertake the paradigmatic shift from "medical paternalism" to a "responsible partnership" purposeful to mitigating the industry-based threats to health and gain intersectoral policy coherence (ibid). In this sense, the report suggests the creation of structures for shared governance such as a National Health Council that would allow the gathering of stakeholders in a whole-of-society perspective, as well as the establishment of parallel structures at the municipal level (ibid). The extension of the NHP 2011-2016 to 2020 was intended to streamline with Health2O2O as well as to respond diagnosis of the unsolved challenges highlighted in the report $A$ Future for Health in Portugal. The extended NHP maintained its strategic axes for health 
promotion: citizenship, access, quality and solidarity, adding four targets to be accomplished by 2020 :

A. The reduction of premature mortality (<70 years) from $22 \%$ to below $20 \%$ of total deaths, namely in relation to cardiovascular diseases, cancer, diabetes, and chronic respiratory diseases;

B. The increase of healthy life expectancy at 65 years from 9,9 years (men) and 9 years (women) to 11,9 years (men) and 14 years (women);

C. To reduce the prevalence of smoking in the population of >15 years and decrease the risk of exposure to environmental tobacco smoke;

D. To limit growth in the incidence and prevalence of overweight and obesity in children.

Among the strategic issues to be achieved in the 2020 timeline the NHP stresses the need to reinforce the implementation of a whole-of-government and whole-of-society approach. In order to achieve such aim the Interim Report on the Extension of the NHP to $202 O$ redacted by WHO Europe suggested the establishment of mechanisms for the implementation of intersectoral action and a clarification of the responsibilities of each sector. In order to proceed to the clarification of responsibilities, the Interim Report suggested the carrying out of an institutional survey upon the potential contribution of different actors to the realization of the NHP at the national, regional and local levels as well as the definition of a matrix of potentially contributing programs (WHO Europe, 2015b).

\section{Health promotion in CSR}

\section{Health promotion in the CSR policy framework}

The pinpointing of the core areas of action considered by international and supranational policy approaches to CSR operated in Chapter 3, organizational governance, human rights, fair operating practices, environment, labour issues, consumer issues, community issues, science and technology, competition, taxation, and disclosure (as resumed in Table 6 of Chapter 3) is purposeful to confirm that health does not figure as a core subject within international and supranational CSR policy frameworks. Although not given prominence, it was found that health, with due differences, is considered within the CSR policy frameworks as a sub-dimension 
of the core areas of action, namely in relation to labour, consumer, community issues and the environment. The ILO Tripartite Declaration considers health as an issue for CSR practice only in terms of occupational safety for exclusively for what concerns labour issues. The OECD Guidelines contemplate health as a dimension relevant in terms of environmental and consumer issues, stressing a specific accent on the need for business entities to carry out health impacts assessments, together with environmental and safety assessments, for what concerns "processes, goods and services of the enterprises over their full life cycle" as well as to periodically review progress towards previously established targets (OECD 2000 p. 19). The UNGC's Ten Principles made no reference to health in their original formulation. Yet, a document presented by the UN Global Compact Leaders Summit in September 2013, Post-2015 Agenda and Related Development Goals: Issue Focus the Role of Business in Improving Health, intended to develop the post-2015 UNGC agenda in relation to the launch of the Sustainable Development Goals (SDGs) replacing the Millennium Development Goals (MDGs), identified health among the priority areas for businesses' socially responsible commitments (Figure 2). As it can be seen from the figure the UNGC Issue Focus considers health, together with education and empowerment, and coherently with the health promotion approach, as a resource and a need for self-help, self-management and the realization of goals and aspirations, it is to say as a social and economic right, relying upon broader social, economic and environmental determinants and ultimately leading to development and equity. The Issue Focus Issue explicitly stresses the intention to "inform governments and policy-makers of the responsible business community's willingness to promote healthy lives regardless of where people live or their ability to pay, and to broadly involve the private sector in a campaign which is so much in their direct interest as well as of universal, global benefit" (UNGC, 2014 p. 2). On these bases, it may appear that the UNGC incorporates a perspective of health promotion within its post-2015 agenda. Nevertheless, this consideration is moderated by the second part of the Issue Focus, in which the context for businesses' willingness to promote healthy lives is bound in a perspective of healthcare, private healthcare providers and pharmaceuticals, and developing countries, when the sustainable development target ${ }^{4}$ (SDGs) to which the Issue Focus makes reference, Ensure Healthy Lives and Promote Wellbeing for All Ages (UN, 2015) is much broader in scope. 


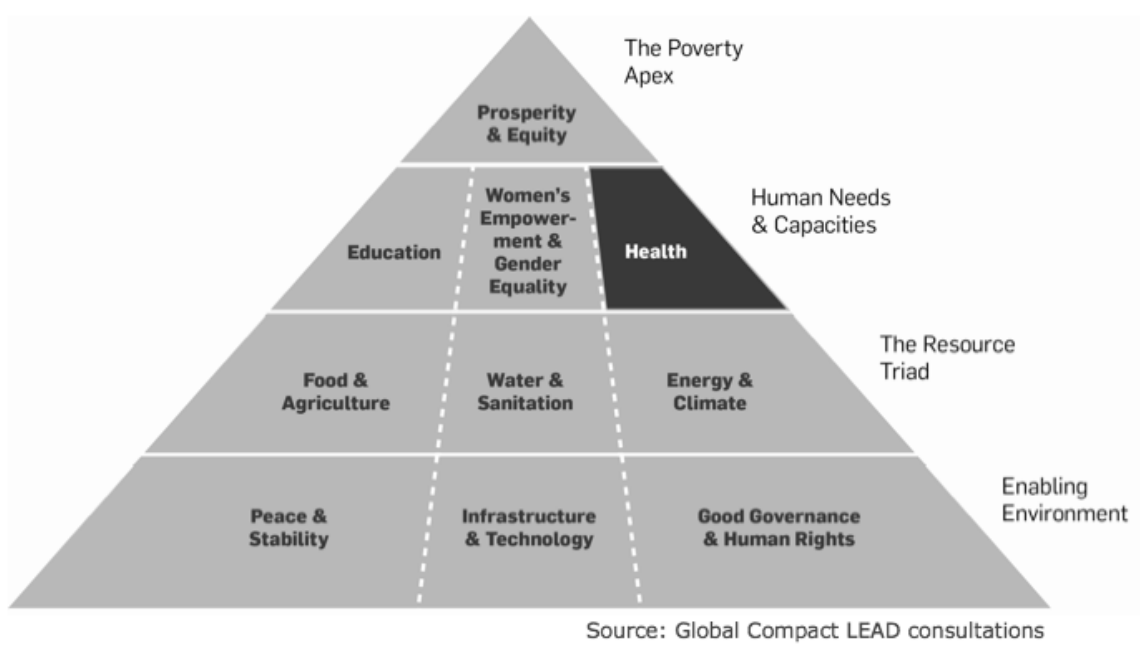

Figure 2: UNGC priority areas for the post-2015 sustainable development agenda

Source: Global Compact LEAD consultations, reprinted with the permission of Global Compact Portugal

As for what concerns UNGC's operational counterpart, ISO 26000, health is considered as a sub-dimension of labour practices (3.3), consumer issues (6.2 and community issues (7) (Table 9). Within the sub-issues of the core subject of environment, issues relevant for health such as pollution, resource use, and climate change, are also considered. Such "compartimentalized" approach to health issues may result, as highlighted by Kjergard et al. (2012), in a non-integrative approach to health, contrary to the one envisaged by the health promotion approach, considering issues as diverse, when they instead are to be understood as different facets of the same production and consumption issues. 
Table 9: Health in ISO 2600o's core subjects and sub-dimensions

\begin{tabular}{|c|c|c|}
\hline \multicolumn{3}{|c|}{ Internal Issues } \\
\hline 2. Human Rights & 3. Labour Practices & 4. Fair Operating Practices \\
\hline $\begin{array}{l}2.1 \text { Discrimination and } \\
\text { vulnerable groups }\end{array}$ & $\begin{array}{l}\text { Employment and } \\
\text { employment relationships }\end{array}$ & 4.1 Anti - corruption \\
\hline 2.2 Civil and political rights & $\begin{array}{l}\text { 3.2 Conditions of work and } \\
\text { social protection }\end{array}$ & 4.2 Fair competition \\
\hline $\begin{array}{l}2.3 \text { Economic, social and } \\
\text { cultural rights }\end{array}$ & $\begin{array}{l}3.3 \text { Health and safety at } \\
\text { work }\end{array}$ & $\begin{array}{l}\text { 4.3 Promoting social } \\
\text { responsibility in the value chain }\end{array}$ \\
\hline 2.4 Due diligence & 3.4 Social dialogue & $\begin{array}{l}\text { 4.4 Responsible political } \\
\text { environment }\end{array}$ \\
\hline $\begin{array}{l}2.5 \text { Human right risk } \\
\text { situation }\end{array}$ & $\begin{array}{l}3.5 \text { Human development and } \\
\text { training in the workplace }\end{array}$ & $\begin{array}{l}4.5 \text { Promoting social } \\
\text { responsibility in the value chain }\end{array}$ \\
\hline 2.6 Avoidance of complicity & & 4.6 Respect for property rights \\
\hline 2.7 Resolving Grievances & & \\
\hline $\begin{array}{l}2.8 \text { Fundamental principles } \\
\text { and rights at work }\end{array}$ & & \\
\hline \multicolumn{3}{|c|}{ 1. Organizational Governance } \\
\hline \multicolumn{3}{|c|}{ External Issues } \\
\hline 5. Environment & 6. Consumer Issues & 7. Community Issues \\
\hline 5.1 Prevention of pollution & \begin{tabular}{|l|}
6.1 Fair marketing, factual \\
and unbiased information \\
and fair contracting practices
\end{tabular} & 7.1 Community Involvement \\
\hline $\begin{array}{l}5.2 \text { Sustainable resource } \\
\text { use }\end{array}$ & $\begin{array}{l}\text { 6.2 Protecting consumers' } \\
\text { health and safety }\end{array}$ & 7.2 Weatth and income creation \\
\hline $\begin{array}{l}5.3 \text { Climate change } \\
\text { adaptation aand mitigation }\end{array}$ & 6.3 Sustainable consumption & 7.3 Health \\
\hline \multirow[t]{4}{*}{$\begin{array}{l}5.4 \text { Protection of the } \\
\text { environment and } \\
\text { restauration of natural } \\
\text { habitats }\end{array}$} & $\begin{array}{l}\text { 6.4 Consumer service, } \\
\text { support and complaint and } \\
\text { dispute resolution }\end{array}$ & 7.4 Social Investment \\
\hline & $\begin{array}{l}6.5 \text { Consumer data } \\
\text { protection and privacy }\end{array}$ & $\begin{array}{l}\text { 7.5 Technology development } \\
\text { and access }\end{array}$ \\
\hline & $\begin{array}{l}6.6 \text { Access to essential } \\
\text { services }\end{array}$ & $\begin{array}{l}7.6 \text { Employment creation and } \\
\text { skills development }\end{array}$ \\
\hline & $\begin{array}{l}6.7 \text { Education and } \\
\text { awareness }\end{array}$ & 7.7 Education and culture \\
\hline
\end{tabular}

Adapted from ISO 26000 
Opportunities and criticalities of CSR initiatives for health promotion: a literature review

The author divides the identified literature analysing CSR initiatives in relation to health promotion in three groupings. The first grouping deals with the CSR initiatives of sectors whose goods are considered potentially problematic in terms of health outcomes, as previously reviewed in the section concerning industrial epidemics. The articles classified as pertaining to the first grouping share the intention to understand whether CSR initiatives are apt to counteract potential threats to health related with business operations. The second grouping considers CSR initiatives in relation to occupational health, exploring the perks and drawbacks of CSR that take place through expanding the safety-based notion of occupation health into a comprehensive approach directed to foster employee wellbeing. The third grouping focuses on CSR initiatives directed to social issues and specific causes, generally loosely related to business operations, unveiling areas in which CSR initiatives are potentially apt to positively contribute, such as poverty alleviation or the building of social capital. The first grouping, addressing the CSR initiatives of sectors whose goods are considered as being potentially problematic in terms of health outcomes, finds its first focus in the analysis of the CSR health campaigns of the food industry, retailers and supermarkets. According to Mikkelsen (2005), Bhate (2007), Colls (2008), Herrick (2009), Lang (2010), Dorfman et al. (2012) and Raine (2012), CSR initiatives declaring the intention to promote health bring about a displacement of responsibilities for unhealthy eating habits from the industry to the consumer, whilst, at the same time, participate to scaling back of the government's investment in citizen and consumer protection. Lang (2010 p. 341) looks at CSR supermarket health campaigns promoting the idea of "eat well, move more, live longer", concluding they are misleading in what they incentivise exercise and fund sports equipment and structures, whilst failing to promote a reduction in eating, or proceeding on cutting on the levels of salts, fats and sugars, and portion size. Herrick (2009), looking at the CSR initiatives of the food and drink sector, re-affirms the initiatives' focus on sedentary life habits rather than product formulation and marketing, highlighting how such focus is prone to a narrow understanding of health contrary to the health promotion approach, and to dynamics of victim-blaming "cast in the language of consumer empowerment and choice" (p. 52). Herrick (2009) further considers the food and drink industry CSR-driven formulation of "healthy choices ailments" (p. 52), disposing of enhanced nutritional features, as product 
development and branding exercises that don't necessarily reflect research-based nutritional and dietary guidelines. The same author deems such efforts as being both directly and indirectly harmful, in what they position the industry in the field of health promotion education on one side and decision-making on the other (ibid). Colls (2008), looking at CSR initiatives of food retailers directed at curbing obesity in children, observes that such initiatives place the responsibility for healthy eating upon parents, adding that such exclusive consideration of responsibility is harmful in what it diminishes the possibility for the development of collective patterns of responsibility. Dorfman et al. (2012) liken the CSR initiatives of the food and drink industry, retailers and supermarkets to the ones of the tobacco industry, promoting a freedom-of-choice positive-living perspective that lightens the production and sales dimension. A second focus on the first grouping is to be found in the CSR initiatives of industry sectors associated with addictive and health-threatening behaviours: alcohol, tobacco and gambling. Babor (2009) and Babor and Robaina (2013) highlight the fact that the alcohol industry's CSR initiatives, predominantly alcohol education and prevention, research sponsorship, and alcohol control measures, do not engage interventions whose effectiveness is scientifically proven such as random breath testing and lower alcohol concentration limits. Babor (2009) and Babor and Robaina (2013) hence consider they may be used for private outcomes, such as influence research and lobby alcohol policies, or collect data upon the determinants of consumption for commercial reasons. Similarly, Sebrié et al. (2007), Friedman (2009) and Fooks et al., (2011) look at the CSR initiatives of the tobacco industry concluding they embody an effort to establish access to health authorities, normalize tobacco and reach new market niches, enhance reputation and pre-empt regulation, legitimizing private interests rather than producing positive impact on local communities, costumers and the environment. According to Fooks et al. (2011) CSR initiatives will remain public relation efforts inasmuch as managers start from the consideration that the company is already socially responsible, eliminating all possibility for self-assessment and meaningful change. Adams et al. (2009) look at the CSR initiatives of gambling operators, such as gambling codes of practice, player tracking and product modification, concluding that such practices are to gain relevance only in the case where they are made compulsory and audited.

The second grouping can be identified in the CSR initiatives directed at promoting the health of employees. According to Montero et al. (2009) CSR initiatives are apt to reinforce and add to traditional occupational health and safety measures by promoting a culture of prevention through fostering awareness, motivation and 
shared solution seeking. Sorensen (2011) considers health literacy to be the most relevant channel through which CSR initiatives can foster employee wellbeing, providing capabilities and motivation for change. Allender (2006) and Holmqvist (2009) don't share the same enthusiasm concerning the opportunities for employee health promotion embedded in CSR initiatives. According to the authors although CSR employee health promotion initiatives may appear at as a classic win-win instruments, they potentially hinder mechanism of organizational control promoting behaviour adjustments, for instance concerning physical activity, food and drink consumption and sleep routines adjusted towards productivity rather than the employees aspirations that trespass the workplace boundaries and obligations. Finally Radacsi and Hardy (2014) research the availability of CSR initiatives addressing substance misuse, prescription drug abuse and alcohol abuse, a relevant issue in work environments in Hungary, finding little evidence of pertinent initiatives. They concluded that unpleasant issues, such as the one of substance misuse, may fail to be acted upon due to the weakness of representing stakeholders and reluctance of company managers linked to the stigma.

The third grouping considers the potential for business entities to intervene in social issues as to foster social change and social inclusion. Du et al. (2008) focus on oral hygiene campaigns promoted by cosmetic companies among Hispanic communities in the US, concluding that such campaigns are apt to promote healthy hygienic behaviours in less acculturated communities whilst simultaneously creating a space for moderating acculturation. Persson (2008) focuses on the Danish context, observing that CSR initiatives may be a vehicle for sports entities to participate to the Danish social policy agenda through initiatives that bring together individuals from different environments, thus increasing social capital at the local level and participating to social integration and health promotion. On this point Petersson (2008) observes that the notions of CSR and social capital bear resemblances, in what they rely on values and norms and are directed at fostering networks and trust concluding the need for public authorities to acknowledge such potential positive externalities. Bunde Birouste et al. (2008) look at a CSR-based sports initiative in Australia organized conjointly by a corporate sponsor and a community-based organization, highlighting its potential for positive social change notwithstanding the punctual issues arising from the management of such program among the two parties involved. Henderson et al. (2014) consider the CSR initiatives of UK football clubs directed to reduce stigma upon mental issues, concluding that the initiatives were 
found to create a number of benefits, among all increased social capital at the local level and a better understanding of both the problem and the intervention.

The literature review insofar carried out lends itself to a number of considerations. First and foremost that CSR initiatives are considered, on a general basis, as conducive to positive health promotion outcomes, when they deal with positive commitments, it is to say when they engage the ability side of CSR, the one that envisages the potential for business entities to expand their contribution to society. In this case only issues connected with the implementation of multi-stakeholder alliances are identified (Bunde-Biruste et al. 2010). A second consideration to be made is that CSR initiatives are considered in consistently negative terms when they are put in place by business actors whose products is considered as being problematic or potentially problematic in health terms. The main concerns found in literature relate to the fact that CSR initiatives do not aim at counteracting harmful business practices, such as advertising and marketing, and product placement or disposal. Instead, they are found to address the behaviours of end users; either directly, as it is the case for behaviours related to addictive substances, or indirectly, as it is the case for the food industry that balances alimentary habits with the argument of physical activity. Not only such CSR initiatives are deemed to be ineffective, but potentially harmful, in what they lead to a diminishment in public investment as well as to dynamics of co-regulation. As for what concerns the potential for CSR initiatives to beneficially contribute to employee health promotion, as we have seen, the perspectives are divergent. A number of recommendations were found in literature. At the level of societal governance, research is required to identify mechanisms and structures to: guarantee the transparency of the cooperation between corporations and relevant stakeholders, namely policy-makers and public research organizations (Fooks et al., 2011); supervise particular CSR initiatives and guarantee their alignment with public needs as well as harness and shape CSR for public heath objectives (Babor and Robaina, 2013). Concerning practice it is recommended, at the level of business governance, that CSR initiatives should follow a consideration of fundamental changes in the business model and leadership perception (Radacsi and Hardy, 2014; Fooks et al., 2011), be carried out according to definite and measurable objectives (Werner, 2009), and ensuring of competent coordination and forcible role attribution in partnerships with the third sector (Bunde Birouste et al., 2010), and finally, in the existence of safeguards and sanctioning to avoid CSR-driven funding conflicts of interest (Babor, 2009). 
Portuguese public sector health promotion experts' perceptions on CSR initiatives for health promotion

Although admitting that the involvement of the business sector in health promotion is welcome on general grounds, when questioned concerning CSR initiatives tackling health outcomes, three out of seven health promotion experts expressed being very sceptical towards their potential to contribute to health promotion in Portugal, two respondents depicted themselves as cautious, whilst the remaining two expressed viewing CSR initiatives as a positive ground of opportunity for health promotion. The nature of the commitments is put in question on the basis of the existence of tradeoffs between profits and public health interests. Accordingly, in the view of health promotion experts, CSR practice is considered as instrumental to the pursuit of reputational, strategic and commercial objectives, being social commitments secondary and conditional to the fulfilment of a business opportunity. Given that CSR practices are perceived as following a rationale of opportunity, health promotion experts explicit the preoccupation that the range of action and potential effectiveness of CSR initiatives for health promotion may be limited. This point is elucidated by the public health expert speaking for the Priority Program on HIV, who manifests the difficulties encountered in the pursuit of business sponsors for the activities of the Priority Program: "it is a transmittable disease associated with sexual and addictive behaviours upon which weigh stigma and discrimination. Businesses don't want to associate their brand to the HIV cause as they fear it will damage the clean image they wish to transmit" (free translation). An additional aspect generating mistrust in terms of commitment, is the perception that CSR management positions are occupied by marketing representatives, as affirmed by the respondent from the Healthy Nutrition Priority Program, further adding that the scope of CSR should be re-oriented towards corporate governance, rather than directed to impress the consumer as it is currently.

The respondent from the Presidency of the Health Directorate expressed concerns relatively to the scarce impact of CSR initiatives for health promotion, perceived as related to the initiatives' limited number, small portion of population reached, punctual, project-based nature of commitments, and finally, because they lack an alignment with public health promotion objectives. According to the respondent from the Priority Program on HIV, the main limitation of CSR initiatives is to be found in the business sector's lack of sufficient awareness and sensitiveness to social issues. The respondent from the Priority Program on HIV specifies that although business 
actors are sensitized for what concerns their role as employers and attentive of workers' needs, the same cannot be said for what concerns their role as societal actors. The respondent for the Mental Health Program clarifies a standpoint according to which not only CSR initiatives may not be apt to produce beneficial impacts in terms of health promotion, but may hinder negative externalities deriving from the vested manipulation of public health messages for business interests, such as the promotion of brand or products. Among the respondents expressing a cautious posture the interviewee from the Healthy Nutrition Priority Program adds the perception that CSR practice is growing, and that it may have greater reach than what is believed to have by the public health community, although, is added, this is only an impression given the lack of studies on the subject. CSRHPIs could have a great function in generating social change, especially at the local level, a former General Health Director complements. Among the health promotion experts that declare to view CSRHPIs as potentially producing positive impacts in health promotion, are the respondents from the Priority Program for Cardiovascular Diseases and the Priority Program for Diabetes. The former considers that CSRHPIs could have a great utility in leading health-related values and messages, whilst the latter suggests that CSRHPIs are both useful and effective, and that they would have a greater reach and an increased alignment with public objectives if public authorities accepted to approximate themselves to businesses, lowering their antagonistic stance.

For what concerns experiences of CSR-based cross-sectoral collaboration, among the seven interviewees, two respondents identified their department as having punctual CSR-based collaborations and two to have permanent collaborations, whilst the remaining declared having no experience of collaboration. Punctual collaborations are carried out through the reception of in-kind or financial sponsors for prompt initiatives, as it is the case of the HIV Priority Program, or by the offering of technical advice under request, as it is the case of the Priority Program for Cardiovascular diseases. Permanent collaborations are realized through health promotion experts' consultation and validation of CSR initiatives. The respondent from the Diabetes Priority Program, involved in permanent CSR-based collaboration with business entities, clarified the department's initiative to create a seal of approval for CSRHPIs submitted to the attention of the department. The seal of approval, that in the respondent's words serves the double purpose of legitimising and giving transparency to CSR initiatives through giving evidence of the endorsement of the Priority Program's public authority, is granted after an assessment verifying its coherence with the Program's strategy and, when needed, after the inclusion of 
suggested modifications. The second respondent engaging in permanent collaboration, from the Healthy Nutrition Priority Program, carries a similar posture, although without the seal of approval tool. His experience includes counselling of business entities to help select best-candidate initiatives among a range of tentative CSR initiatives submitted by businesses to the department's attention, or facilitating the interaction of business actors with health actors. All respondents agree on the need for the public sector to further its involvement in CSR; merely the respondent for the Mental Health Priority Program advocates the need for regulation, whilst the general approach is one calling for the public sector's monitoring, endorsement and facilitation of CSR practices. Foremost obstacles to the involvement of business actors are identified in the scarce focus set on health promotion as opposed to healthcare within the Portuguese health system, the lack of tradition of business public collaboration in Portugal, and the fear to be tied by commercial vincula in the case of engaging in collaboration. As reported by the representatives of the Mental health, Cardiovascular Diseases and Healthy Nutrition Priority Programs, to scarce focus on health promotion in Portugal is to be ascribed to a failure of public political powers in stressing sufficient accent on the importance of health promotion in the operationalization of the PNHP, as activities so far engaged by Priority Program departments have been directed to the reorganization of health services, having just few, unsystematic health promotion campaigns been launched up to 2012. Further, as the General Health Directorate spokesperson points out, the strict separation among economic sectors and the lack of a tradition of intersectoral collaboration is an heritage of the ostracizing attitude towards private initiative that followed the Revolution of the 25th of April 1974, reflection that mirrors the portrait of the Portuguese context delineated in Chapter 3. This refute towards cross-sectoral collaboration creates, according to the spokesperson for the Diabetes Priority Program a context of "out of reality" sectoral isolation, where scepticism, instead of leading to further monitoring, sets the case for a complete unconcern of the public sector towards CSR, when instead it could have represented a space for dialogue, sensibilization and co-optation of investments. According to the respondents involving in permanent collaborations the concern should be to create proactive involvement. A proactive stance of the Priority Programs' departments would be desirable, for instance, in suggesting initiatives, or recruiting partners or investors for initiatives that are believed to be relevant at a public health promotion levels but for which no public funds are made available. According to the respondent from the Healthy Nutrition Priority Program the lack of resources is the main limitation to a proactive approach; situation which leaves public actors which insufficient time and 
planning resources to instruct and recruit business actors to participate in the planning or implementation of initiatives that follow the goals and objectives of the Priority Program agenda, rather than the other way round. In order for the public sector to engage in the monitoring, endorsement and facilitation of CSR initiatives, health promotion experts indicate the need for the creation and reinforcement of channels and structures for cross-sectoral communication, in national forums, for instance, as it has been the case for the National Platform Against Obesity (Plataforma Contra a Obesidade) or through intersectoral bodies, as it is the case for the High Commissary of Health. The creation of structures for intersectoral dialogue is believed to create space and stimuli to foster awareness and articulation with public priorities believed to be key to increase commitment and investment. Additional means of facilitation are identified in the establishment of mechanisms of validation, such as seals of approval, and fiscal incentives. Finally the public sector is indicated as having a responsibility towards the scientific assessment of CSR initiatives, conducive to understand their potential to create impacts in general and for what concerns health in particular. 


\section{Chapter 5: Real-world CSR practices relevant for health}

Chapter 4 ended by bringing together the spheres of CSR and health promotion. In a first instance, by analysing how health is considered within the main CSR policies, successively by portraying the main opportunities and criticalities for health promotion inherent to CSR practices as identified in international literature and as perceived by a number of health promotion experts at the head of the Portuguese General Health Directorate Priority Health Programs. As a successive step it was considered relevant to explore the opportunities and criticalities for health promotion inherent to CSR practices by looking at real-world case studies. As previously mentioned, the case studies of CSR health promotion initiatives (CSRHPIs) serve the purpose of delineating how CSR practices for health promotion work, by portraying in detail their specificities of formulation and of implementation. The comprehension of their functioning will serve as a basis for the researcher to discuss the dilemmas, contributions and inherent limits that CSR initiatives pose to health promotion as identified by literature review and health promotion experts, information that will constitute the basis of analysis and conclusions of Chapter 6 (forthcoming). As to prepare the ground for the case studies, the present chapter begins by briefly introducing general features of the business entities implementing the CSRHPIs as well of their CSR strategies. It continues by depicting the CSRHPIs, coherently with the stages heuristic approach, in their phases of initiative formulation, design and implementation. Were considered as features of initiative formulation: the criteria motivating the choice of a given initiative as well as the sources of information supporting such choice. Were considered as features of initiative design: the objectives set, beneficiaries intended and focus of each CSRHPIs. Finally, as for what concerns the phase of implementation, timeframe, reach and implementation of each CSRHPI were portrayed. The third section of the chapter reports the perceptions of the involved actors, CSR managers and managers of the social partners of collaborative CSRHPIs, concerning the limits and opportunities inherent to the CSRHPIs as well as their causes, thus preparing the grounds for the researcher's analysis of causes, also operated in Chapter 6. 


\section{Introducing the CSRHPIs}

As briefly addressed in Chapter 2 the companies participating in the study are predominantly MNEs, exception made for E2 and E3, which are domestic companies, all with national headquarters in the Lisbon metropolitan area. Table 10 furnishes some basic information concerning the CSR strategy of the companies participating in the study, reminding the reader that the code (A) is used to identify companies pertaining to the pharmaceutical sector, (B) for PHPs, (C) for ICTs, (D) for food retailers, (E) for the hotel sector. The dimensions of inherent to CSR strategy portrayed are: responsible department, beginning of strategy, existence of a local report, and policy references engaged for strategy formulation. It was considered relevant to begin by stressing out the departmental affiliation of the CSR manager as, as pointed out in Chapter 3, the way in which a given company considers CSR practices is mirrored in the CSR department's affiliation. The first formulation of a CSR strategy as well as the existence of a national CSR report give us indication concerning the state of development of CSR practices in each company as well as specify the existence of a national, as opposed to global approach in the case of MNEs. Finally the specification of the policies used as reference to formulate initiatives serve to confirm the information given in Chapter 3 concerning the prevalence of the UNGC/ISO referential for the case in analysis and detect, when relevant, additional policy references engaged.

Table 10: Dimensions of CSR management

\begin{tabular}{|lllll|}
\hline Company & Department responsible for CSR & Launch of CSR strategy & Reporting & Policy reference \\
\hline A1 & Marketing & 2012 & Global & UNGC \\
A2 & Communication and Drug Access & 2004 & Global & UNGC \\
A3 & External Affairs and Policy & 2004 & Global & UNGC \\
\hline B1 & Marketing & under construction & - & \\
B2 & Board of Administration & 2000 & National & UNGC \\
B3 & Board of Administration & 2007 & National & EU Strategy \\
\hline C1 & Sustainability and Quality & 2008 & National & UNGC \\
C2 & CSR and Foundation & 2003 & National & UNGC \\
C3 & CSR and Foundation & 2001 & National & UNGC \\
\hline D1 & Nutrition, Health and Wellness & 2005 & National & \\
D2 & Public Relations & 2008 & National & UNGC \\
D3 & Nutrition & 2009 & National & \\
\hline E1 & CSR & 2011 & National & UNGC \\
E2 & Sustainability & 2010 & - & \\
E3 & Quality and Environment & 2011 & - & \\
\hline
\end{tabular}

As for what concerns the departmental affiliation of CSR management, it can be said that CSR practice is approached in three manners by the companies participating in 
the research: as an issue of competence of the board of administration (B2 and B3), as an issue of competence of a department/manager solely responsible for CSR, where the notion of CSR is understood in a broad sense and used interchangeably with the notions of sustainability and quality $\left(\mathrm{C}_{1}, \mathrm{C}_{2}, \mathrm{C}_{3}, \mathrm{E} 1, \mathrm{E} 2 \mathrm{and} \mathrm{E}_{3}\right)$, as an issue whose competence is attribute to a previously existing department, such as those of marketing, communication, external affairs, nutrition, public relations and nutrition, health and wellness (A1, A2, A3, B1, D1, D2, D3). Although it is beyond the scope of this research to discuss industry trends, some common points were found among the companies pertaining to the same industries. The companies representative of the pharmaceutical sector participating in the study address their CSR practice in terms of external affairs and communications, PHP companies as an issue of competence of the board of administration, ITCs and hotel industry companies as a separate issue both related to quality and philanthropy, whilst food retailers relate it to product management and public relations. The timeline of uptake of CSR strategies ranges from 2001 to 2012. All three companies pertaining to the hotel industry have CSR strategies formulated after 2010, and hence comparatively more recent in relation to the other; yet this result is to be explained by the fact that two out of the three companies opened at the end of the first decade of 2000. For the remaining companies, the launch of a CSR strategy starting soon after the beginning of this century can be explained coherently with the establishment of the UNGC Initiative in 2000 and the subsequent mainstreaming of CSR practice explained in Chapters 1 and 3. PHPs, ICTs and food retailers all dispose of national CSR reports whilst pharmaceuticals and companies from the hotel industry do not. The reason for the lack of local reports of the two industries are divergent: in the case of pharmaceuticals, this is due to the fact that CSR departments follow global, rather than local approaches, whilst in the case of the hotel industry this can be explained in terms of a scarce development of CSR strategies, at the time of redaction only reported through webpages instead of reports. The CSR policies referenced as constituting basis for the formulation of CSR strategies are (predominantly) the UNGC and the EU's Strategy for Corporate Social Responsibility. None of the interviewees declared following the OECD Guidelines or the ILO Tri-partite Declaration, or even the UNGC Initiatives' operational counterpart ISO 2600o. The predominance of the use of the UNGC Initiative as a reference over other international and supranational CSR policies is in line with the information provided in Chapter 3, stating that the UNGC Initiative and ISO 26000 are the main referential for the context in analysis. Its streamlining and eradication within the CSR practice of the Portuguese business environment is to be linked to the 
communication and dissemination efforts of the APEE, country ambassador of the UNGC Initiative, and arguably the most active CSR private association in Portugal, as also pointed out in Chapter 3. The lack of mentioning by the CSR representatives of the UNGC Initiatives' operational counterpart, ISO 26000, can be explained by the fact that the standard was only normalized in Portugal in 2011 (NP ISO 26000:2011) and it had not been incorporated by the companies at the time of interviews beginning in early 2013. Indeed the first company to begin the process of evaluation and integration of practices contemplated by NP ISO 26000 in Portugal was one of the ITCs participating in the research. The ICT integrated the NP ISO 26000 in June 2013, short after being interviewed for the present research.

Table 11: Juxtaposition of general CSR statements and areas of action

\begin{tabular}{|c|c|c|}
\hline & General CSR statement & CSR Areas of Action \\
\hline $\begin{array}{l}\text { A1 } \\
\text { A2 } \\
\text { A3 }\end{array}$ & $\begin{array}{l}\text { "To invest in the community, commit workers and make a difference in society" } \\
\text { "Understanding how we can collaborate with other private entities or the state" } \\
\text { "Collaborate with the community in which we are inserted" }\end{array}$ & $\begin{array}{l}\text { Community; Labour } \\
\text { Community } \\
\text { Community }\end{array}$ \\
\hline $\begin{array}{l}\text { B1 } \\
\text { B2 } \\
\text { B3 }\end{array}$ & $\begin{array}{l}\text { "Improving the quality of life of our patients" } \\
\text { "Betterning and widening our services and opening to communities" } \\
\text { "Dedicating ourselves to the community, not necessarily for what concerns health" }\end{array}$ & $\begin{array}{l}\text { Consumer } \\
\text { Consumers; Community } \\
\text { Community }\end{array}$ \\
\hline $\mathrm{C} 1$ & "The way in which we manage our organization, our environmental footprint, our & Organizational Governance; \\
\hline C3 & $\begin{array}{l}\text { "Creating shared value for all involved parties through our technologies and managing } \\
\text { social, environmental resources with ethics, accountability and dialogue" } \\
\text { "Responsible business management, staff relations and positioning technology towards } \\
\text { the public" }\end{array}$ & $\begin{array}{l}\text { Consumer; Organizational } \\
\text { governance; Fair operating practices } \\
\text { Organizational governance; Labour; } \\
\text { Consumer }\end{array}$ \\
\hline D2 & $\begin{array}{l}\text { "To create shared value through enhancing nutritional behaviours in our consumers, } \\
\text { educating our staff and creating partnerships with scientifc associations" } \\
\text { "Promoting healthy lifestyles in consumers, communities and staff and protecting the } \\
\text { environment" } \\
\text { "To create health through nutrition, respect the environment, buy responsibly, support } \\
\text { envolving communities and be a reference employer" }\end{array}$ & $\begin{array}{l}\text { Consumer; Labour; Community } \\
\text { Consumer; Community; Labour; } \\
\text { Environment } \\
\text { Consumer; Environment; Fair } \\
\text { operating practices; Community; }\end{array}$ \\
\hline E1 & $\begin{array}{l}\text { "Being a reference employer, paying attention to the enviroment and furthering links with } \\
\text { envolving communitites" }\end{array}$ & Labour; Environment; Community \\
\hline E2 & $\begin{array}{l}\text { "Paying attention to the environment, deepen relationships with communities and staff } \\
\text { and motivate the citizen in general" }\end{array}$ & Environment; Community; Labour \\
\hline E3 & "Having special sensibility to social, envirionmental and financial concerns" & Organizational Governance \\
\hline
\end{tabular}

Table 11 over poses each company's CSR general statement with the areas of action for CSR individuated in Chapter 3 (Table 8 p.97). The areas of action addressed by each statement were reported in order of priority given by the CSR manager. General CSR statements can be described as the core of each company's self-presentation concerning CSR addressed to the public, highlighting key issues of commitment and main stakeholders, and, at times, further clarifying the principles or operational forms undertook to address commitments and relationships (Snider et. al, 2003). As made clear in Chapter 3 the areas of action identified by CSR policies refer to the stage of agenda-setting, delineating broad areas among which specific issues are to be 
chosen. Also in this case, some common patterns concerning the prioritization of areas of action can be detected among the companies according to their industry of affiliation. For instance, it can be observed that pharmaceuticals and PHPs consider fewer areas of action than companies pertaining to the remaining industries, respectively, community and labour issues, and consumer and community issues. Companies pertaining to food retail, ICTs and the hotel industry mention a wider range of areas of action within their statements. ICTs take prioritize the area of action of organizational governance, followed by air operating practices, and environment, consumer and labour issues. Food retailers, whilst roughly considering the same areas of action of ICTs (minus organizational governance) pose priority upon consumer issues. Hotel companies consider both labour, community and environment issues together with organizational governance. These findings resonate, to some extent, with what discussed concerning the department of affiliation of CSR management, which indicated that CSR practice was dealt as an external affairs issue by companies pertaining to the pharmaceutical sector, as a competence of the board of administration for ICTs and in relation to product management for food retailers. Worth mentioning, is the fact that the companies pertaining to the pharmaceutical sector participating in the study address their CSR practice in terms of external affairs and communications, PHP companies as an issue of competence of the board of administration, ITCs and hotel industry companies as a separate issue both related to quality and philanthropy, whilst food retailers relate it to product management and public relations. Worth stressing out is that the area of action of community involvement, which has been used in Table 11 to designate all intention to establish and reinforce involvement with third parties, fails to picture the diversity of actors and objectives embedded within third-party link establishment as those, for instance, intended with the CSR general statement "understand how we can collaborate with other private entities or the state" (A2). Stakeholders considered are, as we will see in the forthcoming section, not solely communities intended as social units, but social representatives such as civil society actors or public authorities, for which the categorization within the sphere of community appears reductive and misleading. From the portrait of the policy references used to formulate CSR strategies it has been possible to note that no public health or health promotion references, neither national nor international, were engaged by any of the interviewees to contextualize activities directed at promoting health. This finding is expected in the perspective that health promotion has not insofar been individuated as an area of intervention in CSR practice, as we have seen in the previous section. 


\section{Presenting the CSRHPIs}

The forthcoming section is dedicated to presenting the case studies. Table 12 shows that a universe of 53 CSRHPIs was found among the selected companies. The initiatives in bold are the CSRHPIs selected as case studies, separately listed in Table 13 accompanied by the code with which they will be indicated throughout this Chapter. Coherently with the stages heuristic approach each CSRHPI will be depicted concerning specificities of formulation and implementation. Worth reminding the reader, as already specified in Chapter 2, is that the fifteen CSRHPIs were selected at the sectoral, as opposed to the company level. The code a1, for instance, does not refer to the company indicated as A1 in the previous section. Coherently with what explained in Chapter 2, it refers to the CSRHPI case study for an in-house initiative realized by one of the companies pertaining to the pharmaceutical sector, the code b2 to a partnering initiative implemented by a PHP company, the code c3 to a sponsoring initiative realized by a ICT company, and so on.

Table 12: Universe of CSRHPIs found within the selected companies

\begin{tabular}{|c|c|c|}
\hline In-house & Partnering & Sponsoring \\
\hline \multicolumn{3}{|c|}{ (A) PHARMACEUTICALS } \\
\hline $\begin{array}{l}\text { Cais at work } \\
\text { Diverse awareness campaigns } \\
\text { Research and Development }\end{array}$ & $\begin{array}{l}\text { Mental health program for youngsters } \\
\text { Senior health promotion project }\end{array}$ & $\begin{array}{l}\text { Donation of ailments } \\
\text { Scientific prizes } \\
\text { Sponsoring of patients' associations }\end{array}$ \\
\hline \multicolumn{3}{|c|}{ (B) PRIVATE HEALTHCARE PROVIDERS } \\
\hline $\begin{array}{l}\text { External quality certification } \\
\text { Community health Information, } \\
\text { prevention and screening activities } \\
\text { Patient holydays } \\
\text { Personalized clinical pathways } \\
\text { Risk management for error containement }\end{array}$ & $\begin{array}{l}\text { Food Reciclying Initiative } \\
\text { Health workshops } \\
\text { Priority treatment for local institutions } \\
\text { School health education } \\
\text { Transplant campaign }\end{array}$ & $\begin{array}{l}\text { Scientific prizes } \\
\text { Social marketing } \\
\text { Sponsoring of caregivers' association } \\
\text { Sponsoring of equipment for medical units }\end{array}$ \\
\hline \multicolumn{3}{|c|}{ (C) INFORMATION AND COMMUNICATION TECHNOLOGIES } \\
\hline $\begin{array}{l}\text { Children online safety initiative } \\
\text { Measurement of electromagnetic waves }\end{array}$ & $\begin{array}{l}\text { Accessible design technologies } \\
\text { Healthcare information systems } \\
\text { Remote medical consultations } \\
\text { Remote control of new-borns in hospitals } \\
\text { Texting and driving campaign }\end{array}$ & $\begin{array}{l}\text { Blood collection } \\
\text { Bone marrow collection } \\
\text { Social marketing reverting to mobile healthcare units } \\
\text { Sponsoring of research on electromagnetic } \\
\text { waves } \\
\text { Sponsoring of the construction of a pediatric hospital }\end{array}$ \\
\hline \multicolumn{3}{|c|}{ (D) FOOD RETAIL } \\
\hline $\begin{array}{l}\text { Ailments with positive health claims } \\
\text { In-store nutritional education }\end{array}$ & $\begin{array}{l}\text { Food policy } \\
\text { Food Recycling }\end{array}$ & $\begin{array}{l}\text { Fundraising reverting to NGO dealing with blindness } \\
\text { Social marketing reverting to various } \\
\text { healthcare initiatives } \\
\text { Sponsoring of a rare pathologies care unit } \\
\text { Sponsoring of food coupons } \\
\text { Sponsoring of "Healthy walks" } \\
\text { Sponsoring school breakfast initiative }\end{array}$ \\
\hline \multicolumn{3}{|c|}{ (E) TOURISM } \\
\hline $\begin{array}{l}\text { SPA and Feng-Shui treatments } \\
\text { Venues' safety standards }\end{array}$ & $\begin{array}{l}\text { Co-organisation of the Terry Fox Run } \\
\text { Food reciclying initiative } \\
\text { Organic, gluten-free, vegeterian and } \\
\text { menu options }\end{array}$ & $\begin{array}{l}\text { Social Marketing reverting to NGO dealing with } \\
\text { dignity in death } \\
\text { Social Room Initiative } \\
\text { Sponsoring of NGOs dealing with autism } \\
\text { Sponsoring of NGOs dealing with oncology }\end{array}$ \\
\hline
\end{tabular}


Table 13: List of selected case study CSRHPIs

\begin{tabular}{|c|c|c|c|}
\hline Sector & Code & Initiative & Initiative Type \\
\hline A & $\begin{array}{l}\text { a1 } \\
\text { a2 } \\
\text { a3 }\end{array}$ & $\begin{array}{l}\text { Cais at Work } \\
\text { Mental Health Program for Youngsters } \\
\text { Sponsoring of patients' associations }\end{array}$ & $\begin{array}{l}\text { In - house } \\
\text { Partnering } \\
\text { Sponsoring }\end{array}$ \\
\hline B & $\begin{array}{l}\text { b1 } \\
\text { b2 } \\
\text { b3 }\end{array}$ & $\begin{array}{l}\text { Patient holydays } \\
\text { School health education } \\
\text { Sponsoring of caregivers association }\end{array}$ & $\begin{array}{l}\text { In - house } \\
\text { Partnering } \\
\text { Sponsoring }\end{array}$ \\
\hline C & $\begin{array}{l}\text { c1 } \\
\text { c2 } \\
\text { c3 }\end{array}$ & $\begin{array}{l}\text { Children online safety initiative } \\
\text { Accessible design technologies } \\
\text { Sponsoring of research on electromagnetic waves }\end{array}$ & $\begin{array}{l}\text { In - house } \\
\text { Partnering } \\
\text { Sponsoring }\end{array}$ \\
\hline D & $\begin{array}{l}\text { d1 } \\
\text { d2 } \\
\text { d3 }\end{array}$ & $\begin{array}{l}\text { In-store nutritional education } \\
\text { Food policy } \\
\text { Sponsoring school breakfast initiative }\end{array}$ & $\begin{array}{l}\text { In - house } \\
\text { Partnering } \\
\text { Sponsoring }\end{array}$ \\
\hline$E$ & $\begin{array}{l}\text { e1 } \\
\text { e2 } \\
\text { e3 }\end{array}$ & $\begin{array}{l}\text { Spa and Feng-Shui treatments } \\
\text { Food reciclying initiative } \\
\text { sponsoring of association for autistic sindrome }\end{array}$ & $\begin{array}{l}\text { In - house } \\
\text { Partnering } \\
\text { Sponsoring }\end{array}$ \\
\hline
\end{tabular}


Table 14: Description of CSRHPIs of pharmaceutical companies

\begin{tabular}{|c|c|}
\hline \multicolumn{2}{|r|}{ (A) PHARMACEUTICALS } \\
\hline In-house & a1) Cais at work \\
\hline Overall description & $\begin{array}{l}\text { The initiative is a small social entrepreneurship initiative offering } \\
\text { shopping and errand services to employees in the workplace. The } \\
\text { service is carried out by previously homeless or convicted citizens, } \\
\text { with the objective of contributing to their social insertion whilst sparing } \\
\text { employees of some routine chores. }\end{array}$ \\
\hline Evidence-basis & None disclosed \\
\hline $\begin{array}{l}\text { Design } \\
\text { Implementation }\end{array}$ & $\begin{array}{l}\text { The initiative model, conceived and planned by company employees } \\
\text { has been taken on by neighboring companies, participating in the } \\
\text { diffusion of CSR practices. No set timeframe. }\end{array}$ \\
\hline Assessment & NA \\
\hline Partnering & a2) Mental Health Program for Youngsters \\
\hline Overall description & $\begin{array}{l}\text { The initiative is the local adaption of the corporate global CSR Health } \\
\text { Program for Youngsters. For Portugal, the selected health youth issue } \\
\text { was mental health. In specific, the initiative aims to increase self- } \\
\text { esteem through after-school group sessions dealing with sensitive } \\
\text { themes such as addiction, bullying, school failure, and more. }\end{array}$ \\
\hline Evidence-basis & $\begin{array}{l}\text { The initiative references the Portuguese National Health Plan for } \\
\text { Mental Health (2007 - 2016), a consultation with professor from the } \\
\text { Superior Institute of Health Sciences in Lisbon working on mental } \\
\text { health in youth, and the endorsement of the Portuguese secretary of } \\
\text { state. }\end{array}$ \\
\hline Design & $\begin{array}{l}\text { The mental health theme was defined by the company, whilst } \\
\text { project's, population, timeframe and specific objectives were defined } \\
\text { conjointly. }\end{array}$ \\
\hline Implementation & $\begin{array}{l}\text { The program reaches a population of } 100 \text { youngsters between } 10 \text { and } \\
12 \text { years of age in } 7 \text { social neighborhoods of the Lisbon metropolitan } \\
\text { area. Group sessions, held by NGO social workers, follow a bottom- } \\
\text { up approach of participation addressing themes through debate and } \\
\text { games. Resources made available by the company consist of full } \\
\text { financial sponsoring (not disclosed)and volunteering staff. Participants } \\
\text { in the project and their parents are informed on the responsibilities of } \\
\text { parties involved and source of sponsoring. Timeframe 2012-2015. }\end{array}$ \\
\hline Assessment & $\begin{array}{l}\text { The project is ongoing and has not been assessed to date. A } \\
\text { comparison between on mental health competence based on an } \\
\text { evaluation administered on youngsters before and after the } \\
\text { implementation of the project is planned following implementation. }\end{array}$ \\
\hline Other & $\begin{array}{l}\text { The program overlaps an existing educational program from the } \\
\text { Ministry of Education and Social Solidarity, adding hours to the time } \\
\text { the social workers spend with the children as to } \\
\text { "complement/reinforce already existing resources, without duplicating } \\
\text { or substituting their intervention, but becoming part of it". }\end{array}$ \\
\hline Sponsoring & a3) Sponsoring of patient association \\
\hline Overall description & $\begin{array}{l}\text { The initiative foresees the permanent sponsoring of one of the main } \\
\text { Portuguese patient associations for rheumatoid arthritis, of the } \\
\text { therapeutic areas of business of the pharmaceutical company. Among } \\
\text { the objectives of such sponsoring in a company perspective figure the } \\
\text { validation of self-assessment measurement tools and learning from } \\
\text { the patients perspective. }\end{array}$ \\
\hline Evidence-basis & None disclosed \\
\hline Funding & $\begin{array}{l}\text { Funding relies on : a) a written proposal on the project, including the } \\
\text { ways in which the funding will advance educational and disease- } \\
\text { awareness objectives and an internal company review; b) consistency } \\
\text { with corporate policies and procedures, including those related to } \\
\text { contributions; advertising and promotion; sales and marketing; and } \\
\text { ethical business practices. }\end{array}$ \\
\hline Implementation & None disclosed \\
\hline Assessment & None disclosed \\
\hline
\end{tabular}


Table 15: Description of CSRHPIs of private healthcare providers

\begin{tabular}{|c|c|}
\hline \multicolumn{2}{|r|}{ (B) PRIVATE HEALTHCARE PROVIDERS } \\
\hline In-house & b1) Patient Holydays Abroad \\
\hline Overall description & $\begin{array}{l}\text { The initiative foresees the furnishing of a free service allowing patients } \\
\text { affected kidney chronic diseases to go on holydays nationally or } \\
\text { abroad. The initiative was conceived on the basis of the consideration } \\
\text { that travelling is particularly complicated for patients that have to } \\
\text { undergo routine dialysis }\end{array}$ \\
\hline Evidence-basis & none disclosed \\
\hline Design & $\begin{array}{l}\text { The initiative was shaped through the consultation with patient } \\
\text { associations who exposed the needs and difficulties that patients } \\
\text { experience in holyday planning and during abroad permanence. }\end{array}$ \\
\hline Implementation & $\begin{array}{l}\text { The company is in charge of all administration relevant to guarantee } \\
\text { equal levels of care for patients, be them in other national regions or } \\
\text { abroad. This stands true even in absence of the company's subsidiary } \\
\text { in the territory of destination, case in which care within other providers } \\
\text { are arranged. he project has benefited, since its beginning in } 2010 \text {, } \\
\text { roughly } 10.000 \text { patients every year plus family members. Resource- } \\
\text { wise, the company deploys human resources to deal with bureaucratic } \\
\text { matters and make arrangements with foreign healthcare providers and } \\
\text { Specialized Travel Agencies. No limits in the timeframe of the project } \\
\text { are set. }\end{array}$ \\
\hline Assessment & none disclosed \\
\hline Partnering & b2) School Health Education \\
\hline Overall description & $\begin{array}{l}\text { The initiative, organized in collaboration with neighbouring schools, } \\
\text { has the objective to increase children and youngsters' knowledge } \\
\text { about what healthy lifestyles entail through basic information on risk } \\
\text { factors and preventive behaviours. }\end{array}$ \\
\hline Evidence-basis & none disclosed \\
\hline Design & $\begin{array}{l}\text { The content of the School Health Education activities is different for } \\
\text { each school being designed conjointly by local healthcare units and } \\
\text { school representatives by the means of informal meetings }\end{array}$ \\
\hline Implementation & $\begin{array}{l}\text { In } 2012 \text { the initiative reached } 50 \text { schools in communities of ocal } \\
\text { healthcare centres in the districts of Lisbon, Braga, Vila Franca de } \\
\text { Xira, Torres Vedras and Porto, for a total of more or less } 5600 \\
\text { children reached. Activities are carried out by interdisciplinary teams } \\
\text { of voluntary healthcare professionals (general practicioners, nurses, } \\
\text { pharmacists etc.). No timeframe for the activities was disclosed. }\end{array}$ \\
\hline Assessment & none disclosed \\
\hline$\overline{\overline{\text { Sponsoring }}}$ & b3) Sponsoring of caregiver's association \\
\hline Overall description & $\begin{array}{l}\text { The initiative foresees the sponsoring of an association, ADVITA, } \\
\text { whose core mission deals with the figure of caregivers. In specific the } \\
\text { association aims tosupport and inform caregivers concerning the } \\
\text { practical and ethical dimensions of their role, with a special attention } \\
\text { on guaranteeing the autonomy, liberty, privacy and dignity of the } \\
\text { persons they are caring for. }\end{array}$ \\
\hline Evidence-basis & European innovation partnership (EIP) on active and healthy ageing \\
\hline Funding & none disclosed \\
\hline Implementation & none disclosed \\
\hline Assessment & none disclosed \\
\hline
\end{tabular}




\begin{tabular}{|c|c|}
\hline \multicolumn{2}{|r|}{ (C) INFORMATION AND COMMUNICATION TECHNOLOGIES } \\
\hline In-house & c1) Children Online Safety Initiative \\
\hline Overall description & $\begin{array}{l}\text { The initiative was conceived within a supranational industry-based } \\
\text { initiative: The Mobile Alliance Against Child Sexual Abuse Content, } \\
\text { counting twenty-three signatories at the European level. Both the } \\
\text { initiative and the alliance aim at increasing protection of children from } \\
\text { the exposure to online contents and communications that may be } \\
\text { inappropriate for them }\end{array}$ \\
\hline Evidence-basis & $\begin{array}{l}\text { EU Safer Mobile Framework and The Mobile Alliance Against Child } \\
\text { Sexual Abuse Content. }\end{array}$ \\
\hline Design & $\begin{array}{l}\text { The initiative was planned by industry leaders pertaining to the ICT } \\
\text { coalition and redacted into a protocol -Principles for the Safer Use of } \\
\text { Connected Devices and Online Services by Children and Young } \\
\text { People in the EU Framework- counting twenty-three signatories at the } \\
\text { European level. }\end{array}$ \\
\hline Implementation & $\begin{array}{l}\text { The enactment of the principles contained in the Mobile alliance } \\
\text { protocol contemplates the following responsibilities of the signatary: } \\
\text { the design of products as to guarantee the privacy of all users, } \\
\text { including children, during navigation; the furnishing of advice and tools } \\
\text { destined to parents and carers allowing to monitor and limit children's } \\
\text { online access, geographically localize children and get in contact with } \\
\text { relevant authorities and child protection services to report abuses; } \\
\text { and, finally, the support destined to enforcement authorities in } \\
\text { removing and retracing sources of illegal content.Timeframe 2012-. }\end{array}$ \\
\hline Assessment & $\begin{array}{l}\text { Reporting and benchmark of results are due regularly within the group } \\
\text { membership, with an independent panel appointed to carry out } \\
\text { autonomously an appraisal of the outcomes, but not disclosed within } \\
\text { this study. }\end{array}$ \\
\hline Partnering & \begin{tabular}{|c|} 
c2) Accessible Design Solutions \\
\end{tabular} \\
\hline Overall description & $\begin{array}{l}\text { Adapting or reformulating of existing technological and communication } \\
\text { services and solutions with the objective of reducing the potential } \\
\text { isolation of vulnerable segments of the population. The initiative } \\
\text { foresees } 3 \text { actions. Telemedicine allows individuals to obtain medical } \\
\text { assistance without being on medical grounds as well as helping } \\
\text { medical teams to obtain specialist tutoring without having to displace } \\
\text { patients. Teleassistance is conceived to minimize segregation of } \\
\text { senior citizens and provide rapid aid in emergency situations. } \\
\text { Teleclass helps disabled or chronically ill children to attend regular } \\
\text { education through remote connection. Special solutions, on the other } \\
\text { side, offer the possibility to people with auditory, speech and } \\
\text { neuromotorial impairments to be able to communicate through } \\
\text { devices designed especially to overcome their disabilities. }\end{array}$ \\
\hline Evidence-basis & Corporate R\&D. \\
\hline Design & $\begin{array}{l}\text { Solutions are designed by companies in collaboration with relevant } \\
\text { stakeholders: healthcare units and professionals for what concerns } \\
\text { Telemedicine; NGOs and local municipalities for Teleassistance; } \\
\text { Regional Educational Directories for Teleclass; and patient } \\
\text { associations and advocacy groups for Special Solutions. }\end{array}$ \\
\hline Tmplementation & $\begin{array}{l}\text { Technologies are either offered or subsidiazed, in case of offering end- } \\
\text { users still support communication costs. C } 2 \text { offers } 20 \text { Teleclass } \\
\text { solutions whose allocation is coordinated by the Portuguese General } \\
\text { Directory of Education; C3 indicates that } 261 \text { Special Solutions and } \\
1432 \text { Teleassistance equipment are currently functioning. No limits in } \\
\text { the timeframe of the project are set. }\end{array}$ \\
\hline Assessment & none disclosed \\
\hline Sponsoring & c3) Research on Electromagnetic Waves \\
\hline Overall description & $\begin{array}{l}\text { Sponsoring of a research project carried out by the Portuguese } \\
\text { Institute of Telecommunications (Instituto de Telecomunicações - IT) } \\
\text { aimed at making available information concerning electromagnetic } \\
\text { waves, as well as measurement of waves close to antennas, to the } \\
\text { general public and professionals of the field. }\end{array}$ \\
\hline Evidence-basis & $\begin{array}{l}\text { WHO Guidelines on Sodium/Sugar/Fat intake; Eu Platform on Diet, } \\
\text { Physical Activity and Health; Portuguese National Nutritional Plan }\end{array}$ \\
\hline Funding & information to be added \\
\hline Tmplementation & none disclosed \\
\hline Assessment & none disclosed \\
\hline
\end{tabular}


Table 17: Description of CSRHPIs of food retail companies

\begin{tabular}{|c|c|}
\hline \multicolumn{2}{|r|}{ (D) FOOD RETAIL } \\
\hline In-house & d1) In-store Nutritional Education \\
\hline Overall description & $\begin{array}{l}\text { Activities foreseen by the initiative range from in-store nutritional } \\
\text { counselling and screening to awareness events are aimed at raising } \\
\text { consumers' attentiveness for the adoption of a diet in line with } \\
\text { nutritional necessities and age and create awareness on the link of } \\
\text { nutrition with obesity and non-communicable diseases (NDCs). }\end{array}$ \\
\hline Evidence-basis & $\begin{array}{l}\text { Directives from WHO, the Portuguese National Nutritional Plan - } \\
\text { PNPAS (Plano Nacional de Promoção da Alimentação Saudavel). }\end{array}$ \\
\hline Design & $\begin{array}{l}\text { Corporate dieticians and nutritionists design activities in collaboration } \\
\text { with various national stakeholders, above all the General Directorate } \\
\text { for Health - DGS (Direção Geral da Saúde) and other scientific } \\
\text { associations such as the Portuguese Institute for Nutrition. }\end{array}$ \\
\hline Implementation & $\begin{array}{l}\text { In } 2013,3.384 \text { screenings and } 1.685 \text { general nutritional counselling, of } \\
\text { which } 900 \text { through personal nutritional shoppers were carried out; } \\
\text { more than } 700 \text { awareness events were organized on issues such as } \\
\text { the intake of fruit and vegetables, the role of breakfast and the fish } \\
\text { alternatives to meat dishes, reaching circa } 16.700 \text { participants. No } \\
\text { limits in the timeframe of the project are set. } \\
\text { none disclosed }\end{array}$ \\
\hline Partnering & d2) Food Policy \\
\hline Overall description & $\begin{array}{l}\text { Reformulation of own-brand producs as to add ailments that: are } \\
\text { produced organically; contain minimum percentages of fats, sugars } \\
\text { and salts; respond to specific dietary needs such as gluten } \\
\text { intolerances; or preferences, as it is the case for vegetarian or vegan } \\
\text { ailment. Reformulation of own-brand prouct offer as to reduce portion } \\
\text { size and redefine nutrient configuration (reduction of sugars, salts and } \\
\text { facts; the augmentation of fibres and vitamins and the lessening of } \\
\text { minimum standards of taste intensifiers, colourings, additives and } \\
\text { allergens). }\end{array}$ \\
\hline Evidence-basis & $\begin{array}{l}\text { Internal Policies for Health and Nutrition, in turn based on Directives } \\
\text { from WHO, the Portuguese National Nutritional Plan - PNPAS (Plano } \\
\text { Nacional de Promoção da Alimentação Saudavel). }\end{array}$ \\
\hline Design & $\begin{array}{l}\text { Corporate dieticians and nutritionists design initiatives in collaboration } \\
\text { with various national stakeholders, above all the General Directorate } \\
\text { for Health - DGS (Direção Geral da Saúde) and other scientific } \\
\text { associations such as the Portuguese Cardiology Association and the } \\
\text { Portuguese Association for Celiacism }\end{array}$ \\
\hline Implementation & $\begin{array}{l}\text { According to the respondent, thanks to nutritional reformulations in } \\
\text { own-brands in } 2013 \text { it was possible to withdrawal from the market } 3 \\
\text { tons of fats, of which half saturated, } 5 \text { tons of salt and approximately } \\
161 \text { tons of sugar. }\end{array}$ \\
\hline Assessment & none disclosed \\
\hline Sponsoring & (d3) School Breakfast Initiative \\
\hline Overall description & $\begin{array}{l}\text { The initiative intends to contribute to infant nutritional security by } \\
\text { guaranteeing breakfast to a number of pupils attending schools in } \\
\text { areas designed as being at risk of hunger. }\end{array}$ \\
\hline Evidence-basis & $\begin{array}{l}\text { Governmental report clarifying that almost one-third of the Portuguese } \\
\text { is at risk of poverty and malnutrition according to the standards } \\
\text { defined by Europe2020, and that children represent the most } \\
\text { vulnerable segment of the population, with a risk of living in poverty } \\
\text { set at } 31.6 \% \text { at in augment from previous years. }\end{array}$ \\
\hline Sponsoring & $\begin{array}{l}\text { Adding of } 2.300 \text { breakfasts (bread, cheese, ham and milk) to } \\
\text { strengthen and integrate the Governmental project for nutritional } \\
\text { strengthening on school grounds (PERA - Projecto Escolar de } \\
\text { Reforço Alimentar) led by the Portuguese Ministry of Education. }\end{array}$ \\
\hline Implementation & $\begin{array}{l}64 \text { schools reached in the academic year 2012/2013. No timeframe } \\
\text { disclosed }\end{array}$ \\
\hline Assessment & none disclosed \\
\hline
\end{tabular}


Table 18: Description of CSRHPIs of hotel companies

\begin{tabular}{|c|c|}
\hline \multicolumn{2}{|r|}{ (E) HOTEL AND CATERING } \\
\hline In-house & e1) SPA and Feng-Shui \\
\hline Overall description & $\begin{array}{l}\text { The initiative aims at enhancing physical and mental wellbeing in a } \\
\text { perspective of holistic healthcare. }\end{array}$ \\
\hline Evidence-basis & none disclosed \\
\hline Design & $\begin{array}{l}\text { Planned by shareholders following sectoral trends and evidence and } \\
\text { in collaboration with wellness specialists. }\end{array}$ \\
\hline Implementation & $\begin{array}{l}\text { Wellness measures are built-in, have unlimited timeframe and no } \\
\text { specific budget/resources in terms of CSR. The utilization of facilities } \\
\text { is generally reserved to costumers with exception of specific cases in } \\
\text { which members of local communities or targeted populations are } \\
\text { invited for punctual events. }\end{array}$ \\
\hline Assessment & none disclosed \\
\hline Partnering & $\begin{array}{l}\text { e2) Food Recycling Initiative } \\
\end{array}$ \\
\hline Overall description & $\begin{array}{l}\text { To obviate food inefficiencies provoked by buffet/catering waste and } \\
\text { contriibute to food security in neighbouring vulnerable communities. }\end{array}$ \\
\hline Evidence-basis & $\begin{array}{l}\text { Initiative-specific guidelines redacted by partnering NGO togheter with } \\
\text { ASAE. }\end{array}$ \\
\hline Design & $\begin{array}{l}\text { The realization of the initiative was made possible through a multi- } \\
\text { stakeholder partnership of E1 with the NGO leading the initiative } \\
\text { which provided guidelines for recycling processes conform to health } \\
\text { safety standards and the the receiving entity, the neighbouring } \\
\text { municipality, who deals with the individuation of beneficiaries and the } \\
\text { logistics of the food transfer. }\end{array}$ \\
\hline Implementation & $\begin{array}{l}\text { The initiative readily-cooked meals available to } 60 \text { families per week. } \\
\text { Timeframe 2012-. }\end{array}$ \\
\hline Assessment & In progress by the NGO \\
\hline Sponsoring & e3): Sponsoring of NGO dealing with autism \\
\hline Overall description & $\begin{array}{l}\text { The initiative aims at increasing social integration of individuals } \\
\text { affected by the spectrum of autism, a cause that the sponsoring } \\
\text { company believes to be seldom addressed }\end{array}$ \\
\hline Evidence-basis & none disclosed \\
\hline Sponsoring & none disclosed \\
\hline Implementation & none disclosed \\
\hline Assessment & none disclosed \\
\hline
\end{tabular}


Specificities of initiative formulation

Table 19: Basis for initiative formulation

\begin{tabular}{|c|c|c|c|c|}
\hline \multicolumn{4}{|c|}{ Appraisal criteria for initiative formulation } & \multirow{3}{*}{ Stakeholder counsulted } \\
\hline & \multicolumn{2}{|c|}{ Assessment of impacts } & \multirow{2}{*}{ Stakeholder consultation } & \\
\hline & Positive & Negative & & \\
\hline $\mathrm{a} 1$ & $\boldsymbol{V}$ & & $\boldsymbol{V}$ & Employee \\
\hline a2 & $\boldsymbol{\nu}$ & & $\nu$ & Government \\
\hline a3 & $\boldsymbol{\alpha}$ & & $\boldsymbol{\nu}$ & Consumer \\
\hline b1 & $\boldsymbol{V}$ & & $\boldsymbol{V}$ & Consumer \\
\hline b2 & $\boldsymbol{\nu}$ & & $\checkmark$ & Local Community \\
\hline b3 & $\boldsymbol{\nu}$ & & $\boldsymbol{\nu}$ & Consumer \\
\hline c1 & $\boldsymbol{V}$ & $\boldsymbol{\nu}$ & $\boldsymbol{V}$ & Consumer/Government \\
\hline c2 & $\boldsymbol{\sim}$ & & $\boldsymbol{\nu}$ & Consumer \\
\hline c3 & $\checkmark$ & $\checkmark$ & $\checkmark$ & Consumer/Government \\
\hline d1 & $\boldsymbol{V}$ & $\boldsymbol{\nu}$ & $\boldsymbol{V}$ & Government \\
\hline d2 & $\boldsymbol{\nu}$ & $\boldsymbol{\nu}$ & $\boldsymbol{\nu}$ & Government \\
\hline d3 & $\boldsymbol{\alpha}$ & & $\boldsymbol{\nu}$ & Government \\
\hline $\mathrm{e} 1$ & $\boldsymbol{N}$ & & $\boldsymbol{V}$ & Investor \\
\hline e2 & $\boldsymbol{\nu}$ & $\boldsymbol{\nu}$ & $\boldsymbol{\nu}$ & Local Community \\
\hline e3 & $\boldsymbol{\nu}$ & & $\boldsymbol{\nu}$ & Local Community \\
\hline
\end{tabular}

The first column of Table 14 elucidates whether the basis foreseen by ISO 26000 for the identification of relevant and significant issues, assessment of impacts and stakeholder consultation, were used as appraisal criteria to identify matters within the selected areas of action depicted in Table 11 and consequently formulate the CSRHPIs. It can be seen that all of the CSRHPIs are formulated on the basis of an assessment of positive impacts as well as in consultation with stakeholders whilst only five of them also rely on the consideration of negative impacts (c1; c3; d1; d2; e2). Among the CSRHPIs that have been marked as reliant on an appraisal of negative impacts we find two distinct situations. The initiatives c1, d1, d2 and e2 appraise potential negative impacts through evidence produced by entities other than the company (Table 15, complementary evidence - forthcoming) namely: harm related to children's exposure to inappropriate or violent content, or virtual harassment (c1), morbidity and mortality related with ailments whose composition or size has been linked to obesity and NCDs ( $\mathrm{d} 1$ and $\mathrm{d} 2$ ), avoidable food waste connected with sub-optimal disposal processes (e2). $\mathrm{C}_{3}$, on the other side, is per sè an initiative destined to assess whether the levels of electromagnetic radiation are within interval recommended by the EC and Portuguese government. The 
stakeholders consulted can be distinguished in five categories, two of which are constituted by internal stakeholders (employees and investors) and three by external stakeholders (consumers, governmental actors, and community actors).

Table 20: Complementary evidence

\begin{tabular}{|c|c|c|c|}
\hline & ANI & Consulted Policy & Consulted experts \\
\hline $\begin{array}{l}\text { a1 } \\
\text { a2 }\end{array}$ & & $\begin{array}{l}\text { - } \\
\text { Portuguese National Health Plan for Mental Health } \\
\text { (2007-2016) }\end{array}$ & Professor of the Institute Edgas Moniz Lisbon; \\
\hline $\begin{array}{l}\text { b1 } \\
\text { b2 } \\
\text { b3 }\end{array}$ & & $\begin{array}{l}- \\
\text { European Innovation Partnership ( EIP) on Active and } \\
\text { Healthy Ageeing }\end{array}$ & - \\
\hline $\begin{array}{l}\text { c1 } \\
\text { c2 } \\
\text { c3 }\end{array}$ & $\checkmark$ & $\begin{array}{l}\text { Mobile Use by Younger Teenagers } \\
\text { and Children; Mobile Alliance Against Child Sexual } \\
\text { Abuse Content; Code of Conduct for Activities Involving } \\
\text { the Provision of Content Services in Portugal } \\
\text { - } \\
\text { European Council Recommendation on } \\
\text { Electromagnetic Pollution } 199 / 519 / \text { EC; Portuguese } \\
\text { Ordinance on population exposition on electromagnetic } \\
\text { fields } 1421 / 2004\end{array}$ & ICT industry leaders \\
\hline $\begin{array}{l}\text { d1 } \\
\text { d2 } \\
\text { d3 }\end{array}$ & $\checkmark$ & $\begin{array}{l}\text { Eu Platform on Diet, Physical Activity and Health; } \\
\text { Portuguese Platform Against Obesity } \\
\text { WHO Guidelines on Sodium/Sugar/Fat intake; Eu } \\
\text { Platform on Diet, Physical Activity and Health; } \\
\text { Portuguese National Nutritional Plan } \\
\text { - }\end{array}$ & $\begin{array}{l}\text { Portuguese Cardiology Association, Portuguese } \\
\text { association for Celiacs; Portuguese General } \\
\text { Directory of Health, division of Nutrition } \\
\text { - }\end{array}$ \\
\hline $\begin{array}{l}\text { e1 } \\
\text { e2 } \\
\text { e3 }\end{array}$ & $\checkmark$ & ASAE - Procedures for food reciclying & - \\
\hline
\end{tabular}

Table 15 details the complementary evidence used to motivate the choice of issue addressed by the CSRHPI as well as the definition of specific objectives. The evidence is depicted as complementary in the perspective that ISO 26000, the operational reference considered for the present research, postulates that the basic evidence supporting the choice of a given CSR initiative is to come from within the company, after an internal assessment of positive and negative impacts associated with business operations has been carried out. The evidence depicted by the table above has been deemed complementary in the measure it comes from outside the company. Among the sources of information depicted in Chapter 3 the CSRHPIs were found to rely on two kinds sets of informed opinion: policy and informed opinion, that add to the stakeholder consultation portrayed in the previous table. It is possible to see that roughly half of the CSRHPIs use complementary evidence. It was considered of relevance to over pose some of the findings from Table 14 to Table 15. In specific, in the second column, identified with the code ANI which stands for assessment of 
negative impacts, shows that that the CSRHPIs formulated on the basis of an assessment of negative impacts also rely on complementary evidence. On the other hand, only two of the CSRHPIs identified as relying on an assessment of positive impacts (a2 and b3) were found to deploy complementary evidence. Policy consulted is both national (a2 and e2), EU-based and European Region-based (b3) or a combination thereof $(\mathrm{c} 1, \mathrm{c} 3, \mathrm{~d} 1, \mathrm{~d} 2)$. The case of e2 is peculiar in what the initiative relies on the consultation of a private regulation formulated by the Portuguese NGO Dar e Acordar and endorsed by the Association for Alimentary Safety (ASAE). The private regulation had itself been developed in the context of a CSR initiative, as to respond to a necessity made explicit by a business entity willing to donate ailments exceeding from caterings, being it translated into a procedure with the objective of being replicated in similar situations. All of the experts consulted are locally based and pertain to research, professional and governmental entities. Questioned concerning their motivation for using complementary evidence for the formulation of CSRHPIs, respondents pointed out three motivations: increase the base of legitimacy of interventions (a2; b3;) align with best-practice (c1; c3; d1; d2) and engage in issues whose tackling was previously prohibited (e2). For the remaining CSRHPIs the choice not to engage in any complementary evidence was supported by two broad motivations. On one side respondents manifested the will to engage complementary evidence in the formulation of CSRHPIs, specifying that such practice, although considered as desirable, had been until that moment prevented by a lack of culture or mechanisms allowing to take in consideration information other than the one inherent to corporate governance. On the other side, respondent clarified that the choice not to consider complementary evidence was a strategic one, in the perspective that CSR is a domain that should remain voluntary and autonomous and not overlap with other fields of decision-making, namely the public policy process, for it is in its space of voluntariness that the potential for CSR to find innovative solutions to social problems lies. 


\section{Specificities of initiative design}

As previously specified, were considered as relevant dimensions of initiative design the objectives set and beneficiaries addressed by each CSRHPI, on the basis of which it was possible to discern what will below be described as the focus and type of CSRHPIs. Focus describes whether the CSRHPIs are internally directed to the redefinition of business operations, or externally aimed, destined to increase the resources, intended as capacities and infrastructures, of recipients external to the company. Initiatives that are internally directed are additionally distinguished as expanding the sphere of business activity or limiting it. The analysis of the focus and nature of CSR initiative was relevant to categorize, during the analysis portrayed in the next chapter, the CSRHPIs according to the types of commitments portrayed in chapter 3 , innovation and adaptation, value chain reconfiguration, local development and policy dialogue. Also it was purposeful to uncover the rationale underlying initiatives. Furthermore, the specification of objectives set for the identification of the CSRHPIs alignment with the priorities and strategic approaches set for the context in analysis, also operated in the next chapter.

Table 21: Objectives

\begin{tabular}{|c|c|}
\hline $\begin{array}{l}\mathrm{a} 1 \\
\mathrm{a} 2\end{array}$ & $\begin{array}{l}\text { Participate to the rehabilitation and social insertion of individuals at risk of poverty } \\
\text { Increase self-esteem in pre-teens by } 30 \% \text { (i) and increase training in mental health by } \\
30 \% \text { (ii) } \\
\text { Improve access to therapies, validate measurement tools and increase awareness upon } \\
\text { risk factors }\end{array}$ \\
\hline $\begin{array}{l}\mathrm{b} 1 \\
\mathrm{~b} 2\end{array}$ & $\begin{array}{l}\text { Empowering individuals with chronic disease to travel abroad } \\
\text { Increase knowledge in youngsters about healthy lifestyles risk factors and preventive } \\
\text { behaviours. } \\
\text { Support and inform caregivers }\end{array}$ \\
\hline $\begin{array}{l}\mathrm{c1} \\
\mathrm{c} 2 \\
\mathrm{c3}\end{array}$ & $\begin{array}{l}\text { Protect children from the exposure to inappropriate online contents and communications } \\
\text { Adapt or reformulate ICTs to meet special needs } \\
\text { Measure waves close to antennas and make available information concerning } \\
\text { electromagnetic waves to the general public }\end{array}$ \\
\hline $\begin{array}{l}\text { d1 } \\
\text { d2 }\end{array}$ & $\begin{array}{l}\text { In-store screening and awareness activities focused on obesity and NCDs } \\
\text { Reformulate own-brand product offer as to: increase ailments with positive health claims } \\
\text { and adapted to specific dietary needs; reduce fats, sugars and salts; taste intensifiers, } \\
\text { colourings, additives and allergens). } \\
\text { Contribute to alimentary security by guaranteeing breakfast to a number of pupils } \\
\text { designed as being at risk of hunger }\end{array}$ \\
\hline $\begin{array}{l}\text { e1 } \\
\text { e2 }\end{array}$ & $\begin{array}{l}\text { Offer alternative water treatments } \\
\text { Reduce food inefficiencies provoked by buffet/catering waste and contribute to food } \\
\text { security in neighbouring communities. } \\
\text { Participate to the support of individuals affected by the spectrum of autism }\end{array}$ \\
\hline
\end{tabular}


It is possible to make two observations concerning the specific objectives set for the CSRHPIs. In a first instance, that they are miscellaneous in scope, which is unsurprising considering the broad scope of health promotion, and secondl, that they are, for the major part, broad and unspecific in nature. In this context a2, with its precise objective to increase the level of self-esteem and awareness on mental health issues in a population of pre-adolescents by $30 \%$, constitutes an exception vis-à-vis other initiatives aiming to address a cause broadly without setting specific or measurable objectives.

Table 22: Focus and beneficiaries

\begin{tabular}{|c|c|c|c|c|c|}
\hline & \multicolumn{3}{|c|}{ Focus } & \multicolumn{2}{|l|}{ Beneficiaries } \\
\hline & internal & External & Nature & Population & Population type \\
\hline $\begin{array}{l}\text { a1 } \\
\text { a2 } \\
\text { a3 }\end{array}$ & & $\underset{v}{\nu}$ & & $\begin{array}{l}\text { Socioeconomic condition } \\
\text { Age group/ socioeconomic condition } \\
\text { Interest Group }\end{array}$ & $\begin{array}{l}\text { Community } \\
\text { Community } \\
\text { Community }\end{array}$ \\
\hline $\begin{array}{l}\text { b1 } \\
\text { b2 } \\
\text { b3 }\end{array}$ & $\boldsymbol{\nu}$ & $v$ & Expansive & $\begin{array}{c}\text { - } \\
\text { Age group } \\
\text { Interest Group }\end{array}$ & $\begin{array}{l}\text { Consumers } \\
\text { Community } \\
\text { Community }\end{array}$ \\
\hline $\begin{array}{l}c 1 \\
\text { c2 } \\
\text { c3 }\end{array}$ & $\underset{\nu}{\nu}$ & & $\begin{array}{l}\text { Expansive } \\
\text { Expansive }\end{array}$ & $\begin{array}{l}\text { Age group } \\
\text { Health condition } \\
\text { General public }\end{array}$ & $\begin{array}{l}\text { Consumers } \\
\text { Consumers } \\
\text { Community }\end{array}$ \\
\hline $\begin{array}{l}d 1 \\
d 2 \\
d 3\end{array}$ & $\nu$ & $\boldsymbol{\nu}$ & $\begin{array}{l}\text { Expansive } \\
\text { Restrictive }\end{array}$ & $\begin{array}{c}- \\
- \\
\text { Age group/ socioeconomic condition }\end{array}$ & $\begin{array}{l}\text { Consumers } \\
\text { Consumers } \\
\text { Community }\end{array}$ \\
\hline $\begin{array}{l}\text { e1 } \\
\text { e2 } \\
\text { e3 }\end{array}$ & $\checkmark$ & $\boldsymbol{\nu}$ & $\begin{array}{l}\text { Expansive } \\
\text { Restrictive }\end{array}$ & $\begin{array}{l}\text { - } \\
\text { Vulnerable population } \\
\text { Vulnerable population }\end{array}$ & $\begin{array}{l}\text { Consumers } \\
\text { Community } \\
\text { Community }\end{array}$ \\
\hline
\end{tabular}

Table 17 distinguishes among the initiatives that are externally oriented (a1, a2, a3, b2, b3, d3, e3) and the ones that are internally oriented (b1, c1, c2, c3, d1, d2, e1, e2). Based on the types of impacts considered as depicted in Table 14, internally oriented CSRHPIs were further distinguished in two groups. The first group is constituted by initiatives that are expansive in nature, it is to say, that are intended to expand business operations as to offer anew products and services, or adapt existing ones, as to meet previously non-tackled necessities and reach new markets or segments of the population (b1, c1, c2, d1, e1). The second group is constituted by CSRHPIs that are internally directed but are restrictive, in the sense that they create additional obligations at the level of business operations, whose boundaries exceed the requests made by existing laws, directed to minimize negative externalities connected with business operations (d2, e2). Also in this case the situation of $\mathrm{c} 3$ is peculiar, in what 
the initiative only potentially engages a redefinition of business practices. Internally oriented CSRHPIs are majorly directed to consumers, being there two c3 and e2, for which the intended beneficiaries are external stakeholders defined in terms of general public (c3) and community (e2). In the case of c3 this is given by the fact that the initiative intends to operate upon impacts that are environmental, hence public in nature. In the case of $\mathrm{d} 2$ this is due to the fact that the redefinition of business practice, which is a matter of organizational governance at the level of waste disposal, was conceived, as to benefit the local vulnerable community in a perspective of circular economy. What have been defined as externally oriented CSRHPIs do not foresee a redefinition of core business operations, being describable as social investments destined to external stakeholders, also in this case broadly identified with the term community. The term community in this context portrays groups that, other than bearing links of geographical proximity to the company implementing the CSRHPI are bound by additional features of nearness in terms of age group and socio-economic and interest. The targeting by socioeconomic group (a, e2, e3) addresses vulnerable communities in a perspective of reduction of poverty and social exclusion whilst the age-related targeting (a2, b2, c1, d3) tackles needs, in this case of children and adolescents in a perspective of life stages-adapted approach, where the segmenting for age and vulnerable community are at times over posed (a2, d3). Finally the targeting of interest groups as beneficiaries, in this case linked to a given disease, or to the position as a caregiver, intends to respond to the needs and claims of a population whose interest is perceived as close and relevant to business operations. In this context the interest-based grouping is to be acknowledged as a synonym of stakeholder, differently for the case beneficiaries addressed on the basis of their status as desirable recipients of social initiatives.

\section{Specificities of initiative implementation}

As for what concerns the implementation of the CSRHPIs were considered the time frame set for each CSRHPI, their geographical reach as well as their reach in terms of population, as well as the existence of an evaluation of impacts. The information contained in this subsection is purposeful for the discussion of the perceptions brought forward by health promotion experts, as well as to discuss limits and potentialities of CSRHPIs in terms of commitment and potential impacts, operated in the next chapter. 
Table 23: Timeframe, reach and evaluation

\begin{tabular}{|c|c|c|c|c|c|}
\hline & Timeframe (years) & Population reach & Geographical reach & Evaluation & Social Partners \\
\hline $\begin{array}{l}\text { a1 } \\
\text { a2 } \\
\text { a3 }\end{array}$ & $\begin{array}{c}\text { Not defined } \\
3 \\
\text { Not defined }\end{array}$ & $\begin{array}{l}<5 \\
100 \\
\text { NA }\end{array}$ & $\begin{array}{c}\text { Lisbon met. area } \\
\text { Lisbon met. area } \\
\text { National }\end{array}$ & $\begin{array}{c}- \\
\text { Planned } \\
-\end{array}$ & $\begin{array}{l}- \\
\text { CSO } \\
\text { CSO }\end{array}$ \\
\hline $\begin{array}{l}\text { b1 } \\
\text { b2 } \\
\text { b3 }\end{array}$ & $\begin{array}{c}\text { Not defined } \\
1 \\
\text { Not defined }\end{array}$ & $\begin{array}{c}10.000 \\
5.600 \\
\text { NA }\end{array}$ & $\begin{array}{l}\text { National } \\
\text { National } \\
\text { National }\end{array}$ & $\begin{array}{l}- \\
- \\
-\end{array}$ & $\begin{array}{c}- \\
\text { School } \\
\text { CSO }\end{array}$ \\
\hline $\begin{array}{l}\mathrm{c} 1 \\
\mathrm{c} 2 \\
\mathrm{c} 3\end{array}$ & $\begin{array}{c}\text { Not defined } \\
\text { Not defined } \\
3\end{array}$ & $\begin{array}{l}\text { NA } \\
1.700 \\
\text { NA }\end{array}$ & $\begin{array}{l}\text { National } \\
\text { National } \\
\text { National }\end{array}$ & $\begin{array}{c}- \\
- \\
N A\end{array}$ & $\begin{array}{c}- \\
\text { CSO } \\
\text { Research Unit }\end{array}$ \\
\hline $\begin{array}{l}\text { d1 } \\
\text { d2 } \\
\text { d3 }\end{array}$ & $\begin{array}{c}\text { Not defined } \\
\text { Not defined } \\
1\end{array}$ & $\begin{array}{l}16.700 \\
\text { NA } \\
2.300\end{array}$ & $\begin{array}{l}\text { National } \\
\text { National } \\
\text { National }\end{array}$ & $\begin{array}{c}- \\
\text { - } \\
\text { Planned }\end{array}$ & $\begin{array}{c}- \\
\text { CSO/Government } \\
\text { Government }\end{array}$ \\
\hline $\begin{array}{l}\text { e1 } \\
\text { e2 } \\
\text { e3 }\end{array}$ & $\begin{array}{l}\text { Not defined } \\
\text { Not defined } \\
\text { Not defined }\end{array}$ & $\begin{array}{c}\text { NA } \\
5000 \\
\text { NA }\end{array}$ & $\begin{array}{c}\text { Lisbon area } \\
\text { Lisbon area } \\
\text { Lisbon met. area }\end{array}$ & $\begin{array}{c}- \\
\text { Planned } \\
-\end{array}$ & CSO/Local Municipality \\
\hline
\end{tabular}

The information contained in Table 18 points out that the majority of CSRHPIs do not have an established timeframe; the ones that do, have a timeframe ranging between 1 and 3 years (a2; b2; c3; d3). The majority of CSRHPIs in analysis have a national reach, exception made for a1, a2, e1 and e2 and e3 that have a reach limited to the Lisbon city or metropolitan area. Is worth specifying that the CSRHPIs described as being national in reach are to be pondered on the basis of two aspects: the majority of CSRHPIs take place in the major cities of the country's principal districts (Porto, Braga, Leira, etc.) and do not truly cover the entirety of the national territory. Also, roughly half of the CSRHPIs are, as specified in the second column, destined to consumers, hence their reach, although national, is not to be considered public. As for what concerns the number of beneficiaries reached by the CSRHPIs, for roughly half of the case studies it is not possibly to clear-cut a number (marked by the symbol NA, which stands for non-applicable). CSRHPIs formulated by the pharmaceutical sector are the ones with a more limited number of beneficiaries, whilst for the other sectors the number of beneficiaries ranges amongst 1.700 and 16.700. At the time of redaction none of the initiatives had been assessed in terms of impacts, although an assessment of social impacts, to be carried out independently by the social partners of the said initiatives, was declared as being planned for a2, a3 d2. The information on the basis of which the interviewees declare to evaluate the remaining CSRHPIs are indicators such as people reached or material or nonmaterial resources deployed, information that is apt to assess performance rather than impacts. In this sense, the interviewees' replies highlight confusion on what it is to assess impacts as opposed to assess performance. On this topic the respondent for 
c1 expressed the need to create an internal methodology specific for social impacts given the sole availability of general methodologies for project management. The interviewee further added that the formulation and implementation of a methodology specific to assess social impacts had, until that moment, been impeded by the lack of technical expertize of the CSR department upon the issue. The last column, specifying the partners of the collaborative CSRHPIs, serves to prepare the ground for the next section. On a general basis, it can be noted that the majority of collaborations take place among businesses and civil society organizations (CSOs), followed by school (b1), research (c3) and public entities both at the governmental $(\mathrm{d} 2, \mathrm{~d} 3)$ and local (e2) levels. Furthermore we see that the majority of collaborations involve the participation of the business entity and a partner, whilst two initiatives are implemented on the basis of multi-stakeholder partnerships (d2 and e2).

\section{Involved actors' perceptions concerning the CSRHPIs}

\section{The perspective of CSR managers}

Needless to say the CSR managers, very proud of the initiatives for which they are responsible, identify numerous positive health promotion outcomes connected to the CSRHPIs, above all, the injection of resources for causes, beneficiaries and institutions that would otherwise remain unsupported, and, secondly, the establishment of multi-stakeholder alliances that allow direct communication and negotiation of issues amongst actors that would otherwise difficulty be put in contact. Nevertheless, and on the latter point, when questioned concerning the main the limits and opportunities inherent to the CSRHPIs half of the CSR managers lament the difficulty to establish partnerships with actors from the public sector, namely with health authorities at the governmental level. Such non-cooperative posture is perceived, in general terms, as a senseless resource squandering in what businessbased resources destined to CSR could be converged towards the realization of synergetic initiatives polling the objectives of both public and private actors related to health outcomes. Non-cooperativeness of the public sector is explained through three arguments concerning public actors, both at the governmental and local level: estrangement and ignorance concerning the nature and scope of CSR, latent mistrust of governmental actors, namely health authorities, towards the business sector, and a lack of interest in corporate activity be there no political return. The argument bringing in cause a latent mistrust is clarified by the representative for a3, which 
reasons that governmental actors "have a grudge towards the industry" (free translation), and don't envision the industry as a partner. The spokesperson for e2 attributes estrangement to lack of interest, adding that to gain endorsement for the Food Recycling Initiative, many governmental and public entities were contacted to collaborate first, and audit then, the initiative, but that "the answer was zero" (free translation). The respondent from e3 further adds the perception that public actors, both at the municipal and governmental levels, are unwilling to collaborate with private companies unless they envision a political return connected with collaboration. In line with what reported concerning the motivations to use or not use complementary evidence for the formulation of CSRHPIs, the interviewees that believe that the realm of CSR should bring along public-private synergies through the convergence of objectives and processes, point out the need for the public sector to renew its approach towards the industry by adopting a posture open to intersectoral dialogue. Recommendations for the establishment of public-private synergies captured were diverse, but all envisioned a greater involvement of the public sector towards CSR practices, both in terms of incentives and monitoring. Incentives are foreseen in terms of public contracting and tax incentives, as well as through the adoption of postures apt to encourage the encounter of different stakeholders, by, for instance, establishing multi-stakeholder platforms or endorsing joint actions with great political visibility. On this point, and for what concerns in specific the role of public actors in encouraging multi-stakeholder encounter, dialogue and collaboration in the area of health promotion the spokesperson for b3 points out that, although the PNHP sets priority areas and calls for the responsibility of both the social and business sectors, a major challenge remains ensuring that responsibilities are complied in practice. In this respect, the same interviewee points out the need to establish an anew public health authority competent to clarify objectives and responsibilities of each stakeholder in health as well as clarify the resources and methods necessary to meet them. According to the representative for c2 and in relation to monitoring the setting at an institutional level of clear benchmarks for what responsible business means and of transparency rules specifically adapted to the context of CSR would facilitate the work of CSR managers as well as setting the grounds for the building of trust relations. Secondly the monitoring of initiatives is foreseen in relation to outcomes. Still according to b3 it should be a governmental responsibility, to be carried out, for instance, by a potential anew public health authority as mentioned above, to verify the alignment of initiatives with public priorities and to assess outcomes both in relation to health impacts as well as in terms of compliance with the expectations and objectives set by the same entities. In 
a concluding note, the spokesperson for the initiative b3 noted that the achievement of a whole of society commitment to health promotion is not realistic be health promotion not set as a priority at the governmental level first.

\section{The perspective of social partners}

Social partners appear largely supportive of the CSRHPI and of CSR practices in general, predominantly in the perspective of collaboration with business entities being often the only possibility to finance their projects or entities. In this regard the social partner for $\mathrm{d}_{3}$, belonging to the Portuguese government's General Directorate for Education, clarifies how the totality of the initiative, which fed 2.300 pupils in the academic year 2012/2013 through ailments donated entirely by a number of business partners, would not have been realized without the presence of CSR sponsorship, reflecting on how, in this perspective, CSR highlights an interference of the business sector with the welfare state, minimizing problems which should be a governmental responsibility. Further, the social partner for the e3 initiative clarifies that the relevance of collaboration goes beyond economic motives in what the approximation of business entities and private actors allows to give visibility to their cause, autism in this specific case, fostering social inclusion and valorisation of competences through the cause-related marketing of craft objects produced by the residents of the facility, and through the organization of joint events which allow the establishment of relationships with the local community. Finally, according to the CSO social partner of the multi-stakeholder initiative d2, the realm of CSR allows a channel for dialogue and negotiation and a more direct access to both business and public entities, fostering channels for civil-society based negotiation and lobbying, in this particular case concerning the redefinition of products on the basis of specific condition-related needs. Social partners were reticent to share the boundaries of collaborations engaged through CSR, most likely due to the fact they were invited to participate in the research by their business partners, not wanting to risk their relationship. As no problems were reported according to autonomy of choices or the existence of power dynamics, social partners stated few concerns related to the nature of collaborations. The CSO social partner for $\mathrm{d} 2$ reported that partnerships are based on personal relationships, and not institutionalized within entities in the long term, creating a condition were "if I (the social worker) or my partner (the CSR manager) would be replaced, the partnership may be in jeopardy" (free translation). The social partner for a2 individuates the main weakness of CSRHPIs to be associated with a lack of sufficient monitoring and assessment of the outcomes of initiatives, giving rise to 
doubts concerning their effectiveness and the interest of businesses in creating impacts. Further, the same social partner reports that the economic convergence has made so that business entities have seen their revenues diminished whilst pleas from social actors augment, leading, within the social sector, to an increase in competition for CSR funding, which has harshened inequalities between famous long-standing association and association pursuing visible causes, and their counterparts. The social partner for e3 reinforces this point, expressing the concern that CSRHPIs are directed towards specific groups of population, such as local communities or children and youngsters, increasing segregation of rural areas and marginalization of causes not connected with business activities. All social partners agree that the role of the state should be one to responsibilize business actors for the impacts connected with business operations on one side, and allow benefits to companies who are more socially responsible on the other. According to the social partner for e3, among the possible forms of state intervention in CSR, regulation is the only undesirable one as it is may scare away commitment. 


\section{Chapter 6: Analysis and Conclusions}

\section{Implications of CSR initiatives for health promotion}

The latter part of Chapter 4 has been purposeful to identify, on the basis of a literature review and the perceptions of a number of health promotion experts responsible for the Priority Programs of the Portuguese General Health Directorate, (many) potential dilemmas and (some) potential opportunities inherent to CSR initiatives for health promotion policy and practice. In literature divergent perspectives were found according to the type of companies implementing CSR initiatives and the issues dealt with by said initiatives. CSR initiatives put in place by industries whose goods are considered potentially problematic in terms of health outcomes as to counteract or mitigate potential harm connected with goods and business practices, are depicted as being not only ineffective, but also potentially harmful. The initiatives' ineffectiveness and harm are motivated preponderantly on the grounds of CSR practices' opportunistic nature, intended to prioritize business, as opposed to social, outcomes. The business returns expected from CSR as identified in literature are: avoidance of hard-regulation, product development, market differentiation, access to policy elites and lobbying, and reputational gains in terms of public opinion. According to literature, CSR practices' opportunistic nature makes so that CSR initiatives are not implemented following relevant priorities or scientifically sound approaches, leading to the initiatives' ineffectiveness in producing social impacts. Also, the uptake of non scientifically based approaches is perceived as being prone to the divulgation of a narrow understanding of health, one that focuses upon behaviours other than systemic change and is hence potentially conducive to victimblaming. Furthermore, the implementation of CSR initiatives is feared to lead to a scaling back of the role of governments, whilst simultaneously offering leverage for private lobbying on public policy-making. CSR health promotion initiatives destined to employees are depicted as underlying opportunities inherent to the consideration of workplaces as settings for health, able to tackle noteworthy health promotion issues such as health literacy and prevention, although being limited by the willingness to tackle unpleasant issues attached to stigma, such as the one of 
substance misuse, and potentially hindering threats of organizational control. Finally, initiatives put in place by unproblematic industry sectors, it is to say industry sectors whose goods are considered as not presenting direct health threats, or even furnishing openings for the production of health outcomes, such as the sports industry, are depicted as bringing about opportunities for positive social impacts at the local level, by offering occasions for social inclusion and the building of social capital amongst citizens, whilst allowing the furthering of social policy objectives, the creation of trust relations and a better understanding of problems and interventions at the level of local organizations. The representatives of the Portuguese Priority Health Programs showed perceptions that are coherent, although less structured, with the ones found in research, reporting both suspicion as well as the mild optimism concerning the potential health gains inherent to CSR practice. The experts that declared being sceptical motivated their scepticism on two grounds. Also in this case, the major argument put forward was the perceived instrumentality of CSR to pursue reputational, strategic, and commercial objectives over social and health objectives. Such instrumentality was reasoned, for instance, in terms of the affiliation of CSR management positions to marketing departments, or on the grounds of the industry's mere support of causes that are highly visible in terms of public opinion, or being apt to being positively associated to brands (from here the lack of CSR-based support of the HIV Priority Program). In a second instance, health promotion experts perceive the limited possibility for initiatives to create impacts as being due to the reduced number of initiatives and beneficiaries reached, lacking alignment with health promotion priorities or adoption of scientifically sound methods, punctual nature of initiatives, and absence of assessment of social performance. In this case, as in literature, some health promotion experts perceived the limits pictured above as grounded on a disinterest tied to the opportunity-oriented nature of CSR, although others attributed it to a scarce awareness of social issues natural for the sphere of action of business actors in a context with weak cross-sectoral ties. One of the health promotion experts also pointed out the potential threats for health promotion associated with the CSR-based divulgation of public health messages not backed by the scientific community, offering a distorted view of best-practice. The health promotion experts that expressed confidence towards CSR practice identified core opportunities, other than in the injection of needed investments for health promotion causes, in the creation of local clusters bringing together companies, CSOs and municipalities at the local level, as well as in the diffusion and furthering of messages, objectives and strategic approaches for health promotion set by health promotion authorities. 
The subsections that follow review the dilemmas, opportunities and inherent limits identified in Chapter 4 in light of the findings relative to the analysis of the CSRHPIs depicted in Chapter 5. Issues were grouped in three clusters. The first cluster considers issues relative to the nature of engagement of CSRHPIs starting from the consideration that the opportunity-driven rationale of CSR practices was identified by both literature and health promotion experts as being the major cause behind the ineffectiveness and potential threats for health associated with CSR initiatives. The second and third clusters examine the two areas in which potential gains were identified: participation to the furthering of health promotion messages, priorities and strategic approaches relevant for the context of implementation, and furthering of social capital, social inclusion and trust-building at the local level.

\section{On the nature of engagement}

Given their miscellaneous nature it was considered relevant to sort the CSRHPIs in three categories bearing different rationales and implementation approaches. The categories, grounded on the types of CSR commitments depicted in Chapter 3, are the following: innovation and adaptation (A), value chain reconfiguration (B) and community development (C). Each CSRHPIs' affiliation to a category (or more), depicted in Figure 1, was ascertained on the basis of the appraisal criteria, the focus, and the beneficiaries of CSRHPIs (Tables 14 and 17 of Chapter 5). In specific, the categories (A) and (C) depict CSRHPIs based on the assessment of positive impacts although the initiatives of type (A) are internally oriented whilst the initiatives of type (C) are externally oriented. Differently, the initiatives of type (B), other than being internally directed, are based on an assessment of negative impacts. 


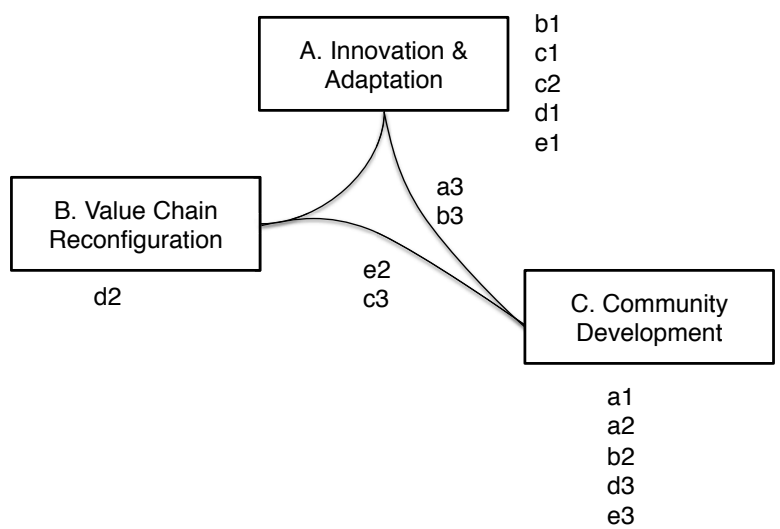

Figure 3: Sorting of CSRHPIs in types of commitment

A

Four initiatives were identified as pertaining to the innovation and adaptation category (b1, c1, c2, d1, e1), by which CSR is used as a vehicle to meet previously nontackled necessities, or to modify the portfolio of products as to reach new markets or segments of the population. The CSRHPIs that pertain to this level are predominantly destined to current or prospective clientele, engaging an expansion of the portfolio of products meeting new segments of the population (youngsters, special needs) or offering anew services to users (patient holydays, water treatments). Another two CSRHPIs (a3) and (b3), although being externally directed, were classified as hybrid between the levels of innovation (A) and community development (C) in what they sponsor groups, that the author characterised as interest groups, whose cause is deeply linked to the core mission of the industry. Such interest groups are, for nature, closer to clientele than they are to local communities. The author considers that the commitments undertaken within to the innovation and adaptation category (A) underpin a predominantly opportunistic understanding of CSR, understood as a positive responsibility to expand the sphere of action of business activities, providing anew services and products simultaneously leading to the expected consequences of market differentiation and reputational gains. Secondly initiatives follow a logic of expected consequences for internal market and relational gains related with initiatives.

$\mathrm{B}$ and hybrid B - C

Commitments relevant in terms of value chain reconfiguration aim at the redefinition of business operations at different phases of the production chain, starting from research and development and reaching across sourcing, manufacture, distribution, 
pricing, marketing and user's support, intended to minimise potential harm identified as being connected with business operations. One initiative has been considered as fitting exclusively in this category: d2; whilst e2 and c3 were considered as hybrid. Both $\mathrm{d} 2$ and $\mathrm{c} 3$ have been considered as hybrid between value chain reconfiguration and community development because they envisage both a current or prospective reconfiguration of the value chain as well as are aimed at protecting and improving local communities. The initiatives that pertain to the level $\mathrm{B}$ and hybrid $\mathrm{B}-\mathrm{C}$ are considered by the author as following first the principle of expected consequences, and then that appropriateness. The consequentiality logic is evident in the intention to avoid or mitigate potential harms connected with business activities, whilst, at the same time, pre-empting the risk for harder regulation or litigation. The logic of appropriateness is to be understood in the initiatives' intention to bring forward public objectives, as to fulfil the obligations and expectations inherent to the membership to a social collectivity.

C.

CSRHPIs relevant for local development are intended to increase capacities, infrastructures, and resources of the environments surrounding business activities. Examples of CSRHPIs relevant merely in terms of local development include: a1; a2; b2; d3. The rationale behind these initiatives can be defined following a mixed logic relying predominantly on the principles of appropriateness/ stakeholder responsiveness, and in a second instance on that of expected consequences. The logic following the principles of appropriateness/stakeholder responsiveness is evident, as mentioned above, in the intention to fulfil expectations set at the community level, whilst the logic of consequentiality derives from the relational and reputational gains expected from the fulfilment of said obligations. An additional differentiation is to be found, distinguishing between a corporate citizenship and a philanthropic approach according to the relation of initiatives with core business. A difference exists in the pharmaceuticals' connection with the cause of mental health promotion (a2) describable as corporate citizenship, and the hotel sector's distant sponsoring of the autism cause (e3), that may be likened to traditional philanthropy. Although purposeful to better business reputation corporate citizenship, and even more so philanthropic CSR, don't engage any modification of business activity.

As previously contended, the main critique addressed to CSR initiatives in a health promotion perspective is that they are driven predominantly by an opportunistic strategy-based rationale, unable to take remedy for negative impacts and prioritizing 
the creation of business over social impacts. The analysis and sorting of CSRHPIs in the three levels discussed above has allowed to comprehend that CSR initiatives do not merely rely on opportunity, although it is true that they carry out different and multiple rationalities concerning the nature and scope of CSR. The initiatives categorized as pertaining to the level A and A-C can be categorized as engaging what in chapter 3 has been depicted as the principle of opportunity, whilst the initiatives categorized as pertaining to the levels $\mathrm{B}, \mathrm{B}-\mathrm{C}$ and $\mathrm{C}$, engage both the principles of expected consequences and appropriateness/stakeholder responsiveness. The consequentialist rationale is coherent with the vision brought forward by the Jakarta and Bangkok declarations (WHO 1997; 2005), whilst the logic following the principle of appropriateness is aligned with the perspective engaged by the United Nations' Committee on Economic, Social and Cultural Rights in the General Comment No. 14 (UN, 2000) as well in the factsheet The Right to Health (WHO, 2007), as explained in Chapter 4. Another finding elapsing from the analysis of the CSRHPI, and that confirms the arguments found in literature and in experts' perspective, is that the rationale hindering initiatives determines the ways in which they are formulated and implemented. The CSRHPIs categorized as following a consequentialist rationale rely on complementary evidence to appraise the existence of potential negative impacts and identify relevant health promotion approaches and issues, whilst such practice, although present, is not routine for the CSRHPIs pertaining to the levels A and C.

As for what concerns the potential for CSRHPIs to survive changes in management and become institutionalized, the author observes, on the basis of Seitanidi and Crane (2008) reflections relative to institutionalization of cross-sectoral initiatives portrayed in Chapter 3, that CSRHPIs pertaining to the level A are extremely likely to become embedded in business practice although, given their opportunity rationale, they are also likely not to be implemented, or to be discontinued, in case the business opportunity on which they rely ceases to exist. CSRHPIs pertaining to level C although providing sponsorship and support to causes and institutions that is declared to be permanent are less likely to be institutionalized in the long term due to their absent or loose link with business operations. The CSRHPIs pertaining to the level B and B-C are more likely to become institutionalized in what they envision a reconfiguration of business practices. Although for some initiatives (a2, a3, d2) an evaluation was mentioned as being planned, CSR managers demonstrated little planning and competence upon the issue of evaluation for all CSRHPIs notwithstanding the affiliation to categories $\mathrm{A}, \mathrm{B}$ or $\mathrm{C}$ suggesting that this may be an 
issue with roots in CSR policy and/or implementation, as we will review in the forthcoming section (6.2).

On the participation to the furthering of contextual health promotion priorities and approaches

This section reviews the potential for the CSRHPIs to participate to the priorities and strategic approaches set for the context of implementation, possibility upon which contrasting stances were found, namely in the consultation of the Portuguese health promotion experts. Such potential is discussed on the basis of the analysis of the CSRHPIs' specific objectives (Table 16 of Chapter 5), looking for an alignment with the priorities set for the context of analysis as specified in Chapter 4, as well as the verifying whether the CSRHPI follow a multi-level approach to health promotion, as suggested for health promotion interventions, as opposed to a narrow, behaviourbased approach prone to victim-blaming criticised in the literature reviewed and by one of the interviewed health promotion experts. Before discussing such issues, it was considered relevant to take a moment to review the case studies' acknowledgement of health promotion as an area of intervention of CSR, as elucidated from the portray of the general CSR statements operated in the first section of the last chapter (Table 11 of Chapter 5). General CSR statements were able to point out that, although embryonic, not transversal among industry sectors and not homogeneously in terms of wording, health promotion for external stakeholders exists as an area of action acknowledged within CSR statements: all of the respondents pertaining to the food retail sector mentioned the intention to pursue healthy behaviours through nutrition whilst one respondent from the ICTs and one from the PHPs expressed the intention to enhance quality of life through CSR. Worth clarifying is the fact that, although traditionally quality of life has been used as an indicator to describe patients' conditions with a focus on functional deficits, the term is also used to describe a comprehensive state of social, psychological and physical health conditions, for Veenhoven (2008) comparable to the notion of health promotion, although with a focus on individuals' auto-evaluation. 


\begin{tabular}{|c|c|c|}
\hline \multicolumn{3}{|c|}{ Chronic Disease } \\
\hline Patient-centred care & Risk Factors & Self-care \\
\cline { 2 - 3 } a3 & a2 & b3 \\
b1 & b2 & \\
& c3 & \\
& d1 & \\
& d2 & \\
\end{tabular}

\begin{tabular}{|c|c|}
\hline \multicolumn{2}{|c|}{ Social Exclusion } \\
\hline Special needs & Poverty/Hunger \\
\hline c2 & a1 \\
e3 & d3 \\
& e2 \\
\hline Safety & Wellness \\
\hline Child abuse & Alternative treatments \\
\hline c1 & e1 \\
\hline
\end{tabular}

Figure 4: Health promotion issues and sub-issues tackled by the CSRHPIs

Figure 4 provides a map of the health promotion issues, and relative sub-issues, addressed by the CSRHPIs as extrapolated from the analysis of the CSRHPIs specific objectives, sorted from the most to the least numerous. The CSRHPIs highlighted in grey are the ones formulated on the basis of policy evidence. Figure 9 shows that there are two major issues addressed by the CSRHPIs, chronic disease and social exclusion and two minor ones, safety and wellness. The sub-issues considered in relation to chronic disease are patient empowerment (a3, b1) self-care (b3), and reduction of risk behaviours (a2, b2, d1, d2). Poverty/hunger (a1, d3, e2) and special needs (c2; e3) are considered as sub-issue relative for the cause of social exclusion, whilst child abuse (c1) and alternative treatments (e1) are considered, respectively, in the perspective of safety and wellness. The focus on chronic diseases considered predominantly in in the perspective of risk factors and additionally in terms of patient empowerment and self-care resonates with the priorities set for both the WHO European Region and Portugal, calling for the tackling of NCDs, the strengthening of people-centred health systems and the empowerment of individuals. The addressing of social exclusion, approached both in the perspective of poverty and hunger and in that of disadvantaged groups, other than being coherent with the objective set within Health2020 to reduce inequities in health in Europe by reducing gaps associated with SDoHs is specifically pertinent for the Portuguese context for which, we have seen in Chapters 3 and 4, high levels of poverty and social inequality 
persist, that in turn represent major threats in terms of morbidity and mortality of the population as well as for the sustainability of health systems. The finding also resonates with Abreu and Crowther's (2005) observation that business actors in Portugal are more likely to uptake social commitments destined to fight poverty and social exclusion. Secondly, it is in line with the trend, depicted by the European Health Report of 2015, according to which the most common focus in addressing health inequalities in Europe has shifted from disadvantaged groups in 2010 to addressing poverty and hunger in 2013 (WHO Europe, 2015). A tentative to overlap the choice of issues with the levels of value creation depicted in the previous section was made, finding no relevant connection among the nature of engagement and the choice of the issues among the CSRHPIs.

Table 19: SDoHs tackled by the CSRHPIs

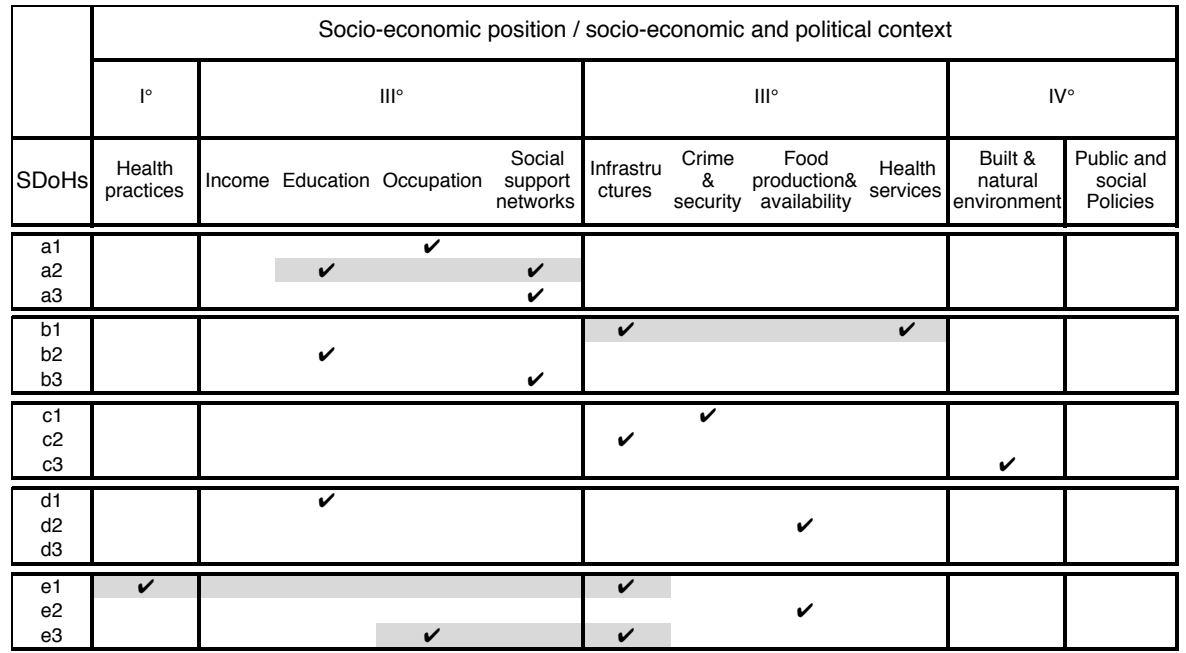

Table 19 pictures which SDoHs 5 were deemed relevant by business entities to tackle the selected health promotion issues. For reasons of clarity the SDoHs have been divided into four levels, ranging from the narrower level of behaviours $\left(\mathrm{I}^{\circ}\right)$, passing through the level capturing the social and economic status $\left(\mathrm{II}^{\circ}\right)$ and to the level of infrastructures, security, food production and health systems (III ${ }^{\circ}$ ), until reaching the level of built and natural environments as well as public and social policies (IV ${ }^{\circ}$.

${ }^{5}$ Adapted from the model presented in Chapter 3, Figure 1. 
It was found that the issues were addressed in the consideration of determinants pertaining to different spheres of action, covering three of the four different levels identified for the socioeconomic position and context in the case of chronic diseases $\left(\mathrm{II}^{\circ}, \mathrm{III}^{\circ}\right.$ and $\left.\mathrm{IV}^{\circ}\right)$, and two in the case of social exclusion $\left(\mathrm{II}^{\circ}\right.$ and $\left.\mathrm{III}^{\circ}\right)$. We see, within the area of chronic diseases, that the sub-issues of patient empowerment (a3, b1) and self-care (b3) are addressed through the fostering of social networks, the creation of infrastructures and the redefinition of health systems. Risk factors are addressed through educational activities (b2; d1) combined, in the case of a2, with a perspective of community engagement aimed at the constitution of social networks (a2) as well as a redefinition of food production and availability (d2). Poverty and hunger within social exclusion are addressed through action upon income, social networks, as well as through food production (d3), whilst special needs (c2; e3) are promoted through the creation of infrastructures and occupation. Child abuse (c1) is addressed through the establishment of additional security measures whilst alternative treatments (e1) are promoted through infrastructure and by incentivising health practices at the level of behaviours. Worth noting, in this perspective, is that only the initiative e2 was found to focus on behaviours as determinants of health; this finding contrasts with the criticisms addressed to CSR initiatives claiming they are almost exclusively based on behavioural, and often victim-blaming, approaches. Although showing that the determinants contemplated by the CSRHPIs cover a range that goes beyond the behavioural sphere, reaching across the socioeconomic and environmental spheres, Table 19 was also purposeful to ponder that, differently from what suggested in terms of best-practice for health promotion, recommending that interventions should rely on multi-strategy approaches, the initiatives were found to rely predominantly on approaches that focus on one determinant at a time. Considering solely the most tackled issues, chronic disease and social exclusion, it can be noted that three CSRHPIs inherent to chronic disease adopt a bi-determinant strategy (a2 focuses on education and community empowerment, b1 on both the reorganization of health services and the strengthening of infrastructures, and e3 on occupation and infrastructures) whilst the initiatives tackling social exclusion all have a single-level approach.

This subsection lends itself to a number of considerations. First and foremost that health promotion exists as an area of action within CSR practice and the CSRHPIs follow issues relevant for the context in which they are to be implemented. Furthermore, the initiatives, although often focusing on a single-level approach, do not rely uniquely on a behavioural focus and hence do not promote messages that 
narrow the sphere of action of health promotion. As for what concern the choice of issues, it is not possible to thoroughly discuss, on the basis of the small number of CSRHPIs reviewed, the concern risen both in literature and by health promotion experts according to which topics associated with stigma, such as addictive behaviours or communicable diseases, are left aside by CSR managers in the phase of initiative formulation, although none of the CSRHPIs analysed was found to address such topics. One question that arises, in this context, is why the choice was made for the CSRHPIs to align with priorities relevant for the context in analysis. Coherently with the rationales identified in the previous sub-section, the researcher explains the choice to tackle health outcomes as driven by opportunity, consequentiality, appropriateness and stakeholder responsiveness; in this sense health is both an area of business development, one sensitive to regulation and litigation, and an area in which involvement is considered as relevant in absolute as well as relative terms. Yet, it is not possible to conclude that the CSRHPI highlight a contribution of the business sector towards the achievement of a whole-of-society approach to health promotion, as they lack a framing, both at the level of CSR policy and at the level of the Portuguese institutions, that would allow a systemic other than incidental participation to health promotion goals and objectives. On the other hand, it is considered grounded the doubt that the systematic picking and choosing of more visible causes, social partners or certain classes of beneficiaries (in terms of age groups or presence in urban areas) may lead to the creation of certain classes of needs, potentially augmenting, rather than decreasing, inequalities amongst most vulnerable populations.

\section{On the advancing of social capital and trust-building at the local level}

The analysis of the objectives of the CSRHPIs brought forward in the previous subsection has allowed to understand that the CSRHPIs aim to the reduction of social exclusion at the local level, nevertheless the nature of the present research did not allow to gain sufficient information as to understand whether greater social inclusion for the beneficiaries of the CSRHPIs was achieved. What the research did allow to examine is the potential for CSRHPIs initiatives to forward social capital and trustbuilding locally and at the level of institutions, creating boundaries between companies and social partners of collaborative initiatives. The relationships established are examined on the basis of the nature of collaborations and partners involved. The nature of collaboration is discussed on the basis of Googins and Rochlin's (2000) scale of cross-sectoral partnerships depicted in Chapter 3. The 
reader may question why partnerships were used as a measure to discuss the creation of social capital and trust building at the local level as opposed to stakeholder engagement. This choice was given by the fact that, although interviewees depicted stakeholder consultation as one of the grounds for initiative formulation, no detailed information was given concerning the level of deliberation their inclusion offered. On the other hand, the relationships with partners were recounted from the first contact until the phases of initiative implementation. Googins and Rochlin's (2000) scale rates collaborations on the basis of the creation of collaborative advantage for parties involved, mutuality of choices, agreement on partnership composition and definition, and trust-building distinguishing collaboration in three types: reciprocal, developmental and symbiotic collaborations. Reciprocal collaborations are considered to be weaker than developmental collaborations, and the latter in turn, to be weaker than symbiotic collaborations. In order to consider the nature of collaborations it is necessary to take a step back to the categories of CSRHPIs A, B and $\mathrm{C}$ (and hybrids) discussed in the subsection relative to the nature of engagement. The researcher distinguishes three different types of relationships inherent to the three types of categories of CSR initiatives identified. The collaborations established within the level of value creation $\mathrm{C}$ (local development) are categorized as pertaining to the lowest level of the scale, that of reciprocal collaborations. They can be described as being transactional, in the sense that they are realized through a twoway transfer, where the allocation of business-based resources are exchanged with the possibility, allowed by partner entities, to access field environments and populations. In this case local communities and their representative institutions are to be considered rather as a locus of intervention than partners. The collaborations concretized in the context of initiatives categorized as pertaining to the levels $\mathrm{A}$ (innovation and adaptation), and hybrid A - C (innovation and adaptation, and local development) are categorized as being developmental. In this case the relationship formed among parties is stronger than an exchange of resources, requiring partners to work together to achieve results, exchanging, as it is the case for c2, were competences and experiences are shared in order to develop and configure ICTs solutions adapted to special needs' users, or as made possible through b3, where healthcare professionals and caregivers share needs and experiences relative to the process of care. In developmental collaborations parties gain a collaborative advantage from the instalment of alliances although, Googins and Rochlin's (2000) specify, it is possible that parties may achieve the same results also working separately. CSRHPIs pertaining to the levels B (value chain reconfiguration) and hybrid B-C (value chain reconfiguration and local development) were categorized as 
pertaining to the level of synergic collaborations. The inclusion of partners in the negative reconfiguration of business practices, as opposed to the consultation-based, consumer focus group-oriented collaborations operated by CSRHPIs pertaining to level A, requires that parties work jointly to achieve results that would not have been achievable without collaboration. This type of initiatives can be depicted as giving origin to synergic collaborations that require strong dependency among partners, a process described by the business representative for e2 in the following terms "a matching process of needs and resources, until we figure out, collaboratively, which path would allow the greatest level of opportunity, and benefit for each party" (free translation). As specified by Vogel (2008) the CSR practices that include third parties in the reconfiguration of the value chain create a strong level of obligation to comply with commitments, creating a situation in which the commitments undertaken can be defined, using Vogel's (2008) wording, as "quasi public" (p. 269). Furthermore, two of the three initiatives categorized as pertaining to these levels, d2 and e2 are the only multi-stakeholder partnerships encountered within the case studies, taking place, respectively, between company - governmental entity - school in the case of d2 and between company - local municipality - CSO in the case of e2. The two public entities, respectively municipal and governmental, partnering in the multistakeholder partnerships installed by $\mathrm{d} 2$ and e2 are, as expressed in the previous chapter, also the only public actors found within the social partners of the collaborative CSRHPIs. The researcher considers the scarce cooperation among the business and the public sector observed within the cases studied as a limit of the social capital and trust-building potential inherent to CSR practices that will be discussed further on in this chapter relatively to the contextual determinants of CSR implications. On the other hand, the lack of collaboration with governmental actors pre-empts, in some way, the risks associated with CSR initiatives offering leverage for lobbying to political élites through collaboration.

\section{Analysis of the limits encountered and of their determinants}

The last section discussed the limits, threats and opportunities found in literature and reported by health promotion experts on the basis of the findings resulting from the analysis of the selected case studies. After refuting the threats inherent to the divulgation of a narrow understanding of health, and of the scaling back of governmental actors, the researcher concluded that CSR initiatives present some dilemmas for health promotion in terms of potential pursuit of opportunistic 
objectives and the creation of inequalities arising from the purposeful selection of causes, beneficiaries and social partners. Two specifications are considered relevant at this point. The fact that CSR initiatives are potentially conducive to the pursuit of strategic objective constitutes a dilemma only when such objectives exclude or substantially leave behind social objectives; in this case practices shouldn't even be considered as CSR. As for what concerns the creation of inequalities arising from the purposeful selection of causes, beneficiaries and social partners the researcher believes the it be an issue to be confronted in all health promotion interventions and not only for the interventions implemented in the context of CSR. It was not possible to comprehend, given the nature of the cases studied, whether CSRHPIs offer leverage for the lobbying of political élites or give origin to processes of organizational control upon employees. A number of limits, nevertheless, were appraised, restricting the potential for CSR practices to contribute to the furthering of health promotion. In the following subsections, and on the basis of the information collected in Chapters 3 and 4 relative to the analysis of the rationales behind the involvement of the business sector in health promotion and the considering of health promotion in the CSR policy framework, such limits will be discussed one by one, together with what the researcher believes to be their causes. Coherently with the objectives set for the research, a distinction will be made between the causes inherent to level of intention, it is to say relative to what has been previously depicted as the CSR policy framework, and those tied to the level of action, namely to the contextual determinants through which the normative basis, areas of action and means of implementation defined at the level of intention are understood and translated in practice.

\section{Co-existing rationalities and one-sided CSR approaches}

One of the most crucial issues, if not the most crucial issue understood throughout the research, is the fact that there are different rationalities hindering the enactment of CSR commitments, strategic, consequential, relational, and fundamental. The coexistence of different rationalities in CSR practice is not, per sé, a problem. As specified by Goodin (2011) in relation to political organizations, different logics coexist and shift in the intentions and action across systems and organizations. In public administration, for instance, it is possible to observe the co-existence of approaches engaging a consequence-oriented rationality of cost-benefit utility, as well as following the principle of appropriateness, without one rationality undermining the other or the activity of said administration (ibid). Even more so, as 
specified by Goodin (2011 p. 490) it is "difficult to deny the importance of each of them (and others) and inadequate to rely exclusively on one of them". What represents a challenge is to combine and harmonize the different logics in a given framework (ibid). Inherent to, and preceding, the phase of harmonization is the issue of identifying and clarifying the co-existence of different logics, failure of which may result in a one-sided reading of CSR. Such one-sided reading constitutes an issue under two points of view. At level of CSR managers it may give origin to partial approaches to CSR practices considering, for instance, solely the facet of strategy or that of expected outcomes, failing to capture the complex and multi-dimensional nature of CSR. On the other hand, beyond the business environment one-sided readings foster a reception of CSR as being solely driven by opportunity, stirring mistrust and adversity and hence limiting the possibility for the diffusion and development of CSR. Resuming, what constitutes an issue is the possibility for CSR to be understood partially, both in its practice and in its reception, issue that derives from the inherent complexity of CSR as explained in Chapter 3. We have seen in Chapter 3 that international and supranational CSR policies hinder different rationalities, in turn reflecting different theoretical approaches concerning the role of business in society and the purpose of CSR commitments. The author believes the first cause of the one-sided understanding of CSR to lie in the fact that the policies organizing its meaning and practice fail to address the existence and implications of the different rationalities hindering commitment. As we have seen in Chapter 3 the UNGC, OECD, and ILO call in cause the principle of appropriateness and that of public responsibility, whilst the EC and ISO bring forward the principles of stakeholder responsiveness and expected consequences. This creates a lack of univocal framing that lends itself to punctual and pick-and-choose interpretations on the field. In specific, the referential UNGC - ISO 2600o, is the principal frame used within the EU, is particularly problematic in what its underlying assumptions appear to be alternative rather complementary, the former focusing on the redefinition of business practices in terms of doing the right thing from an ethical perspective, whilst the latter considering that business entities are merely responsible for the impacts inherent to their sphere of influence.

The sorting of the selected case studies in categories, and the analysis of each categories' underlying rationale, allowed comprehending that CSR health initiatives may follow either the principles of appropriateness/stakeholder responsiveness consequentiality, or opportunity. If the engagement of the former two can be explained in terms of a different interpretation of the CSR policy framework, and of 
the one-sided divulgation efforts of local CSR networks, is relevant to note, in this context, that the principle of public responsibility was not found at the level of implementation, whilst the principle of opportunity, although not present in policy, was individuated. As for what concerns the lack of engagement of the principle of public responsibility its avoidance is to be contextualized in a perspective, coherent with what depicted since Chapter 1 , in which the state is no longer considered, or trusted, as the central and agenda-setting authority of societal governance whose priorities set through the public policy process are to be followed. On the contrary, as we have seen for the context in analysis, it is at times believed as an obsolete and bureaucratic machine incapable of promptly responding to collective needs. Such belief may be reinforced by the lack of governmental involvement or public discussion upon the need for business entities to follow the principle of public responsibility. On the other hand, the strategic view on CSR, although not present in policy, appears to be widespread in practice, heritage of the business environment's debate according to which doing good leads to doing well at the level of the bottom line, debate that proved fundamental to the development of a global notion of CSR, then adapted locally through mimetic and isomorphic processes, and that was brought back to attention in Porter and Kramer's (2011) consolidation of the notion of shared value. At the local level, such perspective has been found to be brought forward by trade associations and business and management schools whose debating, teaching and researching upon CSR is often centred upon the business, as opposed to the social, impacts of CSR.

\section{The lack of awareness concerning health promotion}

Through the depiction and analysis of the CSRHPIs it was possible to confirm one of the initial assumptions of the research, it is to say that health promotion represents an area of action of CSR in practice and the CSRHPIs follow issues relevant for the context in which they are implemented. On the other hand, it was concluded that the intention to pursue health outcomes, perceived by the private sector as being a strategic, sensitive and appropriate issue to tackle, is not brought forward in awareness of the health promotion approach, with its value-laden and transformative dimensions aimed to achieve equity-based social change through socio-ecological and assessment-based approaches. This represents a problem in what the pursuit of health outcomes within CSR misses the opportunity to reinforce both the normative and operational goals of the health promotion agenda, allowing for what have been described, in line with Kickbush (2010), as co-benefits. 
The researcher stands by the perspective that the consideration of health operated within the policies that make up the CSR policy frameworks in general, and especially within ISO 26000, even in its post-2015 programmatic agenda, is unfit for the purpose of sustainable development. In particular, ISO 2600o's lack of acknowledgement of health as a core area of action, as opposed to a sub-issue inherent to consumer, environmental, and community health appears bizarre in the perspective of the standard having resulted from a lengthy process of participation, interaction and negotiation among numerous stakeholders, representatives from CSOs, the business sector, academia, and state entities, that was aimed to the obtainment of legitimacy of the standard itself. Such lack of consideration highlights a missed occasion to plea the cause for health promotion. The fact that human rights figure as a core area of intervention, whilst health promotion doesn't, could be explained resorting to the criticism made by Porter (2007) concerning the changes that took place within the social justice and health promotion discourse in the period between the Ottawa and Bangkok Charters. According to Porter (2007 p. 77):

\begin{abstract}
"Ottawa mentions human needs six times, rights not once; the Bangkok Charter talks almost exclusively about human rights. Rights language is supported by most corners of the health promotion field as useful for fighting legal battles. However, rights language is also part of an individualistic, legalistic discourse (Robertson, 1998). It 'has no terms for those dimensions of the human good which require acts of virtue unspecifiable as a legal or civil obligation' (Ignatieff, 1985, p. 14). For example, the Ottawa Charter states, 'health promotion generates living and working conditions that are safe, stimulating, satisfying and enjoyable'. Rights can only help get you to safe"
\end{abstract}

Another cause can be individuated in the failure of the health promotion community at the international level, as well as in the context of analysis, as we have seen in Chapter 4, to correctly advocate the health promotion cause, define which responsibilities are to be allocated to which societal parties, and monitor on their implementation, as well as set clear standards and tools for health promotion interventions and collaborations. As mentioned in Chapter 4, co-existing rationalities motivating the involvement of business actors in the pursuit of public health objectives were found also within the health promotion approach. In specific, it was observed that the Jakarta Declaration and the Bangkok Charter engage a consequential perspective in which businesses' responsibilities for health are framed as elapsing from the impacts connected with business activities, whilst the perspective offered in UNESCO's Report of the International Bioethics Committee on Social Responsibility and Health and the Declaration on Bioethics and Human Rights 
appoint a perspective of appropriateness were business responsibility for health is framed a moral obligation inherent to the nature of society. Unsurprisingly, business responsibility for health is never framed in strategic terms. On the basis of the consideration that it is WHO the major entity shaping the policy and practice of the health promotion approach, the author considered that the health promotion approach as framed by the Jakarta and Bangkok charters fails to stress and accent on the perspective of appropriateness, according to which business entities should pursue health promotion because it is their moral responsibility as well as a societal expectation to do so, notwithstanding of impacts. Also, following Porter (2007) it was argued that the perspective relying on the principle of expected consequences within the Jakarta and Bangkok declarations is inherently flawed in what, although emphasizing impacts, it fails to establish clear links of causality between causes and effects of business activities upon health, or putting health promotion at the core of the health agenda.

To date, in Portugal, as reported by the interviewed public health experts, health promotion isn't a public health priority, with Priority Programs' departments predominantly focused on the reorganization of health services, and publicly funded health promotion activities atomized and delegated to third-party actors. Further, according to public health respondents, there is a lack of research able to collect information showing the effect of non primacy health policies and activities on population health as well as a lack of political will to take a stance in appropriately denouncing and reprimanding the effect of production and trade on human health and its determinants. Such scarce political intervention overlaps with citizens' weak empowerment and community participation, heritage of the Salazarian dictatorship period, to which local municipalities are trying to pose remedy through action of education and social empowerment, although the weight of such activities is far from that of other European countries (Loureiro, 2013). Such inability translates, as we have seen for the case studies, in a situation in which the Portuguese General Health Directorate finds itself, due to the absence of resources, of having to respond to request for collaborations by companies, other than proactively setting strategic areas of action, priorities or approaches. In this sense, as specified by Freudenberg (2014), health is a powerful frame to advocate for social responsibility, but it is first and foremost the responsibility of health promotion advocates to provide theory and practice motivating and orienting involvement and change in given policy areas and in line with the normative precepts set by the health promotion approach. 


\section{The issue of the positive understanding of responsibility}

The analysis of the CSRHPIs suggests that the majority of businesses consider the exercise of CSR as relying on positive commitments, expanding the sphere of action of business activities, providing anew services and products through innovation and adaptation, or making available material or non-material resources intended to increase capacities, infrastructures and resources of the environments surrounding business activities. This is a problem in the measure it does not allow to effectively counteract harmful practices elapsing from business operations, or give space to patterns of accountability. In this perspective it is worth specifying that although some industries may be viewed as being more problematic and other less, all companies, notwithstanding industry of affiliation, are apt to produce negative impact through corollary business practices relative to employment, lobbying, research and public affairs. In this sense the companies that begin the planning of their CSR strategies by the perspective that they are already socially responsible, avoid all significant self-reflection on their business model and on how to redirect growth as to strive towards sustainable development.

Other than connected with the engagement of a one-sided CSR rationality, relying on principles other than those of expected consequences, additional causes for the positive understanding of responsibility both at the level of the CSR policy framework and at that of its implementation were found. At the level of policies some responsibility for a superficial or limited appraisal of negative impacts is to be associated with the notion of sphere of influence provided by ISO 26000 . In 2008, during one of the final meetings of ISO's working group on social responsibility, the Special Representative of the UN Secretary-General on Business and Human rights John Ruggie, author of the notion of global public domain, argued that the term sphere of influence is misleading, ambiguous, morally flawed and susceptible to strategic manipulation. Ruggie (2008) argues that the concept is prone to different interpretations: it may be considered for what concerns impacts, but it may also be intended in terms of leverage or proximity, not allowing a coherent and precise establishment of liability for outcomes to which corporate activities have contributed. As for what concerns factors inherent to implementation, a first motive can be individuated the business sector's scarce sensitivity or reluctance to admit the existence of negative impacts connected with business operations both on the micro and broad scales. Secondly, it may be connected to the lack of knowledge concerning appropriate methodologies, or absence of skills, apt to quantify social externalities at 
a corporate level, as it is the case for the instruments provided by the disciplines of health economics and environmental economics. Dinah A. Koehler, a retired Deloitte partner (2014), has appropriately and straightforwardly addressed the problem concerning the lack of engagement of methods quantifying social externalities in CSR:

\begin{abstract}
"For many companies the problem is not a lack of environmental, social and governance (ESG) issues that stakeholders think are important. The challenge has been figuring out when and why these issues might become financially material to a company (...) The costs of the externalities to others in the community, the supply chain, and in the broader ecosystem are real and can be quantified via health economics and environmental economics. This is knowledge that needs to be more integrated into corporate decision-making on the trade-off between total (social and environmental) costs and benefits of every product and technology being used and produced. Omission of this type of information means that it has zero value to the company."
\end{abstract}

Finally ,even outside of the business environment there seems to be a scarce focus at the level of Portuguese authorities on the issue of accountability, as evidenced by the problems encountered in the enforcement of laws limiting negative impacts, for instance the ones connected with marketing, as argued in Chapter 4, which does not stimulate the acknowledgement of negative impacts. In this sense the recommendation is to focus its interpretation and divulgation on the issue accountability, rather than to change the notion of sphere of influence. In addition to focus the debate on the issue of harm, the business actor's adoption of tools apt to operate an impact assessment of actual or prospective impacts of business activities is needed.

The weak pursuit of social outcomes

One of the findings of the research presented in the first section of this chapter was that even though the author observed different types of initiatives to be formulated differently, all the cases studied shared the fact that little planning was dedicated to the issue of evaluation of social outcomes elapsing from CSR initiatives. Even more so, it was found that CSR managers confused the notion of CSR performance with that of social outcomes. Within CSR social performance evaluation and social outcomes evaluation are two activities that are connected, although they do not refer to the same thing. As outlined in the document Beyond Compliance: Measuring to Learn, Improve, and Create Positive Change issued by the The Center for High 
Impact Philantropy of the Stanford University (2013 p. 3), the measurement of performance can be depicted as:

"The ongoing collection of data with the purpose of managing, measuring, and accounting for programmatic or organizational results. Typically, this means data are focused on the relationship between inputs, activities, outputs, and sometimes outcomes"

The measurement of social impact, on the other hand, is defined as

\begin{abstract}
"A change or improvement that is meaningful to the people or communities a non-profit and/or donor seek to serve (...) assed by using data and performance feedback from the organization, program and/or the field (i.e., evidence of what works) to determine whether the inputs and activities not only resulted in the desired outputs and outcomes, but also achieved the ultimate goal - social impact."
\end{abstract}

The lack of evaluation within CSR constitutes a problem in what it does not allow to comprehend which typologies of CSR initiatives are most likely to be successful and hence set standards for best practice. Additionally, it participates in reinforcing the mistrust that CSR practices face vis-à-vis academia and governmental actors concerning the possibility for CSR initiatives' effectiveness. As for what concerns the factors influencing the scarce culture of evaluation, the researcher observes in a first instance, comparably to what argued for the consideration of negative responsibilities, it to be related to an insufficient sensitivity concerning social impacts at the level of the business sector. In a second instance, and reporting one of the explanations brought forward by the interviewed CSR managers, scarce evaluation of CSR practices may relate to the absence of adapted methodologies to appraise the social impacts of CSR practices. It should be in this context mentioned that, although not analysed within the policy frameworks reviewed in Chapter 3, a CSR framework for reporting on social performance exists, the $\mathrm{G}_{4}$ Sustainable Reporting Guidelines, produced by the Global Reporting Initiative (GRI), founded in 1997 and having launched the first guidelines in 2000. As for what concerns social impacts the IMPACT PROJECT - Impact Measurement and Performance Analysis of CSR, launched in 2010 and funded by the European commission, other than promoting the need to assess CSR impacts, has created tools to measure the impact of CSR across different levels in European Countries operating in the automotive, retail, ICT, construction and textile. Given the existence of some instruments, their scarce uptake by the companies participating in the study may, similarly for what concerns the appraisal of negative impacts, be linked to the weakness of the public debate on CSR, and to the related scarce external pressure imposed upon business actors concerning 
CSR. The researcher further highlights the need for CSR strategies to explicitly differentiate among company and social impacts expected from CSR initiatives. A second remark concerns the need to discern amongst social performance and social impacts generated, considering that the first relate to the achievement of programmatic results and the second to the generation of systematic change. Such impacts may be assessed both quantitatively, through the consideration of indicators such as the ones of disease incidence, literacy, life expectancy, and so on, or qualitatively, trough interviews and case studies. It may be opposed, at this point, that some metrics, such as the one of life expectancy, are long-term and not apt for short-term management objectives. Still, long-term and short-term metrics could be combined. Also, the adoption of long-term metrics may motivate the establishment of long-term CSR initiatives, fact that would counteract the often project-based nature of CSR initiatives.

\section{Limited instruments for cross-sectoral negotiation and collaboration}

In the first part of this chapter it was argued that CSRHPIs highlight a contribution of the business sector to health promotion objectives, although not one that is coherent with a whole of society perspective in the measure it lacks the systematic reference to a broader framing, the public policy process, as well as mechanisms and structures to allow cross-sectoral negotiation and collaboration. If the issue of the lack of systematic reference to the public policy process, linked with the scarce relevance imposed upon the principle of public responsibility within CSR policy and practice, has been already dealt with at the beginning of this section, we will focus at this point upon the lack of appropriate mechanisms for cross-sectoral negotiation and collaboration within CSR. The issues inherent to negotiation are to be found in the lack of mechanisms to guarantee stakeholder deliberation; it is to say the consideration and inclusion of concerns raised by stakeholders. Such concern found confirmation in the reports of the CSR managers responsible for the case studies, which depicted how selected stakeholders were consulted as experts for initiative formulation, whilst failing to portray the existence of mechanisms for the systematic inclusion of stakeholders into agenda-setting, factor which lead the researcher to consider that such mechanisms are not available. As for what concerns cross-sectoral partnerships, problems were found relative to the scarce presence of governmental entities in partnerships, as well as in the scarcity of synergic as opposed to transactional collaborations. The lack of appropriate mechanisms for cross-sectoral negotiation and collaboration within CSR practice constitutes a problem in what it 
limits the possibility for CSR to represent a vehicle for the negotiation and mediation of interests among different societal actors as well as for the convergence of action necessary to solve complex social problems.

As for what concerns the limits inherent to stakeholder negotiation the author considers them as being inherent to CSR policy. As explained by De Colle et al (2012), although the consultation phase foreseen by ISO 26000 allows business entities to gain awareness regarding issues considered noteworthy by stakeholders, it is inappropriate to speak of stakeholder engagement, where by engagement it is intended the transfer of power from the haves to the haves nots (Cummings 2010). Colle et al (2013 p. 186) argue that this is due to the inner-oriented, managerial approach to social responsibility that ISO 26000 promotes:

\begin{abstract}
"The tendency to focus on the managerial/procedural aspect of a CSR standard, especially in its implementation process, can be detrimental for the outward-looking stakeholder-orientation of the organization's members, by shifting the organizational members attention on the implementation process itself: Rules and regulations [...] encourage people to be oriented inwards-towards doing the job as they felt it should be done-rather than out- wards, towards the users of public services. (...) (Organizations) somehow lose ownership of the process: it becomes something exterior to them. [..] It is not really something they feel responsible for"
\end{abstract}

Such inner-orientation leads to a configuration where stakeholder engagement is neither participative nor compelling (Colle et al., 2013). Stakeholders are not considered based on the measure in which they are affected by given business outcomes, they are mapped and prioritized by the organization according to their power to affect business outcomes. Even when stakeholders are considered, there is no guarantee that their insight will be included into decision-making, leaving CSR planning to be a question that follows business agendas rather than stakeholder's interests (Matten and Moon, 2008). According to Marens (2010), the flaws related to stakeholder engagement are to be considered a heritage of the North-American construction of the concept of CSR, where relevant stakeholder groups, namely labour unions, were excluded from the participation in the process, leading to a situation in which CSR was defined unilaterally, being the effort one to bypass stakeholder empowerment rather than foster it. According to Herbert (2005) for stakeholder engagement to be truly participative, and hence social responsibility to be thoroughly legitimate, each affected stakeholder should have a seat at the table of decision, being, in a best-case scenario, representatives of stakeholders deliberatively elected, given that the normative legitimacy of the stakeholder engagement process 
depends upon the extent to which the ones affected by the decisions have been included in the decision-making process. As for what concerns the limits inherent to cross-sectoral collaboration, on the other hand, causes are to be determined both as being inherent to the CSR approach as well as external to it. Similarly to the case of stakeholder engagement, no specific criteria are defined for how responsibilities should be allocated within partners in the phases of initiative planning, design and formulation, or of how, for instance, conflict of interest should be avoided. On the other hand, the author considers it to be also the responsibility of parties external to the business environment, the civil society and predominantly that of governmental entities, to set guidelines, instruments, structures and spaces of discussion apt to facilitate dialogue and collaboration in the belief that responsibilities do not "lie" or are "placed" on a given actor, but are built and negotiated among parties, it is to say, they are collectively defined. In this sense, the Portuguese government has insofar withheld from its responsibility to address CSR practice in Portugal. 


\section{Chapter 7: Discussion and Future Perspectives}

As stressed in the very beginning of the first chapter the present research set out to identify the features of business involvement in health promotion through CSR, examining and discussing the issues arising from such involvement in the context of the Western European welfare state. The purpose set for the research was that of participating to the clarification of the potential contributions and dilemmas CSR initiatives pose for health promotion policy and practice, as well as unveiling the current limits to such contribution. The knowledge produced aims to participate to the debate on the legitimate and effective allocation of societal obligations among state, for-profit and civil actors in the contemporary welfare state. The researcher started by considering CSR as an approach channelling additional normative and operational tools for business involvement in the fulfilment of public objectives in the welfare state, in specific, for objectives relevant in a health promotion perspective. On the basis of the findings the researcher concluded that the CSR approach allows some basis for business actors to reconsider and reconfigure their role in society both at the level of intention and at the level of action. At the level of intention, CSR potentially allows for business practice to appraise objectives of relational, fundamental and consequential nature, other than the strategic ones imposed by the for-profit nature of the firm. At the level of action it defines an agenda and processes, namely evaluation of impacts and stakeholder consultation, apt to select and prioritize noncommercial objectives relevant for the context in which they are to be pursued. In this sense, coherently with Vogel (2005 p. 163) the researcher concludes that: "the market can supply more virtue”.

In specific, CSR initiatives were found to be apt to contribute to health promotion by allowing business actors to participate to the furthering of contextual health promotion priorities and approaches, as well as enabling the advancing of social capital and trust-building at the local level. Nevertheless, such contributions were found to be partial, limited by a number of specific boundaries inherent to both the way the CSR approach is configured and to the way it is applied: co-existent rationalities and partial understandings concerning the CSR approach; lack of awareness of business actors concerning the health promotion approach and its 
dimensions; positive understanding of responsibility; and limited instruments for cross-sectoral negotiation and collaboration. Were identified in literature potential dilemmas posed by CSR initiatives to health promotion policy and practice: divulgation of a narrow understanding of health, scaling back of governmental responsibilities, and channelling of lobbying activities intended to avoid regulation or set policy priorities favourable to commercial, as opposed to social objectives. On the basis of the analysis of the policy process of the CSR policy framework, as well as that of the case studies, the researcher refuted the existence of threats, linked to CSR initiatives, relative to the scaling back of governmental responsibilities or the narrowing of the understanding of health. On the other hand, it confirmed their potential instrumentality to the pursuit of opportunistic objectives, such as market differentiation and regulation avoidance. It was not possible to comprehend, given the nature of the cases studied, whether CSRHPIs offer leverage for the lobbying of political élites or give origin to processes of organizational control upon employees. It was observed, nevertheless, that the purposeful selection of causes, beneficiaries and social partners operated predominantly on principles other than that of appropriateness, might lead to CSR initiatives' emphasising, rather than counterbalancing, of inequalities in the access to resources and opportunities for health.

Based on the conclusions of the research this brief and concluding chapter specifies adjustment needed for a CSR approach as to unlock the full potential of business entities in health promotion through CSR, so to paraphrase the goal set by the Jakarta Declaration (WHO, 1997). Such adjustments are differentiated in imperative adjustments, potential alternative development, and recommendations for the development of a joint CSR - health promotion policy agenda. The presentation of further research perspectives that may continue, deepen and refine the purpose the present research and its specific questions concludes this final chapter. 


\section{Imperative adjustments}

\section{For a stronger normative framing of the CSR approach}

In the previous chapter it was argued that one of the major problems of the CSR approach is the lack of clarification, within the CSR policy framework, of the coexistence and complementarity of the different normative grounds motivating and shaping the logics of action of the social responsibilities of businesses, and of the consequent partiality of interpretation of its normative basis. As previously stated, the partial understanding of the normative basis of CSR constitutes a problem in what it contributes to the lack of univocal framing concerning the grounds, sphere of action, and expected consequences of CSR, but more importantly it is a problem in what it does not allow for CSR activities to be acknowledged as legitimate by nonbusiness actors. Coherently with what stated in the previous chapter, the researcher recommends for the CSR policy framework, and in specific for the UNGC - ISO 26000 referential, to proceed to an effort of making explicit first, and harmonizing then, the normative principles underlying CSR commitments. This should be done by explicitly stressing that it is insufficient to motivate CSR activities on either processbased or outcomes-based grounds, as such grounds are complementary rather than mutually exclusive.

Additionally, the researcher considers the need for the moral grounds of CSR to be arranged hierarchically, setting a higher relevance for principles stressing the fundamental nature of CSR, and only secondly to motivate involvement on the basis of consequential, relational or strategic grounds. Within this research were depicted as relying on a fundamental rationality CSR commitments conceived upon the principles of public responsibility and appropriateness; their nature depicted as fundamental in the measure it relies upon the rightfulness of processes vis-à-vis expectations, as opposed to the pursuit of outcomes in a stakeholder, accountability or strategic perspective. Not discarding the importance of the principle of responsibility, to which specific attention will be dedicated in the forthcoming section, the researcher considers that in the first position of the hierarchy of principles through which to appraise CSR initiatives should figure the principle of appropriateness, followed alternatively by that of public responsibility or stakeholder responsiveness (as will be explored in the sections on partnered and polycentric governance - forthcoming), that of expected consequences, and finally, that of 
opportunity. This prioritization is motivated on the grounds of the consideration that the principle of appropriateness stresses the relevance of complying to shared rules, principles and procedures set by a community as a whole, rather than conforming to more contingent expectations set by the public policy process, given stakeholders or by patterns of accountability. For this to be relevant, though, it would be necessary to build a stronger debate first, and set boundaries and procedure then, concerning roles and behaviours considered appropriate for business actors. The author believes that such extensive framing and organizing of the normative grounds of CSR practices would contribute, other than to a harmonization of understandings, to build a greater case for CSR involvement; limiting the possibility for CSR initiatives to be constructed solely upon strategic grounds whilst increasing their legitimacy-basis. The absence of such normative framing, on the other hand, strongly hinders the transformative potential of CSR.

\section{For a health promotion-based public health agenda}

As stated in different parts throughout this research, one of the main issues to be faced as to unlock the potential of business actors in health promotion has to do with the fact that health promotion is not set as a core focus on the health agenda both internationally and within the context of analysis. This issue transcends the CSR framework and is one of responsibility of public health professionals and advocates first, and public and civil society actors then. In a perspective in which the health promotion approach struggles to gain centrality among a still predominantly biomedical understanding of health, it is unsurprising that health is not a core subject of the CSR policy framework, and that, although health was found to be an area of action in CSR practice, CSR initiatives are carried out without awareness concerning the value-laden, socio-ecological and assessment-based nature of the health promotion approach.

The researcher considers that prominence of the health promotion approach should be sought on two levels. In a first instance, by highlighting the connection existing between social justice and health. In this sense health strategies should be concerned first and foremost with levelling the inequitable conditions in which people are born, live, work and die, and only secondly with morbidity and mortality's behavioural or biological influencers, or with innovations in treatment approaches. This would be made possible through both social mobilization and a reversal of current priority 
setting upon health objectives. In this perspective the researcher considers it worthy to adopt a general understandings of social responsibility for health in line with the one brought forward by UNESCO's Report of the International Bioethics Committee on Social Responsibility and Health and the Declaration on Bioethics and Human Rights as opposed to the one brought forward by WHO's Jakarta and Bangkok conferences. This because the understanding brought forward by UNESCO firmly highlights the nature of health as a right purposeful to the achievement of other human rights. In consideration of the criticism made by Porter (2007 p. 77), according to which "rights language is also part of an individualistic, legalistic discourse" contributing to the understanding of health as a personal, as opposed to collective resource, the researcher stresses the relevance for health to be addressed, in a health promotion perspective, as an inherently political issue that considers the inequitable distribution of resources that comes from the inequitable distribution of power (Bambra, 2005). In order for this to be possible, Kickbush (2010) suggests the need for the development of instruments of policy analysis assessing how to reproduce health as a system's goal, and Bambra (2005) highlights the relevance of the development of the area of study of politics of health, to be added to the existing ones of health economics or sociology of health.

As argued above, the health promotion approach is concerned with the pursuit of the removal of barriers to equal opportunities in controlling the determinants of health. In order to allow this, the researcher identifies a second relevant action to re-orient the health agenda in line with the health promotion approach, to be the elucidation, and were relevant denunciation, of the universe and impact of such non-biological determinants on health. In this sense a crucial way to strengthen the advocacy basis for the centrality of health promotion is to collect information and develop tools apt to show the effect of non primacy health policies and activities on population health as well as set procedures to appropriately denouncing and reprimanding such effects. Such effort has been called upon ever since the Ottawa Charter, and still it has not been acted upon for lack of political will of national and supranational public and civil actors, hindered by a shortage of systemic vision and an excess of self-interest.

As we have seen in Chapter 4, the need to build capacity for, and assess, the health equity impacts of public policies first, and business activities then, is a priority goal which has been stated both for the context in analysis and internationally. In this perspective the author considers that it is first and foremost the responsibility of national public authorities, and that of public health professionals, to work for the 
advocacy and support of a redefinition of health and public services towards health promotion. Only then will it be possible to take an open stance in building the agenda relative to the business sectors' participation to health promotion objectives, based on expectations to contribute to evidence-based health promotion priorities, as well as on the potential negative and positive impacts of business operations upon health.

\section{Two potential alternative developments of the CSR approach}

If a stronger normative framing for CSR and a higher prominence of health promotion appear as unavoidable pre-requisites for the involvement of businesses in health promotion, two alternative developments are postulated concerning the dialogic nature of CSR, it is to say concerning which actors and organizations are businesses to predominantly interact with to appraise relevant objectives to pursue, and expectations to fulfil, within their host environment. In the first chapter of this research it was brought forward that CSR is considered a channel to achieve a social embedding of markets both in a perspective of partnered governance with public authorities, and in a perspective of polycentric governance overcoming the state. Such developments are picture as alternative below.

\section{CSR and partnered governance}

Midtun (2008) stressed that CSR represents a form of self-regulation that may supplement, or even to some extent substitute, public policy-led governance, arguing however, that CSR-based self-regulation could be much more effective if it is was more systematically integrated with political steering in joint partnered governance. The researcher concluded that CSR initiatives were found to partially contribute to contextual health promotion priorities and approaches, and to the building of social capital and trust-building at the local level. If the building of such ties stands true at the local level, it was also observed, within the Portuguese context, a clear estrangement, and at times rivalry, of business actors and governmental actors. Also, it was concluded that although the cases studied did converge with public policy priorities, they cannot be said to highlight a contribution of the business sector towards the achievement of a whole-of-society approach to health promotion, lacking a framing, both at the level of CSR policy and at the level of the Portuguese institutions, that would allow a systemic other than incidental participation to health promotion goals and objectives. 
On the basis of the analysis of case studies and examination of the CSR policy framework, the researcher considers that the CSR approach should take a step back and re-include the state as a coordinating actor, and the public policy-making process as a means to make choices concerning CSR commitment. It is considered as a step back in the measure that, as explained in Chapter 3, it seems that the principle of public responsibility was by-passed when large MNEs moved from being agendafollowers to agenda-setters at the global level. Also, the researcher considers the tendentially state-avoiding nature of the current understanding of CSR as tied to a North-American interpretation of business and government relations to be inappropriate in the context of the Western European welfare state.

A development of the CSR approach towards partnered governance would envision, for instance, for the UNGC - ISO 2600, and for the entities working upon its dissemination, to explicitly acknowledge the relevance of the principle of public responsibility, considered by the OECD Guidelines and MNE Tripartite Declaration, as an appraisal criteria for CSR initiative formulation, given that its avoidance contributes to the separation rather than integration among objectives inherent to economic sectors, limiting the effectiveness and well as legitimacy of CSR interventions. Furthermore it would be of relevance to include the establishment of political relationships as a core area of action of CSR as, as we have seen through the case studies, such motive underlies certain CSR commitments. Making the will to establish such relationship explicit, together with the formulation of appropriate safeguards for interaction, would counteract the argument according to which the access to policy élites is a vested and threatening aspect of CSR practices. At the level of implementation, a partnered governance approach would guarantee the construction of CSR strategies that are adapted and relevant to their local context and beneficiaries, and that can integrate the resources and competences of the public sector, resulting in greater effectiveness other than legitimacy. The researcher considers that, on their side, governmental actors should work towards a steering of CSR for public objectives, through the redaction of national action plans adapted to welfare state tradition, existing relationships between government, business and society, and public objectives, and when relevant through regulation. If it is true that the voluntariness of CSR has been motivated upon a will to complement and at times go beyond existing regulations, the researcher considers, coherently with Vogel (2005), that public facilitating, endorsing, incentivising or boundary stances underpin CSR, in what they set boundaries for activity and rewards for compliance. 
At the same time, as also previously stated, the researcher considers that such commitment would allow for business resources to be co-opted for public objectives, other than the other way round.

\section{CSR and polycentric governance}

In a second instance the present research grounded on the consideration that CSR may be a means for businesses to participate to a furthering of non-business objectives in a perspective of polycentric governance that to some extent bypasses state coordination, being organized around stakeholder interaction, negotiation and deliberation of issues of public interest. As explained in the beginning of this research, the polycentric governance refers to an approach to public administration in which diverse actors, from both government and non-government organizations, each with potentially competing interests, organize their relationships beneath a common system of rules and goals. As specified by Liebset and Gary (2003) behind the view considering that governance is, or will be, polycentric, no agreement can be found on how such polycentric governance is to be arranged. Liebset and Gary (2003) make a differentiation among the alternative possibility to disperse authority among broad parallel administrations, or in task-specific and overlapping ones. Either way, even though seemingly overcoming the coordinating role of the state, the polycentric governance approach requires a hierarchy of actors apt to set the agenda and the common system of rules under which decentralized actors are to function. As specified by Araral and Hartley (2013) a way of conceiving polycentric governance may be locating coordination and monitoring at high governance level, leaving to local units the responsibility to self-manage for what concerns implementation and the achievement of outcomes. Araral and Hartley (2013) further specify that the role of high governance levels goes beyond that of coordination, requiring actions to organize the distribution of responsibilities and redeem disagreement and conflict.

The researcher considers that, although CSR highlights a "politicization" of business decision-making, as stressed in the beginning of this research, in turn leading to the acquisition of institutional power and legitimacy by a business-based organization, there are, to date, little or no examples of polycentric governance initiatives through which business actors have participated via their CSR strategy, but merely examples of partnered governance (Midtun, 2008). This is due to be ascribed, in general terms, in the lack of research, political consensus, and political will concerning the processes of institutional change needed to delineate agenda and boundaries of autonomy. In 
the perspective of the company, on the other hand, for the polycentric governance model and participating stakeholders to be able to impact business decision-making, there is a need to take remedy to the lack of mechanisms and procedures apt to guarantee stakeholder deliberation and stronger ties with the community. For what concerns the context in analysis, that of Portugal, the potential for CSR to allow businesses' participation to polycentric governance public administration approaches appears even more distant due to lack of a institutional tradition of cross-sectoral coordination, as well as due to a weak competence of private actors (both non-profit and for-profit) and influence of CSOs concerning the process of public policy-making. If such model was to be deemed relevant fur further public administration developments, there would be a need for public entities, civil society organizations, and management schools and associations, to participate to the raising of awareness concerning overall scope of the sustainable development agenda, local priorities and objectives, as well precise contribution of citizens, organizations and institutions. Collaborative models for decision-making could be tried out, studied and assessed, for instance, by creating issue-specific clusters at the local, regional and national levels.

\section{Towards a joint CSR - health promotion policy agenda}

On the basis of what insofar argued the researcher considers, coherently with Kickbush (2010) and Kjærgard et al. (2011), that a future area should be development of a joint policy agenda for sustainable development and health promotion. Kjærgard et al, (2011 p. 558) suggest that the establishment of a joint policy is dependent upon the uptake of an approach deemed as following a "duality of structure", which would allow taking a new stance at a normative and strategic level. The authors portray duality of structure in the following terms:

\footnotetext{
"Thinking along the lines of duality of structure means that the integration of health promotion strategies and sustainable development strategies cannot be based on an approach to integration in which either health or sustainability is given precedence over the other. From a duality perspective, integration means conceiving sustainability from a health perspective and health from a sustainability perspective".
}

The researcher considers that a first step for developing a joint agenda for CSR and health promotion would be reconsideration of the conceptualization of development 
envisaged for the 21st century in terms of healthy and sustainable development (we agree that the notion of health is, at least supposedly, included in sustainable, but making it explicit would make contribute to highlight the existence of synergies). A following step would be the identification of areas of action, as it may be for instance, food production or air pollution, which are purposeful to the setting of targets that are relevant for both agendas. Successively, and coherently with what advocated in the previous section, there would be the need for the outlining of a (top-down or bottom-up) model for collective action that allows individual partners or coalitions of partners to tackle specific parts of a challenge, build capacity for collaboration, and monitor the compliance of objectives and outcomes.

The researcher considers that, for the context of analysis a specific department of the General Health Directorate, or section of the Portuguese NHP, could be dedicated to the identification of relevant areas for CSR engagement in health promotion, participating in the a priori definition of relevant priorities to tackle. Such engagement may even be made compulsory for business entities attaining a certain threshold of volume of affairs, or that are involved in public procurement, as to give origin to an obligation to engage in one or more health promotion priorities within CSR. In order to proceed towards such involvement, public officials should be able to be adequately informed, other than on the actual or potential negative and positive impacts of business operations upon health, of when it is opportune to frame businesses' participation to health promotion objectives through binding frameworks, as it is the case of the FCTC pictured in Chapter 4, and when it is sufficient for the business sector to get involved through CSR (Lee, 2007). For this to be possible, are required institutions apt to coordinate interaction, dialogue and learning among parties and among businesses and health promotion agendas as well as to establish rules and procedures purposeful to coordinate collaboration. The researcher considers that such function could be took in charge, at the national level, by the National Health Council (Conselho Nacional da Sáude) and replicated at the community level with local heath councils. The national health council was reestablished in April of 2016 with the objective of encouraging cross-sectoral dialogue, collaboration, and consensus among social, scientific and economic stakeholders at the national level concerning health policy.

In a concluding summarisation, the author wishes to have highlighted, in the chapter as well as throughout the research, some of the contributions that the health promotion approach underlies for health promotion policy and practice as well the 
issues it poses in a perspective of welfare state development towards models of partnered or polycentric governance. As for what concerns actors concerned with the development and diffusion of the CSR approach the researcher highlights the need to pay attention as to never leave behind the normative and dialogic facets of the CSR approach, as it is in the former that its transformative potential is to be found, and it is the latter that distinguishes CSR from traditional philanthropy. Ultimately, it would be advisable for the term CSR to be modified as to better fit the ensemble of business actors that may engage the approach, for instance, by substituting it with the more encompassing term social responsibility of businesses, or any other term apt to the depict the dialogic purpose of CSR for the furthering of business, society and governmental relations.

\section{Recommendations for further research}

On the basis of what has been discussed up to this point, the researcher considers it relevant to carry out research bringing forward knowledge upon how the co-existence of different CSR rationalities may be brought together, harmonized and prioritized within the CSR policy framework. These kinds of studies exist in political theory concerning political institutions (Goodin, 2011) but not concerning CSR in economic institutions. On the same line, it would be of relevance to carry out context-based research on the institutional, cultural and social factors that participate in the building of perceptions concerning the role of business actors in society and the purpose of CSR. As for what concerns the addressing of health promotion through CSR initiatives, although extensive research dedicated to building the case for involvement on the basis of impacts exists, little research was found exploring the non-consequential grounds of businesses' social responsibility for health. As for what concerns the potential outcomes of CSR initiatives for health promotion, the researcher highlights the need of assessing the impacts of initiatives through both biomedical and social markers. Also, the present research may be extended through analysing the features of CSR involvement in health promotion may be narrowed as to furnish a more detailed insight distinguishing the analysis according for industry, cause, phase of the CSR process (design, formulation, implementation), or business size. On this issue, it is considered relevant to dedicate greater attention to the study of CSR is SMEs, which represent the most prevalent typology of business activity in the context of analysis. As for what concerns the potential for CSR to constitute a vehicle for cross-sectoral development in a perspective of partnered and polycentric 
governance, as previously stated, relevant case studies should be found and scrutinized, developing, for instance, specific knowledge concerning capacitybuilding, political steering, and conflict resolution at both high and low levels of governance. Related to this point, it would be relevant explore the whether CSR initiatives for health promotion offer leverage for the lobbying of political élites, as, given the scarce collaboration with governmental entities found in the cases studied, it was not possible to explore such topic within the present research. 


\section{Bibliography}

Abrams A.K. (2001). A Short History of Occupational Health, Journal of Public Health Policy, 22(1), 34-80.

Abreu L. (2009). Purgatório, Misericórdias e caridade: condições estruturantes da assistência em Portugal (séculos XV-XIX). DYNAMIS, 20, 395-415.

Abreu R., David F. and D. Crowther (2005), Corporate Social Responsibility in Portugal: Empirical Evidence of Corporate Behavior. Corporate Governance, 5(5), 3-18.

Adams P.J., Raeburn J.,De Silva J. (2009), Gambling Beneficiaries Having Their Cake And Eating It: The Attractions Of Avoiding Responsible Gambling Regulation. (2009). Addiction, 104(5), 697-698.

Allender S., Colquhoun D. and Kelly P. (2006). Governing the working population through workplace health: Knowledge, self and power in workplace health programs. Critical Public Health, 16(2), 131-142.

Annan K. (1995). Statement to the World Economic Forum. From: http://www.un.org/press/en/1999/19990201.sgsm6881.html (Accessed September 2012).

Antonovsky A. (1996). The salutogenic model as a theory to guide health promotion. Health Promotion International, 11(1), 11-18.

Albareda L., Lozano J.M. and Tamyko I. (2007). Public Policies on Corporate Social Responsibility: the role of Governments in Europe. Journal of Business Ethics, 74(4), 391-407.

Araral E. and Hartley K. (2013). Polycentric Governance for a New Environmental Regime: Theoretical Frontiers in Policy Reform and Public Administration. Paper presented at the 1st International Conference on Public Policy. Grenoble, France.

Argadoña A. (2006). From ethical responsibility to corporate social responsibility.

From:https://www.researchgate.net/publication/228622284_From_ethical_respon sibility_to_corporate_social_responsibility (accessed Jun 2012).

Asongu J.J. (2007). Innovation as an Argument for Corporate Social Responsibility. Journal of Business and Public Policy, 1(3), 1-21.

Ayo N. (2012). Understanding health promotion in a neoliberal climate and the making of health conscious citizens. Critical Public Health, 22(1), 99-105.

Babor T. (2009). Alcohol research and the alcoholic beverage industry: issues, concerns and conflicts of interest. Addiction, 104(S1), 34-47.

Babor T.F. and Robaina K. (2013). Public Health, Academic Medicine, and the Alcohol Industry's Corporate Social Responsibility Activities. American Journal of Public Health, 103(2), 206-214.

Bambra C. (2005). Towards a politics of health. Health Promotion International, 2O(2), 187-193.

Barbazza E. and Tello J.E. (2014). A review of health governance: Definitions, dimensions and tools to govern. Health Policy, 116 (1), 1-11.

Barley S. R. (2007). Corporations, Democracy, and the Public Good.Journal of Management Inquiry, 16(3), 201-215.

Basu K. and Palazzo G. (2008). Corporate social responsibility: A process model of sensemaking. Academy of Management Review, 33(1), 122-136. 
Baum F. (2008). The Commission on the Social Determinants of Health: Reinventing health promotion for the twenty-first century? Critical Public Health, 18(4), 457466.

Baum F. E., and Sanders, D. M. (2011). Ottawa 25 years on: A more radical agenda for health equity is still required. Health Promotion International, 26(Suppl 2), Ii253-Ii257.

Baxter P. and Jack S. (2008), Qualitative Case Study Methodology: Study Design and Implementation for Novice Researchers. The Qualitative Report, 13(4), 544-559.

Bertelsmann Stiftung (2006). Government as Partner? CSR Policy in Europe. Study.

Bhate S. (2007). Health of the nation: An individual or a corporate social responsibility? A preliminary investigation into consumer perceptions. Journal of Public Affairs, 7, 164-180.

Birkland T. A. (2007). Agenda Setting in Public Policy, in Handbook of Public Policy Analysis - theory, politics and methods, Taylor and Francis Group.

Bogner A., Littig B. and Menz W. (2009). Introduction: Expert Interviews - An Introduction to a New Methodological Debate, in Interviewing Experts, Palgrave MacMillan UK.

Bouten L., Everaert P., Liedekerke L., De moor L. and Christiaens J. (2011). Corporate Social Responsibility reporting: a comprehensive picture? Accounting Forum 35(3), 187-204.

Bowen G. A. (2009). Document Analysis as a Qualitative Research Method. Qualitative Research Journal, 9(2), 27-40.

Brammer S., Gregory J. and Matten D. (2012). Corporate Social Responsibility and institutional theory: new perspectives on private governance. Socioeconomic Review 10(1), 3-28.

Brejnining J. (2012). Corporate Social Responsibility and the Welfare State: The Historical and Contemporary Role of CSR in the Mixed Economy of Welfare. Ashgate.

Brenner N. and Theodore N. (2002). Cities and the geographies of "actually existing neoliberalism". Theodore, 34(3), 349- 379.

Brezis M. Wiist H.W (2011). Vulnerability of Health to Market Forces. Medical Care, 49(3) 232-239.

BSR (2012). A New CSR Frontier: Business and Population Health, Report Mobilizing CSR to Strengthen Corporate Engagement on Health and Wellness across the Value Chain. San Francisco, California, USA.

Brown T.M., Fee E. and Stepanova V. (2016). The Meaning of "Health for All by the Year 2000". American Journal of Public Health, 106(1), 36-38.

Budge I. (1997). The politics of the new Europe: Atlantic to Urals. Longman.

Bunde-Birouste A. Bull N. and McCarroll B (2010). Moving beyond the 'Lump-Sum': football united and JP Morgan as a case study of partnership for positive social change. Cosmopolitan Civil Societies Journal, 2(2), 92-114.

Buse K. and Lee K. (2005). Business and Global Health Governance. Discussion paper $\mathrm{n}^{0} 5$, Centre on Global Change and Health, London School of Hygiene \& Tropical Medicine, UK.

Buse K. and Walt G. (2000). Global public-private partnerships: part I - a new development in health? Bulletin of the World Health Organization, 78(4), 549561. 
Buse K. and Walt G. (2000). Global public-private partnerships: Part II--What are the health issues for global governance? Bulletin of the World Health Organization, 78(5): 699-709.

Buse K. and Waxman A. (2001). Public-private health partnerships: a strategy for WHO. Bulletin of the World Health Organization, 79(8), 748-754.

Campbell J.L. (2007). Why would corporations behave in socially responsible ways? An institutional theory of corporate social responsibility. Academy of Management Review, 32(3), 946-967.

Carolo D.F.S. (2006). A institucionalização do Estado-providência em Portugal: da reforma da Previdência Social de 1962 à actual Reforma da Segurança Social. XXVI Encontro de APHES, Ponta Delgada, Portugal.

Carroll A.B. (1979). The pyramid of corporate social responsibility: toward the moral management of organizational stakeholders. Business horizons, 34(4), 39-48.

Carroll A.B. (1999). Corporate Social Responsibility evolution of a definitional construct. Business and Society, 38(3), 268, 295.

Carroll A.B. (2008). A History of Corporate Social Responsibility: Concepts and Practices. The Oxford Handbook of Corporate Social Responsibility, Oxford University Press.

Carter E. D. (2015). Making the Blue Zones: Neoliberalism and nudges in public health promotion. Social Science \& Medicine, 133, 374-382.

Castles F.G. (2002). The future of the welfare state: crisis myths and crisis realities. International Journal of Health Services, 32(2), 255-277.

Center for High Impact Philantropy of the Stanford University (2013). Beyond Compliance: Measuring to Learn, Improve, and Create Positive Change, Philadelphia, Pennsylvania, USA.

Colle S. D., Henriques A. and Sarasvathy S. (2013). The Paradox of Corporate Social Responsibility Standards. Journal of Business Ethics, 125(2), 177-191.

Committee for Economic Development (1971) Social responsibilities of business corporations. A statement from the research and policy committee. Arlington, Virginia, USA.

Cummings, J. (2001). Engaging stakeholders in corporate accountability programmes: A cross-sectoral analysis of $\mathrm{UK}$ and transnational experience. Business Ethics, 1O(1), 45-52.

Castelo Branco, M. and Rodrigues, L. L. (2008). Factors Influencing Social Responsibility Disclosure by Portuguese Companies. Journal of Business Ethics, 83(4), 685-701

Castelo Branco M. and C. Delgado (2011). Research on corporate social responsibility and disclosure in Portugal. Social Responsibility Journal, 7(2), 202-217.

Clarkson M.E. (1995). A Stakeholder Framework For Analyzing And Evaluating Corporate Social Performance. Academy of Management Review, 2O(1), 92-117.

Colebatch H.K. (2009). Governance as a conceptual development in the analysis of policy. Critical Policy Studies, 3(1), 58-67.

Costa R. and Menichini T. (2013). A multidimensional approach for CSR assessment: The importance of the stakeholder perception. Expert Systems with Applications, 4O(1), 150-161.

Colls R. (2008). Embodying responsibility: children's health and supermarket initiatives. Environment and Planning, 40, 615-631. 
Crane A., Palazzo G., Spence L. J. and Matten, D. (2014). Contesting the Value of "Creating Shared Value". California Management Review, 56(2), 130-153.

Craveiro C. and Cunha S. (2007). Publicidade e alimentação: mistura explosiva?, Revista Nutrícias, 7.

Crawford R. (1977). You are dangerous to your health: the ideology and politics of blaming the victim. International Journal of Health Services, 7(4), 663-680.

Cresswell, J. W. (2009). Qualitative, quantitative and mixed methods. Sage Publications.

Crisp N., Berwick D., Kickbusch I., Bos W., Lobo Antunes J., Pita Barros P. and Soares J. (2014). Um futuro para a saúde. Report of the Calouste Gulbenkian Foundation, Lisboa, Portugal.

Crook C. (2005). The good company. From:http://www.economist.com/node/3555212 (Accessed September 2013).

Cunha Filho H., Fonseca Marques R. and de Faria P. L. (2010). Dificuldades políticas, éticas e jurídicas na criação e aplicação da legislação sobre álcool e tabaco: contributo para o desenvolvimento da investigação em Direito da Saúde Pública. Revista Portuguesa de Saúde Pública, 28(2), 205-218

De Leeuw E. D., Tang K. C., \& Beaglehole, R. (2006). Ottawa to Bangkok - Health promotion's journey from principles to 'glocal' implementation. Health Promotion International, 21(Supplement 1), 1-4.

De Shutter O. (2008). Corporate Social Responsibility European Style. European Law Journal, 14(2), 203-236.

Diário Económico (2012). 1000 maiores empresas. Editorial Dezembro.

Direção Geral Saúde (2013), Plano Nacional da Saúde 2012-2016. Ministero da Saúde.

Direção Geral Saúde (2015), Plano Nacional da Saúde - revisão e extensão a 2020. Ministero da Saúde.

Doh J. P., and Guay T. R. (2006). Corporate Social Responsibility, Public Policy, and NGO Activism in Europe and the United States: An Institutional-Stakeholder Perspective. Journal of Management Studies, 43(1), 47-73.

Dogson R., Lee K. and Drager N. (2002). Global health governance - a conceptual review. Department of Health and Development World Health Organization, Discussion Paper $\mathrm{n}^{\mathrm{0}}$, London, UK.

Dorfman L., Cheyne A., Friedman L.C., Wadud A. and Gottlieb M. A. (2012). Soda and Tobacco Industry Corporate Social Responsibility Campaigns: How Do They Compare? PLoS Medicine, 9(6), 1-7.

Du S., Sen S. and Bhattacharya, C. B. (2008). Exploring the Social and Business Returns of a Corporate Oral Health Initiative Aimed at Disadvantaged Hispanic Families. Journal of Consumer Research, 35(3), 483-494.

Dunn W.N. (1994). Public policy analysis: an introduction. Englewood Cliffs.

Eberhard Harribey L. (2006). Corporate Social Responsibility as a new paradigm in the European policy: how CSR comes to legitimate the European regulation process. Corporate Governance, 6(4), 358-368.

European Centre for Health Policy (1999). Health Impact Assessment: Main concepts and suggested approach. Gothenburg Consensus Paper, Gothemburg, Sweden. 
Esping-Andersen G. (1990). The Three Worlds of Welfare Capitalism. Princeton University Press.

Esping-Andersen G. (1996). Welfare States in Transition: National Adaptations in Global Economies. Sage.

Esping-Andersen G. Gallie D., Hemerijck A. and Myles J. (2002). A New Welfare Architecture for Europe? Report submitted to the Belgian Presidency of the European Union. Bruxelles, Belgium.

Evers A. (2005). Mixed Welfare Systems and Hybrid Organizations: Changes in the Governance and Provision of Social Services. International Journal of Public Administration, 28(9-10), 737-748.

European Commission (2001). Promoting a European framework for Corporate Social Responsibility. COM, 366 final.

European Commission (2006). Implementing the partnership for growth and jobs: making Europe a pole of excellence on corporate social responsibility. COM 136 final.

European Commission (2007). Together for Health: A Strategic Approach for the $E U$. COM 630 final.

European Commission (2011). A renewed EU strategy 2011-14 for Corporate Social Responsibility. COM, 681 final.

European Commission (2013). An analysis of policy references made by large EU companies to internationally recognised CSR guidelines and principles.

European Commission (2014). Corporate Social Responsibility - national public policies in the European Union.

European Commission (2015), DG Health and Consumers. From: http://ec.europa.eu/dgs/health_food-safety (accessed online 2015).

Fidler D.P. (2006). Health as foreign policy: harnessing globalization for health. Health Promotion International, 21 (Supplement 1), 51-58.

Flyvbjerg B. (2004), Five misunderstandings about case-study research. In Qualitative Research Practice. Sage, 420-434.

Fooks G., Gilmore A., Smith K., Collin J., Holden C. and Lee K. (2011). Corporate social responsibility and access to policy elites: an analysis of tobacco industry documents. PLoS Medicine, 8(8). 1-12.

Fox, T., Ward, H. and Howard, B. (2002). Public Sector Roles in Strengthening Corporate Social Responsibility: A Baseline Study. Washington, DC: World Bank.

Fransen L. (2012). Multi-stakeholder governance and voluntary programme interactions: Legitimation politics in the institutional design of Corporate Social Responsibility. Socio-Economic Review, 1O(1), 163-192.

Frederick W.C. (2006). Corporation, be good! Dog Ear Publishing.

Freeman R. E. (1984). Strategic management: A stakeholder approach. Pitman.

French P. (1979). The corporation as a moral person. American Philosophical Quarterly, 16(3), 207-215.

Freudenberg N. Galea S. (2008). The Impact of Corporate Practices on Health: Implications for Health Policy. Journal of Public Health Policy, 29 (2008) 86104. 
Freudenberg N. (2012). The manufacture of lifestyle: The role of corporations in unhealthy living. Journal of Public Health Policy, 33 (2012) 244-256.

Freudenberg N. (2014). Lethal But Legal: Corporations, Consumption, and Protecting Public Health. Oxford University Press.

Friedman M. (1970). The Social Responsibility of Business is to Increase its Profits. The New York Times Magazine.

Friedman L. (2009). Tobacco industry use of corporate social responsibility tactics as a sword and a shield on secondhand smoke issues. Journal of Law, Medicine \& Ethics, 37(4), 819-27.

George F. (2012). Causas de morte em Portugal e desafios na prevenção. Acta Medica Portuguesa, 25(2), 61-63.

Giddens A. (1998). The Third Way - The Renewal of Social Democracy. Polity Press.

Gilbert N. (2005). The "Enabling State?" from public to private responsibility for social protection: Pathways and pitfalls. OECD Social, employement and migration working papers. Paris, France.

Goodin R.E. (2009). The Oxford handbook of political science. Oxford University Press.

Goodpaster K. E. (1991). Business Ethics and Stakeholder Analysis. Business Ethics Quarterly, 1(1), 53-73.

Googins B. K., and Rochlin S. A. (2000). Creating the Partnership Society: Understanding the Rhetoric and Reality of Cross-Sectoral Partnerships. Business and Society Review, 105(1), 127-144.

Graça L. (2006). Políticas integradas de protecção e promoção da saúde e segurança do trabalho nas empresas portuguesas. Promoção da Saúde, 6, 75-94.

Gruening G. (2001). Origin and theoretical basis of New Public Management. International Public Management Journal, 4(1), 1-25.

Gruskin S., and Raad Z. (2010). Are Drug Companies Living Up to Their Human Rights Responsibilities? Moving Toward Assessment. PLoS Medicine, 7(9).

Guthman J. (2006). Embodying neoliberalism: Economy, culture, and the politics of fat. Environment and Planning, 24(3), 427-448.

Hajer M. and Wagenaar H. (2003). Deliberative policy analysis - understanding governance in the network society. Oxford University Press.

Haluza D., and Jungwirth D. (2014). Ict And The Future Of Health Care: Aspects Of Doctor-Patient Communication. International Journal of Technology Assessment in Health Care, 30(03), 298-305.

Hamann R., and Acutt N. (2003). How should civil society (and the government) respond to 'corporate social responsibility'? A critique of business motivations and the potential for partnerships. Development Southern Africa, 2O(2), 255270.

Hancock T. (1986). Beyond healthcare, From public health policy to healthy public policy. Canadian Journal of Public Health, 76(1), 9-11.

Hart O. (1995). Corporate Governance: Some Theory and Implications. The Economic Journal, 105(430) 678.

Harvard School of Public Health and World Economic Forum (2011), The Global Economic Burden of Non-communicable Diseases. Geneva, Switzerland.

Harvey D. (2005). A brief history of capitalism. Oxford University Press. 
Hatch P.C. and Godfrey N.W. (2007). Researching Corporate Social Responsibility: An Agenda for the 21st Century. Journal of Business Ethics, 7O(1), 87-98.

Henderson C., O'Hara S., Thornicroft G., and Webber M. (2014). Corporate social responsibility and mental health: The Premier League football Imagine Your Goals programme. International Review of Psychiatry, 26(4), 460-466.

Hendriks A., Habraken J., Jansen M. W., Gubbels J. S., Vries N. K., Oers H. V. and Kremers, S. P. (2014). 'Are we there yet?' - Operationalizing the concept of Integrated Public Health Policies. Health Policy, 114(2-3), 174-182.

Herbert S. (2005), the trapdoor of community. Annals of the Association of American Geographers, 95(4), 850-865.

Herrick C. (2009). Shifting blame/selling health: corporate social responsibility in the age of obesity. Sociology of Health \& Illness, 31(1), 51-65.

Hirshorn N. (2004). Corporate social responsibility and the tobacco industry: hope or hype? Tobacco Control, 13, 447-453.

Hofferberth M., Brhl T., Burkart E., Fey M. and Peltner A. (2011). Multinational Enterprises as "Social Actors"-Constructivist Explanations for Corporate Social Responsibility. Global Society, 25(2), 205-226.

Holmqvist M. (2009). Corporate social responsibility as corporate social control: The case of work-site health promotion. Scandinavian Journal of Management, 25(1), 68-72.

Hubley J., Copeman J. and Woodall J. (2013). Practical health promotion. Polity Press.

Husted B. W. (2003). Governance Choices for Corporate Social Responsibility: To Contribute, Collaborate or Internalize? Long Range Planning, 36(5), 481-498.

Instituto Nacional de Saúde Ricardo Jorge (2013). Evaluation of capacity building workshop on Equity-focused Health Impact Assessment. Lisboa, Portugal

International Labour Organization (1977; 2000; 2006). Tripartite Declaration of Principles concerning Multinational Enterprises on Social Policy.

ISO (2010). ISO 26000 Guidance Standard on Social Responsibility.

Jahiel R.I., Babor T.F. (2007). Industrial epidemics, public health advocacy and the alcohol industry: Lessons from other fields. Addiction, 102(9), 1335-1339.

Jahiel, R. I. (2008). Corporation-induced Diseases, Upstream Epidemiologic Surveillance, and Urban Health. Journal of Urban Health, 85(4), 517-531.

Kawulich B.B. (2005), Participant Observation as a Data Collection Method. Qualitative Social Research, 6(2), art. 43.

Kickbush I., De Leeuw E. (1999). Global public health: revisiting healthy public policy at the global level. Health Promotion International, 14(4), 285-288.

Kickbush I. (2003). The Contribution of the World Health Organization to a New Public Health and Health Promotion. American Journal of Public Health, 93(3), 383-388.

Kickbusch, I. (2003b). Twenty-first century health promotion: The public health revolution meets the wellness revolution. Health Promotion International, 18(4), 275-278.

Kickbush I. (2010). The food system, a prism of present and future challenges for health promotion and sustainable development. White Paper, Switzerland Health Promotion Foundation. Geneva, Switzerland. 
Kinderman, D. (2013). Corporate Social Responsibility in the EU, 1993-2013: Institutional Ambiguity, Economic Crises, Business Legitimacy and Bureaucratic Politics. Journal of Common Market Studies, 51(4), 701-720.

Kitsis E.A. (2011). The Pharmaceutical Industry's Role in Defining Illness. Virtual Mentor, 13(12), 906-911.

Kjærgård B., Land B. and Pedersen K. B. (2014). Health and sustainability. Health Promotion International, 29(3), 558-568.

Klein, N. (2000). No space, no choice, no jobs, no logo: Taking aim at the brand bullies. Picador USA.

Klemsdal L. (2013). From Bureaucracy to Learning Organization: Critical Minimum Specification Design as Space for Sensemaking. Systemic Practice and Action Research, 26, 39-52.

Knudsen J. S., Moon J. and Slager R. (2015). Government Policies for Corporate Social Responsibility in Europe: Support and Institutionalization. SSRN Electronic Journal.

Koeler D. (2014), Looking Ahead: The Importance of Materiality. From:http://www.csrwire.com/blog/posts/1183-looking-ahead-the-importanceof-materiality (Accessed January 2015).

Koivusalo, M. (2010). The state of Health in All policies (HiAP) in the European Union: Potential and pitfalls. Journal of Epidemiology \& Community Health, 64(6), 500-503.

Kotler P. and Lee N. (2006). Corporate social responsibility: doing the most good for your company and your cause. Academy of Management Perspectives, 20(2) 90-93.

Kramer R.M. (2000). A Third Sector in the Third Millennium? Voluntas: International Journal of Voluntary and Nonprofit Organizations, 11(1), 1-23.

Labonté R. and Schreker T. (2007). Globalization and social determinants of health: The role of the global marketplace. Globalization and Health, 3(6).

Lalonde M. (1974). A New Perspective on the Health of Canadians. Minister of Supply and Services.

Lang T. and Reyner G. (2007). Overcoming policy cacophony on obesity: an ecological public health framework for policymakers. Obesity Revue, 8(S1) 165181.

Lang T. (2010). Corporate responsibility in public health: the government's invitation to the food industry to fund social marketing on obesity is risky. British Medical Journal, 341, 110-111.

Lee K., Buse K. and Fustukian S. (2002). Health policy in a globalising world. Cambridge.

Lee, K. (2006). Global health promotion: How can we strengthen governance and build effective strategies? Health Promotion International, 21(S1), 42-50.

Leitão J. and Silva M.J. (2007). CSR and Social Marketing: What is the desired role for Universities in fostering Public Policies? MPRA Paper No. 2954. Beira Interior, Portugal.

Lélé S.M. (1991). Sustainable development: a critical review. World Development, $9(6), 607-621$.

Liesbet H and Gary M. (2003). Unraveling the central state, but how? Types of multilevel governance. American Political Science Review, 97(2), 233-243. 
Lindorff M., Jonson E. P. and Mcguire L. (2012). Strategic Corporate Social Responsibility in Controversial Industry Sectors: The Social Value of Harm Minimisation. Journal of Business Ethics, 110(4), 457-467.

Loureiro I., Miranda N. and Miguel J.M. (2013). Promoção da saúde e desenvolvimento local em Portugal: Refletir para agir. Revista Portuguesa De Saúde Pública, 31(1), 23-31.

Magalhães L. (2007). Publicidade televisiva e obesidade infantil, Comunicação e Cidadania - Paper presented at the fifth congress of the Portuguese Association of Communicational Sciences. Braga, Portugal.

Maignan I. and Ralston D. (2002). Corporate Social Responsibility in Europe and the U.S.: Insights from Business' Self-Presentations. Journal of International Business Studies, 33(3), 497- 514.

Majnoni d'Intignano B. (1995), Epidémies industrielles. Commentaire, 71(5) 585-96.

March, J.G. and Olsen J.P. (2004). The Logic of Appropriateness. Arena Centre for European Studies, Working Paper 4/o9. University of Oslo, Norway.

Marens, R. (2010). Destroying the village to save it: Corporate social responsibility, labour relations, and the rise and fall of American hegemony. Organization, 17(6), 743-766.

Margolis J.D. and Walsh J.P. (2003). Misery Loves Companies: Rethinking Social Initiatives by Business. Administrative Science Quarterly, 48, 268-205.Martins,

Antunes M.d.C. (2005). A Promoção da saúde: percursos e paradigma. Revista de saúde Amato Lusitano, 22(4), 42-46.

Mathews J.A. (2002). Competitive Advantages of the Latecomer Firm: A ResourceBased Account of Industrial Catch-Up Strategies. Asia Pacific Journal of Management, 19, 467-488,

Matten D. and Crane A. (2003). Corporate Citizenship: Towards an Extended Theoretical Conceptualization. Academy of Management Review, 3o(1), 166179.

Matten D. and Moon J. (2008). 'Implicit' and 'Explicit' CSR: A Conceptual Framework for a Comparative Understanding of Corporate Social Responsibility. Academy of Management Review, 33(2), 404-424.

Mcmichael A.J. and Butler C.D. (2006). Emerging health issues: The widening challenge for population health promotion. Health Promotion International, 21(S1), 15-24.

McDaniel P.A. and Malone R.E. (2009). The Role of Corporate Credibility in Legitimizing Disease Promotion. American Journal of Public Health, 99(3), 452461.

Mcwilliams, A., Siegel D.S. and Wright P.M. (2006). Corporate Social Responsibility: Strategic Implications. Journal of Management Studies, 43(1), 1-18.

Mcwilliams, A. and Siegel D. . (2010). Creating and Capturing Value: Strategic Corporate Social Responsibility, Resource-Based Theory, and Sustainable Competitive Advantage. Journal of Management,37(5), 1480-1495

Midtun A. (2005). Realigning business, government and civil society: Emerging embedded relational governance beyond the (neo) liberal and welfare state models. The international journal of business in society, 5(3), $159-174$. 
Midtun A. (2008). Partnered governance: aligning corporate responsibility and public policy in the global economy. Corporate Governance: The international journal of business in society, 8(4) $406-418$.

Mikkelsen B.E. (2005). Declining role of governments in promoting healthy eating: time to rethink the role of the food industry? Scandinavian Journal of Nutrition, 49(3), 127-130.

Min-Dong P. L. (2008). A Review of the Theories of Corporate Social Responsibility: Its Evolutionary Path and the Road Ahead. International Journal of Management Reviews, 10(1), 53-73.

Ministero das Finançãs de Portugal (1999). Lei do Mecenato. Decreto-lei 74/99, de 16 de Março.

Ministero das Finançãs de Portugal, Comissão de Normalização contabilística (2002). Diretiva 29/2002.

Minkes J.P. and Minkes A.L. (2005). Decentralisation, Responsibility and Ethical Dilemmas. Social Responsibility Journal, 1(1), 16 - 20.

Mitchell R. K., Agle B.R. and Wood D.J. (1997). Toward A Theory Of Stakeholder Identification And Salience: Defining The Principle Of Who And What Really Counts. Academy of Management Review, 22(4), 853-886.

Moldash M. and Fischer D. (2004). Beyond the Management View: A ResourceCentered Socio-Economic Perspective. Management Revue, 15(1), 122-151.

Molteni M. and Pedrini M. (2009). The corporate social responsibility manager map, Corporate Ownership \& Control, 6(3), 26-38.

Monachino M.S., Moreira P.K. (2014). Corporate Social Responsibility and the health promotion debate: An international review on the potential role of corporations. International Journal of Healthcare Management, 7(1), 53-59.

Montero, M. J., Araque, R.A., and Rey, J.M. (2009). Occupational health and safety in the framework of corporate social responsibility. Safety Science, 47(10), 14401445 .

Moon J., Crane M. and Matten D. (2005). Can corporations be citizens? Corporate Citizenship as a Metaphor for Business Participation in Society, Business Ethics Quarterly, 15(3), 429-453.

Moon J. (2007). The Contribution of Corporate Social Responsibility to Sustainable Development. Sustainable Development, 15, 296-306.

Moon J., Rieneke S. Anastasiadis S., Brunn C., Hardi P., Knudsen J.S. (2011). Analysis of National and EU Policies Supporting CSR and Impact, Impact Working Paper.

Mozzicafreddo J. (1992). O estado prêvidencia em Portugal: estratégias contraditórias. Sociologia Problemas e Praticas, 12, 57-89.

Nelson J. (2008). CSR and public policy: new forms of engagement between business and government. Corporate Responsibility Initiative Working Paper $\mathrm{N}^{\mathrm{o}}$ 45, John F. Kennedy School of Government, Harvard University, USA.

Nordenfelt, L. (2006). The concepts of health and illness revisited. Medicine, Health Care and Philosophy, 10(1), 5-10.

Nutbeam, D. (1986). Health promotion glossary. Health Promotion International, 1(1), 113-127. 
Observatório Português dos Sistemas de Saúde (2012). Relatório de Primavera Crise \& Saúde, Um país em Sofrimento. Coimbra, Portugal.

O'Connor-Fleming M.L. and Parker E. (2009). Introduction to Public Health. Livingstone/Elsevier.

Organization for Economic Cooperation and Development (2009), Guidelines for Multinational Enterprises.

Osborne D. and Gaebler T. (1992). Reinventing government. Addison-Wesley Publications.

Palazzo G., Krings F. and Hoffrage U. (2012). Ethical Blindness. Journal of Business Ethics, 109, 323-338.

Pearce J.A. and Doh J.P. (2005). The High Impact of Collaborative Social Initiatives. MIT Sloan Management Review, 46(3), 30-39.

Pedersen, E. R. (2006). Making Corporate Social Responsibility (CSR) Operable: How Companies Translate Stakeholder Dialogue into Practice. Business and Society Review, 111(2), 137-163.

Peloza, J., an Shang, J. (2010). How can corporate social responsibility activities create value for stakeholders? A systematic review. Journal of the Academy of Marketing Science, 39(1), 117-135.

Pereirinha J.A. and Carolo D.F. (2009). A construção do Estado-Providência em Portugal: evolução da despesa social de 1935 a 2003. Working Paper Instituto Superior de Economia e Gestão, Lisboa, Portugal.

Perrini F. (2009). Building a European Portrait of Corporate Social Responsibility. European Management Journal, 23(6), 611-627.

Persson, H.T. (2008). Social Capital and Social Responsibility in Denmark: More than Gaining Public Trust. International Review for the Sociology of Sport, 43(1), 35-51.

Petit P. (2007). Responsibility Incorporated. Ethics, 117, 171-201.

Pinto G.R. (2004). Corporate Social Responsibility: state of the art in Portugal. Report CECOA. Lisboa, Portugal.

Pollitt C., Van Thiel S. and Homburg V. (2007). New public management in Europe. Palgrave Macmillan Uk.

Porter C. (2007). Ottawa to Bangkok: changing health promotion discourse. Health Promotion International, 22(1), 72-79.

Porter M.E. and Kramer M.R. (2006). Strategy and society: the link between competitive advantage and corporate social responsibility. Harvard Business Review, December Issue.

Porter M.E. and Kramer M.R. (2011). Creating shared value. Harvard Business Review, January-February Issue.

Post J.E., Preston L.E. and Sachs S. (2002). Redefining the corporation stakeholder management and organizational wealth. Stanford University Press.

Powell W.W. and Dimaggio P. J. (1992). The New Institutionalism in Organizational Analysis. University of Chicago Press.

Presidencia do Conselho dos Ministros, Resolução do Conselho dos Ministros 49/2008.

Preston L.E. and Post, J.E. (1975). Private management and public policy: The principle of public responsibility. Prentice-Hall. 
Radacsi, G. and Hardi, P. (2014). Substance Misuse Prevention as Corporate Social Responsibility. Substance Use and Misuse, 49(4), 352-363.

Rego A., Moreira J.M. and Sarrico C. (2003). Gestão etica e responsabilidade social das empresas: um estudo da situação portuguesa. Principia Editions.

Reich, R. (2014). The rebirth of stakeholder capitalism? From: http://robertreich.org/post/94260751620 (Accessed May 2015)

Reis J. (1995). Estado, Instituições e Economia: a despesa pública em Portugal. Revista Critica de Ciencias Sociais, 44, 25-58.

Rosenau J., Czempiel E.O. (1992). Governance without Government: Order and Change in World Politics. Cambridge University Press.

Ruggie J.G. (2004). Reconstituting the global public domain - issues, actors, and practices. European Journal of International Relations, 10(4), 499-531.

Ruggie J.G. (2008). Clarifying the concepts of "sphere of influence" and "complicity". Human Rights Council, Report of the Special Representative of the Secretary-General on the Issue of Human Rights and Transnational Corporations and other Business Enterprises.

Saan, H. and Wise, M. (2011). Enable, mediate, advocate. Health Promotion International, 26(Suppl 2), Ii187-Ii193.

Sebrié, E.M. and Glantz S.A. (2007). Attempts to Undermine Tobacco Control. American Journal of Public Health, 97(8), 1357-1367.

Raine, G. (2007). Commercial activities in primary schools: A quantitative study. Oxford Review of Education, 33(2), 211-231.

Santana, P. (2002). Poverty, social exclusion and health in Portugal. Social Science \& Medicine, 55(1), 33-45.

Saracci, R. (1997). The world health organisation needs to reconsider its definition of health. British Medical Journal, 314(7091), 1409-1409.

Scherer A.G. and Palazzo G. (2011). The New Political Role of Business in a Globalized World: A Review of a New Perspective on CSR and its Implications for the Firm, Governance, and Democracy. Journal of Management Studies, 4O(4), 899-931.

Schirmer W. and Michailakis D. (2012). The latent function of 'responsibility for one's health' in Swedish healthcare priority-setting, Health Sociology Review, 21(1), 36-46.

Sebrié E.M., Glantz S.A. (2007). Tobacco industry use of corporate social responsibility tactics as a sword and a shield on Secondhand smoke issues, American Journal of Public Health, 97(8), 1357-67.

Seitanidi, M.M. and Crane, A. (2008). Implementing CSR Through Partnerships: Understanding the Selection, Design and Institutionalisation of NonprofitBusiness Partnerships. Journal of Business Ethics, 85(S2), 413-429.

Semplici S. (2011). The importance of 'social responsibility' in the promotion of health. Medicine, Health Care and Philosophy, 14(4), 355-363.

Smith M. and Kelly C. (2006). Wellness Tourism. Tourism Recreation Research, 31(1), 1-4.

Snider J., Hill R.P. and Martin D. (2003). Corporate Social Responsibility in the 21st Century: A View from the World's Most Successful Firms. Journal of Business Ethics, 48(2), 175-187. 
Sorensen K. (2011. Health Literacy - A Strategic Asset for Corporate Social Responsibility in Europe. Journal of Health Communication, 16, 322-327.

Stake R. E. (2010). Qualitative research: Studying how things work. Guilford Press.

Steurer R., Langer M.E., Konrad A. and Martinuzzi, A. (2005). Corporations, Stakeholders and Sustainable Development I: A Theoretical Exploration of Business-Society Relations. Journal of Business Ethics, 61(3), 263-281

Steurer R. (2010). The Role of Governments in Corporate Social Responsibility: Characterising Public Policies on CSR in Europe. Policy Sciences, 43(1), 49-72.

Swerissen H. (2004). The sustainability of health promotion interventions for different levels of social organization. Health Promotion International, 19(1), 123-130.

Sweeney L. and Coughlan J. (2008). Do different industries report corporate social responsibility differently? An investigation through the lens of stakeholder theory, Journal of Marketing Communication, 14(2), 113-124.

Syme, S. L. (2007). The prevention of disease and promotion of health: The need for a new approach. The European Journal of Public Health, 17(4), 329-330.

Tugwell P., Robinson V. and Morris, E. (2007). Mapping global health inequalities: challenges and opportunities, Conference paper.

$\begin{array}{llll}\text { Turismo de } & \text { Portugal } & \text { (2012). }\end{array}$ https://rnt.turismodeportugal.pt/RNT/ConsultaAoRegisto.aspx (accessed online January 2012).

Unesco (2005), Universal Declaration on Bioethics and Human Rights.

Unesco (2010). On social responsibility and health. Report of the International Bioethics Committee.

United Nations (1992). Rio Declaration on Environment and Development.

United Nations (2000). Global Compact Initiative.

United Nations (200ob). Committee on Economic, Social and Cultural Rights, General Comment 14, The right to the highest attainable standard of health.

United Nations High Commissioner for Human Rights and WHO (2007). The Right to Health, Fact Sheet No. 31.

United Nations Global Compact (2010). An Introduction to Linkages Between the UN Global Compact Principles and ISO Core Subjects.

United Nations Global Compact (2011). Annual review of business policies and actions to advance sustainability, Global Compact Implementation Survey.

United Nations Global Compact (2015). Sustainable development goals.

Vallentin S. (2012). Neoliberalism and CSR: overcoming stereotypes and embracing ideological variety. Paper presented at the 28th EGOS Colloquium in Helsinki, Finland.

Valverde J.L. (2012). Corporate responsibility and pharmaceutical fraud. Pharmaceuticals, Policy and Law, 14, 129-156.

Van der Heijden A., Driessen P.P.J. and Cramer J.M. (2010). Making sense of Corporate Social Responsibility: Exploring organizational processes and strategies. Journal of cleaner production, 18(18), 1787-1796. 
Veenhoven, R. (2008). Healthy happiness: Effects of happiness on physical health and the consequences for preventive health care. Journal of Happiness Studies, 9, $449-469$.

Vivas (2015). Diálogo transatlântico: agricultura, alimentação e TTIP. Conference oral presentation. Lisboa, Portugal

Vogel D. (2005). The Market for Virtue. Brookings Institution press.

Vogel D. (2008). Private Global Business Regulation. The Annual Review of Political Science, 11, 261-282.

Waddock, S. A. and Graves S. B. (1997). The Corporate Social Performance-Financial Performance Link. Strategic Management Journal 18(4), 303-319.

Weimar D.L. and Vining A.R. (2016). Policy Analysis: Concepts and Practice. Taylor and Francis Group, fifth edition.

Wernerfelt, B. (1984). A resource-based view of the firm. Strategic Management Journal, 5(2), 171-180

Wallerstein, N. and Bernstein, E. (1988). Empowerment Education: Freire's Ideas Adapted to Health Education. Health Education and Behavior, 15(4), 379-394.

Walt G., Brugha R., Haines A. (2002) Working with the private sector: the need for institutional guidelines. British Medical Journal, 325(7361): 432-435.

Walt G., Shiffman J., Schneider H., Murray S.F., Brugha R. and Gilson L. (2008). Doing health policy analysis: methodological and conceptual reflections and challenges. Health Policy and Planning, 23(5), 308-317.

Werner W.J. (2009). Corporate social responsibility initiatives addressing social exclusion in Bangladesh. Journal of Health Population and Nutrition, 27(4), 545-62.

Wiist W.H. (2006). Public Health and the Anticorporate Movement: Rationale and Recommendations. American Journal of Public Health, 96(8), 1370-1375.

Wiist William H. (2010). The bottom line or public health: tactics corporations use to influence health and health policy and what we can do to counter them. Oxford University Press.

World Bank (2002). Corporate Social Responsibility and Sustainable Competitiveness.

World Commission on Environment and Development (1987), Our Common Future.

World Economic Forum and the Harvard School of Public Health (2011). The Global Economic Burden of Non-Communicable Diseases.

World Health Assembly (2004). Global Strategy on Diet, Physical Activity and Health.

World Health Organization (1981). International Code of Marketing of Breast-milk Substitutes.

World Health Organization (1986), The Ottawa Charter for Health Promotion. First International Conference on Health Promotion.

World Health Organization (1997). The Fourth International Conference on Health Promotion: New Players for a New Era - Leading Health Promotion into the 21st Century.

World Health Organization (2003), Framework Convention on Tobacco Control. 
World Health Organization (2005). The Bangkok Charter for Health Promotion in a Globalized World.

World Health Organization (2009). Milestones in health promotion, statements from global conferences.

World Health Organization (2015). Global burden of disease. From: http://www.who.int/topics/global_burden_of_disease/en/(Accessed November 2014).

World Health Organization Regional Office for Europe (2010). Evaluation of the national health plan of Portugal (2004 - 2010), methods, findings and policy recommendations.

World Health Organization Regional Office for Europe (2011), The new European policy for health - Health 2020: Vision, values, main directions and approaches.

World Health Organization Regional Office for Europe (2012) Health 2020: a European policy framework supporting action across government and society for health and well being.

World Health Organization Regional Office for Europe (2015). The European health report - Targets and beyond, reaching new frontiers in evidence.

Wry T.E. (2008). Does Business and Society Scholarship Matter to Society? Pursuing a Normative Agenda with Critical Realism and Neoinstitutional Theory. Journal of Business Ethics, 89(2), 151-171.

World Trade Organization (1994). Agreement on Trade-Related Aspects of Intellectual Property rights.

Yin R. (1994), Case Study Research. Design and Methods. Sage.

Young I.M. (2006). Responsibility And Global Justice: A Social Connection Model. SOY Social Philosophy and Policy, 23(01), 102

Ziglio, E. (2000). Health promotion development in Europe: Achievements and challenges. Health Promotion International, 15(2), 143-154.

Zizek S. (2010). First as tragedy, then as farce. From: https://www.youtube.com/watch?v=cvakA-DF6Hc (Accessed September 2013). 


\begin{tabular}{l} 
Annexes \\
Standard Interview Protocol I: Health promotion experts \\
\hline Data \\
Entrevistado \\
Função \\
Instituição
\end{tabular}

Tema I : Introdução

1. Descreva por favor o seu percurso profissional, a posição que ocupa (ou ocupou) e as suas principais responsabilidades

2. Descreva o contexto da promoção da saúde em Portugal hoje: eixos estratégicos, desafios e áreas de investimento

Tema III: Perspectivas gerais sobre RSE e promoção da saúde

3. Como vê o envolvimento das empresas em ações de promoção da saúde no âmbito de iniciativas de RSE?

4. Qual acha que sejam os maiores riscos e as maiores oportunidades associadas ao envolvimento das empresas na promoção da saúde via as suas iniciativas de RSE?

5. Em que medida acha que os projectos de RSE a decorrer na área da promoção da saúde tem em conta as prioridades do Ministerio da Saude?

6. Qual acha que deveria ser o papel do governo face a RSE?

7. Até que ponto o governo português tem sucedido na criação de plataformas/estratégias intersectorias?

8. Como se poderia obter uma efectiva partilha de responsabilidades ao acto practico?

Tema II : Experiencia de colaboração inerente com empresas no âmbito da RSE

9. Descreva sua experiencia de colaboração com empresas privadas no âmbito da RSE (modalidade, limites, mais-valias) 
Standard Interview Protocol II: CSR representatives

\begin{tabular}{|l|l|}
\hline Data \\
Entrevistado & - \\
Função & \\
Instituição & \\
\hline
\end{tabular}

Tema I: Atividades e perspectivas da empresa sobre a RSE

1. Descreva por favor o seu percurso profissional, a posição que ocupa hoje e as suas principais responsabilidades

2. Faça, por favor, uma pequena descrição da cultura organizacional da empresa e dos seus valores

3. Apresentação geral da abordagem de RSE (objectivos, origens, áreas de ação, stakeholders referenciais)

\section{Tema II : CSRHPIs}

4. Fale-me, por favor das iniciativas relevantes em termos de promoção da saúde (objectivos, áreas, parceiros, beneficiários, timeframe, avaliação, etc.)

5. Em que medida tiveram em conta prioridades nacionais ou internacionais quando escolheram os objectivos destas iniciativas?

6. (Iniciativas colaborativas) Como surgiu a colaboração com $x$ no âmbito do projeto/apoio $\mathrm{x}$ ?

7. (Iniciativas colaborativas) Que mais valias surgiram desta parceria?

Tema III Perspetivas gerais e projetos futuros

8. De uma forma geral, em Portugal, como se criam projetos de responsabilidade social que tragam valor para as duas partes e que duram no tempo?

9. Em que medida acha que estas colaborações entre ONG e empresas deveriam ser avaliadas, aferidas ou reguladas por entidades governamentais ou outras?

10. Quais são as vossas perspetivas futuras no âmbito deste projeto/colaboração?

11. Quais condições externas e internas seriam desejáveis para vocês investir mais? 
Standard Interview Protocol III: Partners of collaborative CSRHPIs

\begin{tabular}{l|l|}
\hline Data & \\
Entrevistado & \\
Função & \\
Instituição & \\
\hline
\end{tabular}

Tema I : Introdução

1. Descreva, por favor, o seu percurso profissional, a posição que ocupa hoje e as suas principais responsabilidades

2. Faça, por favor, uma pequena descrição da entidade

Tema II : Experiencia de colaboração inerente à iniciativa

3. Como surgiu a colaboração/sponsorização no âmbito do projeto/apoio $x$ ?

a) NO CASO DE PARCERIA: como furam definidos os objectivos do projecto?

b) NO CASO DE SPONSORIZAÇÃO : sobre quais expectativas e limitações foi garantida a sponsorização?

4. Descreva o processo de interação/dialogo com a entidade

5. Detalhes sobre a implementação: recursos recebidos/timeframe/ beneficiários

6. Quais têm sido as maiores dificultadas da interação e colaboração? Quais as mais valias?

7. De que forma avaliam, ou tencionam avaliar, os resultados deste projeto?

Tema III: Perspectivas gerais sobre a RSE e projetos futuros

8. Como vê o papel e envolvimento das empresas em ações de promoção da saúde?

9. Em que medida acha que a promoção da saúde é, ou deveria ser, uma área de investimento para os programas de RSE das empresas?

10. Quais são as maiores razões de envolver-se com a empresa $x$ ?

11. Até que ponto vê a empresa como um parceiro?

12. De uma forma geral, em Portugal, como se poderiam criar projetos de responsabilidade social que tragam valor para as duas partes e que duram no tempo? 
13. Em que medida acha as colaborações entre ONG e empresas deveriam ser avaliadas, aferidas ou reguladas por entidades governamentais ou outras?

14. Quais são as vossas perspetivas futuras no âmbito da RSE? 
